Departamento de Ciencias Sociales de la Actividad Física, del Deporte y del Ocio

Facultad de Ciencias de la Actividad Física y del Deporte

\title{
Intervención Docente y Situación Profesional de los Recursos Humanos de la Actividad Física y Deporte: Monitores de Fitness y Monitores de Actividad Física y Deporte en España
}

\author{
Autora: \\ Beatriz Bernabé Mahamud \\ Licenciada en Ciencias de la Actividad Física y del Deporte
}

Director:

Antonio Campos Izquierdo

Doctor y licenciado en Ciencias de la Actividad Física y del Deporte 



\section{TRIBUNAL DE LA TESIS}

Tribunal nombrado por el Mgfco. y Excmo. Sr. Rector de la Universidad Politécnica de Madrid, el día

Presidente D.

Vocal D.

Vocal D.

Vocal D.

Secretario D.

Realizado el acto de defensa y lectura de Tesis el día,

en

Calificación: 



\section{Quiero expresar mi agradecimiento:}

A mi director de tesis, Antonio Campos Izquierdo, por todo el apoyo y la ayuda que he recibido. Gracias por su paciencia, dedicación, aliento y motivación. Igualmente gracias por haberme enseñado tantas cosas desde que estudiaba la carrera.

A María Dolores González Rivera, por haberme ayudado tanto y ser tan buena en lo que hace, transmitiéndome serenidad y ánimo.

Al Ministerio de Ciencia e Innovación de España por financiar la investigación aquí presentada formando parte del Proyecto de Investigación Fundamental no orientada de I+D+i DEP2009-12828.

A mis padres, por el apoyo incondicional desde que nací, por haberme ayudado tanto y aconsejado tan bien a lo largo de mi vida, por su cariño y su confianza y por haberme brindado la oportunidad de estudiar la carrera que quería. Gracias a ellos me he convertido en la persona que soy ahora.

A Sergio, mi futuro marido, por los ánimos, la confianza, el amor, el consuelo y la ayuda constante. Por estar diariamente preocupándose por mí y por enseñarme que la improvisación es una de las sorpresas de la vida. Por la infinidad de fines de semana que no hemos podido disfrutar por estar trabajando en esta investigación.

A mi hermana, por corregirme artículos en inglés y por querer ayudarme a escribir esta tesis doctoral. Por sus ánimos constantes, su cariño, su preocupación por mí y sus puntos de humor que tan bien me vienen. Por creer en mí aun cuando yo no creía.

A mi amiga y compañera Ana Correa, por ser una experta con el inglés y corregirme tantos artículos. Por sus ánimos constantes y palabras de aliento.

A mi abuela Tere, por dedicarme tanto tiempo y por estar tan orgullosa de mí.

A toda mi familia en general, por sus ánimos y su continuo apoyo. 
A todos mis amigos, en especial a las BRRECSS, a las goteras y a mis compañeros de trabajo Marta y Juan Pedro, por todas sus palabras de ánimo y por todos los momentos que hemos pasado juntos que han hecho que siga con más alegría.

A todos los que he entrevistado, porque sin ellos no podría haberse hecho realidad esta investigación. 


\section{ÍNDICE GENERAL}

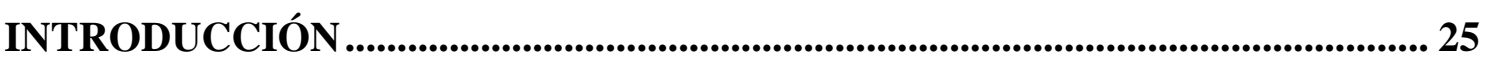

CAPÍTULO 1. LOS RECURSOS HUMANOS DE LA ACTIVIDAD FÍSICA Y DEPORTE: EL MONITOR DE ACTIVIDAD FÍSICA Y DEPORTE Y EL

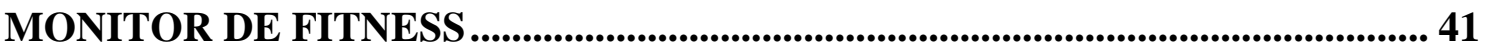

1.1. LOS RECURSOS HUMANOS DE LA ACTIVIDAD FÍSICA Y DEPORTE .................46

1.2. LOS MONITORES DE ACTIVIDAD FÍSICA Y DEPORTE ...........................................52

1.3. LOS MONITORES DE FITNESS ............................................................................................54

1.4. ÉTICA, DEONTOLOGÍA Y CONDUCTA DE LOS RECURSOS HUMANOS DE LA

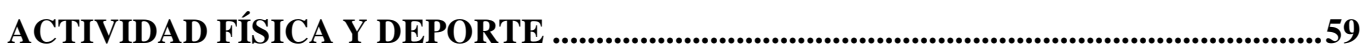

1.5. LA FORMACIÓN DE LOS RECURSOS HUMANOS DE ACTIVIDAD FÍSICA Y

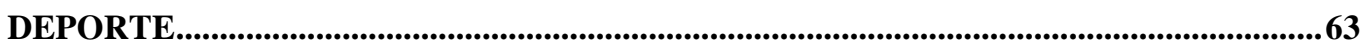

1.5.1. LA FORMACIÓN INICIAL DE ACTIVIDAD FÍSICA Y DEPORTE...........................65

1.5.2. LA FORMACIÓN PERMANENTE DE LOS RECURSOS HUMANOS DE LA ACTIVIDAD FÍSICA Y DEPORTE. 
CAPÍTULO 2. LA INTERVENCIÓN DOCENTE Y PROFESIONAL DE LOS RECURSOS HUMANOS DE LA ACTIVIDAD FÍSICA Y DEPORTE: EL MONITOR DE ACTIVIDAD FÍSICA Y DEPORTE Y EL MONITOR DE FITNESS 81

2.1. LA PLANIFICACIÓN EN LA ACTIVIDAD FÍSICA Y DEPORTE 83

2.1.1. LOS RECURSOS HUMANOS DE LA ACTIVIDAD FÍSICA Y DEPORTE Y LA PLANIFICACIÓN.

2.2. LA EVALUACIÓN Y LAS HERRAMIENTAS DE EVALUACIÓN EN LA ACTIVIDAD FÍSICA Y DEPORTE 89

2.2.1. LOS RECURSOS HUMANOS DE LA ACTIVIDAD FÍSICA Y DEPORTE Y LA EVALUACIÓN

2.3. ELEMENTOS QUE PRIORIZAN LOS RECURSOS HUMANOS DE ACTIVIDAD FÍSICA Y DEPORTE EN SU ENSEÑANZA Y DESEMPEÑO PROFESIONAL.................95 2.4. LAS FUENTES DE CONOCIMIENTO EN LA ACTIVIDAD FÍSICA Y DEPORTE. . .97

CAPÍtULO 3. LA SATISFACCIÓN LABORAL DE LOS RECURSOS HUMANOS DE LA ACTIVIDAD FÍSICA Y DEPORTE: EL MONITOR DE ACTIVIDAD FÍSICA Y DEPORTE Y EL MONITOR DE FITNESS 105

3.1. LA SATISFACCIÓN LABORAL DE LOS RECURSOS HUMANOS DE LA ACTIVIDAD FÍSICA Y DEPORTE 112

3.2. LOS DETERMINANTES QUE INFLUYEN EN LA SATISFACCIÓN LABORAL DE LOS RECURSOS HUMANOS DE LA ACTIVIDAD FÍSICA Y DEPORTE .115 
4.1. OBJETIVOS DEL ESTUDIO

4.2. METODOLOGÍA (DISEÑO DE LA INVESTIGACIÓN) 125

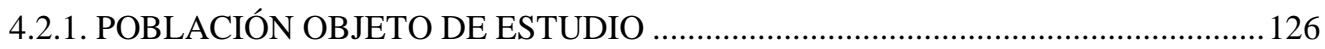

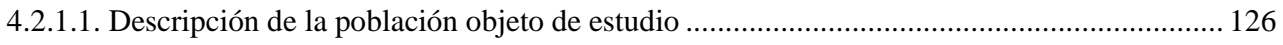

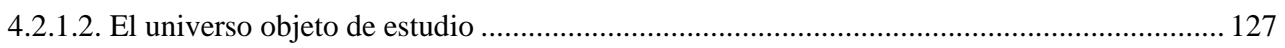

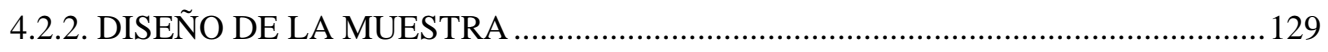

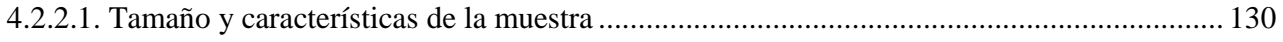

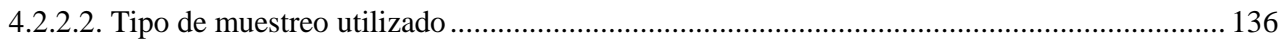

4.2.2.3. Proceso de selección de la muestra ...................................................................... 137

4.2.3. INSTRUMENTO DE RECOGIDA DE LA INFORMACIÓN ………………...........138

4.2.4. PROCEDIMIENTO DE RECOGIDA DE LA INFORMACIÓN .................................145

4.2.5. PROCEDIMIENTO DE PROCESAMIENTO, TRATAMIENTO Y ANÁLISIS DE

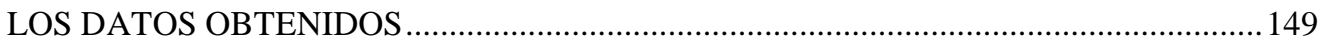

CAPÍTULO 5. RESULTADOS DEL ESTUDIO...................................................... 151

\subsection{RECURSOS HUMANOS DE LA ACTIVIDAD FÍSICA Y DEPORTE QUE}

TRABAJAN COMO MONITORES DE ACTIVIDAD FÍSICA Y DEPORTE....................154

5.1.1. FORMACIÓN GENERAL INICIAL Y PERMANENTE DE LOS MONITORES DE

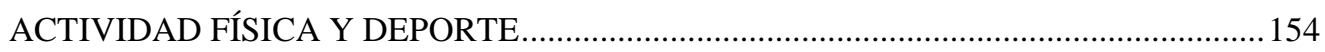

5.1.2. INTERVENCIÓN DOCENTE Y PROFESIONAL DE LOS MONITORES DE

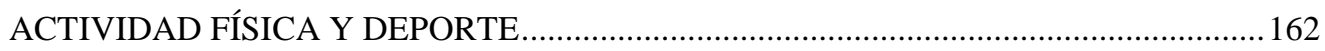

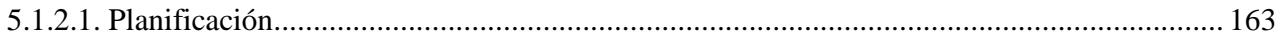

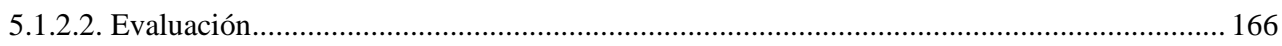

5.1.2.3. Elementos que priorizan en su enseñanza y desempeño profesional .................................. 176

5.1.2.4. Fuentes de conocimiento ................................................................................... 181 
5.1.3. SATISFACCIÓN LABORAL DE LOS MONITORES DE ACTIVIDAD FÍSICA Y

DEPORTE

5.2. RECURSOS HUMANOS DE LA ACTIVIDAD FÍSICA Y DEPORTE QUE TRABAJAN COMO MONITORES DE FITNESS

5.2.1. FORMACIÓN GENERAL INICIAL Y PERMANENTE DE LOS MONITORES DE FITNESS

5.2.2. INTERVENCIÓN DOCENTE Y PROFESIONAL DE LOS MONITORES DE FITNESS

5.2.2.1. Planificación

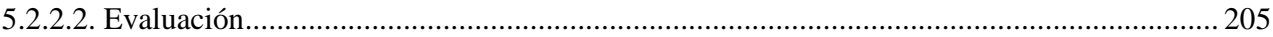

5.2.2.3. Elementos que priorizan en su enseñanza y desempeño profesional ............................. 217

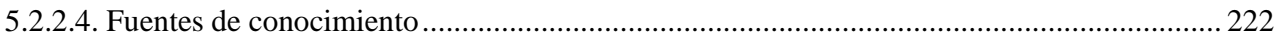

5.2.3. SATISFACCIÓN LABORAL DE LOS MONITORES DE FITNESS .........................2230

CAPÍTULO 6. DISCUSIÓN DE LOS RESULTADOS OBTENIDOS ................... 237

6.1. RECURSOS HUMANOS DE LA ACTIVIDAD FÍSICA Y DEPORTE QUE TRABAJAN COMO MONITORES DE ACTIVIDAD FÍSICA Y DEPORTE. .240

6.1.1. FORMACIÓN GENERAL INICIAL Y PERMANENTE DE LOS MONITORES DE ACTIVIDAD FÍSICA Y DEPORTE. 240

6.1.2. INTERVENCIÓN DOCENTE Y PROFESIONAL DE LOS MONITORES DE

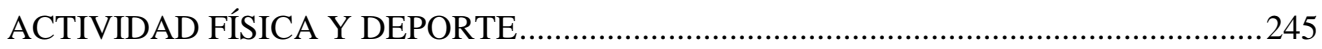

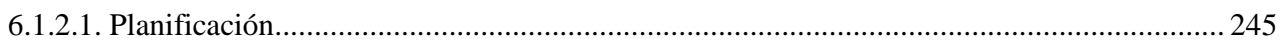

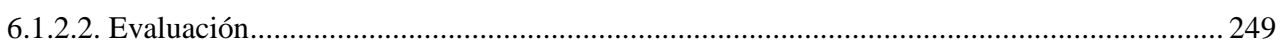

6.1.2.3. Elementos que priorizan en su enseñanza y desempeño profesional ................................... 252

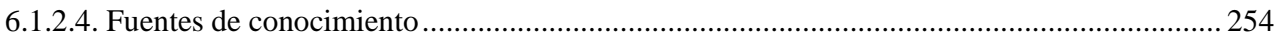

6.1.3. SATISFACCIÓN LABORAL DE LOS MONITORES DE ACTIVIDAD FÍSICA Y DEPORTE 


\subsection{RECURSOS HUMANOS DE LA ACTIVIDAD FÍSICA Y DEPORTE QUE TRABAJAN COMO MONITORES DE FITNESS}

6.2.1. FORMACIÓN GENERAL INICIAL Y PERMANENTE DE LOS MONITORES DE FITNESS

6.2.2. INTERVENCIÓN DOCENTE Y PROFESIONAL DE LOS MONITORES DE FITNESS

6.2.2.1. Planificación........................................................................................................ 268

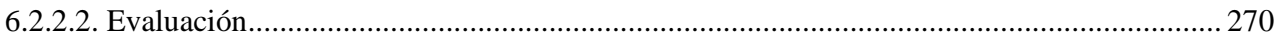

6.2.2.3. Elementos que priorizan en su enseñanza y desempeño profesional ..............................273

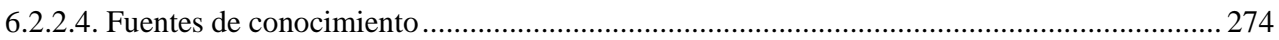

6.2.3. SATISFACCIÓN LABORAL DE LOS MONITORES DE FITNESS ......................277

CAPÍTULO 7. CONCLUSIONES ...................................................................... 281

7.1. MONITORES DE ACTIVIDAD FÍSICA Y DEPORTE 



\section{ÍNDICE DE TABLAS}

\section{CAPÍTULO 1. LOS RECURSOS HUMANOS DE LA ACTIVIDAD FÍSICA \\ Y DEPORTE. EL MONITOR DE ACTIVIDAD FÍSICA Y DEPORTE Y \\ EL MONITOR DE FITNESS}

Tabla 1. 1. Funciones laborales básicas y ocupaciones de actividad física y deporte estándar o base desempeñadas (Campos-Izquierdo et al., 2016, p.104)......

Tabla 1. 2. Titulaciones oficiales de actividad física y deporte en España en conexión con el EQF (Campos-Izquierdo, 2016, p. 1353) 51

\section{CAPÍTULO 4. OBJETIVOS Y MARCO METODOLÓGICO}

Tabla 4. 1. Dimensiones, variables e ítems de la entrevista estandarizada por medio de cuestionario "PROAFIDE. Recursos humanos de la actividad física y deporte" utilizados en la presente investigación (adaptado de Campos-Izquierdo, 2011, pp.58-60) 144

\section{CAPÍTULO 5. RESULTADOS DEL ESTUDIO}

Tabla 5. 1. Actividades de formación permanentes a las que han asistido los monitores de actividad física y el deporte en los últimos tres años en relación al sexo $(\mathrm{N}=600)$ 157 
Tabla 5. 2. Actividades de formación permanentes a las que han asistido los monitores de actividad física y el deporte en los últimos tres años en relación a la edad $(\mathrm{N}=600)$ 158

Tabla 5. 3. Actividades de formación permanentes a las que han asistido los monitores de actividad física y el deporte en los últimos tres años en relación a la experiencia laboral $(\mathrm{N}=600) \ldots$ 159

Tabla 5. 4. Actividades de formación permanente a las que han asistido los monitores de actividad física y el deporte en los últimos tres años en relación a la formación inicial general $(\mathrm{N}=600)$..... 161

Tabla 5. 5. La planificación que llevan a cabo los monitores de actividad física y deporte en relación al $\operatorname{sexo}(\mathrm{N}=600)$

Tabla 5. 6. La planificación que llevan a cabo los monitores de actividad física y deporte en relación a la $\operatorname{edad}(\mathrm{N}=600)$ 164

Tabla 5.7. La planificación que llevan a cabo los monitores de actividad física y deporte en relación al nivel de estudios $(\mathrm{N}=600)$

Tabla 5. 8. La planificación que llevan a cabo los monitores de actividad física y deporte en relación a la experiencia laboral $(\mathrm{N}=600)$ 165

Tabla 5. 9. Evaluación llevada a cabo por los monitores de actividad física y deporte en relación al sexo

$$
(\mathrm{N}=600) \text {. }
$$

Tabla 5. 10. Regularidad en la evaluación llevada a cabo por los monitores de actividad física y deporte en relación al sexo $(\mathrm{N}=600)$

Tabla 5. 11. Evaluación llevada a cabo por los monitores de actividad física y deporte en relación a la edad $(\mathrm{N}=600)$

Tabla 5. 12. Regularidad en la evaluación llevada a cabo por los monitores de actividad física y deporte en relación a la edad $(\mathrm{N}=600)$

Tabla 5. 13. Evaluación llevada a cabo por los monitores de actividad física y deporte en relación al nivel de formación $(\mathrm{N}=600)$

Tabla 5. 14. Regularidad en la evaluación llevada a cabo por los monitores de actividad física y deporte en relación a la formación $(\mathrm{N}=600)$

Tabla 5. 15. Evaluación llevada a cabo por los monitores de actividad física y deporte en relación a la experiencia laboral $(\mathrm{N}=600)$

Tabla 5. 16. Regularidad en la evaluación llevada a cabo por los monitores de actividad física y deporte en relación a la experiencia laboral $(\mathrm{N}=600)$. 
Tabla 5. 17. Herramientas de evaluación utilizadas por los monitores de actividad física y deporte en relación al sexo $(\mathrm{N}=600)$.

Tabla 5. 18. Herramientas de evaluación utilizadas por los monitores de actividad física y deporte en relación a la edad $(\mathrm{N}=600)$

Tabla 5. 19. Herramientas de evaluación utilizadas por los monitores de actividad física y deporte en relación al nivel de estudios $(\mathrm{N}=600)$

Tabla 5. 20. Herramientas de evaluación utilizadas por los monitores de actividad física y deporte en relación a la experiencia laboral $(\mathrm{N}=600)$.

Tabla 5. 21. Elementos que priorizan en su enseñanza y desempeño profesional los monitores de actividad física y deporte en relación al sexo $(\mathrm{N}=600)$

Tabla 5. 22. Elementos que priorizan en su enseñanza y desempeño profesional los monitores de actividad física y deporte en relación a la edad $(\mathrm{N}=600)$

Tabla 5. 23. Elementos que priorizan en su enseñanza y desempeño profesional los monitores de actividad física y deporte en relación al nivel de estudios $(\mathrm{N}=600)$ 180

Tabla 5. 24. Elementos que priorizan en su enseñanza y desempeño profesional los monitores de actividad física y deporte en relación a la experiencia laboral $(\mathrm{N}=600)$ 181

Tabla 5. 25. Fuentes de conocimiento de los monitores de actividad física y deporte, medias, deviaciones típicas y varianzas $(\mathrm{N}=600)$

Tabla 5. 26. Fuentes de conocimiento de los monitores de actividad física y deporte en relación al sexo

$(\mathrm{N}=600)$

Tabla 5. 27. Fuentes de conocimiento de los monitores de actividad física y deporte en relación a la edad

$(\mathrm{N}=600)$ 186

Tabla 5. 28. Las fuentes de conocimiento de los monitores de actividad física y deporte en función del nivel de estudios $(\mathrm{N}=600)$

Tabla 5. 29. Las fuentes de conocimiento de los monitores de actividad física y deporte en función de la experiencia laboral $(\mathrm{N}=600)$

Tabla 5. 30. Ítem, media y desviación típica de la satisfacción laboral de los monitores de actividad física y deporte $(\mathrm{N}=545)$

Tabla 5. 31. Satisfacción laboral de los monitores de actividad física y deporte en función del sexo

$(\mathrm{N}=545)$ 
Tabla 5. 32. Satisfacción laboral de los monitores de actividad física y deporte en función de la edad

$$
(\mathrm{N}=545)
$$

Tabla 5. 33. Actividades de formación permanentes a las que han asistido los monitores de fitness en los últimos tres años en relación al sexo $(\mathrm{N}=631)$

Tabla 5. 34. Actividades de formación permanentes a las que han asistido los monitores de fitness en los últimos tres años en relación a la edad $(\mathrm{N}=631)$ 198

Tabla 5. 35. Actividades de formación permanentes a las que han asistido los monitores de fitness en los últimos tres años en relación a la experiencia laboral $(\mathrm{N}=631)$

Tabla 5. 36. Formación permanente que los monitores de fitness han realizado durante los últimos 3 años en relación con la formación inicial general $(n=631)$ 201

Tabla 5. 37. La planificación que llevan a cabo los monitores de fitness en relación al sexo

$$
(\mathrm{N}=631)
$$

Tabla 5. 38. La planificación que llevan a cabo los monitores de fitness en relación a la edad

$$
(\mathrm{N}=631)
$$

Tabla 5. 39. La planificación que llevan a cabo los monitores de fitness en relación al nivel de estudios

$$
(\mathrm{N}=631)
$$

Tabla 5. 40. La planificación que llevan a cabo los monitores de fitness en relación a la experiencia

$$
\text { laboral }(\mathrm{N}=631)
$$

Tabla 5. 41. La evaluación llevada a cabo por los monitores de fitness en relación al sexo $(\mathrm{N}=631) \ldots .207$

Tabla 5. 42. Regularidad con la que los monitores de fitness evalúan en relación al sexo (N=631)

Tabla 5. 43. La evaluación llevada a cabo por los monitores de fitness en relación a la edad

$$
(\mathrm{N}=631)
$$

Tabla 5. 44. Regularidad con la que los monitores de fitness evalúan en relación a la edad (N=631) .....208

Tabla 5. 45. La evaluación llevada a cabo por los monitores de fitness en relación al nivel de estudios

$$
(\mathrm{N}=631)
$$

Tabla 5. 46. Regularidad con la que los monitores de fitness evalúan en relación al nivel de estudios

$$
(\mathrm{N}=631) \text {. }
$$

Tabla 5. 47. La evaluación llevada a cabo por los monitores de fitness en relación a la experiencia laboral

$$
(\mathrm{N}=631)
$$


Tabla 5. 48. Regularidad con la que los monitores de fitness evalúan en relación a la experiencia laboral

$(\mathrm{N}=631)$

Tabla 5. 49. Las herramientas de evaluación utilizadas por los monitores de fitness en relación al sexo

$$
(\mathrm{N}=631)
$$

Tabla 5. 50. Las herramientas de evaluación utilizadas por los monitores de fitness en relación a la edad

$$
(\mathrm{N}=631)
$$

Tabla 5. 51. Las herramientas de evaluación utilizadas por los monitores de fitness en relación al nivel de formación $(\mathrm{N}=631)$

Tabla 5. 52. Las herramientas de evaluación utilizadas por los monitores de fitness en relación a la experiencia laboral $(\mathrm{N}=631)$

Tabla 5. 53. Elementos que priorizan en su enseñanza y desempeño profesional los monitores de fitness en función del sexo $(\mathrm{N}=631)$

Tabla 5. 54. Elementos que priorizan en su enseñanza y desempeño profesional los monitores de fitness en función de la edad $(\mathrm{N}=631)$

Tabla 5. 55. Elementos que priorizan en su enseñanza y desempeño profesional los monitores de fitness en función del nivel de estudios $(\mathrm{N}=631)$

Tabla 5. 56. Elementos que priorizan en su enseñanza y desempeño profesional los monitores de fitness en función de la experiencia laboral $(\mathrm{N}=631)$.

Tabla 5. 57. Fuentes de conocimiento de los monitores de fitness, medias, deviaciones típicas y $\operatorname{varianzas}(\mathrm{N}=631)$

Tabla 5. 58. Fuentes de conocimiento de los monitores de fitness en relación al sexo $(\mathrm{N}=631)$

Tabla 5. 59. Fuentes de conocimiento de los monitores de fitness en relación a la edad (N=631)

Tabla 5. 60. Fuentes de conocimiento de los monitores de fitness en relación al nivel de estudios

$$
(\mathrm{N}=631)
$$

Tabla 5. 61. Fuentes de conocimiento de los monitores de fitness en relación a la satisfacción laboral

$$
(\mathrm{N}=631)
$$

Tabla 5. 62. Ítem, media y desviación típica de la satisfacción laboral de los monitores de fitness

$$
(\mathrm{N}=519)
$$

Tabla 5. 63. Satisfacción laboral de los monitores de fitness en relación al sexo $(\mathrm{N}=519)$.

Tabla 5. 64. Satisfacción laboral de los monitores de fitness en relación a la edad $(\mathrm{N}=519)$ 


\section{ÍNDICE DE FIGURAS}

\section{CAPÍTULO 4. OBJETIVOS Y MARCO METODOLÓGICO}

Figura 4. 1. Porcentaje de hombres y mujeres de los monitores de actividad física y deporte según Campos-Izquierdo et al. (2016, p.116).

Figura 4. 2. Edad de los monitores de actividad física y deporte según Campos-Izquierdo et al. (2016,

p.116).

Figura 4. 3. Experiencia laboral de los monitores de actividad física y deporte

Figura 4. 4. Porcentaje de hombres y mujeres de los monitores de fitness según Campos-Izquierdo et al.

(2016, p.116)

Figura 4. 5. Edad de los monitores de fitness según Campos-Izquierdo et al. (2016, p.116).

Figura 4. 6. Experiencia laboral de los monitores de fitness

\section{CAPÍTULO 5. RESULTADOS DEL ESTUDIO}

Figura 5. 1. Formación general inicial de los monitores de actividad física y deporte $(\mathrm{N}=600)$.

Figura 5. 2. Actividades de formación permanente formal a las que han asistido los monitores de actividad física y el deporte en los últimos tres años $(\mathrm{N}=600)$.

Figura 5. 3. Actividades de formación organizadas por su entidad para los monitores de actividad física y deporte en los últimos 12 meses $(\mathrm{N}=600)$.

Figura 5. 4. La planificación que llevan a cabo los monitores de actividad física y deporte $(\mathrm{N}=600) \ldots 163$

Figura 5. 5. La evaluación de los monitores de actividad física y deporte $(\mathrm{N}=600)$. 166

Figura 5. 6. Regularidad con la que evalúan los monitores de actividad física y deporte $(\mathrm{N}=600)$. 167 
Figura 5. 7. Las herramientas de evaluación usadas por los monitores de actividad física y deporte

$(\mathrm{N}=600)$

Figura 5. 8. Elementos que priorizan en su enseñanza y desempeño profesional los monitores de actividad física y deporte $(\mathrm{N}=600)$

Figura 5. 9. Formación general inicial de los monitores de fitness $(\mathrm{N}=631)$

Figura 5. 10. Formación permanente de los monitores de fitnes $(\mathrm{N}=631)$.

Figura 5. 11. Actividades de formación organizadas por su entidad para los monitores de fitness en los últimos 12 meses $(\mathrm{N}=631)$.

Figura 5. 12. La planificación que llevan a cabo los monitores de fitness $(\mathrm{N}=631)$

Figura 5. 13. La evaluación llevada a cabo por los monitores de fitness $(\mathrm{N}=631)$.

Figura 5. 14. Regularidad con la que los monitores de fitness evalúan (N=631)

Figura 5. 15. Las herramientas de evaluación usadas por los monitores de fitness $(\mathrm{N}=631)$. ...

Figura 5. 16. Elementos que priorizan en su enseñanza y desempeño profesional los monitores de fitness

$(\mathrm{N}=631)$ 


\section{RESUMEN}

La actividad física y deporte constituye uno de los fenómenos sociales más importantes de nuestros tiempos ya que genera multitud de beneficios ayudándonos a obtener una buena salud, calidad de vida y bienestar social. Estos beneficios dependen fundamentalmente de las personas que trabajan realizando las funciones laborales de actividad física y deporte. Por lo tanto, la finalidad principal del presente estudio se ha centrado en conocer la formación general inicial, la formación permanente y la intervención docente (planificación, evaluación, elementos que priorizan en su enseñanza y desempeño profesional y fuentes de conocimiento) de los monitores de actividad física y deporte y de los monitores de fitness de España, analizándolas y comparándolas con las variables sexo, edad, nivel de estudios y experiencia laboral. Además de concocer la satisfacción laboral de los monitores de actividad física y deporte y de los monitores de fitness de España, analizándolas y comparándolas con las variables sexo y edad.

La investigación se enmarca dentro de la metodología cuantitativa de corte descriptivo en la que se utilizó la entrevista estandarizada por medio del cuestionario "PROAFIDE: Recursos humanos de actividad física y deporte". Este cuestionario se aplicó a 600 monitores de actividad física y deporte y a 631 monitores de fitness que estaban trabajando en todas las provincias y comunidades autónomas de España.

Los resultados obtenidos indican que, en general la intervención docente de ambos no es la adecuada, habiendo un elevado número de profesionales en las dos ocupaciones que no planifican y que no evalúan. La observación diaria es la herramienta de evaluación más utilizada por los que sí evalúan. Asimismo, utilizan fuentes de conocimiento asociadas con el aprendizaje de las vías formal, no formal e informal. Los 
monitores de actividad física y deporte también sostienen que los aspectos actitudinales son los que más priorizan en su enseñanza y desempeño profesional y los monitores de fitness los aspectos actitudinales y técnicos. Por otro lado los monitores de fitness realizan más formación permanente que los monitores de actividad física y deporte, siendo la más común los cursos. En relación a la satisfacción laboral, ambos profesionales están bastante satisfechos con sus trabajos.

Palabras clave: formación; intervención docente y profesional; satisfacción; deporte; fitness. 


\section{ABSTRACT}

Sport and physical activity is one of the most important current social phenomena and it generates a multitude of benefits helping to obtain good health, quality of life and social welfare. These benefits basically depend on the people who work in occupational functions of physical activity and sport. Therefore, this research is focused on studying the initial general training, the lifelong learning and the teaching intervention (planning, evaluation, principal elements in their teaching and professional performance and sources of knowledge) of Spanish sport and physical activity instructors and fitness instructors as well as to analyze and compare the variables in terms of their gender, age, level of studies and work experience. In addition, this research is focused on studying the job satisfaction of Spanish sport and physical activity instructors and fitness instructors and to analyze and compare it in terms of their gender and age.

This research falls inside the quantitative type methodology of descriptive cut through standardized interview using the standardized questionnaire "PROAFIDE: Human resources of sport and physical activity". The questionnaire was completed by 600 sport and physical activity instructors and by 631 fitness instructors from all provinces and regions in Spain.

Key results revealed that, in general, the teaching intervention of both labor occupations are not adequate, having a high number of professionals in these two occupations that do not plan and that do not evaluate. Daily observation is the evaluation tool most used by those who evaluate. Likewise, they use knowledge sources associated with formal, non-formal and informal learning. Physical activity and sport instructors also sustain that the attitudinal aspects are those that they prioritize in their 
teaching and professional performance and fitness instructors the attitudinal and technical aspects. On the other hand, fitness instructors perform more lifelong learning than sport and physical activity instructors, being courses the most common training. Regarding job satisfaction, both professionals are quite satisfied with their working conditions and performance.

Keywords: training; professional and teaching intervention; job satisfaction; sport; fitness. 
INTRODUCCIÓN 



\section{INTRODUCCIÓN}

El interés social de la actividad física y deporte debido a los múltiples beneficios físicos, psicológicos, sociales, educativos y económicos, constituye uno de los fenómenos sociales más importantes de nuestros tiempos. Estos beneficios dependen fundamentalmente de las personas que trabajan realizando las funciones laborales de actividad física y deporte (Campos-Izquierdo, González-Rivera y Taks, 2016), ya que si no es guiada, diseñada, planificada, desarrollada, organizada y evaluada por un profesional con la titulación de actividad física y deporte oficial adecuada, los beneficios se pueden convertir en riesgos para la salud, educación e integridad física (Campos-Izquierdo, 2007; 2010). Además estos profesionales deben estar adaptados a las demandas individuales y sociales y deben ser responsables y poseer una intervención docente y profesional adecuada, eficiente y de excelencia (Campos-Izquierdo y MartínAcero, 2016; González-Rivera, 2008).

La generalización del fenómeno de la actividad física y deporte, unida a la marcada incidencia en la salud de las personas, requiere que los poderes públicos velen para que los consumidores, usuarios y deportistas estén dirigidos, enseñados y/o entrenados por profesionales de la actividad física y deporte cualificados y competentes, a los que les corresponde garantizar que la actividad física y deporte se realice de forma adecuada y segura, garantizando los beneficios expuestos anteriormente (CamposIzquierdo, 2016; González-Rivera y Campos-Izquierdo, 2014).

La actividad física y deporte ha sufrido un cambio desde su organización simple en los primeros tiempos del deporte moderno hasta convertirse en una institución social, debido a las dimensiones o procesos de racionalización y especialización desarrolladas en la sociedad (aumento del sector servicios y mayor industrialización). Esta institución 
social tiene unas estructuras de organización y administración complejas, tendiendo a adquirir las características de burocratización, racionalización, formalización y jerarquización (Campos-Izquierdo, 2010; García Ferrando, 1990).

La Ley 3/2008 de 23 de abril, del ejercicio de las profesiones del deporte en Cataluña determina que una vez consolidado el modelo de sociedad del desarrollo y del bienestar, la actividad física y deporte ocupa un lugar privilegiado en el mercado económico. Las actividades físico-deportivas forman parte de la industria del ocio, de la recreación, del tiempo libre, de la salud, del turismo e incluso de la estética, propiciando el nacimiento y proliferación de numerosas ocupaciones en torno a la actividad física y deporte.

La organización de la actividad física y deporte es una entidad social compuesta por varias personas, regulada por unas normas y procedimientos y estructurada mediante una ordenación y coordinación racional e intencionada. Esta organización está orientada a ofrecer uno o varios servicios de la actividad física y deporte de forma eficiente, profesional y con una adecuada calidad. En ella sus miembros desarrollan procesos, actividades, funciones y tareas relacionadas, directa o indirectamente, con la actividad física y deporte con unos recursos materiales, económicos y deportivos (Campos-Izquierdo, 2010; Chelladurai, 1999; Fernández-Ríos, 1995).

Centrándonos en los profesionales de la actividad física y deporte y en sus funciones laborales, varias comunidades autónomas han desarrollado una ley específica por la que se ordena el ejercicio de las profesiones del deporte y otras lo han incluido dentro de la ley del deporte. Estas leyes son la Ley 3/2008, del ejercicio de las profesiones del deporte de Cataluña; la Ley 15/2015, por la que se ordena el ejercicio de las profesiones del deporte en Extremadura; la Ley 6/2016, por la que se ordena el ejercicio de las profesiones del deporte en la Comunidad de Madrid; la Ley 1/2015, del 
ejercicio físico y del deporte de La Rioja y la Ley 5/2016, del Deporte de Andalucía. Con esta legislación se pretende velar por una actividad físico-deportiva impartida de forma correcta y segura y por el derecho de las personas que solicitan la prestación de servicios deportivos a que los mismos se presten aplicando conocimientos específicos y técnicas propias de las ciencias de la actividad física y deporte, además que fomenten un práctica deportiva saludable, evitando situaciones que puedan perjudicar la seguridad e integridad física del consumidor, usuario o deportista.

Por ello, hay una constatada necesidad de una adecuada intervención docente y profesional y de calidad en las profesiones de actividad física y deporte (CamposIzquierdo, 2005; 2010; Campos-Izquierdo et al., 2016; González-Rivera, 2008; Martínez del Castillo, 1991; Martínez-Serrano, 2007; Nash, Sproule y Horton, 2008; Wright, Atkins y Jones, 2012). Desafortunadamente no hay muchas investigaciones específicamente en las ocupaciones de monitor de actividad física y deporte y monitor de fitness (Abbott, 2009; Alves, da Costa, Castañer, Fernández y Anguera, 2013; Barranco, 2013; Boned, Felipe, Barranco, Grimaldi-Puyana y Crovetto, 2015; Boned, Rodríguez y López de Viñaspre, 2004b; García-Merino, 2011; Gonzalo, 2013; Koehler, 1998; Koustelios, Kouli y Theodorakis, 2003; Liu y Xu, 2016; Whaley, 2003a), no siendo así en otras ocupaciones de actividad física y deporte como por ejemplo en el profesor de educación física (Amarantidou, Mantis y Koustelios, 2009; CamposIzquierdo, González-Rivera y Jiménez-Beatty, 2012; Escudero, 1998; Medina, 1999; Sáenz-López, Sicilia y Manzano, 2010) y en el entrenador deportivo (Feu, 2004; Nash y Sproule, 2009; 2011; Pérez, 2002; Singh y Surujlal, 2006; Sullivan y Gee, 2008; Sullivan, Paquette, Holt y Bloom, 2012; Vallée y Bloom, 2005; Werthner y Trudel, 2009). 
Por consiguiente, el estudio de la intervención docente y situación profesional de los recursos humanos de actividad física y deporte, es un tema importante y relevante en el ámbito de la actividad física y deporte tanto a nivel nacional como internacional. Son numerosos los estudios e investigaciones que centran su interés en este ámbito (Campos-Izquierdo, 2005; Campos-Izquierdo, 2010; Campos-Izquierdo et al., 2016; Carter y Bloom, 2009; Erickson, Côté y Fraser-Thomas, 2008; González-Rivera, 2008; Koustelios et al., 2003; Koustelios y Tsigilis, 2005; Martínez del Castillo, 1991; Martínez-Serrano, 2007; Nash et al., 2008; Nash y Sproule, 2009; 2011; Wright et al., 2012), analizando más concretamente, la planificación y evaluación que desarrollan, los elementos que priorizan en su enseñanza y desempeño profesional, la formación que poseen y las fuentes de conocimiento que utilizan para realizar un desempeño profesional adecuado, eficiente y de excelencia en su trabajo. También el estudio de la satisfacción laboral que poseen y la comprensión de las causas de satisfacción y/o insatisfacción que se experimentan en el trabajo es un área de interés en el ámbito de la actividad física y deporte ya que constituye una dimensión actitudinal que ocupa un lugar central en la consideración de la experiencia del hombre en el trabajo (Aldag y Brief, 1978; Koehler, 1998; Moodley y Coopoo, 2006; Singh y Surujlal, 2006; Oshagbemi, 1997).

Las dos ocupaciones de la actividad física y deporte con sus respectivas actividades profesionales, funciones laborales y tareas específicas de actividad física y deporte elegidas para investigar el presente estudio han sido la de monitor de actividad física y deporte y la de monitor de fitness, ya que son dos ocupaciones cada vez más solicitadas. La ocupación de monitor de actividad física y deporte en España es una de las ocupaciones de actividad física y deporte más demandadas en relación a otras. Estudios que lo abalan son el de Martínez-Serrano, Campos-Izquierdo, Pablos y Mestre 
(2008), donde es la ocupación de la actividad física y deporte en la que más personas trabajaban y el estudio de Campos-Izquierdo (2005) donde los resultados fueron similares. También el de Gallardo y Campos-Izquierdo (2011) en el cual se demostró que las dos ocupaciones de actividad física y deporte en las que más gente trabaja son la de entrenador deportivo y monitor de actividad física y deporte. Asimismo, en el estudio de Campos-Izquierdo et al. (2016) encontramos que la ocupación de monitor de actividad física y deporte es la tercera en la que más profesionales de la actividad física y deporte están trabajando.

Por otro lado y continuando con la segunda ocupación de actividad física y deporte objeto de estudio, los monitores de fitness desempeñan un papel clave en la industria del fitness (Koehler, 1998), que está creciendo exponencialmente en este siglo en respuesta a una gran demanda de servicios de salud y fitness (Consejo Superior de Deportes, 2007). En la investigación llevada a cabo por Campos-Izquierdo (2005) se afirmó que más del $30 \%$ de los profesionales que trabajan en alguna ocupación de la actividad física y deporte lo hacen como monitores de fitness, desarrollando la función laboral de cuidar y mantener la forma física para grupos, siendo la segunda ocupación de actividad física y deporte más demandada por detrás de la de monitor de actividad física y deporte. Esta misma línea siguió el estudio de Campos-Izquierdo et al. (2016) en el que se obtuvo que la ocupación de monitor de fitness es la segunda en la que más profesionales trabajan.

Otro factor que se ha tenido en cuenta a la hora de elegir para estudiar estas dos ocupaciones de la actividad física y deporte es que tienen grandes similitudes. Además, se suele dar el caso de que los profesionales que trabajan en varias ocupaciones de la actividad física y el deporte eligen estas dos ocupaciones para desarrollarlas conjuntamente (Campos-Izquierdo, 2010; Campos-Izquierdo et al, 2016). 
En España, la ocupación de monitor de actividad física y deporte es una ocupación de la actividad física y deporte (Campos-Izquierdo, 2010; Campos-Izquierdo et al., 2016) regulada en la Ley 3/2008 del ejercicio de las profesiones del deporte de Cataluña, en la Ley 15/2015 por la que se ordena el ejercicio de las profesiones del deporte en Extremadura, en la Ley 6/2016 por la que se ordena el ejercicio de las profesiones del deporte en la Comunidad de Madrid, en la Ley 1/2015 del ejercicio físico y del deporte de La Rioja y en la Ley 5/2016 del Deporte de Andalucía. Al respecto, enseñar actividad física y deporte es la función laboral que desempeñan los monitores de la actividad física y deporte (Campos-Izquierdo, 2010; 2016; CamposIzquierdo y Viaño, 1999). Esta función laboral difiere de enseñar educación física ya que no se realiza dentro del sistema educativo. Los monitores de actividad física y deporte enseñan una variedad muy amplia de deportes y de actividades físico-deportivas y se diferencian de las actividades extraescolares porque no están programadas y dirigidas por el centro educativo en su proyecto educativo de centro (González-Rivera y Campos-Izquierdo, 2014).

Por otro lado, la ocupación de monitor de fitness es una reconocida ocupación de actividad física y deporte (Campos-Izquierdo, 2010; Campos-Izquierdo et al., 2016; Consejo superior de Deportes, 2007), la cual está delimitada en algunas comunidades autónomas españolas gracias a las leyes por las que se ordenan el ejercicio de las profesiones del deporte. Éstas son la Ley 3/2008 del ejercicio de las profesiones del deporte de Cataluña, la Ley 15/2015 por la que se ordena el ejercicio de las profesiones del deporte en Extremadura, la Ley 6/2016 por la que se ordena el ejercicio de las profesiones del deporte en la Comunidad de Madrid, la Ley 1/2015 del ejercicio físico y del deporte de La Rioja y la Ley 5/2016 del Deporte de Andalucía. Las funciones laborales que realizan los monitores de fitness según la Ley 6/2016, por la que se ordena 
el ejercicio de las profesiones del deporte en la Comunidad de Madrid son: elaborar y ejecutar actividades de acondicionamiento físico básico en grupo, vigilar y orientar para la utilización elemental del equipamiento y maquinaria deportiva para la realización segura y adecuada en la ejecución de actividades de acondicionamiento físico básico y asignar rutinas grupales generales de ejercicios estandarizados y prediseñados previamente para la población en general en actividades de acondicionamiento físico básico. Esta ocupación de la actividad física y deporte es diferente de la de entrenador personal, ya que esta última está integrada dentro de la profesión de preparador físico como se expone en el artículo 10 de la Ley 6/2016, por la que se ordena el ejercicio de las profesiones del deporte en la Comunidad de Madrid. En dicha ley se manifiesta que preparador físico es todo aquel profesional del deporte que orienta su actividad profesional al asesoramiento, planificación, diseño, evaluación técnico-científica, desarrollo y ejecución de actividades físico-deportivas y ejercicio físico orientado al mantenimiento, desarrollo, mejora, optimización y recuperación de la condición física y las capacidades coordinativas de las personas con el objetivo de mejorar su calidad de vida y su salud así como prevenir, reeducar, readaptar y reentrenar a aquellas con lesiones y patologías (diagnosticadas y/o prescritas por un médico), mediante actividades físico-deportivas y ejercicios físicos adecuados a sus características y necesidades.

Dentro de este contexto y partiendo de estas dos ocupaciones, el hecho de conocer la intervención docente y situación profesional de las personas que trabajan en funciones laborales y ocupaciones de actividad física y deporte ha sido objeto de mi interés desde que inicié mis estudios en la Licenciatura en Ciencias de la Actividad Física y del Deporte. Siempre he creído que es fundamental que los trabajadores en funciones laborales de actividad física y deporte posean la titulación acorde al trabajo 
que desempeñan, al igual que una formación permanente adaptada a las necesidades e intereses de la sociedad. De la misma forma, es necesario que realicen un adecuado desempeño profesional con una adecuada y detallada planificación en la tengan muy en cuenta todos los aspectos que hay que trabajar al impartir una clase, que prioricen los elementos adecuados en su enseñanza y desempeño laboral y que realicen una evaluación adecuada a la actividad con los instrumentos apropiados. Por último pero no menos importante, es necesario que estén satisfechos con su trabajo para garantizar un buen desempeño laboral. Otra de mis inquietudes, estrechamente relacionada con la primera, es que los beneficios y la calidad de la práctica de actividad física y deporte que realiza la población estén garantizados con los profesionales adecuados. Esta motivación me condujo a analizar y estudiar la situación actual en España en relación a la formación inicial general y formación permanente, la intervención docente y profesional y la satisfacción laboral de las personas que trabajan en funciones laborales de actividad física y deporte.

En relación a otros estudios similares a nivel estatal, el principal, antes del proyecto de investigación fundamental no orientada de I+D+i DEP2009-12828 dirigido por Campos-Izquierdo (2013), financiado por el Ministerio de Ciencia e Innovación de España y titulado "Estructura ocupacional y organizativa de los recursos humanos de actividad física y deporte en España", fue el de Martínez del Castillo (1991) "La estructura ocupacional del deporte en España: encuesta de los sectores de entrenamiento, docencia, animación y dirección". Sin embargo en las últimas décadas se han llevado a cabo investigaciones similares a nivel autonómico o provincial, en los cuales su principal objetivo era abordar el tema de los recursos humanos en la actividad física y deporte, algunos de estos son: Campos-Izquierdo (2005) "Situación profesional de las personas que trabajan en funciones de actividad física y deporte en la Comunidad 
Autónoma Valenciana", Martínez-Serrano (2007) "Los recursos humanos de la actividad física y deporte en la Comunidad Autónoma Valenciana”, González-Rivera (2008) "El deporte escolar en la Comunidad Autónoma de Madrid: intervención didáctica y recursos humanos en las actividades físico-deportivas extraescolares en los centros educativos" y Gallardo y Campos-Izquierdo (2011) "Situation of human resources for physical activity and sport in the area of Coslada" (Situación de los recursos humanos de la actividad física y el deporte en la zona de Coslada). Otros estudios a nivel nacional relacionados son los de Barranco (2013), García-Merino (2011), Gómez Tafalla (2003), Pablos (2007) y Puig y Viñas (2006) y a nivel internacional, entre otros, están los de European Observatoire of Sport and Employment (2014), Juillet, Buisine y Gouju (2013), Le Roux, Chantelat y Camy (1999) y Petry, Froberg y Madella (2006; 2008). En el caso de los monitores de actividad física y deporte y los monitores de fitness, los estudios más relevantes al respecto en España, son: Alves et al. (2013), Barranco (2013), Boned et al. (2004b), Boned et al. (2015), García-Merino (2011), Gonzalo (2013) y Juan-Llamas (2015) y en otros países son: Abbott (2009), Koehler (1998), Koustelios et al. (2003), Liu y Xu (2016), Viallon, Camy y Collins (2003) y Whaley (2003a).

Por todo ello, el propósito de esta tesis doctoral es el de conocer y analizar la intervención docente (planificación, evaluación, fuentes de conocimiento y elementos que priorizan en su enseñanza y desempeño profesional) y situación profesional (formación inicial general y permanente y la satisfacción laboral) de los recursos humanos de la actividad física y deporte que trabajan como monitores de actividad física y deporte y monitores de fitness en España. Debido a la escasez de literatura investigada en relación a estas dos ocupaciones, para poder saber cuál es el estado de la cuestión y lograr contrastar los resultados obtenidos, es necesario apoyarse en los 
estudios realizados en otras ocupaciones laborales y profesiones de actividad física y deporte.

La investigación aquí presentada forma parte del Proyecto de Investigación Fundamental no orientada de I+D+i DEP2009-12828 que ha sido financiada por el Ministerio de Ciencia e Innovación de España y dirigida por Antonio Campos Izquierdo.

En relación con esta tesis doctoral se han publicado cuatro artículos y se han realizado dos comunicaciones en congresos internacionales de acuerdo con los criterios de calidad para el rendimiento científico habilitador para la lectura de tesis doctorales incluidos en la normativa vigente recogida en los criterios aprobados por la Comisión de Postgrado de la Facultad de Ciencias de la Actividad Física y del Deporte- INEF, el 24 de octubre de 2013 para el Programa de Doctorado "Ciencias de la actividad física y del Deporte” del Real Decreto 99/2011, que se pasan a exponer:

- "Job satisfaction of sport and physical activity instructors in Spain according to gender and age" en la revista indexada en Journal Citation Reports (JCR (2016) Impacto: 0.190. Q4 (92/96) en Social, Sciences, interdisciplinary): South African Journal for Research in Sport, Physical Education and Recreation.

- "The evaluation and planning method of Spanish sport and physical activity instructors: A comparative study across gender, age, level of studies and work experience" en la revista indexada en Journal Citation Reports (JCR (2016) Impacto: 2.806. Q1 (15/64) en Multidisciplinary sciences): Plos one.

- "How Spanish fitness instructors are trained: a comparative study across a range of variables" en la revista indexada en la base Difusión y Calidad Editorial de las Revistas Españolas de Humanidades y Ciencias Sociales y Jurídicas (DICE) 
y en la base Matriz de Información para el Análisis de Revistas (MIAR) (impacto ICDS en 2016: 3,7): Actividad Física y Deporte: Ciencia y Profesión.

- "Las fuentes de conocimiento utilizadas por los monitores de actividad física y deporte españoles, en la revista indexada en la base Difusión y Calidad Editorial de las Revistas Españolas de Humanidades y Ciencias Sociales y Jurídicas (DICE) y en la base Matriz de Información para el Análisis de Revistas (MIAR) (impacto ICDS en 2016: 4): Revista de educación física. Renovar la teoría y práctica.

- "The competency to plan, implement and evaluate the process of training for Spanish sport instructors" en el VII Congreso Internacional de la Asociación Española de Ciencias del Deporte (Cáceres).

- "Generic competencies for sport and physical activity instructors in Spain" en el IX Congreso Internacional de la Asociación Española de Ciencias del Deporte (Toledo).

La estructura de esta tesis sigue el orden y distribución de los pasos, tareas y actuaciones realizados en dicha investigación, la cual está acorde con lo expuesto sobre este aspecto por autores como Cea (1998) y García Ferrando (2002).

Así en los tres primeros capítulos se establece el marco teórico y social de la investigación realizada, todo ello elaborado a partir de una extensa búsqueda y revisión bibliográfica sobre el tema objeto de estudio. En el primero de ellos, se contextualiza la definición de recursos humanos y se desarrollan los recursos humanos de la actividad física y deporte que trabajan como monitores de actividad física y deporte y monitores de fitness en España, tratando las titulaciones de actividad física y deporte, las 
ocupaciones de actividad física y deporte, las funciones laborales de actividad física y deporte, la formación inicial general y la formación permanente.

En el segundo capítulo, se contextualiza la intervención docente y profesional que poseen. Detallando la planificación, la evaluación, los elementos que priorizan en su enseñanza y desempeño profesional y las fuentes de conocimiento.

En el tercer capítulo, se expone la satisfacción laboral de los recursos humanos de actividad física y deporte y los determinantes que en ella influyen.

En la segunda parte, dentro del capítulo cuarto, se exponen los objetivos y el proceso metodológico que se ha realizado en la investigación. Para lograr estos fines se ha empleado una metodología cuantitativa de corte descriptivo, que, según Alvira (2002), trata de dar a conocer cómo es la realidad de manera detallada, aproximándose al establecimiento de relaciones entre fenómenos y características de esta realidad. Para ello se ha utilizado como instrumento de recogida de la información la entrevista estandarizada por medio de cuestionario "PROAFIDE: Recursos humanos de la actividad física y deporte" a partir de la cual se ha entrevistado a las personas que trabajan en las ocupaciones de monitor de actividad física y deporte y monitor de fitness en España.

La tercera parte comprende los capítulos quinto, sexto y séptimo (resultados del estudio, discusión de los resultados obtenidos y conclusiones, respectivamente). Los tres capítulos se presentan siguiendo los objetivos de la investigación y la misma estructura que en el marco teórico.

Finalmente, esta investigación se completa con las referencias bibliográficas y los anexos correspondientes. 


\section{MARCO TEÓRICO Y SOCIAL}

CAPÍTULO 1. Los recursos humanos de la actividad física y deporte: el monitor de actividad física y deporte y el monitor de fitness.

CAPÍTULO 2. La intervención docente y profesional de los recursos humanos de la actividad física y deporte: el monitor de actividad física y deporte y el monitor de fitness.

CAPÍTULO 3. La satisfacción laboral de los recursos humanos de la actividad física y deporte: el monitor de actividad física y deporte y el monitor de fitness.

\section{MARCO METODOLÓGICO}

CAPÍTULO 4. Objetivos y marco metodológico.

\section{RESULTADOS, DISCUSIÓN Y CONCLUSIONES}

CAPÍTULO 5. Resultados del estudio.

CAPÍTULO 6. Discusión de los resultados obtenidos.

CAPÍTULO 7. Conclusiones. 

CAPÍTULO 1. LOS RECURSOS HUMANOS DE LA ACTIVIDAD FÍSICA Y DEPORTE: EL MONITOR DE ACTIVIDAD FÍSICA Y DEPORTE Y EL MONITOR DE FITNESS 



\section{CAPÍTULO 1. LOS RECURSOS HUMANOS DE LA ACTIVIDAD FÍSICA Y DEPORTE: EL MONITOR DE ACTIVIDAD FÍSICA Y DEPORTE Y EL MONITOR DE FITNESS}

Según la Ley 15/2015 por la que se ordena el ejercicio de las profesiones del deporte en Extremadura, la actividad física y deporte constituyen una de las manifestaciones humanas con mayor transformación en los últimos años. La práctica del deporte ha evolucionado en las últimas décadas desde el minoritario y exclusivo deporte de competición, propio de hace tan sólo unos años, hacia una progresiva generalización de la actividad deportiva, incrementándose año tras año no sólo el número de practicantes sino también el de los colectivos a los que pertenecen.

Según García y Llopis (2011) se ha producido un incremento del 20\% en los practicantes de actividades físico deportivas desde el año 1980 al 2010 provocando que el sector se diversifique, generando multitud de empleos (Ministerio de Educación, Cultura y Deporte, 2017).

Tal y como reconoce la Ley 3/2008, de 23 de abril, del ejercicio de las profesiones del deporte de Cataluña, la difusión del deporte para todos y la incorporación de numerosos colectivos a la práctica de la actividad física, así como el interés cada vez mayor de los antiguos deportistas en reprender la práctica deportiva en la edad adulta, son algunas de las causas de la proliferación de profesionales en este sector.

Asimismo, la Ley 15/2015 por la que se ordena el ejercicio de las profesiones del deporte en Extremadura cita que el progresivo aumento del interés por la práctica de los deportes de aventura, de riesgo o en el medio natural, y el mismo fenómeno de la revalorización del propio cuerpo por motivos estéticos o de salud, han alimentado una 
variada oferta de profesionales de actividad física y deporte que requiere de una urgente regulación. Esta proliferación de numerosas ocupaciones profesionales en torno a la actividad física y deporte, en algunos casos, de forma un tanto desordenada y con escaso control, ha hecho que sea preciso ordenar las profesiones y a los profesionales de la actividad física y deporte con la finalidad de proteger la vida, la salud y la integridad física de los clientes.

Además, la generalización de la práctica deportiva ha convertido a la actividad física y deporte en un pujante sector económico en el que intervienen un creciente número de personas, de empresas y de entidades de todo tipo. Para atender a esta demanda es preciso contar con más y mejores profesionales de la actividad física y deporte y exigir a éstos la adecuada titulación de la actividad física y deporte y una adaptación y especialización permanente que satisfaga plenamente las nuevas necesidades con todas las garantías para los usuarios (Campos-Izquierdo, 2010; Consejo Superior de Deportes, 2000).

En la actualidad los servicios deportivos vienen siendo ofrecidos frecuentemente por personas sin la cualificación adecuada lo que resulta impropio de un sistema deportivo moderno, seguro y de calidad. Este intrusismo profesional puede llevar aparejado, en algunas ocasiones, el desarrollo de malas prácticas que inciden en la salud de las personas, con el consiguiente gasto socio-sanitario (Almeida, 2007; CamposIzquierdo, 2005; 2010; 2016; Ley 15/2015 por la que se ordena el ejercicio de las profesiones del deporte en Extremadura; Madella, 2002).

Esta generalización del fenómeno deportivo y la marcada incidencia que el deporte puede producir en la salud y en beneficios socio-educativos requieren que las ocupaciones de la actividad física y deporte estén organizadas, dirigidas e impartidas por profesionales cualificados (titulación de actividad física y deporte correspondiente) 
a los que corresponde garantizar que la actividad físico-deportiva se realice de forma correcta. Para poder alcanzar este objetivo sería necesario que hubiera una ley de ordenación del ejercicio de las profesiones a nivel estatal (Boned et al., 2004b; CamposIzquierdo, 2008; 2010; Campos-Izquierdo, González-Rivera, Pablos y Jiménez-Beatty, 2008; Campos-Izquierdo, Martínez, Mestre y Pablos, 2007; Gambau, 2011) aunque de momento, varias comunidades han elaborado una ley por las que se ordena el ejercicio de las profesiones del deporte, como son:

- Cataluña: Ley 3/2008, de 23 de abril, del ejercicio de las profesiones del deporte de Cataluña.

- Extremadura: Ley 15/2015, de 16 de abril, por la que se ordena el ejercicio de las profesiones del deporte en Extremadura.

- Comunidad de Madrid: Ley 6/2016, de 24 de noviembre, por la que se ordena el ejercicio de las profesiones del deporte en la Comunidad de Madrid.

En otras comunidades autónomas esta ordenación está incorporada dentro de la ley del deporte autonómica correspondiente, como son:

- La Rioja: Ley 1/2015, de 23 de marzo, del ejercicio físico y del deporte de La Rioja.

- Andalucía: Ley 5/2016, de 19 de julio, del Deporte de Andalucía.

Las leyes de ordenación del ejercicio de las profesiones del deporte de las anteriores comunidades autónomas citadas, determinan:

- Las profesiones del deporte.

- Las competencias/funciones y actividades profesionales asignadas a cada profesión del deporte. 
- La/s titulación/es de actividad física y deporte oficial/es necesaria/s para el ejercicio de cada profesión del deporte.

Los objetivos de las citadas leyes son los de regular los aspectos esenciales del ejercicio de determinadas profesiones del deporte, reconocer expresamente cuáles son estas profesiones, asignarles las competencias asociadas, determinar las titulaciones de la actividad física y deporte necesarias para ejercerlas y atribuir a cada profesión el ámbito funcional específico que le corresponda (Ley 3/2008, de 23 de abril, del ejercicio de las profesiones del deporte de Cataluña). Velando así por una actividad física y deportiva impartida de forma correcta y segura y por el derecho de las personas que solicitan la prestación de servicios deportivos a que los mismos se presten aplicando conocimientos específicos y técnicas propias de las ciencias de la actividad física y deporte que fomenten un práctica deportiva saludable, evitando situaciones que puedan perjudicar la seguridad del consumidor (Ley 6/2016, de 24 de noviembre, por la que se ordena el ejercicio de las profesiones en la Comunidad de Madrid).

\subsection{LOS RECURSOS HUMANOS DE LA ACTIVIDAD FÍSICA Y DEPORTE}

Siguiendo a Bayo y Merino (2002), los recursos humanos son las personas que trabajan en una organización, siendo uno de los activos más importantes, así como uno de los determinantes de su progreso. Igualmente, Campos-Izquierdo (2010) expone que los recursos humanos de una organización de la actividad física y deporte son las personas que trabajan en y para la propia organización. 
No se puede saber con exactitud el número de recursos humanos de la actividad física y deporte que están trabajando en funciones laborales y ocupaciones de actividad física y deporte, pero en el anuario de estadísticas deportivas del 2016 (Ministerio de Educación, Cultura y Deporte, 2017) se encuentra que en el 2015 el 1\% y en el 2016 el 1,1\% del total del empleo en España estaba vinculado a ocupaciones de actividad física y deporte, siendo 31.139 las empresas de actividad física y deporte registradas en el 2005 y 33.071 las registradas en el 2016. Las diferencias más significativas de los recursos humanos de la actividad física y deporte con respecto a los recursos humanos del empleo total de España se registran en la edad, en la formación académica y en los contratos. Habiendo una proporción superior de jóvenes de 16 a 34 trabajando en ocupaciones de actividad física y deporte, con una formación académica superior a la media, más empleo asalariado y con tasas de temporalidad y de empleo a tiempo parcial más elevadas a las registradas en el total del empleo en España.

Autores como Bayón (2002), Camy, Chantellat y Le Roux (1999), Camy y Le Roux (1998), Dolan, Shuler y Valle (2007), Fernández-Ríos (1995), García y García (2007), Peiró y Prieto (1999), Peiró y Ramos (1995), Porret (2006) y Puchol (2005) consideran que el factor fundamental y esencial de una organización son sus recursos humanos. Asimismo, Pablos y Biedma (2013) señalan que los responsables de la dirección de las organizaciones son conscientes de la importancia de los recursos humanos en el éxito y desarrollo de las mismas, por ello la gestión de los recursos humanos es un área clave (Serrano y Barba, 2012), siendo la forma de ordenarlos, estructurarlos y clasificarlos el primer elemento a tener en cuenta.

Campos-Izquierdo (2010, p.20) expone una clasificación, la cual sirve para analizar, estructurar y dirigir a los recursos humanos que trabajan en los distintos servicios de la actividad física y deporte en cualquier instalación o espacio deportivo y 
en cualquier ámbito de actuación. Este autor diferencia dentro de los recursos humanos que trabajan en las organizaciones que ofertan y desarrollan actividad física y deporte entre:

- Recursos humanos indirectos de la actividad física y deporte: son las personas que trabajan en servicios de la actividad física y deporte, que realizan funciones laborales y ocupaciones que no son propias de la actividad física y deporte. Como pueden ser:

○ Los que no pertenecen a una profesión, pero sí a una ocupación remunerada (atención a los clientes, limpieza, mantenimiento...).

- Los que pertenecen a una profesión (médicos, fisioterapeutas, arquitectos, periodistas...).

- Recursos humanos directos de la actividad física y deporte o profesionales de la actividad física y deporte: son las personas que trabajan desarrollando una o varias funciones laborales de la actividad física y deporte y que están cualificados (titulación de actividad física y deporte correspondiente), según su formación inicial, para garantizar la realización adecuada de dichas funciones y como tal los beneficios propios de la actividad física y deporte, además de constituir el elemento determinante en la calidad de los servicios de actividad física y deporte que realiza la población (Campos Izquierdo, 2005).

Por ello, el profesional de la actividad física y deporte tiene que cumplir las condiciones de (Campos-Izquierdo, 2010):

- Trabajar desarrollando una o varias funciones laborales de la actividad física y deporte (tabla 1.1). 
- Estar formado específicamente en la actividad física y deporte, es decir, debe poseer la titulación oficial de la actividad física y deporte correspondiente (tabla 1.2).

Durante la última década del siglo XX y en estos años del siglo XXI se está configurando un nuevo y distinto panorama sobre titulaciones oficiales de actividad física y deporte. Todo esto se debe a los procesos de cambio y transformación de la sociedad española, el mercado laboral y en especial de la actividad física y deporte, caracterizada por su crecimiento y diversificación (Campos-Izquierdo, 2005).

Por consiguiente, a todos los profesionales se les ordena, clasifica y delimita en ocupaciones de la actividad física y deporte, en las cuales se realiza una o varias funciones laborales de actividad física y deporte.

Para el desarrollo de este estudio nos hemos basado en la clasificación de las funciones laborales y ocupaciones de actividad física y deporte estándar de CamposIzquierdo et al. (2016, p. 104) (véase tabla 1.1). 


\section{Tabla 1.1}

Funciones laborales básicas y ocupaciones de actividad física y deporte estándar o base desempeñadas

\begin{tabular}{|c|c|}
\hline FUNCIÓN LABORAL DE ACTIVIDAD FÍSICA Y DEPORTE & $\begin{array}{l}\text { OCUPACIONES DE ACTIVIDAD FÍSICA Y } \\
\text { DEPORTE }\end{array}$ \\
\hline Entrenar deportes para la competición & Entrenador deportivo \\
\hline Enseñar educación física dentro del sistema educativo & Profesor de educación física \\
\hline Desarrollar acondicionamiento físico & \\
\hline básico grupal & Monitor de fitness \\
\hline Enseñar actividad física y deporte & Monitor de actividad física y deporte \\
\hline Dirigir, organizar y/o coordinar actividad física y deporte & Director de actividad física y deporte \\
\hline $\begin{array}{l}\text { Entrenar físicamente a personas o grupos (incluye a } \\
\text { deportistas de competición) }\end{array}$ & Entrenador físico - Entrenador personal \\
\hline $\begin{array}{l}\text { Enseñar actividad física y deporte extraescolar en centro } \\
\text { educativo }\end{array}$ & $\begin{array}{l}\text { Profesor de extraescolares de actividad física } \\
\text { y deporte }\end{array}$ \\
\hline $\begin{array}{l}\text { Readaptar y reeducar mediante actividad física y deporte y } \\
\text { ejercicio físico (incluye deportistas de competición) }\end{array}$ & Readaptador físico-deportivo \\
\hline $\begin{array}{l}\text { Desarrollar animación-recreación mediante actividad física } \\
\text { y deporte }\end{array}$ & Animador deportivo \\
\hline $\begin{array}{l}\text { Enseñar contenidos específicos sobre actividad física y } \\
\text { deporte en cursos }\end{array}$ & $\begin{array}{l}\text { Profesor de cursos de formación de actividad } \\
\text { física y deporte }\end{array}$ \\
\hline Inspeccionar los servicios de actividad física y deporte & Inspector de la actividad física y deporte \\
\hline $\begin{array}{l}\text { Asesoramiento, investigación y certificación de la actividad } \\
\text { física y deporte }\end{array}$ & $\begin{array}{l}\text { Asesor, investigador y consultor de actividad } \\
\text { física y deporte }\end{array}$ \\
\hline
\end{tabular}

Nota: recuperado de Campos-Izquierdo et al. (2016, p.104).

El panorama de las titulaciones de actividad física y deporte en España se muestra en la tabla 1.2 (Campos-Izquierdo, 2016, p. 1353). Todo ello en conexión con el Marco Europeo de Cualificaciones para el Aprendizaje Permanente (EQF) 
establecido por el Parlamento Europeo (2008) y el Marco Español de Cualificaciones para la Educación Superior (MECES).

Tabla 1.2

Titulaciones oficiales de actividad física y deporte en España en conexión con el EQF

TITULACIÓN NIVEL EQF

\section{ENSEÑANZAS UNIVERSITARIAS}

Licenciatura o Grado en Ciencias de la Actividad Física y del Deporte (Real Decreto 1670/1993 de 24 de septiembre).

Maestro Especialista en Educación Física (Real Decreto 1440/1991, de 30 de agosto) o

Grado en Educación Primaria con mención de Educación Física (Orden $\mathrm{ECI} / 3857 / 2007$, de 27 de diciembre).

\section{FORMACIÓN PROFESIONAL}

Técnico Superior en Acondicionamiento Físico (Real Decreto 651/2017, de 23 de junio).

Técnico Superior en Enseñanza y Animación Sociodeportiva (Real Decreto 653/2017, de 23 de junio).

Técnico Deportivo Superior (de cada deporte o modalidad deportiva) (Real Decreto 1363/2007, de 24 de octubre).

Técnico en Conducción de Actividades Físico-deportivas en el Medio Natural (Real Decreto 2049/1995, de 22 de diciembre).

Técnico Deportivo (de cada deporte o modalidad deportiva) (Real Decreto de 1363/2007, de 24 de octubre).

Técnico en Actividades Ecuestres (Real Decreto 652/2017, de 23 de junio).

\section{CERTIFICADOS DE PROFESIONALIDAD}

Acondicionamiento físico en grupo con soporte musical (Real Decreto 1518/2011, de 31 de octubre)

Fitness acuático e hidrocinesia (Real Decreto 1076/2012, de 13 de julio)

Acondicionamiento físico en sala de entrenamiento polivalente (Real Decreto 1518/2011, de 31 de octubre)

Animación físico-deportiva y recreativa (Real Decreto 1076/2012, de 13 de julio)

Animación físico-deportiva y recreativa para personas con discapacidad (Real Decreto 1076/2012, de 13 de julio)

Actividades de natación (Real Decreto 1518/2011, de 31 de octubre)

Instrucción de yoga (Real Decreto 1076/2012, de 13 de julio)

Guía por itinerarios en bicicleta (Real Decreto 1209/2009, de 17 de julio)

Guía por itinerarios ecuestres en el medio natural (Real Decreto 711/2011, de 20 de mayo)

Guía de espeleología (Real Decreto 982/2013, de 13 de diciembre)

Guía por itinerarios de baja y media montaña (Real Decreto 611/2013, de 2 de agosto)

Guía por barrancos secos o acuáticos (Real Decreto 982/2013, de 13 de diciembre)

Nota. Recuperado de Campos-Izquierdo (2016, p. 1353). 


\subsection{LOS MONITORES DE ACTIVIDAD FÍSICA Y DEPORTE}

Los monitores de actividad física y deporte juegan un papel muy importante en la sociedad, no solo influyen en la experiencia deportiva de los niños y adultos, sino que también tienen un impacto en el desarrollo psico-social, sobre todo en las personas más jóvenes (Liu y Xu, 2016; Petitpas, Cornelius, Van Raalte y Jones, 2005). Los monitores de actividad física y deporte también ayudan a mejorar la calidad de vida y la autoconfianza de las personas, de todas las edades, contribuyendo a la consecución de logros que los motive a continuar (Duda, 1991; Hardcastle y Taylor, 2001).

Enseñar actividad física y deporte es la función laboral que desempeñan los monitores de la actividad física y deporte (Campos-Izquierdo, 2010; Campos-Izquierdo y Viaño, 1999). La ocupación de monitor de actividad física y deporte en España es una de las ocupaciones más demandadas en relación a otras ocupaciones de actividad física y deporte. Estudios que abalan esta afirmación son los de Martínez-Serrano et al. (2008), donde el 33,7\% de los entrevistados trabajaban como monitores de actividad física y deporte, siendo la ocupación de la actividad física y deporte con un tanto por ciento más alto. El de Campos-Izquierdo (2005) donde los resultados fueron similares con un $20 \%$ de los profesionales entrevistados trabajando en esta misma ocupación. También el de Gallardo y Campos-Izquierdo (2011) en el cual se demostró que las dos ocupaciones de actividad física y deporte en las que más profesionales trabajaban son la de entrenador deportivo y monitor de actividad física y deporte. Y por último en el estudio de Campos-Izquierdo, et al. (2016) donde la ocupación de monitor de actividad física y deporte fue la tercera más demandada con un $16,3 \%$.

Como tal, la función laboral de enseñar actividad física y deporte puede ser considerada como una de las funciones laborales de la actividad física y deporte que 
más se desarrolla, por tanto la ocupación de monitor de actividad física y deporte es una de las ocupaciones en las que más profesionales de la actividad física y deporte trabajan en España y también es una de las ocupaciones de la actividad física y deporte que más usuarios atrae.

Por último, la ocupación de monitor de actividad física y deporte en el caso de la Ley $15 / 2015$ por la que se ordena el ejercicio de las profesiones del deporte en Extremadura y en la Ley 6/2016 por la que se ordena el ejercicio de las profesiones del deporte en la Comunidad de Madrid, se denomina "Monitora Deportiva/Monitor Deportivo en Actividad Física Deportiva de Carácter Formativo" y sus funciones y tareas son realizar instrucción e iniciación deportiva no enfocada a la competición. Esta especialidad delimitada anteriormente, es la que se estudia en esta investigación y a su vez es la ocupación denominada por Campos-Izquierdo et al. (2016) "monitor de actividad física y deporte” cuya función laboral estándar es enseñar actividad física y deporte y por ello el nombre de "monitor de actividad física y deporte" de esta ocupación, que es en el que se centra este estudio.

Más específicamente, en el artículo 8 de la Ley 6/2016, de 24 de noviembre por la que se ordena el ejercicio de las profesiones del deporte en la Comunidad de Madrid se expone que corresponde al monitor deportivo en actividad física deportiva de carácter formativo (monitor de actividad física y deporte) realizar las funciones de:

- Instrucción e iniciación deportiva no enfocada a la competición, si bien en el caso de las competiciones dentro del deporte en edad escolar o eventos de carácter recreativo el monitor deportivo también podrá desarrollar su actividad profesional para estas competiciones o eventos. 


\subsection{LOS MONITORES DE FITNESS}

La demanda de servicios relacionados con la actividad física y salud ha aumentado exponencialmente en nuestro país en los últimos años (Calabuig, Quintanilla y Mundina, 2008). Concretamente el sector del fitness se ha convertido en un mercado asentado y con cifras que van en aumento ya que en la actualidad, el número de usuarios de centros de fitness en España es de 7,98 millones, lo que hace que el mercado del fitness español se sitúe en segundo lugar a nivel mundial tras Estados Unidos (International Health and Racquet Sports Association-IHRSA, 2011). España lidera el ranking europeo, situándose por delante de países como Alemania (7,90 millones) y el Reino Unido (7,40 millones) (International Health and Racquet Sports AssociationIHRSA, 2011). Según el Real Decreto 651/2017, de 23 de junio, el sector fitness en Europa en el año 2010 generó 22 mil millones de euros en ingresos, dio empleo a 370.000 personas y sirvió a 40 millones de ciudadanos en toda Europa. De acuerdo con el informe de IHRSA del 2013, las cifras van aumentando ya que el ámbito del fitness en Europa generó aproximadamente 25 billones de euros en ganancias en un total de 48.000 clubes con cerca de 44 millones de usuarios (International Health and Racquet Sports Association, 2013). Además, esto ha hecho que en España existan más de 7000 centros deportivos y gimnasios de titularidad privada (Rial, Alonso, Rial y Picón, 2009). Este elevado número de usuarios y de centros de fitness unido a la importancia de desarrollar el acondicionamiento físico básico se ha visto, de igual manera, reflejado en el número de profesionales que ofrecen sus servicios en estos centros ya que ha generado multitud de oportunidades de empleo para los monitores de fitness (Consejo Superior de Deportes, 2007; García-Merino, 2011; Instituto Nacional de las Cualificaciones-Consejo Superior de Deportes, 2008). Rial et al. (2009) sitúan en más 
de 80.000 a las personas que trabajan en centros de fitness y gimnasios españoles, cuyo negocio supera los 2000 millones de euros, con un incremento anual del $10 \%$ en los últimos años.

Los monitores de fitness desempeñan un papel clave en la amplia industria del fitness, siendo determinantes en la retención y fidelización de los clientes (Koehler, 1998). Tradicionalmente, el sector del fitness dio más importancia a las infraestructuras o al equipamiento que al factor humano, sin embargo, esta tendencia ha cambiado en los últimos años. Actualmente existe un mercado cada vez más competitivo y unos clientes más exigentes donde los recursos humanos de la actividad física y deporte que trabajan como monitores de fitness marcan la diferencia entre un centro y otro (Gambau, 2011). Además, los monitores de fitness son uno de factores influyentes en la satisfacción de sus clientes (Nuviala, Tamayo, Iranzo y Falcón, 2008), influyendo su conducta directamente en la satisfacción o insatisfacción de los clientes y usuarios (Alves et al., 2013).

La ocupación de monitor de fitness es una reconocida ocupación de actividad física y deporte (Campos-Izquierdo et al, 2016; Consejo Superior de Deportes, 2007), en la que cuidar, mantener y mejorar la forma física en grupo desarrollando programas básicos de acondicionamiento físico es la función laboral de la actividad física y deporte que realizan (Campos-Izquierdo et al., 2016; European Health and Fitness Association, 2011). Esta profesión se confunde habitualmente con la de preparador físico pero difiere de ésta. Según la Ley 6/2015 por la que se ordena el ejercicio de las profesiones del deporte en la Comunidad de Madrid, el preparador físico es todo aquel profesional del deporte que orienta su actividad profesional al asesoramiento, planificación, diseño, evaluación técnico-científica, desarrollo y ejecución de actividades físico-deportivas y ejercicio físico orientado al mantenimiento, desarrollo, mejora, optimización y 
recuperación de la condición física y las capacidades coordinativas de las personas con el objetivo de mejorar su calidad de vida y su salud así como prevenir, readaptar y reentrenar a aquellas con lesiones y patologías, mediante actividades físico-deportivas y ejercicios físicos adecuados a sus características y necesidades. Esta profesión a su vez queda estructurada en las especialidades de preparador físico como especialista en rendimiento físico-deportivo y en preparador físico como educador físico y/o readaptador deportivo.

El preparador físico como especialista en rendimiento físico-deportivo realiza las funciones de:

- Asesoramiento, prevención, planificación, diseño, evaluación técnicocientífica, desarrollo y ejecución de actividades físico-deportivas y ejercicio físico orientado al mantenimiento, mejora, desarrollo, optimización y recuperación de la condición física y las capacidades coordinativas de las personas, grupos o equipos, enfocada o no a la competición o pruebas oficiales.

- Preparación y entrenamiento personal, sea grupal o individual. A los efectos de esta Ley se considera la denominación de entrenador personal incluido dentro de la profesión de preparador físico.

El preparador físico como educador físico y/o readaptador deportivo realiza las siguientes funciones:

- Prevención, asesoramiento, planificación, diseño, desarrollo y evaluación técnico-científica del trabajo mediante actividades físico-deportivas y ejercicio físico orientado a la mejora de la calidad de vida y salud de las personas. 
- Readaptación, reentrenamiento y/o reeducación de personas, grupos o equipos con lesiones y patologías (diagnosticadas o prescritas por un médico), compitan o no, mediante actividades físico-deportivas $\mathrm{y}$ ejercicios físicos adecuados a sus características y necesidades.

- Preparación, asesoramiento, planificación, desarrollo y evaluación técnico-científica de actividades físico-deportivas y ejercicios físicos orientados a la mejora de la calidad de vida y salud realizado con las siguientes poblaciones que requieren especial atención: mujeres embarazadas o en puerperio, personas mayores y personas con patologías y problemas de salud y asimilados.

En España la ocupación de monitor de fitness es una ocupación de actividad física y deporte que se encuentra dentro de la profesión de monitor deportivo según la Ley 6/2015 por la que se ordena el ejercicio de las profesiones del deporte en la Comunidad de Madrid y la Ley 15/2015 por la que se ordena el ejercicio de las profesiones del deporte en Extremadura, siendo ésta cada vez más demandada. La investigación llevada a cabo por Campos-Izquierdo (2005) afirmó que más del 30\% de las personas que trabajan en actividad física y deporte lo hacen como monitores de fitness, siendo la segunda profesión más demandada por detrás de la de monitor de actividad física y deporte. En esta misma línea siguió la investigación de CamposIzquierdo et al. (2016) en la que se obtuvo que la ocupación de monitor de fitness es la segunda en la que más profesionales trabajaban con el 17,1\%. Además se constata que debido a la diversificación del sector del fitness, desde finales de la década de los 90, ha generado de multitud de empleos (Consejo Superior de Deportes, 2000). Igualmente, 
Boned et al. (2015) afirman que ha habido un incremento en el número de monitores de fitness potenciado por el elevado número de clientes en los centros.

Teniendo en cuenta la ley más reciente, Ley 6/2016, de 24 de noviembre por la que se ordena el ejercicio de las profesiones del deporte en la Comunidad de Madrid, la ocupación de actividad física y deporte que nos ocupa se denomina "monitor deportivo en acondicionamiento físico básico", la cual está dentro de la profesión de monitor deportivo y realizan las funciones de:

- Elaboración y ejecución de actividades de acondicionamiento físico básico en grupo.

- Vigilancia y orientación básica para la utilización elemental del equipamiento y maquinaria deportiva para la realización segura y adecuada en la ejecución de actividades de acondicionamiento físico básico.

- Asignación elemental y básica de rutinas grupales generales de ejercicios estandarizados y prediseñados previamente para la población en general en actividades de acondicionamiento físico básico.

Esta especialidad delimitada anteriormente, es la que se estudia en esta investigación y a su vez es la ocupación denominada por Campos-Izquierdo et al. (2016) “monitor de fitness” cuya función laboral básica o estándar es cuidar, mantener y mejorar la forma física en grupo desarrollando programas básicos de acondicionamiento físico. Por ello en esta investigación se va a referir a esta ocupación de la actividad física y deporte como monitor de fitness. 


\section{4. ÉTICA, DEONTOLOGÍA Y CONDUCTA DE LOS RECURSOS HUMANOS DE LA ACTIVIDAD FÍSICA Y DEPORTE}

La deontología se puede definir como una teoría ética que se ocupa de regular los deberes, traduciéndolos en normas morales y reglas de conducta, dejando fuera de su ámbito específico de interés otros aspectos de la moral (Unión Profesional, 2009).

Cuando esta teoría se aplica al estricto campo profesional hablamos de deontología profesional la cual determina los deberes que son exigibles a los profesionales en el desempeño de su actividad. Estos deberes se plasman en códigos (códigos deontológicos) con el fin de que a través del buen hacer se obtengan resultados deseables (Unión Profesional, 2009). Los códigos que determinan los principios éticos y deontológicos así como la conducta y el comportamiento de las personas en sus lugares de trabajo u organizaciones, son aspectos fundamentales para garantizar la calidad de los servicios que se están prestando a los clientes (Campos-Izquierdo, 2010).

En el ámbito de la actividad física y deporte, estos códigos no suelen estar muy desarrollados ni suelen ser de amplio conocimiento por sus trabajadores (CamposIzquierdo, 2010). Aunque esto no exime para no conocerlos, ya que el perfil competencial de los recursos humanos de la actividad física y deporte determina, entre otras muchas cosas, que deben conocer y actuar dentro de los principios éticos, así como el desarrollo de hábitos de excelencia y calidad en el ejercicio profesional (Del Villar, 2004). Afortunadamente, esta situación poco a poco va cambiando ya que en las leyes de ordenación del ejercicio de las profesiones del deporte y en los estatutos de los colegios profesionales de licenciados de ciencias de la actividad física y deporte autonómicos se incluyen los principios, deberes y obligaciones del ejercicio profesional en la actividad física y deporte. Se determina también que el incumplimiento de los 
principios, deberes y obligaciones dará lugar a la exigencia de las correspondientes responsabilidades administrativas y disciplinarias. Además, hay establecidos unos mecanismos de control e inspección para garantizar que los profesionales que imparten los servicios deportivos los cumplan.

Respecto a los profesionales de la actividad física y deporte, la Ley 3/2008 del ejercicio de las profesiones del deporte de Cataluña, la Ley 15/2015 por la que se ordena el ejercicio de las profesiones del deporte en Extremadura y la Ley 6/2016 por la que se ordena el ejercicio de las profesiones del deporte en la Comunidad de Madrid, incluyen los siguientes principios, deberes y obligaciones que deben cumplir en su actuación profesional:

a) Estar en posesión de los requisitos habilitantes para el ejercicio de cada una de las profesiones que se regulan en la Ley.

b) Prestar unos servicios adecuados a las condiciones y necesidades personales de las personas destinatarias, de acuerdo con el estado de los conocimientos científicos de cada momento y con los niveles de calidad y seguridad que se establezcan en disposiciones específicas.

c) Velar por la salud de las personas destinatarias de sus servicios y colaborar en la erradicación de prácticas que sean nocivas para la salud de los consumidores, usuarios y deportistas.

d) Colaborar de forma activa en la prevención y control del uso de sustancias y fármacos o métodos prohibidos en la práctica del deporte. En particular se debe colaborar en la realización de cualquier control de dopaje y en el cumplimiento de todas las obligaciones previstas en la legislación antidopaje. 
e) Respetar la personalidad, dignidad e intimidad de las personas destinatarias del servicio prestado.

f) Garantizar la igualdad de condiciones en la práctica deportiva independientemente de su sexo, edad, cultura o discapacidad.

g) Ofrecer a las personas destinatarias una información suficiente y comprensible de las actividades físico-deportivas que vayan a desarrollarse bajo su dirección o supervisión.

h) Identificarse ante las personas destinatarias de los servicios e informar a los mismos de su profesión y titulación.

i) Colaborar activamente con cualesquiera otros profesionales que puedan ayudar a las personas destinatarias de la prestación de servicios a mejorar su rendimiento o su salud, en condiciones de seguridad.

j) Procurar un uso respetuoso del material deportivo y desarrollo de la actividad que reduzca al mínimo el impacto medioambiental y no cause daño al medio natural.

k) Difundir, cuando proceda, los valores de juego limpio que forman parte esencial del deporte.

1) Respetar y hacer respetar la labor de jueces y árbitros en las competiciones en las que se participe.

m) Ejercer la praxis profesional bajo la condición de que el deporte contribuye al desarrollo completo y armónico del ser humano, posibilita su formación integral $\mathrm{y}$ favorece mayor y mejor calidad de vida $\mathrm{y}$ bienestar social.

n) Promover condiciones que favorezcan la igualdad efectiva de las mujeres en el deporte y su incorporación a la práctica deportiva a todos los 
niveles, así como evitar todo acto de discriminación de cualquier naturaleza.

o) Promover el debido control médico de los deportistas mediante profesionales sanitarios.

p) Ejercer la actividad profesional fomentando una práctica deportiva exenta de todo tipo de violencia, racismo o xenofobia.

q) Promover el uso del medio natural para ejercer las actividades deportivas de manera sostenible y respetuosa.

r) Proteger a los deportistas, especialmente a los menores de edad, de toda explotación abusiva.

s) Rechazar cualquier tipo de retribución o gratificación de terceros que puedan condicionar los resultados de sus equipos y deportistas y las competiciones en las que participan.

t) Promover el uso de productos deportivos -calzado, ropa, material y equipamientos en cuyo proceso de fabricación no se atente contra el medio natural. Cuando en el ejercicio profesional intervengan animales, deberá garantizarse su trato respetuoso y su cuidado.

u) Comprometerse a la formación permanente para la actualización y perfeccionamiento de sus conocimientos en los nuevos avances científicos y tecnológicos de la disciplina de su profesión.

Tanto en el ámbito público como en el privado se establecen las conductas que deben de tener los empleados. En el ámbito público, la Ley 7/2007, de 12 de abril, del estatuto básico del empleado público, determina que los empleados deben trabajar con: objetividad, integridad, neutralidad, responsabilidad, imparcialidad, confidencialidad, 
dedicación al servicio público, transparencia, ejemplaridad, austeridad, accesibilidad, eficacia, honradez, promoción del entorno cultural y medioambiental y respeto a la igualdad entre hombres y mujeres. Asimismo, en el ámbito privado, el Convenio Colectivo estatal de instalaciones deportivas y gimnasios establece un código de conductas laborales con el objetivo de poseer un ambiente laboral respetuoso con la convivencia normal, ordenación técnica y organización de la entidad, así como la garantía y defensa de los derechos y legítimos intereses de los trabajadores y empresarios.

Un factor en contra de la apropiada conducta de los recursos humanos de la actividad física y deporte es el intrusismo profesional. Éste está implantado de forma muy generalizada entre las distintas profesiones deportivas debido a su reciente impacto en la población, la falta de profesionales cualificados (Campos-Izquierdo, 2016; Feu, 2004) y sobre todo la falta de regulación legal de esta profesión y reconocimiento de la competencia profesional requerida y de los perjuicios derivados de una mala praxis (Martín-Mariscal, 2012).

\subsection{LA FORMACIÓN DE LOS RECURSOS HUMANOS DE ACTIVIDAD FÍSICA Y DEPORTE}

Una de las mayores preocupaciones en las profesiones de actividad física y deporte es la formación, los procesos de formación y los conocimientos que poseen los profesionales de la actividad física y deporte, ya que los diferentes conocimientos que adquieren son un aspecto que puede afectar a la preparación y salud de los clientes (Côté, Samela y Russell, 1995). 
En las dos últimas décadas el concepto de salud ha evolucionado enormemente haciendo referencia a un estado de bienestar físico, mental y social que trasciende a prácticamente todos los aspectos de la vida. Un agente favorecedor lo constituye la práctica de actividad física y deporte (Rial et al., 2009). Por ello la actividad física y deporte tiene un importante interés público y social debido a todos los beneficios que genera en sus practicantes (European Observatoire of Sport and Employment, 2011; 2014). Pero si esta actividad física y deporte no se planifica, desarrolla, organiza e imparte por unos profesionales cualificados y adecuadamente formados con la titulación específica de actividad física y deporte, puede hacer que los beneficios se conviertan en riesgos para la salud (Campos-Izquierdo, 2007; 2016).

En este sentido, la adecuada intervención y desempeño profesional de los recursos humanos de la actividad física y deporte depende de que estas personas posean la apropiada formación inicial en actividad física y deporte así como que se complemente y perfeccione con la necesaria formación permanente (Campos-Izquierdo, 2010; 2016; European Observatoire of Sport and Employment, 2014). Además, en España más del $70 \%$ de estos servicios dependen directa o indirectamente del dinero público (Campos-Izquierdo, 2005; Martínez-Serrano, 2007) y, por tanto, se debe garantizar la calidad de dicha inversión pública y su rentabilidad social (CamposIzquierdo, 2005; 2016).

En numerosos estudios se ha demostrado que los trabajadores de la actividad física y deporte que poseen una adecuada formación tienen niveles más altos de eficacia en su desempeño profesional (Lee, Malete y Feltz, 2002). Además, creen más en sus habilidades, mejoran su confianza y su competencia (Feltz, Hepler, Roman y Paiement, 2009; Lee et al. 2002); así como su motivación, su estrategia y su desempeño profesional (Campbell y Sullivan, 2005; Feltz et al., 2009; Sullivan et al., 2012). 
La formación inicial en actividad física y deporte es el factor más importante para lograr una base sólida de conocimientos y la seguridad en la actividad física y deporte (Malek, Nalbone, Berger y Coburn, 2002). Del mismo modo, la formación permanente es esencial para la mejora, actualización y reconstrucción continua del saber y de las competencias así como del desempeño, intervención y desarrollo profesional (González-Rivera y Campos-Izquierdo, 2014). Por ello, los esfuerzos deben continuar para que los recursos humanos de la actividad física y deporte posean la correspondiente titulación específica de actividad física y deporte acorde a su ocupación (CamposIzquierdo, 2016). Además, éstos deben poner especial énfasis en desarrollar situaciones de aprendizajes relevantes y útiles y en ampliar sus conocimientos hacia nuevas áreas. Asimismo, las entidades deportivas deben proporcionar formación permanente a sus empleados ya que esta formación parece ser una sabia inversión en términos de calidad, efectividad y salud (González-Rivera y Campos-Izquierdo, 2014).

\subsubsection{LA FORMACIÓN INICIAL DE ACTIVIDAD FÍSICA Y DEPORTE}

La formación inicial de actividad física y deporte es el factor más importante para lograr unos conocimientos adecuados en el campo de la actividad física y deporte (Malek et al., 2002). Una titulación de actividad física y deporte asegura que los profesionales del deporte han completado un currículo de formación apropiada y que tienen los conocimientos adecuados para el desarrollo de su profesión (Malek et al., 2002), por lo tanto influirá directamente sobre el bienestar y la salud de sus clientes (Campos-Izquierdo, 2005). 
En España, un alto porcentaje de profesionales del deporte trabajan en actividades físico-deportivas sin una formación inicial de actividad física y deporte adecuada (Campos-Izquierdo, 2016), continuando este porcentaje en aumento en las últimas décadas (Campos-Izquierdo, 2010). Esta situación también ocurre en otros países europeos, como Italia (Madella, 2002) o Portugal (Almeida, 2007) y en países latinoamericanos (Hoyos, Gutiérrez y Pérez, 2012).

El artículo octavo de la carta europea del Deporte de 1975 recogía que "en todo programa de desarrollo del deporte debe reconocerse como imprescindible un personal cualificado a todos los niveles de gestión administrativa, técnica, de promoción y entrenamiento" (Consejo de Europa, 1975, p.2), así como en el artículo noveno de la Carta Europea del Deporte de 1992 en el que se leía, "toda persona dedicada a la dirección o supervisión de actividades deportivas deberá poseer las cualificaciones necesarias, con especial atención a la seguridad y protección de la salud de las personas que tiene a su cargo" (Consejo de Europa, 1992, p.12).

Estos aspectos ya han sido abordados por diversas leyes desde las que se ordena el ejercicio de las profesiones del deporte en las comunidades autónomas de Madrid, Andalucía, Extremadura, La Rioja y Cataluña, en las que se expone entre otros aspectos, cuáles son las titulaciones oficiales de actividad física y deporte que deben poseer estos profesionales del deporte (véase tabla 1.2).

Centrándonos en las dos ocupaciones objeto de estudio y teniendo en cuenta el artículo 14 de la Ley 6/2016, de 24 de noviembre por la que se ordena el ejercicio de las profesiones del deporte en la Comunidad de Madrid, se establece la obligatoriedad de alguna de las siguientes titulaciones para ser monitor deportivo en la especialidad monitor deportivo en actividad física deportiva de carácter formativo:

- Técnico Deportivo de la modalidad y especialidad deportiva correspondiente. 
- Técnico Deportivo superior de la modalidad y especialidad deportiva correspondiente.

- Técnico Superior en Animación de Actividades Físicas y Deportivas. En el caso de las nuevas formaciones de formación profesional, y como se determina en el capítulo primero del Real Decreto 653/2017, de 23 de junio (véase tabla 1.2), se entiende que la obligación será ahora la de ser Técnico Superior en Enseñanza y Animación Sociodeportiva.

- Licenciatura en Ciencias de la Actividad Física y Deporte o el correspondiente título de Grado que la sustituya.

Cuando la actividad se ejerce con niños en el marco de actividades del deporte escolar en educación primaria también podrán ejercer la profesión de monitor deportivo de actividad física deportiva de carácter formativo quienes acrediten su cualificación mediante la posesión de la titulación de diplomatura en magisterio con especialidad en educación física o correspondiente título de grado que la sustituya.

En el artículo 14 también se expone que para ejercer la profesión de monitor deportivo en acondicionamiento físico básico se requiere alguna de las siguientes titulaciones:

- Técnico Superior en Animación de Actividades Físicas y Deportivas. En el caso de las nueva formaciones de formación profesional, y como se determina en el Real Decreto 651/2017, de 23 de junio (véase tabla 1.2), se entiende que la obligación será ahora la de ser Técnico Superior en Acondicionamiento Físico. 
- Licenciatura en Ciencias de la Actividad Física y Deporte o el correspondiente título de Grado que la sustituya.

En relación con la formación inicial de actividad física y deporte, los dominios o áreas de competencias que debe de tener un profesional de la actividad física y deporte, y mucho más, de forma específica, integrada y compleja los Licenciados o Graduados en Ciencias de la Actividad Física y del Deporte, son según Campos-Izquierdo y Martín-Acero (2016):

- Intervención para la prevención, adaptación y mejora mediante la condición física y el ejercicio físico.

- Promoción de hábitos saludables y autónomos mediante actividad física y deporte.

- Intervención mediante las manifestaciones del movimiento humano.

- Intervención educativa.

- Planificación, evaluación y dirección-organización de los recursos y la actividad física y deporte.

- Método y evidencia científica en la práctica profesional.

- Desempeño, deontología y ejercicio profesional en el contexto de intervenciones.

La formación inicial y permanente es esencial para el empleo, la competitividad, la cohesión social y el desarrollo individual de las personas (Parlamento Europeo, 2008), así como para su adaptación a una sociedad en constante cambio. Por tanto, es imprescindible la conexión entre la formación y el mercado laboral y desempeño profesional de calidad (Campos-Izquierdo, 2010; González y Wagenaar, 2003). 
Siguiendo con la formación inicial de actividad física y deporte, los estudios que analizan esta formación inicial de las personas que trabajan en actividad física y deporte son diversos y se llevan a cabo tanto en Europa (Almeida, 2007; Caslavova, Kraft y Voracek, 2011; EOSE, 2011, 2014; Juillet et al., 2013; Le Roux et al., 1999; Madella, 2002), en países latinoamericanos (Hoyos et al., 2012), en Estados Unidos (Gillentine y Hunt, 2000; Malek et al., 2002; McInnis, Hayakawa y Balady, 1997; Spencer, 1999), Canadá (Gillentine y Hunt, 2000; Spencer, 1999; Wethner y Trudel, 2009); como en España (Campos-Izquierdo, 2005; 2016; Fraile, 1996; 2001; Gallardo y CamposIzquierdo, 2011; Giménez, 2000; González-Rivera, 2008; González-Rivera y CamposIzquierdo, 2014; Martínez del Castillo, 1991; Martínez-Serrano, 2007; Nuviala, León, Gálvez y Fernández, 2007; Viñas y Vilanova, 2014). Asimismo, los estudios que se centran en las ocupaciones de monitor de actividad física y deporte y monitor de fitness son los de Boned et al. (2015), Juan-Llamas (2015), Malek et al. (2002) y McInnis et al. (1997).

El estudio realizado sobre la formación inicial de las personas que trabajaban en actividad física y deporte en España de Martínez del Castillo (1991) se obtiene que el 36,7\% no tiene ninguna titulación de actividad física y deporte. En la misma línea, en el estudio de Campos Izquierdo (2005) realizado sobre el conjunto general de las personas que trabajan en las diferentes funciones laborales de actividad física y deporte, se encontró que el 40,6\% de estas personas no poseía ninguno de los diferentes tipos de titulaciones de la actividad física y deporte.

Asimismo, Fraile (1996; 2001) establece que, aunque existe un elevado número de monitores en las actividades físico-deportivas y con una importante experiencia práctica, su formación inicial en actividad física y deporte es deficiente, ya que la mayoría de monitores posee estudios medios y sus titulaciones son exclusivamente 
federativa. También en el estudio de Nuviala et al. (2007) realizado en técnicos deportivos de la provincia de Huelva, se obtiene que los profesionales que no tienen ninguna titulación deportiva ascienden a un 21,1\%. Siguiendo el estudio de GonzálezRivera (2008) en el caso del deporte escolar en los centros educativos, se obtiene que un porcentaje superior al $50 \%$ de personas no posee ninguno de los diferentes tipos de titulaciones de la actividad física y deporte.

Recientemente, en el análisis del panorama de formación inicial del estudio de Campos-Izquierdo (2016), se contrasta que el 38\% de las personas que trabajan en actividad física y deporte en España no posee ninguna titulación de actividad física y deporte, y éstas representan el grupo más numeroso.

En relación con los estudios sobre la formación inicial general de los profesionales de la actividad física y deporte. En el estudio de Boned et al. (2015) el $50,1 \%$ de los monitores de fitness analizados tiene alguna titulación de carácter universitario (19\% de diplomados, 22,4\% de licenciados y $8,7 \%$ de postgraduados), el $27,9 \%$ ha estudiado una formación profesional, el 14,4\% tiene nivel de estudios secundarios y el 7\% primarios. En ese mismo año, Juan-Llamas (2015) destacó que el 96,4\% de los monitores de fitness tienen una titulación superior a la educación secundaria.

En el ámbito internacional, siguiendo a Spencer (1999) en su estudio realizado en Estados Unidos y Canadá, los entrenadores deportivos siempre suelen tener una licenciatura. Gillentine y Hunt (2000) apuntan que casi todos los que trabajan en profesiones deportivas tienen una carrera universitaria. Por el contrario, un estudio en el sur de California ha demostrado que sólo el 3\% de los instructores de fitness estaban en posesión de un máster, el $27 \%$ poseía una licenciatura y el $70 \%$ tenía algún estudio pero inferior a la licenciatura o ningún estudio (Malek et al., 2002). Siguiendo a McInnis et 
al. (1997) en su estudio sobre 110 clubes, se ha podido comprobar que sólo el $34 \%$ de los clubes tenían a todos los instructores con una licenciatura.

\subsubsection{LA FORMACIÓN PERMANENTE DE LOS RECURSOS HUMANOS DE LA ACTIVIDAD FÍSICA Y DEPORTE}

La formación permanente es un proceso educativo continuado que puede definirse como toda amplia variedad de actividades de aprendizaje que se adquieren a lo largo de la vida con el objetivo de mejorar y actualizar los conocimientos, las aptitudes y capacidades de una persona (Macphail, 2011; Nelson, Cushion y Potrac, 2006), así como para una mejor calidad del servicio y para la adaptación constante a los cambios actualizándose y reflexionando sobre las tareas que están realizando (CamposIzquierdo, 2010). Además es considerada como un derecho y una obligación. Esta formación puede tener múltiples finalidades como la de mejorar la capacidad profesional de los recursos humanos en el puesto de trabajo que desempeñan, la de capacitar a los profesionales para nuevos puestos que aparezcan o bien con el objetivo de promoción (Nelson et al., 2006).

La formación permanente es clasificada por muchos autores de necesaria (González-Rivera y Campos-Izquierdo, 2014; Vargas-Tonsing, 2007; Whaley, 2003a; Whaley, 2003b). Es esencial para la actualización continua del saber y de las competencias, del desarrollo profesional (González-Rivera y Campos-Izquierdo, 2014; Mallet, Trudel, Lyle y Rynne, 2009; Medina, 1999) así como para aumentar la empleabilidad y la inclusión social de las personas (Parlamento Europeo, 2008). 
Igualmente es necesaria para asegurar los estándares de desempeño de los profesionales del deporte (Misener y Danylchuk, 2009).

El grado de éxito que los profesionales de la actividad física y deporte experimentan para satisfacer las demandas de la sociedad depende en gran medida del conocimiento y la formación permanente que acumulan para realizar adecuadamente su desempeño profesional (Coombs y Ahmed, 1974). No hay que confundir la formación inicial con la permanente, ya que la primera habilita para el ejercicio profesional y la segunda es un complemento y perfeccionamiento (Campos-Izquierdo, 2010; 2016).

Siguiendo el estudio de Misener y Danylchuk (2009), la formación permanente aumenta la motivación, la estrategia, la técnica y la construcción del carácter de los profesionales de la actividad física y deporte. En este sentido, es importante que la formación permanente de estos profesionales sea continua, coherente y progresiva, favoreciéndose la reflexión constante, y la orientación hacia a la excelencia, así como la innovación de su práctica profesional (González-Rivera y Campos-Izquierdo, 2014; Mallet et al., 2009; Medina, 1999).

De esta forma, en todos los campos de la actividad humana, la formación permanente se ha convertido en una decisión estratégica, ineludible para las organizaciones o corporaciones que pretendan hacer frente, con perspectiva, al presente y futuro (Escudero, 1998). En este sentido, la capacidad de una organización para adaptarse al cambio, evolucionar y ser pionera depende de la capacidad de adaptación y de formación que tengan los recursos humanos que la integran (Campos-Izquierdo, 2010). Por ello, la formación, concretándose en un plan de formación integral, permanente y general (López, 2001), constituye una de las mejores inversiones, así como una de las principales fuentes de satisfacción de las personas (Saavedra, Pérez, Rodrigo y Fernández, 2008). En este sentido el proceso formativo ha de ser prospectivo, 
es decir, debe garantizar no solamente la necesidades actuales de los recursos humanos de la actividad física y deporte sino también las necesidades futuras o próximas (Salanova y Grau, 2000).

La formación por parte de la organización se puede definir como el proceso que permite ajustar las cualidades del trabajador a una actividad, mejorando y actualizando las capacidades, habilidades, actitudes y aptitudes idóneas para su desempeño (Porret, 2006). Más concretamente, la formación y desarrollo de las personas en una organización consiste en un conjunto de actividades y actuaciones con la finalidad de mejorar el desempeño presente y futuro, aumentando su capacidad mediante la modificación y potenciación de sus conocimientos, habilidades-procedimientos y actitudes. La formación se imparte para un puesto específico o para corregir deficiencias del puesto actual mientras que el desarrollo profesional pretende que se formen en su carrera profesional en la organización siendo siempre de forma más genérica (CamposIzquierdo, 2010; Porret, 2006).

La Fundación Europea para la Gestión de la Calidad (2003), en el modelo de calidad denominado modelo EFQM de excelencia, determina que el aprendizaje es la adquisición y comprensión de información que puede conducir a la mejora o al cambio en la organización.

En consecuencia, la planificación de una adecuada formación por parte de las organizaciones de la actividad física y deporte es un elemento esencial en la sociedad actual del conocimiento y de la información, ofreciendo ventajas a los recursos humanos y a la propia organización (Campos-Izquierdo, 2010). Además, De Saá y Ortega (2004) determinan que la formación en las organizaciones puede ayudar a atraer, desarrollar y retener a los empleados excelentes, contribuyendo a aumentar el 
compromiso, productividad, eficiencia y calidad y disminuyendo la rotación del personal y el absentismo.

Los objetivos que se pretenden en una organización al realizar un plan de formación pueden ser (Bayón, 2002; Heyes y Stuart, 1996; Porret, 2006):

- Motivar al personal.

- Abrir nuevos canales de comunicación entre individuos, grupos y empresas.

- Mejorar del desempeño de las actividades de la organización, favoreciendo la adecuación profesional de las personas a las exigencias de sus puestos de trabajo.

- Favorecer el desarrollo profesional de la persona, favoreciéndolo a través de la integración de sus intereses individuales con los objetivos de la organización.

- Mejorar la adaptación del trabajador a su puesto de trabajo, así como a su clima laboral, sus posibilidades de futuro y a los cambios del entorno de trabajo.

- Mejorar la competitividad de la organización y la adaptación a su entorno.

- Mejorar los servicios y los resultados de la organización, así como la racionalización, eficiencia y calidad de los mismos.

- Incrementar la satisfacción laboral del personal.

- Favorecer la planificación de la organización.

- Favorecer la recolocación de las personas, aumentando la polivalencia necesaria.

- Cambiar las actitudes de las personas.

- Crear y mantener una cultura corporativa, marco de referencia de todas las decisiones empresariales y elemento integrador del personal. 
- Generar el cambio, a partir de su aceptación como filosofía y del reconocimiento de la cualificación como medio para afrontar eficientemente la evolución tecnológica.

Después de conocer las ventajas relacionadas con la impartición, ofrecimiento y planificación de cursos de formación por parte de las organizaciones para sus empleados se va a analizar la realidad con respecto a los recursos humanos de la actividad física y deporte.

Las investigaciones en el ámbito de la actividad física y deporte también ilustran el importante papel de las organizaciones deportivas en la promoción de la educación y el desarrollo profesional (Misener y Danylchuk, 2009; Nash y Sproule, 2009; Sullivan et al., 2012). Determinando que, las organizaciones deportivas deben fomentar la realización de los programas de formación permanente ya que son una inversión en eficacia y calidad (Sullivan, el at., 2012).

Sin embargo, aunque los medios más frecuentes para averiguar sobre un curso es a través de la organización deportiva (Misener y Danylchuk, 2009), sólo unas pocas organizaciones deportivas ofrecen la tan necesaria formación permanente (Nash y Sproule, 2009; National Association for Sport and Physical Education, 2008). Nash y Sproule (2009) indicaron en relación con el networking, que los foros para compartir información y experiencias entre compañeros de trabajo de profesión no eran alentados por sus organizaciones deportivas y que cualquier desarrollo era generalmente informal y se encontraba entre amigos cercanos.

Los estudios que analizan la formación permanente de las personas que trabajan en actividad física y deporte son también diversos y son abordados desde diferentes perspectivas (Campos-Izquierdo, 2005; 2010; 2016; González-Rivera y Campos- 
Izquierdo, 2014; Juan-Llamas, 2015; Mallet et al., 2009; Martínez del Castillo, 1991; Medina, 1999; Werthner y Trudel, 2009; Wilson, Bloom y Harvey, 2010)

Primeramente, Martínez del Castillo (1991) observó una escasa actualización del conocimiento donde solamente el $37 \%$ de los recursos humanos de la actividad física y deporte afirmaba haber asistido a algún curso en los últimos cinco años.

A su vez, Campos-Izquierdo, (2005) investigó que las actividades que más realizan los recursos de actividad física y deporte son: asistencia a cursos de formación permanente, a congresos y a jornadas sobre actividad física y deporte, con porcentajes de participación entre el 17 y 49\%. La realización de postgrados y másteres, y la publicación sobre aspectos de actividad física y deporte es escasa, ya que no superan el 3\%. También se observa que el 48,3\% de los profesionales han realizado uno o varios cursos en los últimos cuatro años, mientras que la participación en una o varias jornadas en los últimos cuatro años es del 29,2\%.

Años más tarde, los profesionales de la actividad física y deporte fueron realizando una mayor formación permanente. Martínez-Serrano (2007) y CamposIzquierdo (2010) mostraron que la mayoría de ellos realiza una amplia y diversa formación permanente: asistencia a cursos, jornadas, congresos y grupos de trabajo, siendo los cursos los elegidos siempre en primer lugar.

Recientemente, Campos-Izquierdo, (2016) ha investigado que la mayoría de las personas, un $53,8 \%$, que trabajan en ocupaciones de actividad física y deporte ha realizado en los últimos tres años al menos un curso de actividad física y deporte, el $28,4 \%$ ha asistido a jornadas o a congresos y el $6,2 \%$ ha realizado grupos de trabajo. Asimismo, el $20,4 \%$ de estas personas ha admitido realizarlas porque sus organizaciones lo han fomentado. 
Respecto a la profesión del profesor de educación física, en el estudio de Campos-Izquierdo et al. (2012) se obtiene que el 90\% de ellos en 2004 y el 82,3\% en 2006, realizó cursos de formación o postgrados. Asimismo, el 68,6\% en 2004 y el $66,1 \%$ en 2006, asistió a jornadas o congresos. Además un tanto por ciento muy alto de profesores de educación física, cree que su formación les ha servido para realizar adecuadamente las tareas propias de sus profesión y ser más competentes (CamposIzquierdo et al., 2012).

Respecto a la ocupación de monitor de fitness, Juan-Llamas (2015) obtuvo que un $56,7 \%$ de los consultados en su estudio declaran tomar parte en cursos de una a tres veces al año o más de tres veces al año. Además un 46,8\% de ellos asisten también a seminarios, eventos o convenciones.

Centrándonos en el panorama internacional, algunos profesionales de la actividad física y deporte siguen formándose (Wilson et al., 2010) y otros, en cambio, invierten muy poco tiempo en este área (Erickson et al., 2007). Sin embargo, la mayoría cree que la formación permanente es esencial para poder ejercer su profesión de una manera correcta (Moodley y Coopoo, 2006).

Por otro lado, Werthner y Trudel (2009) afirmaron que los cursos son las situaciones de aprendizaje más comunes para los entrenadores. Este resultado está relacionado con el de Fuller, Feyrer-Melk, Thomas y Harding (1995), quienes afirmaron que los cursos son la fuente más común de aprendizaje a lo largo de la vida, pero enfatizan que ningún curso ha sido realizado por más del $60 \%$ de los profesionales de la actividad física y deporte que han entrevistado. Asimismo, se ha demostrado que los entrenadores deportivos que completaron un curso de formación tenían niveles más altos de eficacia en su trabajo (Lee et al., 2002), ya que después de completarlo, los 
entrenadores creen más en sus habilidades, mejoran su confianza y su competencia (Lee et al. 2002), así como su motivación, su estrategia y su técnica (Feltz et al. 2009).

Sin embargo a pesar de las anteriores afirmaciones, para algunos profesionales, la formación permanente no satisface sus expectativas ni sus necesidades (Nash y Sproule 2009; Vargas-Tonsing, 2007) porque no proporciona conocimiento para el entrenamiento práctico (Dorgo, 2009; Gilbert y Trudel, 2001) o porque simplemente no está adaptada a sus necesidades (Moodley y Coopoo, 2006). Ante esta problemática, Dorgo (2009) propuso que los aspectos pedagógicos debían incluirse en los programas de formación, muy centrados en la técnica y la táctica y desprovistos también de aspectos psicológicos. En este sentido, es importante como ya hemos dicho que, en la formación permanente de estos profesionales se favorezca la reflexión constante y la innovación como medida para impartir sus clases de una forma profesional y efectiva adaptándose siempre a los cambios y desarrollando las competencias para proporcionar una adecuada intervención y desempeño profesional óptimo (González-Rivera y Campos-Izquierdo, 2014; Mallet et al., 2009; Medina, 1999).

Asimismo, cabe señalar que son casi inexistentes los estudios en los que la formación permanente de los recursos humanos de la actividad física y deporte se relaciona con las variables emergentes de sexo, edad y experiencia laboral, no así los estudios que relacionan la formación inicial con la formación permanente.

Por un lado, Misener y Danylchuk (2009) y en relación a la variable sexo, informaron en su estudio sobre entrenadores que los hombres realizan más formación permanente que las mujeres. Por otro lado y vinculando la formación inicial con la formación permanente, se observa que cuanto más avanzada es la formación inicial, más formación permanente se realiza siendo más diversa y compleja (Campos-Izquierdo, 2016; González-Rivera y Campos-Izquierdo, 2014; Medina, 1999). De la misma forma, 
Stacey, Hopkins, Adamo, Shorr y Prud’homme (2010), investigaron que los monitores de fitness que tienen mayores niveles de educación participan en actividades más específicas de formación permanente.

Para comprender y conocer mejor cuál es el estado de la cuestión en este tema se ha sugerido, por parte de muchos autores, que se necesita más investigación en relación a la experiencia laboral de los recursos humanos de la actividad física y deporte y también en relación a la variable sexo (Misener y Danylchuk, 2009; Nash y Sproule, 2011), ya que el número de mujeres que trabajan en puesto de actividad física y deporte en España ha ido en aumento (González-Rivera, 2008; 2016). 

CAPÍTULO 2. LA INTERVENCIÓN DOCENTE Y PROFESIONAL DE LOS RECURSOS HUMANOS DE LA ACTIVIDAD FÍSICA Y DEPORTE: EL MONITOR DE ACTIVIDAD FÍSICA Y DEPORTE $Y$ EL MONITOR DE FITNESS 



\section{CAPÍTULO 2. LA INTERVENCIÓN DOCENTE Y PROFESIONAL DE LOS RECURSOS HUMANOS DE LA ACTIVIDAD FÍSICA Y DEPORTE: EL MONITOR DE ACTIVIDAD FÍSICA Y DEPORTE Y EL MONITOR DE FITNESS.}

La intervención docente y profesional adecuadas son dominios fundamentales que deben desarrollar los recursos humanos de la actividad física y deporte (CamposIzquierdo y Martín-Acero, 2016). En este sentido, su adecuada intervención docente y profesional depende de multitud de factores como son la planificación, la evaluación, las fuentes de conocimiento y los elementos que priorizan en su desempeño profesional.

Debido a la importancia que tiene la intervención docente y profesional en esta profesión, ha sido ampliamente estudiada (Campos-Izquierdo, 2005; 2010; CamposIzquierdo et al., 2016; Erickson et al., 2008; González-Rivera, 2008; Martínez del Castillo, 1991; Martínez-Serrano, 2007; Nash et al., 2008; Wright et al., 2012).

\subsection{LA PLANIFICACIÓN EN LA ACTIVIDAD FÍSICA Y DEPORTE}

Las actividades físico-deportivas requieren, además de un adecuado y eficiente proceso de planificación, de una adecuada priorización de elementos para desarrollar su enseñanza y de un meditado y sistemático proceso de desarrollo de las habilidades de los practicantes o deportistas (Feu, Ibáñez y Gozalo, 2007).

El concepto de planificación nace en Rusia en 1928 relacionado con una finalidad más económica y poco educativa (Viciana, 2002). Ésta ha ido evolucionando definiéndose primeramente en el ámbito educativo y deportivo como una función 
reflexiva del profesional de la actividad física y deporte que consiste en organizar los contenidos de las clases y enseñar las intervenciones de manera flexible y sistemática, cumpliendo los objetivos, para anticipar un futuro plan de acción efectiva (Viciana, 2002) hasta definirse actualmente como una función reflexiva del profesional de la actividad física y deporte que consiste en un proceso de formulación y definición de objetivos y prioridades para organizar las clases promoviendo el aprendizaje por competencias y proponiendo metodologías que lo favorezcan a fin de alcanzar el perfil profesional requerido (Rosales, 2010; Tenutto, Brutti y Algarañá, 2010; Yánez y Villardón, 2006).

La planificación debe considerarse como una de las funciones principales de los profesionales de la actividad física y deporte (Buceta, 2004), contemplándose como un aspecto fundamental dentro de las competencias que definen a este profesional, siendo el aspecto central de la fase preactiva (Viciana, 2002). En el estudio de CamposIzquierdo y Martín-Acero (2016), la planificación es una de las competencias profesionales específicas fundamentales que todo profesional de la actividad física y deporte debe poseer.

El proceso de planificar es un camino indispensable donde se pondrán en marcha la reflexión y la toma de decisiones, para desarrollar la enseñanza con coherencia y asegurando la eficacia (Viciana, 2002). A grandes rasgos, la planificación persigue fomentar una serie de competencias de carácter general y transversal de forma globalizada e interdisciplinar (Rosales, 2010; Tenutto et al., 2010), previendo las respuestas a las preguntas ¿dónde vamos?, ¿cómo vamos a llegar?, ¿cómo sabré que he llegado? (Viciana, 2002).

De igual modo, la planificación proporciona una oportunidad para conectar el aprendizaje previo, las características del deportista y las condiciones ambientales del 
proceso de enseñanza/aprendizaje (Griffey y Housner, 1991). Además, debe de ser un proceso continuo (Dorgo, 2009), ya que los profesionales de la actividad física y deporte tienen que revisar el plan creado originalmente y modificarlo en respuesta a factores relacionados con el propio ejercicio, los deportistas, el entrenador o el contexto (Dorgo, 2009; Feu et al., 2007).

Para que la planificación se lleve a cabo de una forma adecuada hay que tomar numerosas decisiones (preactivas, interactivas y postactivas) durante todo el proceso de la misma, siendo algunas de gran importancia, ya que dependiendo de ellas la planificación puede cambiar (Viciana, 2002). Las decisiones más importantes a tomar en el proceso de planificación se estructuran en cinco fases según Mestre (1995) y cuatro fases según Viciana (2002).

De tal forma, Mestre (1995) estableció que los cinco niveles o fases son:

- Fase diagnóstico: en ella se realiza una investigación y un análisis de la realidad social y de la problemática concreta.

- Fase de determinación de prioridades: selección de los fines y objetivos.

- Fase de metodología de actuación: en ella se elaboran los planes, programas y proyectos.

- Fase de ejecución: en ella se ponen en práctica los proyectos.

- Fase de evaluación: esta es de control de todo el proceso y de los resultados. También se lleva a cabo la comparación de éstos con las perspectivas y los objetivos propuestos.

Unos años más tarde Viciana (2002) concretó en cuatro las fases las decisiones más importantes a tomar en el proceso de planificación:

- Fase diagnóstico: en ella se determina el punto de partida del diseño. 
- Fase de diseño: se encuentra dentro de las decisiones preactivas y en ella se diseñan los objetivos, se seleccionan y estructuran los contenidos, se seleccionan las competencias y los estándares de aprendizaje y se temporaliza.

- Fase de intervención: se encuentra dentro de las decisiones interactivas observando el índice de efectividad de la programación y dentro de las decisiones postactivas a cada clase para poder hacer los cambios oportunos en la programación durante su aplicación.

- Fase de evaluación: se encuentra dentro de las decisiones postactivas a todo el proceso, en la que se realizan cambios para la futura programación.

La planificación es esencial para el funcionamiento práctico del profesional de la actividad física y deporte (Dorgo, 2009), con ella conseguimos que se visualice la dirección apropiada que tiene que llevar su grupo durante todo el año priorizando en el desarrollo de sus habilidades. Una vez establecida esa visión, se transforma en una declaración escrita y tangible (Desjardins, 1996). De la misma forma, la planificación tiene una altísima importancia con el fin de diseñar y desarrollar correctamente el ejercicio de acuerdo a los objetivos y necesidades del usuario (Petry et al., 2006).

El hecho de que los profesionales del deporte tengan una estructuración detallada de todo lo que van a hacer dentro de una planificación bien elaborada es una forma de evitar situaciones que saben que son estresantes, además de permitirles utilizar el tiempo productivamente (Olusoga, Butt, Maynard y Hays, 2010). Es por ello que la planificación es una estrategia de afrontamiento (Olusoga et al., 2010).

Por tanto, se hace imprescindible que todo profesional de la actividad física y deporte en su intervención docente realice una planificación y una adecuada toma de decisiones para el desarrollo de las habilidades del alumnado y de los deportistas, ya 
que, tal y como expone Viciana (2002), la planificación asegura una reflexión sobre los factores más importantes que influirán en la docencia y una toma de decisiones que evitará que la acción docente no esté premeditada.

\subsubsection{LOS RECURSOS HUMANOS DE LA ACTIVIDAD FÍSICA Y DEPORTE Y LA PLANIFICACIÓN}

La planificación es una de las funciones más importantes para desarrollar adecuadamente un proyecto deportivo (Buceta, 2004; Ortega, 2010) aunque no está suficientemente investigada en las ocupaciones de monitor de actividad física y deporte y monitor de fitness (Juan-Llamas, 2015). La planificación ha sido investigada sobre todo, en las ocupaciones de profesor de educación física y en la de entrenador deportivo (Ikonomopoulos, Tzetzis, Kioumourtzoglou y Tsorbatzoudis, 2001; Nash, Sproule y Horton, 2008; Pérez, 2002; Vallé y Bloom, 2005).

Primeramente, Desjardins (1996) investigó que los entrenadores expertos elaboran planificaciones teniendo en cuenta los aspectos mentales y físicos así como las tácticas y técnicas de entrenamiento. Igualmente, los entrenadores que Pérez (2002) estudió afirmaron que la planificación es un aspecto fundamental a tener en cuenta para preparar las clases y que ellos siempre planifican. En la misma línea, Vallé y Bloom (2005) encontraron que los entrenadores expertos siempre elaboran un plan completo para la temporada. De acuerdo con Nash et al. (2008) los entrenadores de su estudio afirman que, la planificación diaria y la planificación a largo plazo son muy importantes. Los mismos resultados fueron obtenidos por Nash, Sproule y Horton (2011), quienes constataron que es vital que los entrenadores adopten una planificación 
a largo plazo sobre todos los aspectos que pueden influir en la formación de los deportistas haciendo así que mejore su práctica. Por su parte, Dorgo (2009) investigó a un entrenador de constatada experiencia observando que trata la planificación como un proceso continuo, ya que perfecciona los diferentes planes a medida que avanza la temporada. De esta manera, demostrando flexibilidad en la planificación, el entrenador es capaz de considerar factores influyentes tales como la fatiga, las lesiones de los deportistas, las limitaciones de gestión de instalaciones y las condiciones meteorológicas. Por otro lado, en la tesis doctoral de Yagüe (1998) en relación con los aspectos didácticos de los entrenadores nacionales de fútbol de Castilla y León, se observó que el $84,48 \%$ creía que es necesario realizar una programación, pero sin embargo casi la mitad de los mismos encuentran dificultades para llevarla a cabo.

La planificación es muy importante también en el ámbito de la enseñanza, de acuerdo con Arends (1995), la planificación por parte de los profesores de educación física mejora los resultados de aprendizaje de los alumnos. Asimismo, Pereira (2002) manifestó que el 76,2\% de los maestros de educación física planifican sus clases, sin embargo, el mismo estudio mostró que la dedican poco tiempo.

No obstante, en el estudio de Saura (1996) se obtuvo que un 50,4\% de los entrenadores del deporte escolar manifiestan no realizar una programación anual, improvisando el desarrollo de las sesiones según el momento. Igualmente, entre los estudios existentes que abordan el tema de la planificación en el deporte escolar, se encuentra el trabajo sobre entrenadores de fútbol sala en Granada (Delgado, Espinar y Goncé, 2002) en el que se observó que muy pocos entrenadores realizan una planificación anual de su entrenamiento, a excepción un grupo de ellos que sí la realizan debido a que se la exigen, pero aun así, algunas veces no es llevada a la práctica. 
En relación a las variables sexo, edad, experiencia laboral y nivel de estudios, Ikonomopoulos et al. (2001) revelaron que las percepciones de los profesores de educación física sobre sus prácticas en la planificación son influenciadas por su experiencia y formación, pero no por su sexo. Siendo los profesores de educación física con más experiencia laboral y mayores estudios más eficientes en el proceso de planificación (Hall y Smith, 2006). Acorde a estos resultados, los entrenadores con más experienccia y con un grado universitario elaboran planes más completos para cada temporada, necesitando planificar con el fin de hacer un mejor trabajo (Vallée y Bloom, 2005). Por otro lado, Côté y Samela (1996), también concluyeron asegurando que los entrenadores de ambos sexos planifican de forma muy similar.

\subsection{LA EVALUACIÓN Y LAS HERRAMIENTAS DE EVALUACIÓN EN LA ACTIVIDAD FÍSICA Y DEPORTE}

La evaluación es la acción cotidiana que todas las personas realizamos con objetivos y finalidades diferentes, la cual es una actividad común y característica del ser humano desde que existe. En las acciones que cada día llevamos a cabo se produce, tanto de manera consciente como inconsciente, un conjunto de valoraciones, estimaciones y comprobaciones que corresponden a procesos evaluativos (Díaz Lucea, 2005).

La evaluación se vincula tradicionalmente al ámbito educativo. Ciertamente ha sido ahí donde ha adquirido mayor relevancia y donde se ha analizado con más intensidad (Blázquez, 1993; Villardón, 2006). 
El nacimiento de la evaluación puede situarse a principios del siglo pasado y va íntimamente ligado al concepto de medición del rendimiento; se considera a Rice su precursor más relevante, sin embargo no es hasta 1904, fecha en que Thorndike publica su obra "Introduction to the theory of mental and social measurement" (Introducción a la teoría de la medición social y mental), cuando se inaugura con plena vigencia (Blázquez, 1993).

La evaluación es definida como la reflexión crítica sobre los componentes y el proceso, con el fin de determinar cuáles están siendo o han sido sus resultados y poder tomar las decisiones más adecuadas para la consecución positiva de los objetivos perseguidos. Además, la evaluación se caracteriza por la necesidad de recoger información sobre el desempeño en diferentes momentos y puede realizarse con instrumentos variados para así tomar decisiones sobre las cuestiones fundamentales de los procesos de enseñanza y aprendizaje (Blázquez, 1990).

En el ámbito deportivo, los temas relativos al control y la valoración del entrenamiento y del rendimiento deportivo preocupan cada vez más a los técnicos, constituyendo un espacio de investigación y estudio. La valoración del deportista es considerada como un elemento clave e importante para constatar los cambios producidos, la eficacia de los métodos y de los recursos empleados y la toma de decisiones (Blázquez, 1993).

En el ámbito educativo se busca conocer el rendimiento de los alumnos, diagnosticar el nivel inicial, valorar la eficacia del sistema de enseñanza, pronosticar las posibilidades del alumnado, motivar a los alumnos y calificarlos (Blázquez, 1993). 


\subsubsection{LOS RECURSOS HUMANOS DE LA ACTIVIDAD FÍSICA Y DEPORTE Y LA EVALUACIÓN}

La evaluación es un elemento muy importante en la enseñanza de la actividad física y deporte y por tanto un paso fundamental en la intervención docente y profesional de los recursos humanos de la actividad física y deporte. Es considerada como uno de los papeles primarios del entrenador deportivo (Kidman y Harahan, 2011) y uno de los aspectos más críticos implicados en el establecimiento de la calidad educativa (Derri, Avgerinos, Emmanouilidou y Kioumourtzoglou, 2012). Con la capacidad de observar y evaluar, la intervención docente puede ser un proceso continuo (Dorgo, 2009), ya que los resultados se utilizan para evaluar la mejora física y los logros de los programas que se llevan a cabo (Dorgo, 2009).

Los profesionales de la actividad física y deporte normalmente desarrollan estrategias a través de un proceso de reflexión (Gilbert y Trudel, 1999). Según estos autores, el proceso de reflexión se compone de seis componentes: las cuestiones del entrenamiento, los roles, el establecimiento de problemas, la generación de estrategias, la experimentación y la evaluación (Gilbert y Trudel, 2001). Otros autores apuntaron que el entrenamiento debe incluir cinco pasos: la recolección de datos, el diagnóstico, la planificación de la acción, la implementación del plan y la evaluación (Cushion, Armour y Jones, 2013). Del proceso de reflexión apuntado por Gilbert y Trudel (2001) a la organización del entrenamiento observado por Cushion et al. (2013), se han llevado a cabo muchas investigaciones y se han propuesto cambios, pero la evaluación siempre ha sido un paso esencial, ya que es necesario que los procedimientos y resultados sean constantemente revisados y evaluados (Cushion et al., 2013). 
Desafortunadamente, la evaluación probablemente constituye el elemento curricular más descuidado en el deporte en edad escolar (Sáenz-López, 2006). Este autor manifiesta que la evaluación también debe ser llevada a cabo en este ámbito valorando los aspectos motores, cognoscitivos y afectivo-sociales a través de los diferentes instrumentos de evaluación, así como la evaluación del proceso de enseñanza-aprendizaje y del profesorado. Del mismo modo, González-Rivera y Campos-Izquierdo (2011) constataron que el 60,7\% de los docentes aseguran no realizar ninguna evaluación del proceso de aprendizaje y de los que afirman realizarla, el 54,5\% manifiesta no emplear ningún instrumento de evaluación.

Contrariamente, Kidman y Harahan, (2011) afirmaron que sus entrenadores normalmente desarrollan estrategias de entrenamiento a través de un proceso de reflexión y evaluación ya que la evaluación es muy importante para ellos. De igual forma, Cregan, Bloom y Reid (2007) en su estudio sobre entrenadores de natación en personas con alguna discapacidad observaron que dichos entrenadores siempre evalúan durante las clases y cuando se acaban los entrenamientos se encargar de dar el feedback pertinente a los deportistas. Asimismo, en el estudio de Gould, Medbery, Damarjian y Lauer (1999), los entrenadores piensan que la evaluación es uno de los aspectos más importantes de todo el entrenamiento. En la misma línea sigue el estudio de Pérez (2002) donde encontramos que todos los entrenadores evalúan los resultados de sus acciones, son críticos y están abiertos a proponer cambios en sus programas si las circunstancias así lo indican. Igualmente, Vallée y Bloom (2005) consideran muy importante la evaluación de los procesos y de los deportistas pero creen que la autoevaluación también es muy importante, la realizan como parte de su proceso de aprendizaje y con ella consiguen mejorar cada día sus clases. 
En cuanto a las variables objeto de estudio y empezando con el sexo, Derri et al. (2012) investigaron que las profesoras de educación física saben cómo evaluar a los estudiantes mejor que sus compañeros varones. Del mismo modo, Papatheofilou, Derri y Kyrgyridisp (2008) encontraron que las percepciones de las profesoras sobre sus prácticas en la evaluación son más altas que las de sus colegas masculinos. En otra línea, Ikonomopoulos et al. (2001) revelaron que las percepciones de los profesores de educación física sobre sus prácticas en evaluación son influenciadas por su experiencia y formación, pero no por su sexo. Siguiendo con la edad, los entrenadores con más experiencia elaboran planes más completos para la temporada, necesitando evaluar con el fin de hacer un mejor trabajo (Vallée y Bloom, 2005). Del mismo modo, los monitores de fitness con más experiencia evalúan con más frecuencia (Da Costa, Álves y Fernandes, 2009). Teniendo en cuenta la formación, Pestana (2006) investigó que los entrenadores con una licenciatura en el ámbito de la actividad física y deporte evalúan más que los que no tienen una licenciatura. Asimismo, los resultados del estudio de González-Rivera y Campos-Izquierdo (2010) en los monitores de actividades físicodeportivas extraescolares sugieren que la intervención docente de las personas no tituladas es menos adecuada. Por último y en relación a la experiencia, los entrenadores deportivos experimentados desarrollan la estrategia de evaluación a través de un proceso de reflexión y experimentación más a menudo que los que tienen menos experiencia laboral (Gilbert y Trudel, 2001).

Los estudios sobre evaluación en los monitores de actividad física y deporte y en los monitores de fitness son bastante escasos. Dentro de estos últimos encontramos los estudios de Alves, Fernandes y Castañer (2008) y Da Costa et al. (2009). El primero expone que los monitores de fitness no evalúan demasiado (Alves et al., 2008) mientas el segundo estudio sostiene que los monitores de fitness sí evalúan y lo hacen 
constantemente, además asegura que los monitores de fitness con más experiencia evalúan con más frecuencia y sostiene que futuras investigaciones deben de relacionar la evaluación de éstos con otras variables como la edad, el sexo o en nivel de estudios (Da Costa et al., 2009).

Debido a la amplia gama de conductas y comportamientos que pueden ser evaluados en la actividad física y deporte, se han generado multitud de instrumentos de evaluación (Díaz Lucea, 2005). Éstos son una pieza clave y gracias a ellos obtenemos los datos que necesitamos de una forma más sencilla. Wright et al. (2012) señalan que hay muchas herramientas de evaluación para utilizar ya que tienen que ser elementos de flexibilidad para poder evaluar a todos los agentes que intervienen en una clase.

Siguiendo a Wright et al. (2012), la observación diaria es la herramienta más utilizada. Apoyando este punto, Cregan et al., (2007) expusieron que los profesionales de la actividad física y deporte son como analizadores; observan aspectos de sus deportistas y deciden mejorar su desempeño. Esto también es apoyado por Kidman y Hanrahan (2011), quienes sostuvieron que la observación debe ser considerada uno de los papeles principales del entrenador. Asimismo Alves et al. (2008) y Da Costa et al. (2009) en sus estudios centrados en el monitor de fitness expusieron que la observación es la herramienta más empleada.

Otra herramienta muy utilizada son las pruebas de ejecución. Díaz Lucea (2005) la destaca ya que ha sido la más utilizada por los profesores de educación física en sus investigaciones.

Asimismo, González-Rivera y Campos-Izquierdo (2011) estudiaron que los monitores de actividades físico-deportivas extraescolares preferentemente utilizan las pruebas de ejecución con un $56 \%$, los tests o pruebas estandarizadas con un $18 \%$, los diarios del profesor con un 16\%; sin embargo los tests confeccionados por ellos mismos 
con un $6 \%$ y, el cronometraje y los exámenes de conocimientos teóricos, con el $2 \%$ cada uno son casi inexistentes.

\subsection{ELEMENTOS QUE PRIORIZAN LOS RECURSOS HUMANOS DE ACTIVIDAD FÍSICA Y DEPORTE EN SU ENSEÑANZA Y DESEMPEÑO PROFESIONAL}

Un elemento importante de la intervención docente y profesional de los recursos humanos de la actividad física y deporte son los aspectos psicológicos, físicos, tácticos, técnicos, actitudinales y conceptuales a tener en cuenta al impartir una clase, muy relacionados con la planificación y con la evaluación anteriormente abordadas.

Una adecuada priorización de estos elementos en las clases es de elevada importancia (Feu et al. 2007), ya que el desarrollo adecuado e integral de los aspectos psicológicos, físicos, tácticos, técnicos, actitudinales y conceptuales de los clientes son de vital importancia (Cagigal, 1964; González-Rivera y Campos-Izquierdo, 2014; Vallée y Bloom, 2005).

Tradicionalmente, los aspectos técnicos y tácticos fueron los que aparecieron con más frecuencia en las clases de actividad física y deporte (Carreras y Giménez, 2010; Fuentes y Gusi, 1996), igualmente la principal preocupación era desarrollar habilidades motrices. Pero, los recientes avances científicos han demostrado la importancia de los procesos cognitivos en la toma de decisiones, la necesidad de proporcionar autonomía al alumnado o la influencia de las emociones en la adecuada elección de respuestas (Iglesias, Cárdenas y Alarcón, 2007). 
Se han encontrado estudios en los que los aspectos técnicos y de actitud fueron los más importantes. Obteniéndose que el modelo técnico es el modelo predominante (Bloom, Crumpton y Anderson, 1999; Carreras y Giménez, 2010) y que todos los entrenadores se encargan de fomentar y enseñar la generosidad, la educación en valores y la disciplina, tres habilidades fundamentales dentro de los aspectos actitudinales, así como los aspectos relacionados con la higiene y salud corporal (Lubanski, 2008). De acuerdo con González-Rivera y Campos-Izquierdo (2010) de entre los aspectos que prioriza el profesorado en la enseñanza de las actividades físico-deportivas extraescolares se encuentran en primer lugar con un 39,6\% los aspectos técnicos, después con un 26,4\% los aspectos físicos, con un $18 \%$ los aspectos actitudinales y con un $12,5 \%$ los aspectos tácticos.

En cuanto a las habilidades tácticas, el estudio de Bloom, Crumpton y Anderson (1999) sostiene que son las más importantes, pero sobre todo en un nivel alto de competición. Otro estudio a favor de los aspectos tácticos es el de Leite, Vicente y Sampaio (2009), en el que se afirma que el trabajo táctico debe ser desarrollado intensivamente entre los 11 y los 14 años, pero sobre todo después de los 19 años, reforzando así la importancia del trabajo táctico en etapas posteriores del desarrollo. También expresó que la táctica es mejor que la técnica para entender los sistemas de juego. De acuerdo con estos últimos autores, la investigación de Fuentes y Gusi (1996) en entrenadores sostiene que el modelo metodológico más representativo de la enseñanza es el táctico.

Por último, el estudio de Roberts, Fairclough, Ryrie y Sharpe (2012) investigó que el trabajar los aspectos físicos es lo que menos importa a los profesores de educación física y a los entrenadores. Contrariamente, en el estudio de Fraile (2001) se establecen diferencias entre la intervención didáctica llevada a cabo por entrenadores de 
deporte escolar y la realizada por el profesorado de educación física: mientras que los primeros destacan los aspectos físicos sobre los actitudinales y los intelectuales del alumnado; los segundos utilizan estrategias de enseñanza que posibilitan una mayor participación en el alumnado.

\subsection{LAS FUENTES DE CONOCIMIENTO EN LA ACTIVIDAD FÍSICA Y DEPORTE}

Tal y como exponen González-Rivera, Campos-Izquierdo, Villalba y Hall, (2017), en el mundo del deporte hay claramente una fuerte creencia acerca del valor inherente de la investigación relacionada con los recursos humanos de la actividad física y deporte y su necesidad de adquisición de conocimientos como un medio para desarrollar adecuadamente la práctica profesional. Esta importancia es evidente en la considerable cantidad de investigaciones que se han publicado sobre las fuentes de conocimiento, sobre todo en la ocupación de entrenador deportivo (Abraham, Collins y Martindale, 2006; Carter y Bloom, 2009; Erickson et al., 2008; Feu, Ibáñez, Lorenzo, Jiménez y Cañadas, 2012; Irwin, Hanton y Kervin, 2004; Lemyre et al., 2007; Nelson et al., 2006; Reade, Rodgers y Hall, 2008; Trudel y Gilbert, 2006; Wilson et al., 2010; Winchester, Culver y Camire, 2013; Wright, Trudel y Culver, 2007).

Por ello, existen estudios que han sugerido que los entrenadores necesitan tener acceso a diferentes oportunidades formativas, para facilitar su desempeño profesional (Carter y Bloom, 2009; Erickson, Bruner, MacDonald y Côté, 2008; Schempp, Webster y McCullick, 2007; Wright et al., 2007). Varios autores además han argumentado que los recursos humanos de la actividad física y deporte tienen diferentes necesidades 
según el contexto en el que trabajan (Côté, Young y North, 2007; Erickson et al., 2008; Winchester et al., 2013).

En consecuencia, la adquisición de conocimientos puede ser por vía formal, por vía informal y por vía no-formal. Se entiende por formación formal a la obtenida en el sistema formal (sistema educativo oficial) con la formación inicial específica (titulación de la actividad física y deporte) (Campos-Izquierdo, 2010; 2016; Coombs y Ahmed, 1974; González-Rivera, et al, 2017; Nelson et al., 2006). Al respecto, como se comentaba en el capítulo anterior, no hay que confundir la formación inicial con la permanente (formación adquirida por vía no formal) ni con otros aprendizajes adquiridos por la vía informal (formación informal), ya que la primera habilita para el ejercicio profesional y la segunda y tercera vías de aprendizaje son un complemento y perfeccionamiento de la primera (Campos-Izquierdo, 2010; 2016). La formación informal se entiende como un conjunto de experiencias y aprendizajes adquiridos fuera del sistema educativo (Feu et al., 2012). Esta formación informal es auto dirigida y está basada en la experiencia personal y en las actividades que se realizan (Nelson et al., 2006). La formación no formal se conceptualiza como toda actividad organizada, sistemática y educativa llevada a cabo fuera del marco del sistema educativo formal para proporcionar aprendizajes seleccionados a subgrupos particulares de la población (Coombs y Ahmed, 1974).

Según Wilson et al. (2010), la formación formal llevaba consigo una formación en las ciencias de la actividad física y del deporte y en experiencias prácticas. Pero se ha visto que partiendo de la base de conocimientos de esta formación formal también se desarrolla una vez que comienzan a trabajar, interactuando con compañeros experimentados y leyendo libros y revistas (Lemyre et al., 2007). Muchos autores investigaron que los profesionales de la actividad física y deporte también usan otras 
fuentes informales como los mentores, los libros, las experiencias personales, la observación de otros profesionales e internet (Lemyre et al., 2007, Nash y Sproule, 2009, Wilson et al., 2010; Wright et al., 2007).

González-Rivera et al. (2017), como se ha comentado anteriormente, explican que en España ha habido escasas investigaciones centradas en las fuentes de conocimiento de los recursos humanos de la actividad física y deporte y las que hay, están centradas en los entrenadores, sobre todo de deportes como el baloncesto, el balonmano y el fútbol (Feu et al, 2012; Jiménez, Lorenzo y Gómez, 2009). En cambio la bibliografía existente sobre este tema es mucho mayor en otros países (Abraham et al., 2006; Carter y Bloom, 2009; Erickson et al., 2008; Irwin et al., 2004; Lemyre et al., 2007; Nelson et al., 2006; Reade et al., 2008; Wilson et al., 2010; Winchester et al., 2013). Todos estos estudios llevados a cabo han sugerido que es necesario reflexionar sobre las fuentes de conocimiento de los recursos humanos de la actividad física y deporte, ya que adquieren sus conocimientos profesionales a través de diferentes vías, más allá y como complemento de la educación formal.

En el ámbito deportivo, las primeras experiencias formativas informales se inician durante la infancia y la adolescencia, adquiridas como alumno (Côté, 2006), observando a los entrenadores y como espectador del deporte. Estas experiencias previas favorecen la socialización del futuro profesional (Lemyre et al, 2007) pero no garantizan una formación adecuada para los futuros profesionales y como tal, es necesaria la formación formal con la formación inicial específica (titulación de la actividad física y deporte) para el adecuado desempeño profesional y que se pueda garantizar los distintos beneficios de la actividad física y deporte así como la salud, seguridad e integridad física de los clientes (Bain, 1990; Campos-Izquierdo, 2010; 2016). 
Lemyre et al., (2007) demostraron que los entrenadores no solo aprenden a través de los programas educativos formales, sino que partiendo de estos, aprenden a través de otras fuentes informales como son: la observación y charlas con entrenadores más expertos, la experiencia propia, la competición y con la existencia de un mentor.

Por su parte, Feu et al., (2012), Lemyre et al., (2007) y Wright et al. (2007) exponen que el aprendizaje a través de la experiencia es un componente básico del desarrollo del entrenador. Por ello, los propios entrenadores valoran la práctica como parte fundamental de su formación inicial y como fuente importante de conocimiento (Giménez, 2000).

Por otro lado, el aprendizaje a través de la interacción y discusión con otros profesionales es también central en la teoría del aprendizaje social de Wenger (1998) y en los estudios de Erickson et al. (2008), Gilber y Trudel (2001), González-Rivera et al., (2017), Lemyre et al. (2007), Mesquita, Isidro y Rosado (2010) y Stacey et al., (2010) los cuales encontraron que los entrenadores usan esa fuente de conocimiento generalmente para resolver sus problemas del día a día. Ghaye y Ghaye, (2001) y Stacey et al. (2010) añaden que los profesionales de la actividad física y deporte aprenden hablando con otros profesionales acerca de su práctica, interactuando con ellos y observándolos. La mentoría se destaca a menudo como una de las maneras más importantes de ayudar al desarrollo de los profesionales de la actividad física y deporte (Stacey et al., 2010; Wright et al., 2007). Siguiendo la tendencia confirmada en Stacey et al (2010), el trabajo en red con los colegas es una de las fuentes de información más comunes de los monitores de fitness, destacando las comunidades de práctica y los líderes de opinión locales. La interacción con otros profesionales es una fuente muy importante de conocimiento y se ha encontrado que se valora muy positivamente (Erickson et al., 2008). Como resultado, existen actualmente numerosos ejemplos de 
iniciativas de desarrollo en todo el mundo que incorporan comunidades de práctica para el aprendizaje y el intercambio de conocimientos (Culver y Trudel, 2008).

La observación de compañeros u otros profesionales es otra fuente real, valiosa y preferida para adquirir conocimiento por parte de los entrenadores (Erickson et al., 2008; González-Rivera et al., 2017), ya que puede proporcionar una mayor comprensión del juego y ayudar a los profesionales de actividad física y deporte a aprender a interactuar con sus deportistas. Más específicamente, pueden aprender qué hacer y qué no hacer debido a los errores observados previamente en otros compañeros.

Abad, Benito, Giménez, y Robles (2011) y Stacey et al. (2010), por otra parte, en sus investigaciones con entrenadores de fútbol y monitores de fitness respectivamente, afirmaron que los cursos se consideran de menor calidad debido a la ausencia de revisión de conocimientos y a que probablemente sean anticuados. Abad et al. (2011) también indicaron que los entrenadores de fútbol asisten a cursos y seminarios formales destinados a mejorar la práctica profesional, pero que prefieren el intercambio de opiniones y experiencias con otros entrenadores. Este hallazgo va en la línea de la investigación de Nash y Sproule (2009) los cuales afirman que los cursos en su forma actual no permiten a los entrenadores satisfacer sus necesidades y no son útiles para sus entrenamientos. De la misma manera, Lemyre et al. (2007) encontraron que los cursos teóricos son percibidos de relevancia limitada pero que los entrenadores deportivos más jóvenes suelen usar la información que en ellos aprenden. Sin embargo, de forma contraria, Erickson et al. (2008) y Mesquita et al. (2010) investigaron que los cursos son útiles a los entrenadores que ellos investigaron. Siguiendo a estos últimos estudios, Wright et al. (2007) informaron de que los entrenadores parecen disfrutar yendo a los cursos y utilizándolos en sus clases. Asimismo, Juan-Llamas (2015) en su estudio realizado en monitores de fitness sostuvo que los cursos eran muy importantes y 
el $56,7 \%$ de los profesionales entrevistados declaran tomar parte en ellos de una a tres veces al año, o más de tres veces al año.

El estudio de Feu et al. (2012) en entrenadores de balonmano expuso que el conocimiento utilizado durante los entrenamientos proviene principalmente de la formación inicial, seguido de las experiencias que adquirieron cuando eran deportistas y de las experiencias profesionales. Estas fuentes de conocimiento también son apoyadas por el estudio de González-Rivera et al. (2017).

Otra fuente de conocimiento útil para los recursos humanos de la actividad física y deporte son los recursos tecnológicos o el internet (Juan-Llamas, 2015). Forsyth, Handcock, Rose y Jenkins (2005) y Stacey et al. (2010) investigaron que el principal uso de internet es localizar sitios web donde puedan acceder a una base de datos de ejercicios o crear los suyos propios (Wright et al., 2007). Internet es una fuente importante también porque les ayuda a adquirir nuevas ideas de entrenamiento (Wilson et al., 2010) e interactuar con sus compañeros (Wright et al., 2007). Además, los entrenadores están utilizando internet como una estrategia para resolver problemas específicos y puntuales (Erickson et al., 2008).

Por último, Stacey et al. (2010) descubrieron que las revistas de fitness y los documentos de investigación eran fuentes de conocimiento usadas por los monitores de fitness. Otros estudios como los de Nelson et al. (2006) también señalan la importancia del autoaprendizaje a través de las lecturas de libros y revistas especializadas.

En cuanto a las variables objeto de estudio, el nivel educativo es identificado como un factor influyente en el uso de las fuentes de conocimiento (Stacey et al., 2010). Los monitores de fitness con niveles más altos de educación son más propensos a usar fuentes de mayor evidencia académica y científica en comparación con aquellos con niveles más bajos de educación (Stacey et al., 2010). En la ocupación de entrenador, los 
entrenadores con niveles más altos de educación usan más el conocimiento que adquieren a lo largo de su vida profesional (Feu et al., 2012). En lo que respecta a la experiencia laboral, los entrenadores con menos experiencia laboral suelen usar sus experiencias como estudiante de educación física o como usuario de actividades deportivas (Feu et al., 2012; Lemyre et al., 2007). Además, tienden a apreciar los programas de educación formal como los cursos, ya que les proporcionan información concreta sobre lo que deben hacer y también les brindan la oportunidad de relacionarse con otros compañeros de profesión (Lemyre et al., 2007). Sin embargo, aquellos con más experiencia frecuentemente utilizan su experiencia personal como principal fuente de conocimiento (Feu et al., 2012).

Con respecto al sexo encontramos que ambos entrenadores en el estudio de González-Rivera et al. (2017) indicaron con mayor frecuencia utilizar las mismas fuentes de conocimiento pero en orden diferente. De esta forma los varones expresan utilizar el intercambio con otros profesionales, seguido de la experiencia previa como deportista y de la observación a otros profesionales como fuentes principales de conocimiento. Y por otro lado, las entrenadoras dan prioridad a la observación de otros entrenadores, después al intercambio con otros profesionales y a continuación la experiencia como deportista (González-Rivera et al., 2017).

Dentro de la investigación de las fuentes de conocimiento en los monitores de fitness nos encontramos los estudios de Stacey et al (2010) y Juan-Llamas (2015). En el estudio de Stacey et al (2010) observamos que para los monitores de fitness la interacción y la observación de otros compañeros de profesión son dos fuentes importantes de conocimiento, al igual que internet, las revistas de fitness y los documentos de investigación, observándose que cuanto más formados están los monitores de fitness utilizan fuentes de mayor evidencia científica. Por el contrario, 
sienten que los cursos son de menor calidad. Por otro lado, Juan-Llamas (2015) expresó que se los monitores de fitness utilizan frecuentemente los cursos e internet para el desarrollo de sus clases. 
CAPÍTULO 3. LA SATISFACCIÓN LABORAL DE LOS RECURSOS HUMANOS DE LA ACTIVIDAD FÍSICA Y DEPORTE: EL MONITOR DE ACTIVIDAD FÍSICA Y DEPORTE Y EL MONITOR DE FITNESS 



\section{CAPÍTULO 3. LA SATISFACCIÓN LABORAL DE LOS RECURSOS HUMANOS DE LA ACTIVIDAD FÍSICA Y DEPORTE: EL MONITOR DE ACTIVIDAD FÍSICA Y DEPORTE Y EL MONITOR DE FITNESS}

La satisfacción laboral constituye una dimensión actitudinal que ocupa un lugar central en la consideración de la experiencia del hombre en el trabajo (Aldag y Brief, 1978). El trabajo que desempeñan cada día los recursos humanos de actividad física y deporte no es sólo una fuente principal de ingresos, sino también una parte importante de su vida que contribuye a su posición social, a desarrollarse como personas y a mejorar el bienestar de la sociedad. En este sentido, la búsqueda de la comprensión de las causas de satisfacción y/o insatisfacción que se experimentan en el trabajo es un área de interés constante para los científicos sociales, gerentes y responsables de políticas en todo el mundo (Landy y Trumbo, 1980). Los empleados satisfechos serán más productivos y permanecerán con la organización para la que trabajan durante más tiempo. Además suelen ser más creativos e innovadores pudiendo llegar a conseguir los avances que permiten a una institución crecer y cambiar positivamente (Sharma y Jyoti, 2009). Sin embargo los empleados insatisfechos serán menos productivos y tenderán a abandonar su puesto de trabajo (Sarker, Crossman y Chinmeteepituck, 2003). Disponer de trabajadores satisfechos y motivados será uno de los factores determinantes del éxito organizacional mientras que si el personal no se siente satisfecho, la organización no podrá alcanzar unos niveles de calidad competitivos, ni podrá dar un buen servicio al cliente (Stewart, 1996).

El interés por la satisfacción laboral como un aspecto fundamental del comportamiento organizacional puede decirse que tiene su origen en Hoppock (1935), quien la definió como la satisfacción fisiológica de los empleados con las circunstancias 
ambientales y explicó que la satisfacción es uno de los resultados más importantes del trabajo humano, existiendo una relación implícita o explícita entre satisfacción y desempeño profesional. Desde que Hoppock desarrolló el concepto de satisfacción laboral, numerosos estudios han explorado este tema llegándose a convertir en un uno de los factores relativos al trabajo más estudiados en psicología (Koustelios et al., 2003). La satisfacción en el trabajo ha sido definida de varias maneras, siendo las definiciones más utilizadas las de Arnold y Feldman (1988), Balzer et al. (1990), Chelladurai (1999), Chelladurai y Ogasawara, (2003), Davis y Newstrom (1999), Dawis y Lofquist (1984), Gruneberg (1979), Locke (1976) y Porter, Lawler y Hackman (1975).

Locke (1976) definió la satisfacción laboral como una respuesta emocional positiva al puesto de trabajo y que resulta de evaluar si dicho puesto cumple, o permite cumplir, las expectativas del individuo. En el polo opuesto sitúa la insatisfacción laboral como una respuesta emocional negativa hacia el puesto de trabajo haciendo que éste no cumpla con las expectativas del trabajador (Locke, 1976). Por otro lado, Gruneberg (1979) definió la satisfacción laboral como la variable de actitud, responsable de cómo se sienten las personas, en relación a sus puestos de trabajo y diferentes aspectos relacionados con ellos. Igualmente, Dawis y Lofquist (1984) definieron la satisfacción en el trabajo como resultado de la evaluación del trabajador sobre el grado en que el ambiente de trabajo satisface las necesidades del individuo. Por su parte, Porter et al. (1975) definieron la satisfacción laboral como una reacción hacia su ocupación u organización. Arnold y Feldman (1988), por otro lado y coincidiendo con Gruneberg, ven la satisfacción laboral como la cantidad de sentimientos positivos generales que las personas tienen acerca de sus experiencias laborales. Balzer et al. (1990) añaden que la satisfacción en el trabajo se describe como los sentimientos de las experiencias laborales 
en relación con experiencias anteriores, expectativas actuales o alternativas disponibles. Por último, otra de las definiciones más difundidas es la propuesta por Davis y Newstrom (1999), según la cual la satisfacción es concebida como un concepto multidimensional que incluye un conjunto de sentimientos favorables y desfavorables del individuo frente a su trabajo y que agrupa diversos factores distinguiendo entre aquellos que están directamente relacionados con la naturaleza de la tarea desempeñada y aquellos relativos al contexto laboral.

En los últimos años ha sido publicada una considerable cantidad de investigaciones sobre la satisfacción laboral (Brunet, 1983; Chelladurai y Ogasawara, 2003; Koustelios et al., 2003; Locke, 1976; 1984; Moodley y Coopoo, 2006; Sing y Surujlal, 2006). Entre otras razones, tal volumen de investigación se justifica por la relación entre la satisfacción laboral de los empleados con la productividad. Así, por ejemplo, se han hecho investigaciones sobre la satisfacción y el compromiso con la organización (Mathieu, 1991), la satisfacción y el absentismo y la rotación del personal (Porter, Steers, Mowday y Boulian, 1974) y la satisfacción y el rendimiento (Petty, McGee y Cavender, 1984). También han tenido un ligero incremento las investigaciones que estudian cuáles son los factores que afectan a la satisfacción laboral (Chelladurai y Ogasawara, 2003; Koustelios et al., 2003; Moodley y Coopoo, 2006; Sing y Surujlal, 2006).

En cuanto a los factores que afecta a la satisfacción laboral, Herzberg, Mausner, y Snyderman, (1959) clasificaron cinco factores relacionados con el trabajo que afectan a las actitudes laborales en una dirección positiva y tiende a contribuir al aumento de la satisfacción. Estos factores son: el logro, el reconocimiento, el trabajo en sí, la responsabilidad y el progreso. Por otro lado, encontraron once factores relacionados con el ambiente de trabajo que contribuyen a la satisfacción o insatisfacción laboral, tales 
como: el salario, el desafío laboral, las relaciones interpersonales con sus jefes, las relaciones interpersonales con sus subordinados, las relaciones interpersonales con los compañeros, la supervisión, la política de la empresa, las condiciones de trabajo, la vida personal y la seguridad laboral. Asimismo, estos autores junto con Kano (1984) y Matzler, Fuchs, y Schubert (2004) argumentaron que la satisfacción y la insatisfacción son en realidad constructos distintos en lugar de extremos opuestos. Como tal, la relación entre diversos factores y la satisfacción o insatisfacción experimentada no es necesariamente lineal. Por ejemplo, Herzberg y sus colegas (1959) expusieron que factores como el desafío laboral están relacionados con la satisfacción, pero no con la insatisfacción, mientras que otros factores como la supervisión están relacionados con la insatisfacción, pero no con la satisfacción. Estos estudiosos (Herzberg et al., 1959; Kano, 1984; Matzler et al., 2004) argumentaron que saber qué factores están relacionados con qué resultados puede ayudar a los gerentes a diagnosticar problemas y motivar a los empleados de manera más efectiva. Este modelo del doble factor satisfacción/insatisfacción ha recibido mucho apoyo en la investigación posterior. Por ejemplo, Chelladurai y Ogasawara (2003) y Raedeke, Warren y Granzyk (2002), a pesar de no abordar la insatisfacción en sus estudios, apoyaron a este modelo en las investigaciones de entrenadores. Sin embargo, los críticos del modelo de Herzberg han argumentado que tiene dos limitaciones principales. En primer lugar, ha sido difícil replicar los resultados de su estudio con una metodología distinta de la técnica de incidente crítico (Friedlander, 1964; Hulin y Smith, 1967). Es decir, generalmente cuando se pide a las personas que recuerden eventos, tienden a atribuir resultados positivos a sus propios esfuerzos y habilidades y atribuyen los resultados negativos a otros agentes (Vroom, 1964). Una segunda limitación es que no todos los factores del trabajo se asignan exclusivamente a la satisfacción o insatisfacción. 
Por otra parte, Lawler y Porter (1967) sostienen que la satisfacción laboral se consigue a través de un trabajo mentalmente desafiante, con recompensas equitativas, unas condiciones de trabajo apropiadas y unas adecuadas relaciones con los compañeros.

Locke (1976) unos años más tarde, fue otro de los autores en profundizar sobre el tema y considerar que el nivel de satisfacción laboral es el sumatorio de una combinación de aspectos que el profesional valora en su trabajo. En concreto, distingue entre eventos o condiciones y agentes de satisfacción laboral. Dentro de los eventos o condiciones incluye los aspectos asociados a la satisfacción con el interés intrínseco del trabajo como: la variedad y la cantidad del mismo, las oportunidades de aprendizaje, su dificultad, las posibilidades de éxito, el control sobre los procedimientos, la retribución cuantitativa, las promociones a partir de las oportunidades de formación, el reconocimiento recibido por el desarrollo de las tareas, la retribución extra salarial y las condiciones de trabajo. Entre los agentes que posibilitan lo anterior destaca la satisfacción con el estilo de supervisión, las relaciones con los jefes, las relaciones personales con los compañeros y la dirección y la empresa en general.

Por otra parte, Puchol (1997) recoge las relaciones interpersonales, la naturaleza del trabajo, la promoción y las posibilidades de mejora, la retribución y la seguridad como las variables que proporcionan satisfacción a los trabajadores. Por su parte y de una forma mucho más sencilla, Leal, Alfaro De Prado, Rodríguez y Román (1999) destacan entre las variables que inciden en la satisfacción de los empleados: el salario, la relación con los superiores y compañeros y las oportunidades de promoción. Para Robbins (2004) la satisfacción en el trabajo está determinada por el atractivo de la tarea, las recompensas asociadas, las relaciones con los compañeros de trabajo y las condiciones laborales a las que los empleados están expuestos. Igualmente, García- 
Bernal, Gargallo, Marzo y Rivera (2005) obtuvieron cuatro factores con los cuales los trabajadores obtienen satisfacción laboral: los relacionados con la realización personal en el empleo, las condiciones de trabajo, las relaciones interpersonales y los aspectos económicos.

En España, para conocer cuáles son los factores que afectan a la satisfacción, surgió el Cuestionario General de Satisfacción en Organizaciones Laborales S4/82 con un muestreo de contenido muy amplio y con el fin de disponer de una medida específica (Meliá, Peiró y Calatayud, 1984). Pero en la búsqueda de nuevas formas del cuestionario de satisfacción que fueran sustancialmente más cortas y ligeras pero manteniendo a la vez la utilidad diagnóstica, la fiabilidad y la validez, se presenta la versión S20/23 que consta de 23 ítems y que puede considerarse como la versión reducida más completa estructuralmente para conocer la satisfacción laboral (Meliá y

Peiró, 1989). Éste último cuestionario se ha tomado como modelo y guía para elaborar el apartado de satisfacción laboral dentro del cuestionario "PROAFIDE. Recursos humanos de la actividad física y deporte" (Campos-Izquierdo, 2011) de la investigación que nos ocupa.

\subsection{LA SATISFACCIÓN LABORAL DE LOS RECURSOS HUMANOS DE LA ACTIVIDAD FÍSICA Y DEPORTE}

Centrándonos en la definición de satisfacción laboral en el ámbito deportivo, Chelladurai (1999) considera que es una condición afectiva placentera que resulta de la valoración de la manera en que la situación laboral experimentada satisface las necesidades, los valores y las expectativas de cada uno. Chelladurai y Ogasawara, 
(2003) por su parte definieron satisfacción laboral como un estado afectivo positivo resultante de una evaluación compleja de las estructuras, procesos y resultados asociados con la experiencia de entrenar. Para concluir, en general, la satisfacción laboral es una reacción afectiva a un trabajo que resulta de la comparación de los resultados reales con aquellos que se desean, se anticipan o se merecen (Oshagbemi, 2000).

En este sentido, la satisfacción en el ámbito deportivo también ha sido objeto de multitud de estudios (Barrett, Gillentine, Lamberth y Daughtrey, 2002; Chelladurai y Ogasawara, 2003; Moodley y Coopoo, 2006; Sing y Surujlal, 2006). Las organizaciones deportivas se enfrentan hoy en día a una mayor competencia a nivel mundial, lo que genera una mayor expectativa de resultados. Esto tiene un impacto en los recursos humanos de actividad física y deporte y en las organizaciones deportivas (Chelladurai y Ogasawara, 2003), experimentando así mayores presiones con respecto al reconocimiento por el trabajo realizado, la relación con los compañeros, la supervisión etc., influyendo todo ello en su satisfacción laboral (Akindutire, 1993). Si los profesionales de la actividad física y deporte están satisfechos con su trabajo, imparten mejores clases y preparan mejor a los clientes, usuarios y deportistas aumentando su productividad e influyendo en su compromiso (Moodley y Coopoo, 2006). Con ello mejoran su desempeño laboral y contribuyen al éxito de la organización (Dixon y Warner, 2010; Raedeke et al., 2002). Campos-Izquierdo (2010) sostiene que la satisfacción laboral de los recursos humanos en el campo de la actividad física y deporte es un factor fundamental para su desempeño laboral y calidad del servicio. En resumen, un mejor desempeño en el trabajo y la calidad del servicio podrían asegurar los beneficios educativos, sociales y de salud para la sociedad (Moodley y Coopoo, 2006). 
La satisfacción de los profesionales de la actividad física y deporte es de considerable importancia para el éxito de las organizaciones deportivas (Li, 1993). Esto se debe a que están frecuentemente en contacto directo con los clientes y si están satisfechos, una imagen positiva de la organización deportiva puede ser comunicada a los clientes. Además, es lógico suponer que unos profesionales de la actividad física y deporte satisfechos contribuyen al éxito de la organización y a la adecuada calidad de los servicios de actividad física y deporte ofrecidos y desarrollados.

La inculcación de la satisfacción laboral es una tarea crucial de la dirección y organización de actividad física y deporte, ya que la satisfacción en el trabajo crea confianza, lealtad, mejora de la calidad y aumento de la producción. Pero ésta, sin embargo, no resulta simplemente de ofrecer más incentivos a los empleados ya que no es un estado estático, sino que está sujeta a influencia y modificación de las fuerzas dentro y fuera del individuo (Lam, 1995).

En general, los profesionales que trabajan en la actividad física y deporte están satisfechos con su trabajo, teniendo una satisfacción entre moderada y alta (Chelladurai y Ogasawara, 2003; Koehler, 1988; Koustelios et al., 2003; Moodley y Coopoo, 2006). Sin embargo, en otros países como Estados Unidos, cada año, un número considerable de profesionales de la actividad física y deporte abandonan sus puestos de trabajo (Raedeke et al., 2002). Contrariamente a los investigado por la mayoría de autores dentro del ámbito de la actividad física y deporte, esto puede deberse a que se sienten insatisfechos con su trabajo y optan por dejarlos (Singh y Surujlal, 2006). 


\subsection{LOS DETERMINANTES QUE INFLUYEN EN LA SATISFACCIÓN LABORAL DE LOS RECURSOS HUMANOS DE LA ACTIVIDAD FÍSICA Y DEPORTE}

Tras establecer el concepto de satisfacción laboral, así como las principales teorías, e identificar la satisfacción de los trabajadores de la actividad física y deporte, es necesario profundizar en los factores que inciden en ella, por ello en este apartado, nos vamos a aproximar a la búsqueda de los factores que proporcionan satisfacción en el trabajo a los recursos humanos de actividad física y deporte.

En el ámbito deportivo, Oshagbemi (1997) investigó que hay muchos factores que pueden contribuir a la satisfacción laboral de los entrenadores deportivos. Entre estos factores están el logro, la supervisión, la responsabilidad, el trabajo en sí mismo, la compensación económica, la seguridad y las condiciones de trabajo. Rogers, Clow y Kash (1994) añaden que el conflicto de roles y la falta de comunicación efectiva dentro de la organización contribuyen a la tensión laboral, lo que a su vez conduce a una disminución en la satisfacción laboral, pudiendo tener un impacto negativo en la productividad y en el éxito del deportista o del equipo.

Por su parte, Koehler (1998) investigó a gerentes de fitness los cuales experimentan satisfacción con su empleo general, los servicios, los valores morales y los logros y, por el contrario sienten menor satisfacción con la supervisión, la falta de oportunidades de ascenso y el sueldo.

Siguiendo a Chelladurai (1999), la satisfacción laboral de los entrenadores deportivos es significativa a tres niveles, a saber, el nivel humanitario, el nivel económico y el nivel teórico. A nivel humanitario, los entrenadores deportivos están preocupados por el bienestar, logros y actuaciones de sus deportistas. En el nivel 
económico obtenemos que si los profesionales están satisfechos con su sueldo están también satisfechos con su trabajo. Y por último, a nivel teórico, siendo más satisfechos cuando tienen mayor entusiasmo, mayor motivación y menos accidentes relacionados con el trabajo. Asimismo, Chelladurai y Ogasawara (2003) estudiaron la satisfacción laboral en los entrenadores americanos y japoneses obteniendo que los factores mejor valorados en cuanto a que proporcionan una mayor satisfacción laboral son el trabajo en sí mismo y la autonomía, por el contrario están menos satisfechos con el salario y con el apoyo de los medios de comunicación. Algo parecido ocurrió en la investigación de Singh y Surujlal (2006) llevada a cabo en entrenadores sudafricanos, los cuales aprecian satisfacción con el trabajo en sí mismo pero insatisfacción con el salario, con el apoyo de los medios de comunicación, con la seguridad y con el trabajo administrativo. En la misma línea, Barrett et al. (2002) obtuvieron que los entrenadores de atletismo no están satisfechos con el salario, siendo el factor con el que están más insatisfechos.

Por otra parte, Smucker y Kent (2004) analizaron la satisfacción laboral comparándola con tres segmentos diferentes de trabajadores de la industria del deporte. Los resultados del estudio mostraron una relación entre la promoción y la satisfacción laboral. Si los empleados no son ascendidos cuando se consideraban dignos de promoción, tienen bajos grados de satisfacción en el trabajo. Los encuestados indican también insatisfacción laboral con respecto a salarios bajos y condiciones de trabajo negativas.

Finalmente, los profesores de educación física de educación secundaria de Grecia parecen estar más satisfechos con el trabajo en sí, la supervisión y con las condiciones de trabajo, aunque están insatisfechos con el salario y la organización en general (Koustelios y Tsigilis, 2005). Unos resultados relativamente similares fueron encontrados por Zournatzi, Tsiggilis, Koustelios y Pintzopoulou (2006) en los 
profesores griegos procedentes de escuelas primarias y secundarias. Por un lado los profesores de educación primaria revelaron niveles ligeramente superiores de satisfacción por el salario y la organización en su conjunto, mientras que los profesores de educación secundaria mostraron niveles ligeramente superiores de satisfacción por las condiciones de trabajo, el trabajo en sí mismo y la supervisión. En el 2009, un estudio similar en profesores de educación física griegos concretó que están satisfechos con el trabajo en sí mismo y con la supervisión pero insatisfechos con las oportunidades de promoción y el salario (Amarantidou et al., 2009).

Pocos estudios han examinado la relación entre la satisfacción laboral y las variables como la edad, la experiencia laboral y la formación. En cuanto al sexo, parece que no hay resultados claros. Siguiendo al estudio de Koustelios (2001), las profesoras de educación física están más satisfechas que sus colegas masculinos. De manera diferente, Moodley y Coopoo (2006) investigaron que los monitores de fitness masculinos están más satisfechos con su trabajo que las mujeres y Howell y Higgins (2005) explicaron que los trabajadores masculinos empleados en programas recreativos estadounidenses y canadienses poseen mayores niveles de satisfacción laboral que las mujeres. Sin embargo, Antoniou, Kourtessis, Koustelios y Papaioannou (2007) informaron de que no hay diferencias en la satisfacción laboral entre profesores de educación física hombres y mujeres. Los mismos resultados se mencionaron en el estudio de Barrett et al. (2002) y Liu y Ramsey (2008), los cuales explicaron que las diferencias de sexo no afectan directamente a la satisfacción laboral.

En cuanto a la edad, los niveles más altos de satisfacción laboral tienden a estar relacionados con una edad más avanzada y con una dilatada experiencia laboral (Barrett et al., 2002; Davis y Newstrom, 1999). 
Los estudios sobre satisfacción laboral en los monitores de actividad física y deporte son muy escasos y los referidos a los monitores de fitness aunque son algo más abundantes igualmente siguen siendo insuficientes, sobre todo si nos centramos en el panorama español. A continuación se detalla las investigaciones al respecto de las dos ocupaciones objeto de estudio en esta investigación.

Respecto a los monitores deportivos, más concretamente los monitores de fitness, Koustelios et al. (2003) obtuvieron una correlación significativamente positiva entre la satisfacción laboral y la seguridad profesional, el trabajo en sí mismo, la supervisión, las condiciones laborales y la organización; en cambio experimentan insatisfacción con respecto al salario. Otra fuente de satisfacción es la relacionada con la educación para la salud y corresponde a mejorar la calidad de vida de las personas.

Unos años más tarde, Moodley y Coopoo (2006) siguieron investigando el panorama de los monitores de fitness encontrando que el salario, las oportunidades de promoción, la falta de oportunidades de formación y las condiciones de trabajo son factores con los que los monitores experimentaban insatisfacción.

Igualmente, Barranco (2003) estudió sobre los profesionales del sector del fitness, obteniendo relaciones significativas entre las buenas prácticas de gestión en el entorno de trabajo y la satisfacción laboral, de manera que trabajar en entornos con una mayor presencia de buenas prácticas de gestión se relaciona con un nivel de satisfacción laboral más alto.

Por su parte, Liu y Xu (2016) estudiaron a los monitores de actividad física y deporte de China, determinando que, aunque muchos factores contribuyen a la satisfacción laboral, los profesionales chinos no están muy satisfechos con su trabajo y eso conlleva a que muy pocos profesionales quieran trabajar en esta ocupación. Por ello 
recomiendan establecer incentivos, recompensas y otras variables para atraer a profesionales de la actividad física y deporte. 

CAPÍTULO 4. OBJETIVOS Y MARCO

METODOLÓGICO 



\section{CAPÍTULO 4. OBJETIVOS Y MARCO METODOLÓGICO}

En este capítulo se describen los diferentes pasos que se han seguido en la realización de la investigación aquí presente. En primer lugar, se definen los objetivos de la investigación y, a continuación, se describe la metodología utilizada, dentro de la cual se especifica: la población objeto de estudio, el diseño de la muestra, el instrumento de recogida de la información utilizado, el proceso seguido de recogida de la información, el procesamiento realizado de los datos obtenidos y el análisis e interpretación de dicha información.

El proceso científico seguido se fundamenta, por un lado, en las orientaciones y criterios de los siguientes expertos en metodología de investigación: Cea (2004), García Ferrando (2002), Heinemann (2003), Rodríguez (2002) y Sierra Bravo (2001). Por otro lado, se basa en los siguientes estudios: "Situación profesional de las personas que trabajan en funciones de actividad física y deporte en la Comunidad Autónoma Valenciana" (Campos-Izquierdo, 2005), "Los recursos humanos de la actividad física y deporte en la Comunidad Valenciana” (Martínez-Serrano, 2007), "El deporte escolar en la Comunidad de Madrid: intervención didáctica y recursos humanos en las actividades físico-deportivas extraescolares en los centros educativos (González-Rivera, 2008), "Situation of human resources for physical activity and sport in the area of Coslada" (Situación de los recursos humanos de la actividad física y deporte en la zona de Coslada) (Gallardo y Campos-Izquierdo, 2011) y "Perfil del entrenador de fútbol en la etapa escolar en escuelas de clubes de élite de la Comunitat Valenciana" (Lledo, Martínez-Serrano y Huertas, 2014). 


\subsection{OBJETIVOS DEL ESTUDIO}

Esta investigación se realiza con el propósito general de conocer la intervención docente y situación profesional (formación general: formación inicial general y formación permanente; y satisfacción laboral) de los recursos humanos de la actividad física y deporte que trabajan como monitores de actividad física y deporte y como monitores de fitness en España. Esta investigación forma parte del Proyecto de Investigación Fundamental no orientada de I+D+i DEP2009-12828 que ha sido financiada por el Ministerio de Ciencia e Innovación de España y dirigida por el doctor Antonio Campos Izquierdo.

Los objetivos de esta investigación son los siguientes:

- Analizar la formación general inicial de los monitores de actividad física y deporte y de los monitores de fitness y analizar su formación permanente y la interacción con las variables: sexo, edad, nivel de estudios y experiencia laboral.

- Conocer la planificación, la evaluación, las fuentes de conocimiento utilizadas y la importancia que otorgan a los aspectos técnicos, tácticos, físicos, psicológicos, actitudinales y conceptuales los monitores de actividad física y deporte y los monitores de fitness y su interacción con las variables: sexo, edad, nivel de estudios y experiencia laboral.

- Conocer la satisfacción laboral de los monitores de actividad física y deporte y los monitores de fitness y su interacción con las variables: sexo y edad. 


\subsection{METODOLOGÍA (DISEÑO DE LA INVESTIGACIÓN)}

En este estudio se describen la formación general (inicial y permanente), la intervención docente y profesional y la satisfacción laboral de los monitores de actividad física y deporte y de los monitores de fitness en España. La investigación aquí presentada forma parte del Proyecto de Investigación Fundamental no orientada de I+D+i DEP2009-12828 que ha sido financiada por el Ministerio de Ciencia e Innovación de España y dirigida por Antonio Campos Izquierdo (Campos-Izquierdo, 2013).

La metodología seguida en esta investigación ha sido cuantitativa de corte descriptivo (Thomas, Nelson y Silverman, 2011) ya que tiene la finalidad de describir los hechos para obtener las características de una población de forma objetiva (Alvira, 2002; Cea, 1998; Cervelló y Moreno, 2001). Los procedimientos fueron los propios de una encuesta seccional (García Ferrando, 2002).

El tipo de método descriptivo que se ha utilizado para realizar esta investigación ha sido la encuesta, en la cual de forma estandarizada, se realiza una obtención de datos a través de preguntas dirigidas a la muestra de la población estudiada (personas que trabajan en funciones laborales y ocupaciones de actividad física y deporte en España) con la intención de conocer y describir cuantitativamente los diferentes parámetros determinados en los objetivos de la investigación, y la posibilidad de comparar la información obtenida y analizarla estadísticamente (Campos-Izquierdo, 2005; García Ferrando, 1990).

La investigación fue de corte transversal, donde la recogida de la información se llevó a cabo en un único periodo (año 2011) aunque dividido en cuatro momentos estacionales (invierno, primavera, verano y otoño). Esta actuación se realiza para 
conocer con mayor profundidad y rigor toda la población objeto de estudio (CamposIzquierdo, 2005; 2013; 2016; Cea, 1998).

\subsubsection{POBLACIÓN OBJETO DE ESTUDIO}

En este apartado se va a realizar la descripción de la población objeto de estudio de esta investigación así como la delimitación del universo objeto de estudio.

\subsubsection{Descripción de la población objeto de estudio}

En esta tesis doctoral, la cual forma parte del Proyecto de Investigación Fundamental no orientada de I+D+i DEP2009-12828, la población estudiada es el conjunto de personas que trabajan como monitores de actividad física y deporte y como monitores de fitness en España, siendo estas ocupaciones de la actividad física y deporte según lo determinado por Campos-Izquierdo et al. (2016). Las funciones laborales que realizan la población objeto de estudio son: enseñar actividad física y deporte, en el caso de los monitores de actividad física y deporte y desarrollar acondicionamiento físico básico grupal, en el caso de los monitores de fitness, funciones laborales estándar de actividad física y deporte según lo determinado por Campos-Izquierdo et al. (2016). Asimismo, estas dos ocupaciones están reguladas y descritas en las leyes que ordenan las profesiones del deporte: Ley 3/2008 del ejercicio de las profesiones del deporte de Cataluña, Ley 15/2015 por la que se ordena el ejercicio de las profesiones del deporte en Extremadura, Ley 6/2016 por la que se ordena el ejercicio de las profesiones del deporte 
en la Comunidad de Madrid, Ley 1/2015 del ejercicio físico y del deporte de La Rioja y Ley 5/2016 del Deporte de Andalucía.

Las características y requisitos que se fijaron para considerar a un individuo persona que trabajaba desarrollando funciones laborales de monitor de actividad física y deporte y monitor de fitness, se basaron en las condiciones que se establecieron en el estudio de Campos-Izquierdo (2005) y Martínez del Castillo (1991):

- Que desarrolle las funciones laborales propias de los monitores de actividad física y deporte y de los monitores de fitness, especificadas anteriormente.

- Que desarrolle las funciones laborales propias de los monitores de actividad física y deporte y de los monitores de fitness en una o varias instalaciones deportivas y/o para una o varias entidades empleadoras dentro del territorio español.

- Que el puesto de trabajo que ocupe sea remunerado económicamente.

- Que la persona lleve más de siete días trabajando (con o sin contrato) en estas funciones laborales propias de los monitores de actividad física y deporte y de los monitores de fitness, para la entidad empleadora.

- Que tengan edades comprendidas entre 16 y 70 años, ambas edades incluidas.

\subsubsection{El universo objeto de estudio}

Antes de comenzar a diseñar la muestra hay que hacer una delimitación clara de la población o universo de estudio. Esta información es imprescindible no sólo de cara a la inferencia de los datos de la encuesta, sino también en la evaluación del diseño de la muestra (Cea, 2004). 
En el caso de este estudio, el universo general es el conjunto de personas que trabajan desarrollando funciones laborales de actividad física y deporte en todos los municipios de España (Campos-Izquierdo, 2013; 2016; Campos-Izquierdo y MartínAcero, 2016). En el caso de esta tesis doctoral, solamente se estudian los que desempeñan las ocupaciones de monitor de actividad física y deporte y de monitor de fitness, que posteriormente se describen cuantitativa y cualitativamente sus características socio-demográficas.

Los puestos de trabajo referidos a la actividad física y deporte no se recogen estadísticamente de forma específica. Estos datos han de deducirse de diversos cálculos, encuestas y estadísticas. El estudio de Martínez del Castillo del año 1991 con el título "La estructura ocupacional del deporte en España. Encuesta de los sectores de entrenamiento, docencia, animación y dirección" estableció en un primer momento que la población que trabajaba en funciones de actividad física y deporte en España era de 57.000 personas, para después determinar que la cantidad de personas con funciones de actividad física y deporte era de 42.679, lo que suponía el $0,3 \%$ de la población activa de España. Este mismo autor, en un estudio posterior denominado "Proyección del mercado deportivo laboral en la España de los noventa”, en el año 1992, estableció la cantidad de personas que trabajarían en funciones de actividad física y deporte en el año 2001 en España:

- Escenario bajo de empleo deportivo con hipótesis de decrecimiento económico: 55.801 puestos de trabajo en el año 2001 en España.

- Escenario referencial de empleo deportivo con hipótesis de crecimiento económico: 65.815 puestos de trabajo en el año 2001 en España.

- Escenario máximo de empleo deportivo con hipótesis de expansión económica: 76.937 puestos de trabajo en el año 2001 en España. 
El Consejo Superior de Deportes (2000) determinó que había 200.000 empleos directos de actividad física y deporte en España. Igualmente, el anuario de estadísticas deportivas del 2012 (Ministerio de Educación, Cultura y Deporte, 2013) indicó que el empleo vinculado al deporte ascendió en 2012 a 163.400 personas.

A pesar de todos estos estudios es complicado saber con exactitud la cantidad de personas que están trabajando en funciones laborales y ocupaciones de actividad física y deporte y más difícil aún es concretar la cantidad exacta de monitores de actividad física y deporte y monitores de fitness (Campos-Izquierdo, 2005; Heinemann, 1998; Madella, 2003; Martínez del Castillo, 1991). Por tanto, para el diseño de la muestra se consideró población infinita.

\subsubsection{DISEÑO DE LA MUESTRA}

Una vez delimitado y definido el universo de estudio, es necesario seleccionar un número de sujetos que sea representativo de esta población (ya que no es posible acceder a toda la población) con el propósito de generalizar los resultados a toda la población que se desea estudiar (García Ferrando, 2002; Gutiérrez- Dávila y Oña, 2005). Este grupo seleccionado, con intención de estimar los valores verdaderos de la población, constituye la muestra. 


\subsubsection{Tamaño y características de la muestra}

Después de haber efectuado la elección del marco muestral hay que determinar cuántas unidades de la población objeto de estudio hay que incluir en la muestra para que la investigación sea válida y fiable (Cea, 2004).

El tamaño de la muestra lo constituyó un número determinado de personas que trabajaban en funciones laborales de actividad física y deporte dentro de las ocupaciones de monitor de actividad física y deporte y de monitor de fitness, los cuales se identificaron, encontraron y entrevistaron en instalaciones deportivas de actividad física y deporte de todas las comunidades autónomas de España (Campos-Izquierdo, 2016). Para el cálculo del tamaño de la muestra representativa de los profesionales de la actividad física y deporte se consideraron varios aspectos: la varianza poblacional, el nivel de confianza elegido y el máximo error permitido (Campos-Izquierdo, et al., 2016; Campos-Izquierdo y Martín-Acero, 2016; Rodríguez, 2002):

- La población objeto de estudio constituía una población infinita ya que como expone Sierra Bravo (1992), las poblaciones infinitas son las poblaciones mayores de cien mil unidades.

- La varianza poblacional, debido a que se desconoce el valor de la misma, se recurre al supuesto más desfavorable donde la relación de probabilidades es igual, es decir, que "P" y "Q" eran iguales con el 50\% cada uno. Autores como Rodríguez (2002) exponen que dicha varianza poblacional exige un mayor tamaño de la muestra, pero nos garantiza no equivocarnos por defecto y nos confiere una mayor validez a la investigación.

- El nivel de confianza que se estableció para esta investigación fue de entre -2 sigmas y +2 sigmas como valores de la distribución normal y donde la 
probabilidad comprendida en este intervalo es del 95,5\%. Cea (1998), Rodríguez (2002) y Sierra Bravo (1992) determinan que el 95,5\% es el nivel de confianza más empleado y aceptado en ciencias sociales, ya que precisiones mayores suelen ser innecesarias y elevarían considerablemente el tamaño de la muestra.

- Con una población muy numerosa, un intervalo de confianza 95,5\% y varianza poblacional de $\mathrm{p}=50 \%$ y $\mathrm{q}=50 \%$, el margen de error para esta investigación es $\pm 2 \%$.

Para seleccionar el número de elementos a incluir en la muestra, el cálculo del tamaño de la muestra se realizó mediante la tabla-prontuario de población infinita o muy numerosa elaborada por Tagliacarne, para una seguridad del 95,5\% y con un margen de error del $\pm 2 \%$ (Rodríguez, 2002, p.455).

El tamaño de la muestra obtenido, después de consultar la tabla-prontuario de población infinita o muy numerosa de Tagliacarne (Rodríguez, 2002, p.455), ha sido de 2500 profesionales de actividad física y deporte. Por tanto, la cantidad final de personas entrevistadas fue de 2500 personas que trabajaban en funciones laborales y ocupaciones de actividad física y deporte de España.

Estas 2500 personas entrevistadas individualmente trabajaban en 1797 instalaciones deportivas de 696 municipios de todas las provincias de España (CamposIzquierdo et al., 2016; Campos-Izquierdo y Martín-Acero, 2016).

La afijación de la muestra fue proporcional según tamaño demográfico de las provincias y los estratos de población de los municipios $(<10.000 ; 10.001-50.000$; 50.001-100.000; 100.001- 500.000; > de 500.000 habitantes) según lo determinado por Campos-Izquierdo (2005). 
Para el presente estudio que nos ocupa en esta tesis doctoral, de la totalidad del tamaño de la muestra se han cogido la ocupación de monitor de actividad física deporte y la ocupación de monitor de fitness. Siendo 600 los monitores de actividad física y deporte entrevistados y 631 los monitores de fitness según lo determinado por CamposIzquierdo et al. (2016).

Respecto a las características socio-demográficas de la muestra estudiada en el caso de los monitores de actividad física y deporte, de los 600 encuestados, el 66,8\% eran hombres y el 33,2\% eran mujeres (Campos-Izquierdo et al., 2016, p.116) (véase figura 4.1).

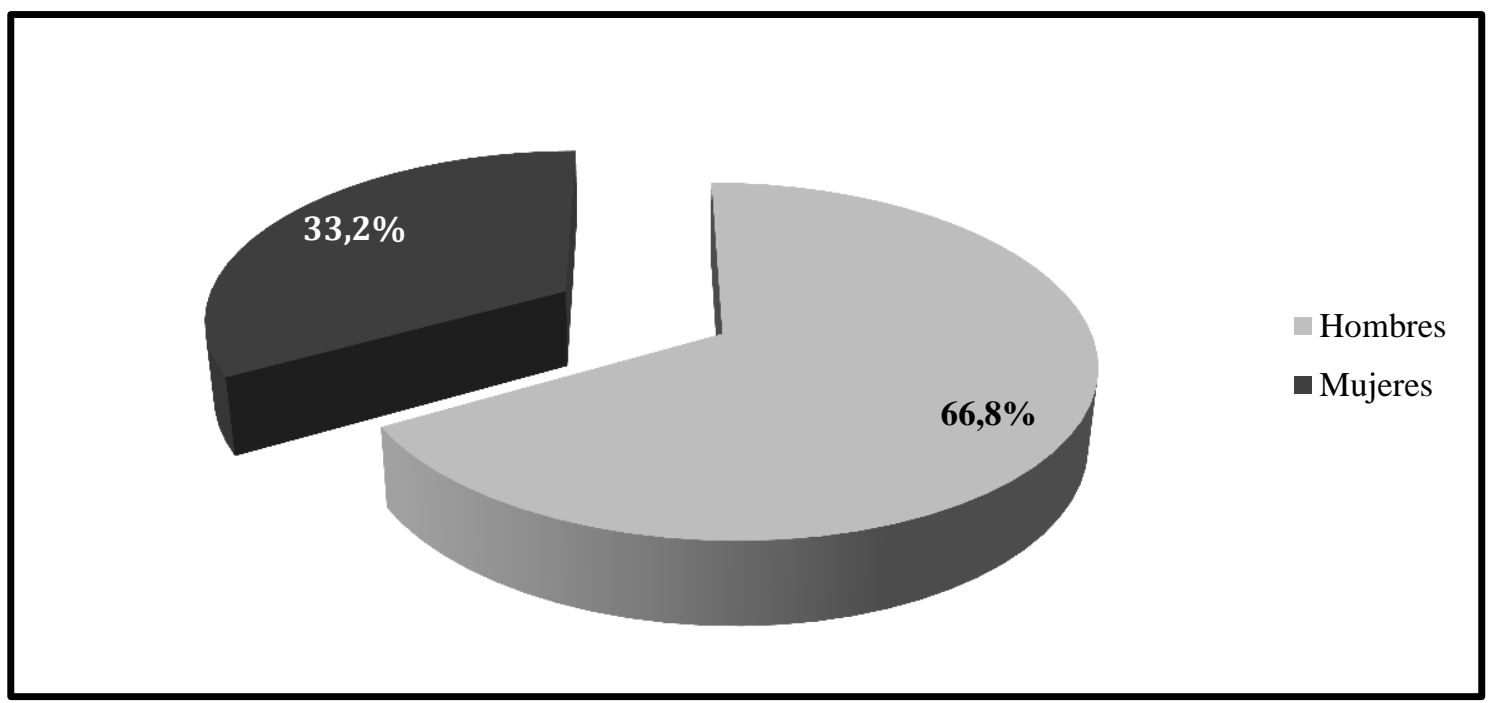

Figura 4. 1. Porcentaje de hombres y mujeres de los monitores de actividad física y deporte según Campos-Izquierdo et al. (2016, p.116).

Las edades de los participantes oscilaron entre 16 y 70 años con una edad media de 30,36 (desviación típica $=9,43$ ); siendo $57,5 \%$ de 16 a $29 ; 32,3 \%$ de 30 a 44; 9,3\% de 45 a 59 y 0,9\% de 60 a 70, según lo determinado por Campos-Izquierdo et al. (2016, p.116) (véase figura 4.2). 


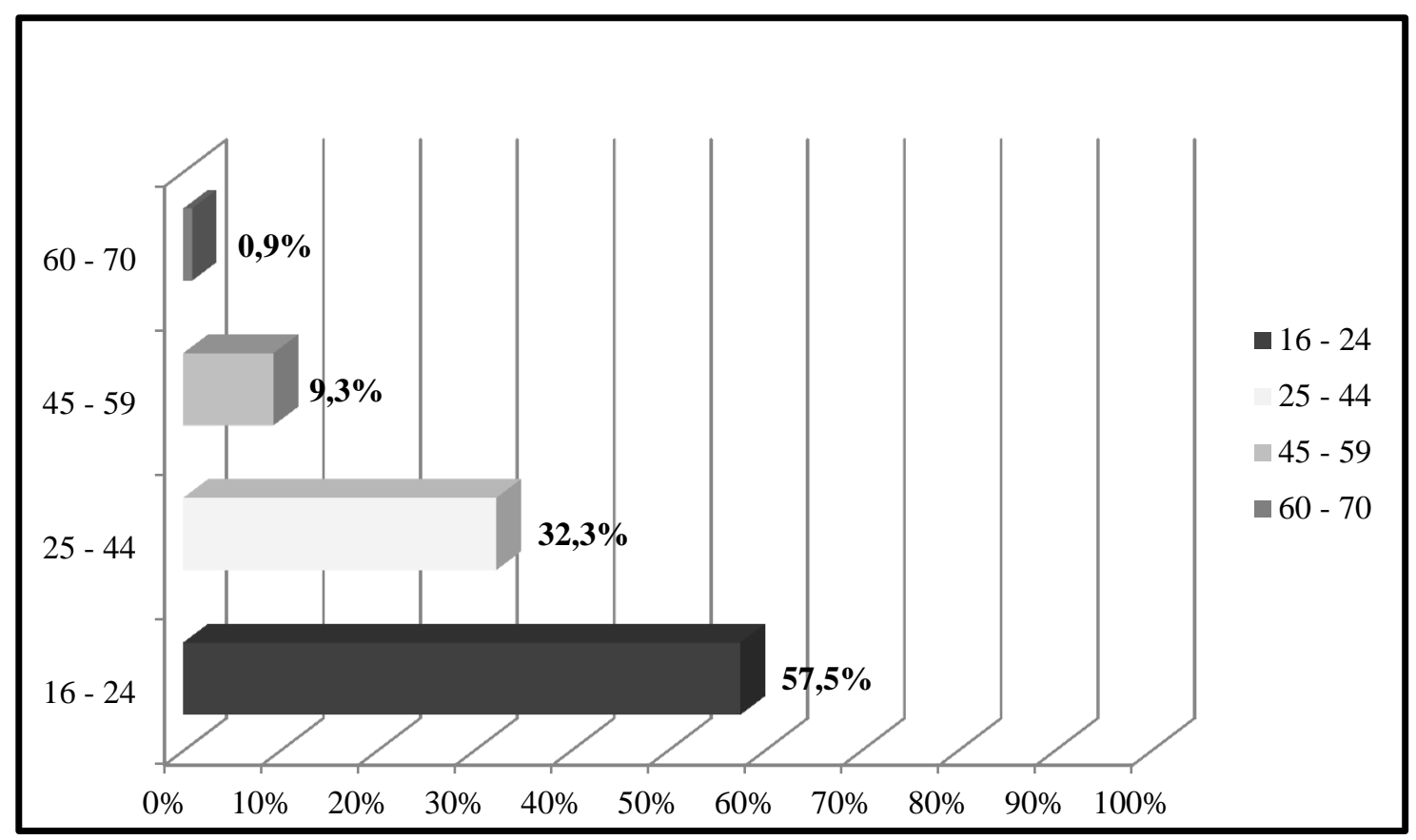

Figura 4. 2. Edad de los monitores de actividad física y deporte según Campos-Izquierdo et al. (2016, p.116).

La experiencia laboral se ha divido en menos de diez años de experiencia y diez años de experiencia o más; teniendo el $67,7 \%$ menos de diez años de experiencia y el 32,3\% diez años o más (véase figura 4.3.).

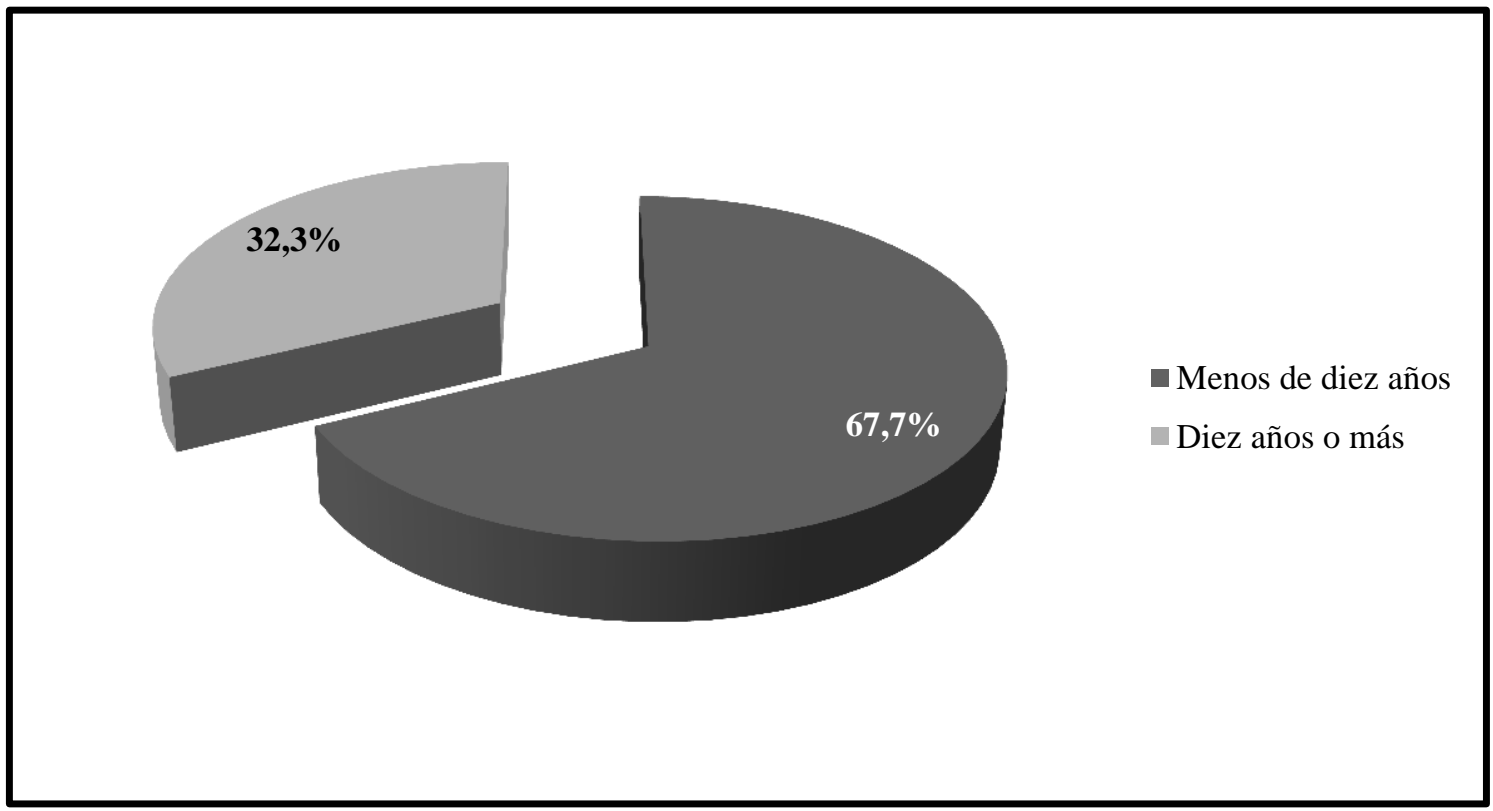

Figura 4. 3. Experiencia laboral de los monitores de actividad física y deporte. 
Respecto a las características socio-demográficas de la muestra estudiada en el caso de los monitores de fitness, de los 631 encuestados, el 59,9\% eran hombres y el 40,1\% mujeres (Campos-Izquierdo et al., 2016, p.116) (véase figura 4.4).

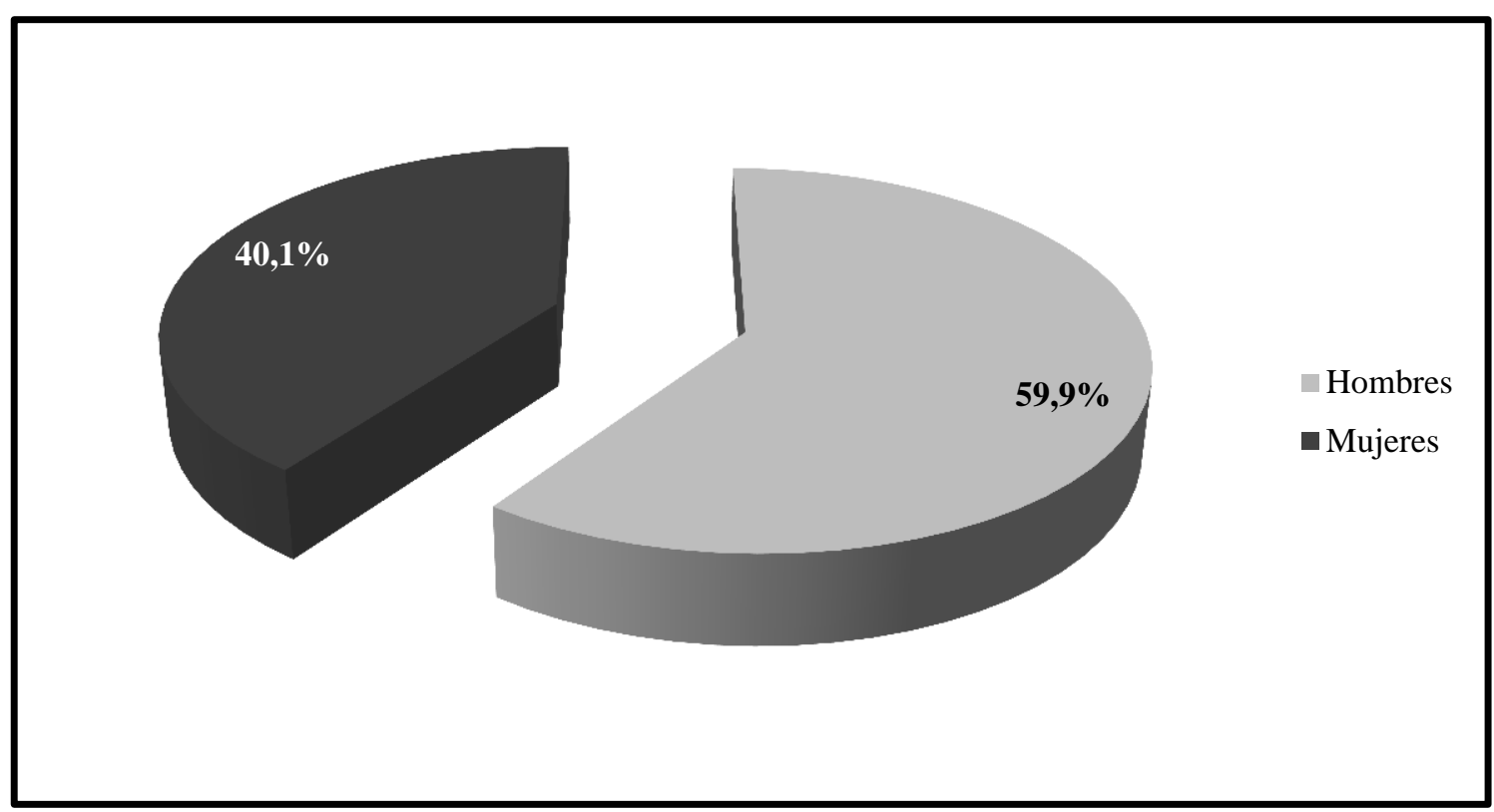

Figura 4. 4. Porcentaje de hombres y mujeres de los monitores de fitness según Campos-Izquierdo et al. (2016, p.116).

Las edades oscilaban entre los 16 y los 70 años con una media de 32,82 años (desviación típica =7,93), siendo 41,7\% de 16 a 29, 49,8\% de 30 a 44, 8,2\% de 45 a 59 y $0,3 \%$ de 60 a 70 según lo determinado por Campos-Izquierdo et al. (2016, p. 116) (véase figura 4.5). 


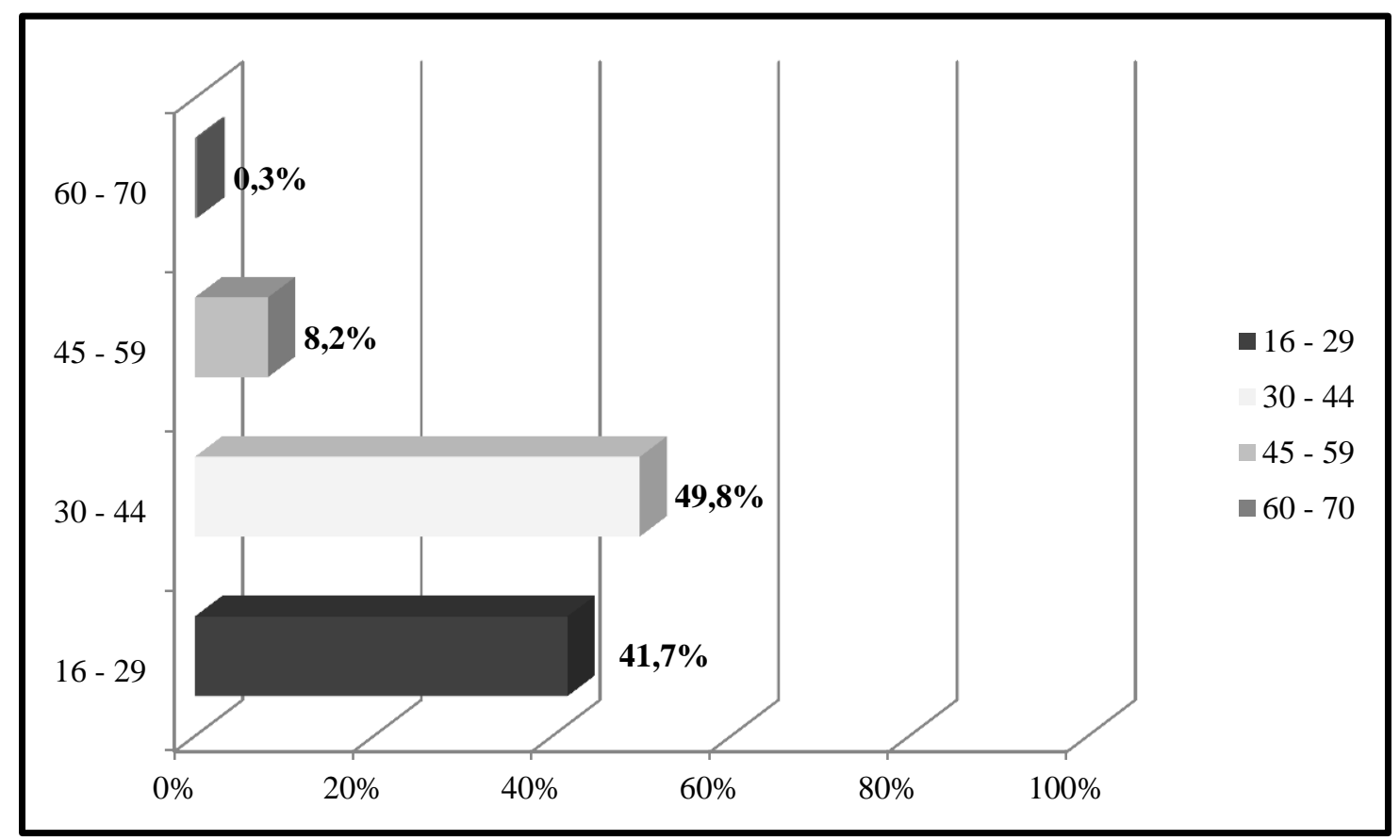

Figura 4. 5. Edad de los monitores de fitness según Campos-Izquierdo et al. (2016, p.116).

En cuanto a la experiencia laboral, el $64,7 \%$ de los monitores de fitness tenía menos de diez años de experiencia y el 35,3\% diez años o más (véase figura 4.6).

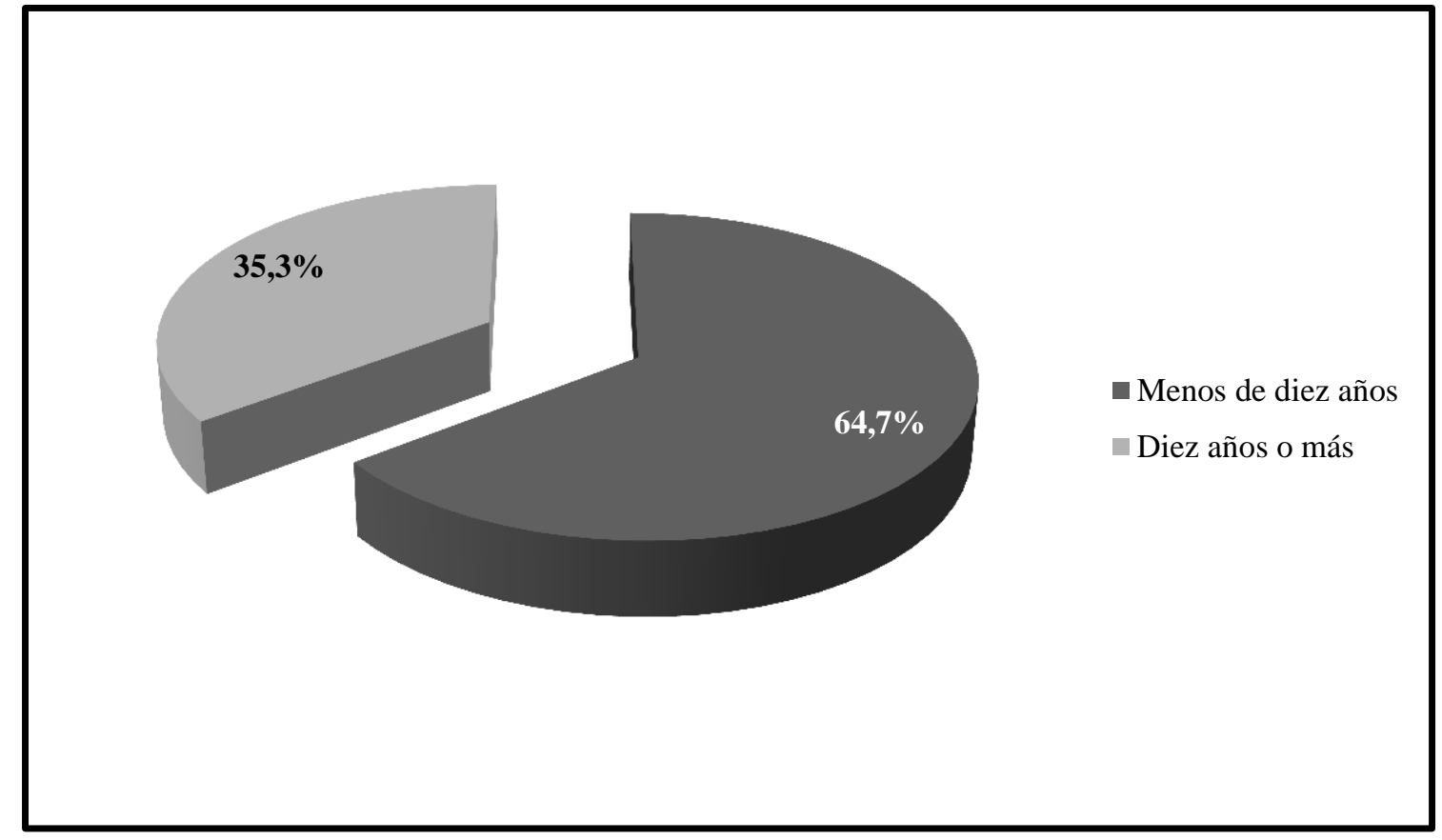

Figura 4. 6. Experiencia laboral de los monitores de fitness. 


\subsubsection{Tipo de muestreo utilizado}

El tipo de muestreo utilizado para esta investigación, dentro del Proyecto de Investigación Fundamental no orientada de I+D+i DEP2009-12828, fue probabilístico de tipo polietápico por conglomerados, estratificado en primera fase (CamposIzquierdo, 2005; 2013; Cea, 2004; Latorre, Del Rincón y Arnal, 1997; Rodríguez, 2002), en el que se siguió una secuencia de etapas (muestreo aleatorio en cada una) de selección de unidades muestrales (comunidad autónoma, provincia, municipio, instalación deportiva) hasta llegar a las personas que trabajaban en funciones laborales de actividad física y deporte. La afijación de la muestra fue proporcional según tamaño demográfico provincial y estratos poblacionales de los municipios (Campos-Izquierdo, 2013; 2016).

Este tipo de muestreo es un proceso de selección aleatoria en el que la unidad muestral es un conjunto de individuos que, bajo determinados aspectos, se puede considerar que forman una unidad denominada conglomerado, donde la unidad de muestreo final son las subdivisiones de los conglomerados y en el que el método para seleccionar las unidades últimas de muestra ha sido la selección de conglomerados en varias fases, y donde cada uno de estos y de las últimas unidades (sujetos objeto de estudio) se ha elegido de forma aleatoria (Azorín y Sánchez-Crespo, 1994; Rodríguez, 2002).

El hecho de haber utilizado el muestreo aleatorio por conglomerados se debe a las características de la población objeto de estudio, ya que no es posible obtener una lista de cada uno de los componentes de la población. En el caso de esta investigación, primero se obtuvo la relación de las provincias que aparecían en cada estrato, después se seleccionaron los municipios, posteriormente se realizó la selección de las instalaciones 
deportivas y finalmente se llevó a cabo la elección de los sujetos a entrevistar (CamposIzquierdo, 2005; 2011). Todas las selecciones y elecciones fueron aleatorias (CamposIzquierdo, 2005; 2011).

\subsubsection{Proceso de selección de la muestra}

La extracción muestral se ha realizado en tres fases o estadios, procedimiento más usual en este tipo de muestreos (Azorín y Sánchez-Crespo, 1994; Cea, 2004; Lynn y Lievesley, 1991). En primer lugar se han extraído los municipios de cada una de las provincias (unidades de muestreo primarias) ya que es la variable que más discrimina, seguidamente las instalaciones deportivas (unidades de muestreo secundarias), y por último, los sujetos que van a ser entrevistados que trabajan desarrollando funciones laborales de actividad física y deporte en España (unidades de muestreo últimas) (Campos-Izquierdo, 2013; 2016; Campos-Izquierdo et al., 2016).

A continuación se explica este proceso de selección de la muestra, siguiendo los pasos de establecidos por Campos Izquierdo (2005), Cea (2004) y Rodríguez (2002):

- En primer lugar, se ha realizado la selección de las unidades primarias de muestreo (Campos-Izquierdo et al., 2016).

- El siguiente paso ha sido la selección de las unidades secundarias de muestreo que representan las instalaciones deportivas en cada uno de los municipios. Después allí se han localizado, identificado, encontrado y entrevistado a las personas objeto de estudio (Campos-Izquierdo, 2013; 2016; Campos-Izquierdo et al., 2016). 
- El último paso del proceso de selección de la muestra ha sido la elección de los individuos objeto de estudio (recursos humanos de la actividad física y deporte) entrevistados en cada instalación deportiva seleccionados aleatoriamente (Campos-Izquierdo, 2013; 2016; Campos-Izquierdo et al., 2016).

Siguiendo a Campos-Izquierdo (2005) y González-Rivera (2008) se tomó la decisión de entrevistar a un máximo de dos personas en cada instalación deportiva. Cuando los entrevistadores visitaron la instalación, identificaron a los profesionales de actividad física y deporte y los invitaron aleatoriamente a participar en el estudio, hasta alcanzar el número requerido de dos. Ocasionalmente, sólo una persona fue entrevistada, éste era el caso si había solamente un profesional de la actividad física y deporte que trabajaba en la instalación, o cuando solamente un profesional de la actividad física y deporte aceptaba participar (Campos-Izquierdo, 2011; 2016).

\subsubsection{INSTRUMENTO DE RECOGIDA DE LA INFORMACIÓN}

El instrumento utilizado para obtener la información es el que García Ferrando (2002) denomina como una entrevista de tipo oral, individual y estandarizada por medio de cuestionario.

La entrevista es el instrumento más importante y utilizado de la investigación social empírica. Además, la entrevista estandarizada por medio de cuestionario como instrumento de obtención de la información es el método más fiable y utilizado de entrevista en las encuestas (García Ferrando, 2002). El objetivo que se persigue con el cuestionario es traducir variables empíricas, sobre las que se desea información, en 
preguntas concretas capaces de suscitar respuestas fiables, válidas y susceptibles de ser cuantificadas. Las ventajas de su utilización según García Ferrando (2002), GonzálezRivera (2010), Heinemann (2003) y Thomas et al. (2011) son:

- Menor espontaneidad en el entrevistado ya que tiene que responder a preguntas perfectamente formuladas en el cuestionario y con frecuencia escogiendo alternativas previamente dadas.

- Permite una comparación mucho más rigurosa entre las respuestas dadas a una misma pregunta por diferentes entrevistados.

- Permite cuantificar de los resultados.

- Confiere un papel protagonista mayor a los encuestados.

- Proporciona una mejor comprensión y aclaración del cuestionario.

- Implica una participación elevada de los encuestados solicitados.

- Otorga calidad y confianza en los datos obtenidos.

- La cumplimentación del cuestionario es más amena.

- Mayor profundidad en las respuestas gracias a la presencia del entrevistador.

- Evita la influencia de terceras personas en la contestación del cuestionario.

En esta investigación el instrumento utilizado para obtener la información es la entrevista estandarizada por medio de cuestionario denominada "PROAFIDE: Recursos humanos de la actividad física y deporte" (Campos-Izquierdo, 2011). Éste es el instrumento con el que se ha obtenido toda la información de las personas que trabajan en funciones laborales y ocupaciones de actividad física y deporte en España, y como tal, de los monitores de actividad física y deporte y de los monitores de fitness, llevándose a cabo durante el año 2011. 
El cuestionario estaba conformado por 5 dimensiones, 37 variables y 57 preguntas con las consiguientes respuestas establecidas de antemano, siendo unas de única posibilidad de respuesta y otras con la posibilidad de varias respuestas (CamposIzquierdo, 2011). Igualmente dicha entrevista se codificó siguiendo lo especificado por Alvira (2004), Cea (2004) y García Ferrando (2002).

A continuación se detalla el cuestionario "PROAFIDE: Recursos humanos de la actividad física y el deporte" (Campos-Izquierdo, 2011).

La entrevista estructurada por medio de cuestionario se componía de 57 preguntas cerradas (García Ferrando, 2002) y categorizadas en el que el orden de las mismas, a la hora de suministrarlo, era inflexible. Las 57 preguntas recogían cinco dimensiones. Estas dimensiones agrupaban las variables o elementos que se desean analizar, de tal forma que recogían informaciones sobre los diversos aspectos de la investigación en concordancia con los objetivos de la misma. En cuanto a las diferentes opciones de respuestas, las posibilidades de las mismas en la mayoría de los casos, estaban determinadas de antemano y éstas cumplían los requisitos de exhaustividad y precisión, pudiendo ser de respuesta alternativa dicotómica y de elección múltiple. Además, había preguntas de control, preguntas filtro y preguntas batería (Cea, 2004; García Ferrando, 2002; Padilla, González y Pérez, 1998; Rodríguez, 2002; Sierra Bravo, 2001).

Para la adecuada organización de la entrevista estructurada por medio de cuestionario, se ha respetado la agrupación en función de las dimensiones, así como una transición cómoda y razonable de un tema a otro (García Ferrando, 2002).

A continuación, se presenta la descripción de las cinco dimensiones de la entrevista estandarizada por medio de cuestionario "PROAFIDE: Recursos humanos de la actividad física y deporte", acompañadas, cada una de ellas las variables objeto de 
estudio (Campos-Izquierdo, 2011). En el anexo 1 se encuentra la tabla donde se relacionan dimensiones y variables.

- Dimensión 1. Características sociodemográficas: edad, sexo y origen.

- Dimensión 2. Funciones laborales de actividad física y deporte: funciones actuales y pasadas, preferencia de funciones, satisfacción profesional general y percepción del desempeño del trabajo.

- Dimensión 3. Desempeño profesional específico: competencias, planificación general, evaluación, aspectos de intervención en la sesión, tipos de actividad, nivel de enseñanza de educación física, actividades físico-deportivas extraescolares, competición, realización de informe, preparación de la intervención profesional, intervención en dirección y organización, tipología de población específica y tipología de instalación deportiva.

- Dimensión 4. Características laborales: entidades, subcontratación, relación laboral, tipo de contratación, dedicación, años trabajando, denominación del puesto de trabajo, ingresos económicos, conocimiento de aspectos laborales, cantidad de personas en la instalación deportiva, satisfacción laboral y selección y obtención de empleo.

- Dimensión 5. Características formativas de estos profesionales: formación inicial, Licenciado en Ciencias de la Actividad Física y del Deporte, relación formación inicial con desempeño en funciones laborales de actividad física y deporte y formación permanente.

Con respecto a las preguntas objeto de estudio de esta tesis doctoral, de las 57 preguntas que consta el cuestionario "PROAFIDE: Recursos Humanos de la Actividad Física y Deporte" (Campos-Izquierdo, 2011), 13 preguntas son las que se han utilizado 
en función de los objetivos de la presente investigación, y todo ello centrado en los monitores de actividad física y deporte y en los monitores de fitness. Las dimensiones, variables e ítems seleccionados están representados en la tabla 4.1, la cual es una adaptación de Campos-Izquierdo (2011, pp. 58-60).

La pregunta 4 (funciones actuales y pasadas) ha sido la base para elegir a las personas que trabajaban en las ocupaciones de monitor de actividad física y deporte y monitor de fitness. Después para conocer su formación general se eligieron la pregunta 45 (formación inicial general) y las preguntas 56 y 57 (formación permanente). Para conocer la intervención docente y profesional de las dos ocupaciones se eligieron la pregunta 11 (planificación general), las preguntas 12 y 13 (evaluación), la pregunta 14 (aspectos de intervención en la sesión) y la pregunta 22 (preparación de la intervención profesional). Además todas ellas se analizaron e interrelacionaron con las variables objeto de estudio que se materializaban en las preguntas 1, 2, 37 y 45 (edad, sexo, experiencia laboral y nivel de estudios respectivamente). Por último para conocer la satisfacción laboral que los profesionales de ambas ocupaciones experimentan se tomaron los datos de la pregunta 44 (satisfacción laboral) y se relacionó con las preguntas 1 y 2 (edad y sexo).

Los ítems de las preguntas 14 (aspectos de intervención en la sesión), 22 (preparación de la intervención profesional) y 44 (satisfacción laboral) fueron estructurados en una escala tipo Likert de 5 puntos que variaba de 1 a 5 . En el caso de los aspectos de intervención la escala variaba del nada importante al muy importante, refiriéndonos a la preparación de la intervención profesional la escala variaba del nunca al siempre y en último lugar en el caso de la satisfacción laboral la escala oscilaba desde el rango muy insatisfecho al muy satisfecho. 
Mediante el cálculo del coeficiente alfa de Cronbach, la pregunta 14 (aspectos de intervención en la sesión) mostró una buena consistencia interna tanto en los monitores de actividad física y deporte $($ alfa $=0.749)$ como en los monitores de fitness $($ alfa $=$ 0,702) (Nunnally, 1978). La pregunta 22 (preparación de la intervención profesional) mostró también una buena consistencia interna en los monitores de actividad física y deporte $($ alfa $=0,751)$ y en los monitores de fitness (alfa $=0,782)($ Nunnally, 1978). Finalmente, la pregunta 44 (satisfacción laboral) mostró una excelente consistencia interna en los monitores de actividad física y deporte $(\mathrm{alfa}=0,900)$ al igual que en los monitores de fitness (alfa $=0.894)($ Nunnally, 1978). 
Tabla 4. 1

Dimensiones, variables e ítems de la entrevista estandarizada por medio de cuestionario "PROAFIDE. Recursos humanos de la actividad física y deporte" utilizados en la presente investigación

\begin{tabular}{lll}
\hline \multicolumn{2}{l}{ DIMENSIÓN 1: CARACTERÍSTICAS SOCIODEMOGRÁFICAS DE LOS RECURSOS HUMANOS } \\
$\qquad \begin{array}{ll}\text { DE LA ACTIVIDAD FÍSICA Y DEPORTE } \\
\text { VARIABLES }\end{array}$ \\
\hline ÍTEMS \\
Sexo & Pregunta 1 & \\
\hline
\end{tabular}

DIMENSIÓN 2: FUNCIONES LABORALES DE ACTIVIDAD FÍSICA Y DEPORTE

VARIABLES ÍTEMS

\begin{tabular}{ll}
\hline Funciones actuales y pasadas & Pregunta 4
\end{tabular}

DIMENSIÓN 3: ACTUACIÓN (DESEMPEÑO) PROFESIONAL ESPECÍFICA

\begin{tabular}{ll}
\hline \multicolumn{1}{l}{ VARIABLES } & ÍTEMS \\
\hline Planificación general & Pregunta 11 \\
Evaluación & Preguntas 12 y 13 \\
Aspectos de intervención en la sesión & Pregunta 14 \\
Preparación de la intervención profesional & Pregunta 22
\end{tabular}
DIMENSIÓN 4: CARACTERÍSTICAS LABORALES DE LOS RECURSOS HUMANOS DE LA
ACTIVIDAD FÍSICA Y DEPORTE

\begin{tabular}{lll}
\hline VARIABLES & ÍTEMS \\
\hline
\end{tabular}

\begin{tabular}{|c|c|}
\hline Años trabajados & Pregunta 37 \\
\hline Satisfacción laboral & Pregunta 44 \\
\hline \multicolumn{2}{|c|}{ DIMENSIÓN 5: CARACTERÍSTICAS FORMATIVAS DE LOS RECURSOS HUMANOS DE LA } \\
\hline \multicolumn{2}{|c|}{ ACTIVIDAD FÍSICA Y DEPORTE } \\
\hline VARIABLES & ÍTEMS \\
\hline Formación inicial & Pregunta 45 \\
\hline Formación permanente & Preguntas 56 y 57 \\
\hline
\end{tabular}

Nota. Recuperado de Campos-Izquierdo (2011, pp.58-60). 


\subsubsection{PROCEDIMIENTO DE RECOGIDA DE LA INFORMACIÓN}

La fase de recogida de la información engloba la localización, identificación y contacto con las personas que iban a ser entrevistadas, la realización de la entrevista estandarizada por medio de cuestionario, el registro de la información y la recogida de la información obtenida.

En cuanto a la dimensión temporal, la investigación fue de corte transversal, donde la recogida de la información se llevó a cabo en un único periodo, éste fue el año 2011, aunque dividido en cuatro momentos estacionales (invierno, primavera, verano y otoño) (Campos-Izquierdo, 2005; 2013; Briones, 1996; Sierra Bravo, 2001). Esta actuación se realiza para conocer con mayor profundidad y rigor toda la población objeto de estudio, debido a que muchos de los servicios de actividad física y deporte son estacionales (Campos-Izquierdo et al., 2016).

El espacio geográfico donde se desarrolló la recogida de la información fueron todas las provincias y comunidades autónomas de España, en las cuales se encontraban todos los individuos objeto de estudio.

Con el fin de que el coste de tiempo y dinero fueran menores y que la organización del proceso de recogida fuera el mejor posible, el recorrido de la recogida de información se realizó por sectores geográficos (Padua, 1979).

Las entrevistas fueron realizadas por 19 entrevistadores que eran principalmente graduados universitarios en Ciencia de la Actividad Física y Deporte o como mínimo titulados universitarios. Todos los entrevistadores completaron un seminario de formación de entrevistadores dirigido por el investigador principal de la Universidad Politécnica de Madrid, Antonio Campos Izquierdo (Campos-Izquierdo, 2013; 2016). En

este seminario de capacitación, se les proporcionó explicaciones detalladas de los 
procedimientos a seguir para recopilar información, estrategias para entrevistar con eficacia y se les dio la oportunidad de realizar entrevistas simuladas (Cea, 2004; Fowler y Mangiones, 1990). Además, cada uno de los ítems del cuestionario fue discutido en profundidad y los entrevistadores tuvieron oportunidad de hacer las preguntas que consideraran oportunas (Campos-Izquierdo, 2013; 2016).

En el momento de realizar las entrevistas, el entrevistador visitó las instalaciones deportivas y entrevistó al azar a dos profesionales de la actividad física y deporte de entre los disponibles para contestar la entrevista estandarizada por medio de cuestionario. Todos los profesionales de la actividad física y deporte fueron entrevistados en su lugar de trabajo. Antes del comienzo de las entrevistas, los profesionales de la actividad física y deporte recibieron detalles completos sobre la naturaleza del estudio. Además, se les informó de que se garantizaba la confidencialidad y el anonimato (Bryman, 2004; Campos-Izquierdo, 2013; 2016; Fink, 1995).

A continuación, los encuestadores completaron el cuestionario PROAFIDE a través de una entrevista oral al entrevistado y siguiendo las directrices de Heinemann (2003), las entrevistas se realizaron individualmente con la persona objeto de estudio (Campos-Izquierdo, 2013; 2016). Para obtener la mayor cantidad de datos posibles, las preguntas se leyeron literalmente con una voz alta y una pronunciación estándar, se anotaron las respuestas en el cuestionario con la mayor exactitud posible y se registraron observaciones sobre los entrevistados y el lugar donde se lleva a cabo la entrevista (Cea, 2004; Heinemann, 2003; Oksenberg y Cannell, 1988). La naturaleza de la recolección de datos proporcionó a los participantes la oportunidad de hacer cualquier pregunta que les surgiera con respecto al cuestionario o del estudio en general. El tiempo de realización de los cuestionarios varió de 12 a 17 minutos, siendo la media de 15 minutos (Campos-Izquierdo, 2013; 2016), tiempo que se encuentra dentro de los 
márgenes de duración de una entrevista expuestos por Azorín y Sánchez-Crespo (1994) y Cea (2004).

Para la realización de este estudio, la autora de esta investigación, licenciada en Ciencias de la Actividad Física y del Deporte, fue una de las encuestadoras, de la que se pasa a contar la experiencia. Para realizar adecuadamente la recogida de todos los datos, primero se organizó una ruta geográfica para cubrir todas las provincias y comunidades autónomas según la estratificación y para ahorrar en costes. Una vez que la entrevistadora estaba en el destino elegido, seleccionaba al azar los centros deportivos a los que iba a asistir. En cada instalación deportiva la entrevistadora se presentaba, asimismo presentaba de manera general el estudio y seleccionaba aleatoriamente a dos profesionales de la actividad física y deporte como posibles candidatos a realizar la encuesta (siempre se les seleccionaba de uno en uno y era habitual tener que esperar a que terminaran su clase o su jornada laboral). Mientras la entrevistadora esperaba, observaba si la instalación deportiva cumplía el artículo 72 de la ley 10/1990, de 15 de octubre, del Deporte, y completaba en una ficha observacional el nombre de la instalación deportiva, seguido de si era pública o privada y de la tipología que era. También dejaba por escrito si la información estaba situada en un lugar perfectamente visible y accesible y si estaba el nombre, la titulación y la descripción de la función o funciones laborales de actividad física y deporte que desempeñaban en dicha instalación deportivas los profesionales que en ella trabajaban.

Una vez que la persona aceptaba participar en el estudio, la entrevistadora leía de forma neutral cada pregunta en orden y anotaba las respuestas, a su vez anotaba en los márgenes otras cuestiones que observaba. La entrevistadora también aclaraba y solucionaba al sujeto entrevistado cuestiones no entendidas por éste y despertaba el interés del entrevistado motivándole para responder las cuestiones que se le formulaban. 
No obstante, se ha intentado reducir al máximo posible el inconveniente del fenómeno del sesgo del entrevistador (León y Montero, 2003) pretendiendo ser lo más objetiva y neutral posible. En las preguntas que pudieran ser más comprometidas o pudieran comprometer a la persona entrevistada, se utilizaba unas tarjetas previamente diseñadas, las cuales contenían unas tablas para que el entrevistado eligiese o señalase entre las opciones que se proponían (Campos-Izquierdo, 2013; 2016).

Antes de dar por finalizada la entrevista y despedir al entrevistado, reiterándole el agradecimiento por su colaboración, era necesario repasar todas las preguntas del cuestionario. La inmediatez en este paso era de suma importancia ya que, siguiendo a Cea (2004), contribuye al recuerdo o la memoria de lo que en la entrevista se ha dicho. Una vez acabada la entrevista, la encuestadora seguidamente cumplimentaba la duración de la entrevista y las posibles incidencias relevantes (Heinemann, 2003). Todas las entrevistas realizadas se guardaban y archivaban para la posterior introducción de la información obtenida en el programa informático de análisis de datos. Una vez terminada la jornada laboral diaria se introducía en una ficha control las entrevistas que se habían llevado a cabo detallando dónde se habían realizado (CamposIzquierdo, 2013; 2016).

La investigación fue aprobada por la Comisión de Ética de la Universidad Politécnica de Madrid (Campos-Izquierdo, 2016; Campos-Izquierdo et al., 2016; Campos-Izquierdo y Martín Acero, 2016; González-Rivera et al., 2017). 


\subsubsection{PROCEDIMIENTO DE PROCESAMIENTO, TRATAMIENTO Y ANÁLISIS DE LOS DATOS OBTENIDOS}

Tras rellenar los cuestionarios se procede a la edición de los mismos, a la codificación de las respuestas y a la grabación de los datos para poder analizarlos (Cea, 2004).

En esta investigación se ha realizado un análisis descriptivo univariable y bivariable y un análisis inferencial a través de tablas de contingencia que incluyen el valor de Chi-cuadrado de Pearson y su significación, y el coeficiente de correlación Phi. El análisis de los datos fue realizado mediante el programa SPSS para WINDOWS (V 19.0) (Pardo y Ruiz, 2005).

Tal y como apuntan López Pintor y Wert (2002), una vez introducida la información en la base de datos, se realizó el tratamiento y análisis estadístico y la exposición de la misma.

En el capítulo de resultados del estudio, estos datos se encuentran representados en números con la frecuencia de casos y porcentajes y a través de tablas y figuras con el fin de favorecer su visualización y comprensión y para facilitar la interpretación de los resultados obtenidos y la posterior discusión y extracción de conclusiones. Igualmente, en algunos casos, los resultados también se presentan a través de tablas que contienen datos estadísticos de frecuencia (media, mediana, desviación típica y varianza). 

CAPÍTULO 5. RESULTADOS DEL ESTUDIO 



\section{CAPÍTULO 5. RESULTADOS DEL ESTUDIO}

En este capítulo se exponen y describen los resultados obtenidos. Por tanto, se presenta la información obtenida a partir de la realización de las entrevistas estandarizadas por medio del cuestionario "PROAFIDE: Recursos humanos de la actividad física y deporte" de Campos-Izquierdo (2011), dirigidas a los monitores de actividad física y deporte y a los monitores de fitness de España.

Dichos resultados se han establecido en función de los objetivos de esta investigación con el fin de facilitar su lectura. De esta forma, el presente capítulo se estructura en dos grandes apartados:

- Los monitores de actividad física y deporte.

- Los monitores de fitness.

Dentro de cada apartado se abordan de forma detallada los aspectos formativos (formación inicial general y formación permanente), la intervención docente y profesional (la planificación, la evaluación, los elementos que priorizan en su enseñanza y desempeño profesional y las fuentes de conocimiento) y la satisfacción laboral que poseen los profesionales que trabajan en estas dos ocupaciones. Además, la formación permanente y la intervención docente y profesional están relacionadas y abordadas en función de las variables sexo, edad, nivel de estudios y experiencia laboral y la satisfacción laboral está relacionada con la edad y el sexo. 


\subsection{RECURSOS HUMANOS DE LA ACTIVIDAD FÍSICA Y DEPORTE QUE TRABAJAN COMO MONITORES DE ACTIVIDAD FÍSICA Y DEPORTE}

En este apartado se pasan a exponer todos los datos investigados objeto de estudio sobre los monitores de actividad física y deporte en relación a su formación inicial general, su formación permanente y su intervención docente y profesional relacionándose estos dos últimos bloques con las variables sexo, edad, experiencia laboral y nivel de estudios. Asimismo se expone la satisfacción laboral y se relaciona con las variables sexo y edad.

\subsubsection{FORMACIÓN GENERAL INICIAL Y PERMANENTE DE LOS MONITORES DE ACTIVIDAD FÍSICA Y DEPORTE}

Respecto a la formación general inicial (figura 5.1), se observa que el 38\% posee estudios universitarios, el $24,2 \%$ ha realizado una formación profesional, el 35,7\% ha estudiado la educación secundaria y un 2,1\% ha terminado la educación primaria o menos. 


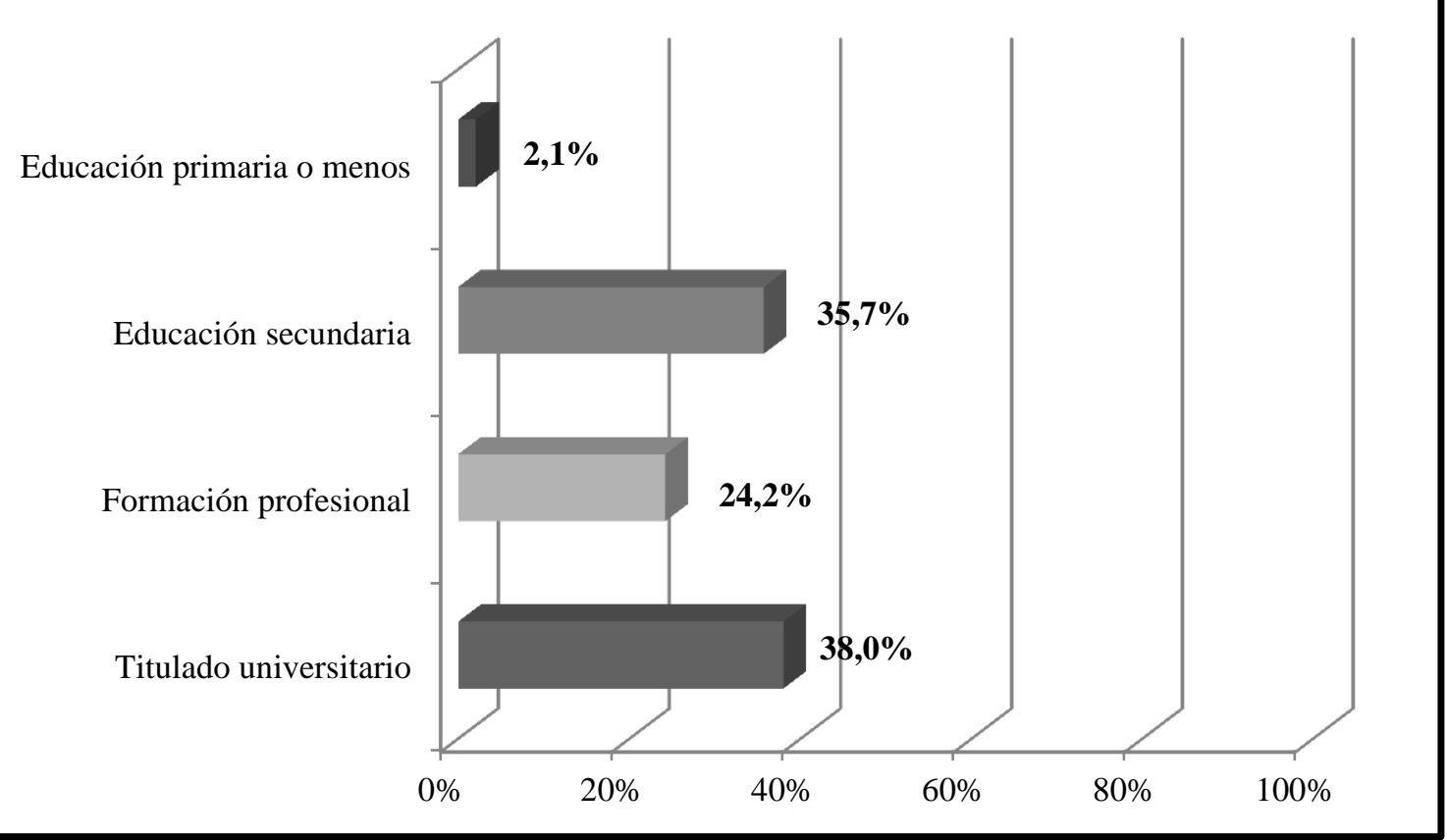

Figura 5. 1. Formación general inicial de los monitores de actividad física y deporte (N=600).

Por otro lado, la formación permanente que desarrollan los monitores de actividad física y deporte españoles es escasa. Si la analizamos con detenimiento (figura 5.2), se puede intuir que los monitores de actividad física y deporte no han llevado a cabo mucha formación permanente durante los tres últimos años. La formación a la que más han asistido son los cursos (48\%). Después, las siguientes formaciones a las que más han asistido son a jornadas (15,3\%) y a congresos (10\%). Las situaciones: realización de un postgrado no oficial $(1,3 \%)$, realización de un máster oficial $(0,8 \%)$ y realización de grupos de trabajo $(0,5 \%)$ son prácticamente inexistentes. 


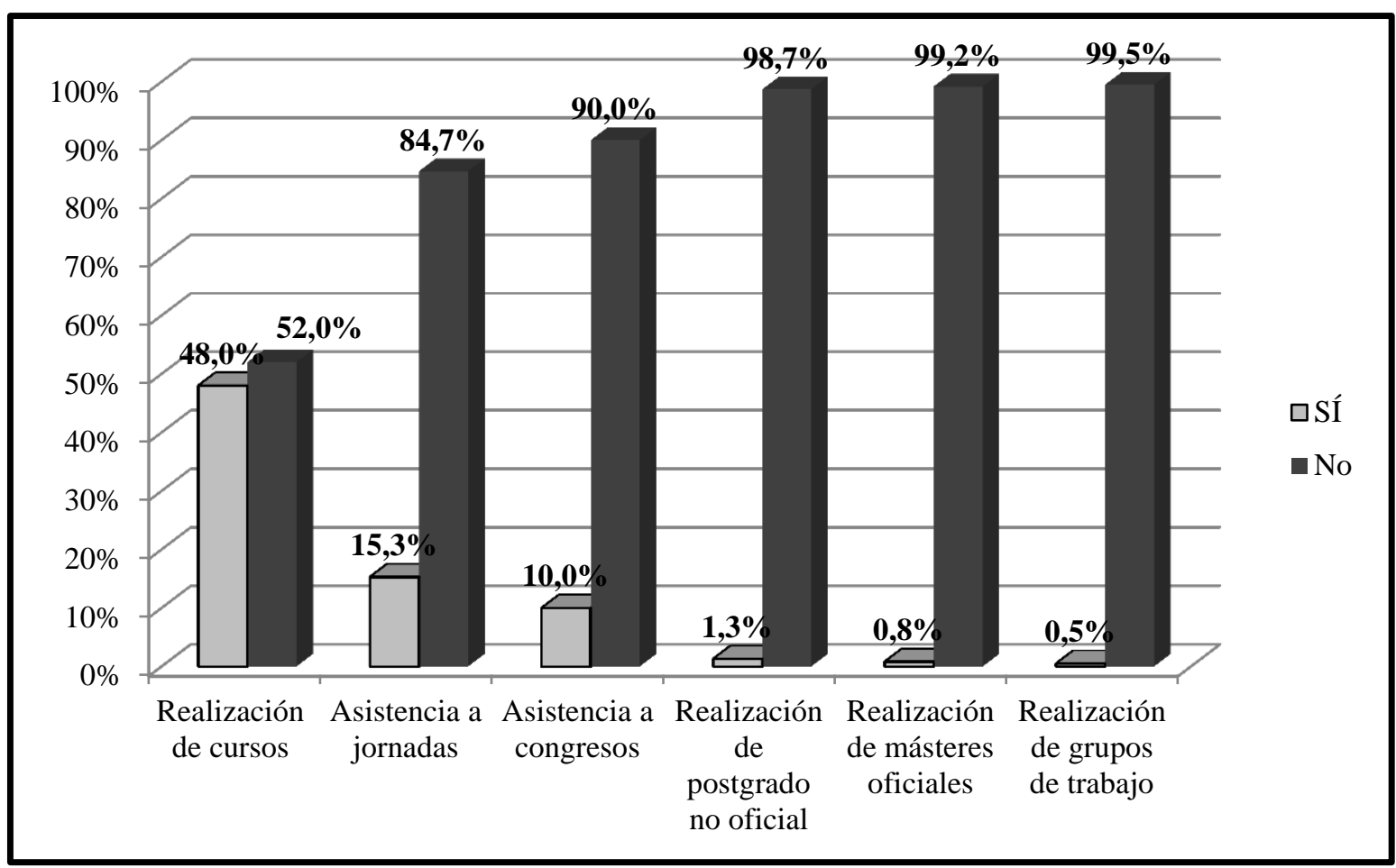

Figura 5. 2. Actividades de formación permanente formal a las que han asistido los monitores de actividad física y el deporte en los últimos tres años $(\mathrm{N}=600)$.

Si observamos la tablas 5.1, 5.2 y 5.3 se puede advertir el panorama descrito anteriormente sobre la formación permanente con más detalle, determinándose qué variables influyen más a la hora de elegirla.

Teniendo en cuenta el sexo (tabla 5.1) se han hallado diferencias significativas encontrando que, los hombres se forman en general más que las mujeres $\left(X_{\text {hombres }}=13,2 \%\right.$ y $\left.X_{\text {mujeres }}=11,7 \%\right)$ aunque ellas realizan más cursos de formación $\left(48,7 \% ; x^{2}=3614 ; p<0,05\right)$ y más másteres oficiales $\left(1 \% ; x^{2}=2361 ; p<0,05\right)$ y asisten a más grupos de trabajo $\left(1 \% ; \mathrm{x}^{2}=3592 ; \mathrm{p}<0,05\right)$. Por el contrario los hombres realizan con más frecuencia el resto de actividades de formación permanente como son: asistencia a jornadas $\left(16,2 \% ; \mathrm{x}^{2}=2653 ; \mathrm{p}<0,05\right)$, asistencia a congresos $\left(12 \% ; \mathrm{x}^{2}=3219\right.$; $\mathrm{p}<0,05)$ y realización de postgrados no oficiales $\left(2 \% ; \mathrm{x}^{2}=2677 ; \mathrm{p}<0,05\right)$. 
La relación existente entre la formación permanente y el sexo está entre considerable y alta, ya que el coeficiente phi varió entre 0,700 y 0,850 y se obtiene que ésta es significativa $(\mathrm{p}<0,05)$.

Tabla 5. 1

Actividades de formación permanentes a las que han asistido los monitores de actividad física y el deporte en los últimos tres años en relación al sexo $(N=600)$

\begin{tabular}{lccc}
\multicolumn{2}{c}{$\begin{array}{c}\text { ACTIVIDADES DE FORMACIÓN } \\
\text { PERMANENTE }\end{array}$} & SEXO (\%) \\
\cline { 3 - 4 } REALIZACIÓN DE CURSOS & No & 52,4 & MUJER \\
\hline ASISTENCIA A JORNADAS & Sí & 47,6 & 51,3 \\
& No & 83,8 & 48,7 \\
ASISTENCIA A CONGRESOS & Sí & 16,2 & 86,4 \\
& No & 88 & 13,6 \\
REALIZACIÓN DE POSTGRADOS NO & Sí & 12 & 94 \\
OFICIALES & No & 98 & 6 \\
& Sí & 2 & 100 \\
REALIZACIÓN DE MÁSTERES & No & 99,3 & 0 \\
OFICIALES & Sí & 0,7 & 99 \\
REALIZACIÓN DE GRUPOS DE & No & 99,5 & 1 \\
TRABAJO & Sí & 0,5 & 99 \\
\hline
\end{tabular}

Nota. $\mathrm{p}<0,05 ; \Phi=0,700-0,850$.

Al relacionar la formación permanente con la edad (relación alta ya que el coeficiente phi varió entre 0,750 y 0,850 y es significativa $p<0,05)$, se obtiene que los monitores de actividad física y deporte españoles entre 45 y 70 años son los que más se forman ya que realizan más formación permanente que el resto de los grupos de edad, con la excepción de la realización de grupos de trabajo que es inexistente para ellos $\left(0 \%, x^{2}=22361 ; p<0,05\right)$. 
Los cursos siguen siendo la formación permanente que más desarrollan independientemente de la edad $\left(\mathrm{X}_{16-29}=41,4 \% ; \quad \mathrm{X}_{30-44}=56,7 \%\right.$ y $\mathrm{X}_{45-70}=61,3 \%$; $\left.x^{2}=22679 ; p<0,05\right)$, seguida de la asistencia a jornadas $\left(X_{16-29}=13 \% ; X_{30-44}=18 \%\right.$ y $X_{45-}$ $\left.{ }_{70}=19,7 \% ; x^{2}=23006 ; p<0,05\right), y$ la asistencia a congresos $\left(X_{16-29}=7,3 \% ; X_{30-44}=13,4 \%\right.$ y $\left.X_{45-70}=14,5 \% ; x^{2}=21987 ; p<0,05\right)$.

Para los monitores de actividad física y deporte que tienen entre 16 y 29 años y los de 45 años o mayores, la realización de grupos de trabajo es la formación permanente que menos realizan $\left(\mathrm{X}_{16-29}=0,6 \%\right.$ y $\left.\mathrm{X}_{45-70}=0 \% ; \mathrm{x}^{2}=19988 ; \mathrm{p}<0,05\right)$, en cambio para aquello de 30 a 44 años es la realización de másteres oficiales (0\%; $\left.x^{2}=19677 ; p<0,05\right)$ (véase tabla 5.2).

Tabla 5. 2.

Actividades de formación permanentes a las que han asistido los monitores de actividad física y el deporte en los últimos tres años en relación a la edad $(N=600)$

\begin{tabular}{|c|c|c|c|c|}
\hline \multirow{2}{*}{\multicolumn{2}{|c|}{$\begin{array}{c}\text { ACTIVIDADES DE } \\
\text { FORMACIÓN PERMANENTE }\end{array}$}} & \multicolumn{3}{|c|}{$\operatorname{EDAD}(\%)$} \\
\hline & & \multirow{2}{*}{$\begin{array}{c}\mathbf{1 6 - 2 9} \\
58,6\end{array}$} & \multirow{2}{*}{$\frac{30-\mathbf{4 4}}{433,3}$} & \multirow{2}{*}{$\begin{array}{r}\mathbf{4 5 - 7 0} \\
38,7\end{array}$} \\
\hline & No & & & \\
\hline REALIZACIÓN DE CURSOS & Sí & 41,4 & 56,7 & 61,3 \\
\hline \multirow{2}{*}{ ASISTENCIA A JORNADAS } & No & 87 & 82 & 80,3 \\
\hline & Sí & 13 & 18 & 19,7 \\
\hline \multirow{2}{*}{ ASISTENCIA A CONGRESOS } & No & 92,7 & 86,6 & 85,5 \\
\hline & Sí & 7,3 & 13,4 & 14,5 \\
\hline \multirow{2}{*}{$\begin{array}{l}\text { REALIZACIÓN DE } \\
\text { POSTGRADOS NO OFICIALES }\end{array}$} & No & 98,8 & 99 & 96,8 \\
\hline & Sí & 1,2 & 1 & 3,2 \\
\hline \multirow{2}{*}{$\begin{array}{l}\text { REALIZACIÓN DE MÁSTERES } \\
\text { OFICIALES }\end{array}$} & No & 98,8 & 100 & 98,4 \\
\hline & Sí & 1,2 & 0 & 1,6 \\
\hline \multirow{2}{*}{$\begin{array}{l}\text { REALIZACIÓN DE GRUPOS DE } \\
\text { TRABAJO }\end{array}$} & No & 99,4 & 99 & 100 \\
\hline & Sí & 0,6 & 1 & 0 \\
\hline
\end{tabular}

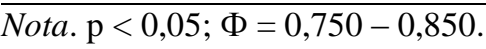


Por último se ha observado que los monitores de actividad física y deporte españoles que tienen diez años de experiencia laboral o más se forman más a lo largo de su vida profesional que los que tienen menos de diez años de experiencia (relación moderada ya que el coeficiente phi varió entre 0,220 y 0,350). Estos monitores más experimentados tienen mayores porcentajes en todas las actividades de formación permanente, siendo éstos en muchos casos bastante superior al porcentaje que le otorgan a las actividades de formación permanente los monitores de actividad física y deporte con menos de diez años de experiencia. Los cursos siguen siendo, igualmente, la formación permanente que más desarrollan independientemente de la experiencia laboral, seguida de la asistencia a jornadas y la asistencia a congresos (véase tabla 5.3).

Tabla 5.3

Actividades de formación permanentes a las que han asistido los monitores de actividad física y el deporte en los últimos tres años en relación a la experiencia laboral $(N=$ 600)

\begin{tabular}{|c|c|c|c|}
\hline \multirow{2}{*}{\multicolumn{2}{|c|}{$\begin{array}{l}\text { ACTIVIDADES DE FORMACIÓN } \\
\text { PERMANENTE }\end{array}$}} & \multicolumn{2}{|c|}{ EXPERIENCIA LABORAL (\%) } \\
\hline & & MENOS DE 10 AÑOS & 10 AÑOS O MÁS \\
\hline \multirow{2}{*}{ REALIZACIÓN DE CURSOS } & No & 53,2 & 49 \\
\hline & Sí & 46,8 & 51 \\
\hline \multirow{2}{*}{ ASISTENCIA A JORNADAS } & No & 86,5 & 81 \\
\hline & Sí & 13,5 & 19 \\
\hline \multirow{2}{*}{ ASISTENCIA A CONGRESOS } & No & 91,8 & 86,1 \\
\hline & Sí & 8,2 & 13,9 \\
\hline REALIZACIÓN DE POSTGRADOS & No & 99 & 97,9 \\
\hline NO OFICIALES & Sí & 1 & 2,1 \\
\hline REALIZACIÓN DE MÁSTERES & No & 99,3 & 99 \\
\hline OFICIALES & Sí & 0,7 & 1 \\
\hline REALIZACIÓN DE GRUPOS DE & No & 99,5 & 99 \\
\hline TRABAJO & Sí & 0,5 & 1 \\
\hline
\end{tabular}

Nota. $\Phi=0,500-0,750$. 
En la interrelación de formación permanente y formación general inicial (tabla 5.4) se han obtenido diferencias bastante notorias en cuanto a la implicación de cada grupo investigado (hay una relación alta ya que el coeficiente phi varió entre 0,750 y $0,850$ y es significativa $\mathrm{p}<0,05)$. Tanto los graduados universitarios $(53,5 \%)$, los que terminaron un ciclo de formación profesional $(46,9 \%)$, los que terminaron la educación secundaria $(42,5 \%)$ y los que tienen estudios primarios o menores $(61,5 \%)$ hicieron algún curso para formarse $\left(\mathrm{x}^{2}=12346 ; \mathrm{p}<0,05\right)$, siendo éstos la formación más solicitada y realizada. La asistencia a jornadas y la asistencia a congresos fueron la segunda y la tercera opción de formación permanente más elegidas en función de la formación inicial general. Después, en cuarto lugar, con porcentajes menores, los monitores de actividad física y deporte realizaron postgrados no oficiales. Por último y con unos porcentajes casi inexistentes, las dos actividades de formación menos solicitadas fueron: realización de másteres oficiales y realización de grupos de trabajo.

En general, los monitores de actividad física y deporte con estudios universitarios fueron los que más se forman, habiendo realizado más variedad de actividades de formación permanente. La actividad de formación permanente que más realizan son los cursos $\left(53,5 \% ; x^{2}=12346 ; \mathrm{p}<0,05\right)$ y las que menos la realización de másteres oficiales $\left(1,7 \% ; x^{2}=13164 ; p<0,05\right)$ y la asistencia a grupos de trabajo $(1,7 \%$; $\left.\mathrm{x}^{2}=11036 ; \mathrm{p}<0,05\right)$. Igualmente, la actividad de formación permanente que más realizan los monitores con formación profesional son los cursos $\left(53,1 \% ; x^{2}=12346 ; p<0,05\right)$ y las que menos la realización de másteres oficiales $\left(0 \% ; x^{2}=13164 ; \mathrm{p}<0,05\right)$ y la asistencia a grupos de trabajo $\left(0 \% ; \mathrm{x}^{2}=11036 ; \mathrm{p}<0,05\right)$. Los monitores de actividad física y deporte con educación secundaria realizan más cursos $\left(42,5 \% ; x^{2}=12346\right.$; $\mathrm{p}<0,05)$ pero ningún grupo de trabajo $\left(0 \% ; x^{2}=11036 ; p<0,05\right)$. Finalmente los que poseen una educación primara o menor prefieren realizar cursos $\left(61,5 \% ; x^{2}=12346\right.$; 
$\mathrm{p}<0,05)$ pero no realizan ni postgrados no oficiales $\left(0 \% ; \mathrm{x}^{2}=11210 ; \mathrm{p}<0,05\right)$, ni másteres oficiales $\left(0 \% ; x^{2}=13164 ; p<0,05\right)$, ni grupos de trabajo $\left(0 \% ; x^{2}=11036 ; p<0,05\right)$.

Tabla 5.4

Actividades de formación permanente a las que han asistido los monitores de actividad física y el deporte en los últimos tres años en relación a la formación inicial general ( $N$ $=600)$

\begin{tabular}{|c|c|c|c|c|c|}
\hline \multirow[b]{2}{*}{$\begin{array}{l}\text { ACTIVIDADES DE } \\
\text { FORMACIÓN } \\
\text { PERMANENTE }\end{array}$} & & \multicolumn{4}{|c|}{ FORMACIÓN GENERAL INICIAL (\%) } \\
\hline & & $\begin{array}{c}\text { TITULADO } \\
\text { UNIVERSITARIO }\end{array}$ & $\begin{array}{l}\text { FORMACIÓN } \\
\text { PROFESIONAL }\end{array}$ & $\begin{array}{l}\text { EDUCACIÓN } \\
\text { SECUNDARIA }\end{array}$ & $\begin{array}{c}\text { EDUCACIÓN } \\
\text { PRIMARIA O } \\
\text { MENOR }\end{array}$ \\
\hline \multirow{2}{*}{ REALIZACIÓN DE CURSOS } & No & 46,5 & 53,1 & 57,5 & 38,5 \\
\hline & Sí & 53,5 & 46,9 & 42,5 & 61,5 \\
\hline \multirow{2}{*}{ ASISTENCIA A JORNADAS } & No & 76,7 & 90,3 & 88,8 & 92,3 \\
\hline & Sí & 23,3 & 9,7 & 11,2 & 7,7 \\
\hline ASISTENCIA A & No & 83,7 & 95,2 & 93 & 92,3 \\
\hline CONGRESOS & Sí & 16,3 & 4,8 & 7 & 7,7 \\
\hline REALIZACIÓN DE & No & 97,4 & 99,3 & 99,5 & 100 \\
\hline $\begin{array}{l}\text { POSTGRADOS NO } \\
\text { OFICIALES }\end{array}$ & Sí & 2,6 & 0,7 & 0,5 & 0 \\
\hline REALIZACIÓN DE & No & 98,3 & 100 & 99,5 & 100 \\
\hline MÁSTERES OFICIALES & Sí & 1,7 & 0 & 0,5 & 0 \\
\hline REALIZACIÓN DE GRUPOS & No & 98,3 & 100 & 100 & 100 \\
\hline DE TRABAJO & Sí & 1,7 & 0 & 0 & 0 \\
\hline
\end{tabular}

Nota. $\mathrm{p}<0,05 ; \Phi=0,750-0,850$.

Estos resultados descritos hasta ahora van a ser complementados con las actividades de formación permanente ofrecidas por las organizaciones en los últimos doce meses a sus empleados (figura 5.3). De acuerdo con los monitores de actividad física y deporte, el 83,8\% afirmó que las organizaciones para las que trabajaban no les habían ofertado ninguna actividad de formación permanente en actividad física y 
deporte en los últimos doce meses. Afirmando un 15,5\% que sus organizaciones sí llevaban a cabo actividades formativas para sus empleados y un $0,7 \%$ aseguraron que alguna de las organizaciones para las que trabaja sí les ofrecen actividades de formación permanente pero otras no.

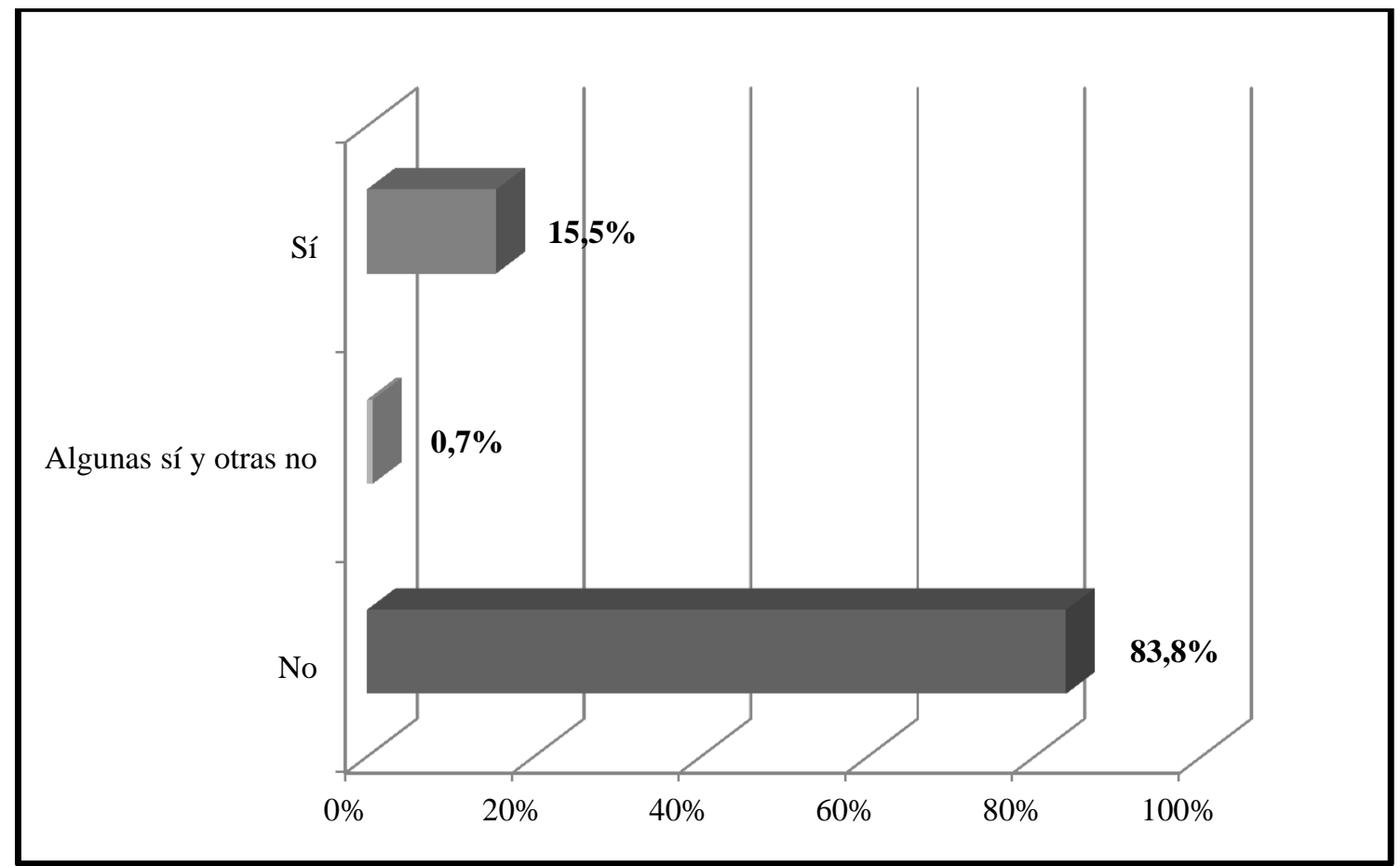

Figura 5. 3. Actividades de formación organizadas por su entidad para los monitores de actividad física y deporte en los últimos 12 meses $(\mathrm{N}=600)$.

\subsubsection{INTERVENCIÓN DOCENTE Y PROFESIONAL DE LOS MONITORES DE ACTIVIDAD FÍSICA Y DEPORTE}

A continuación se va describir la planificación, la evaluación, los elementos que priorizan en su enseñanza y desempeño profesional y las fuentes de conocimientos de los monitores de actividad física y deporte, así como la relación existentes entre éstos y las variables: edad, sexo, experiencia laboral y nivel de estudios. 


\subsubsection{Planificación}

Como se puede observar en el figura 5.4, menos de la mitad de los monitores de actividad física y deporte planifican sus sesiones (48\%), en cambio más de la mitad (52\%) de los monitores de actividad física y deporte no planifican.

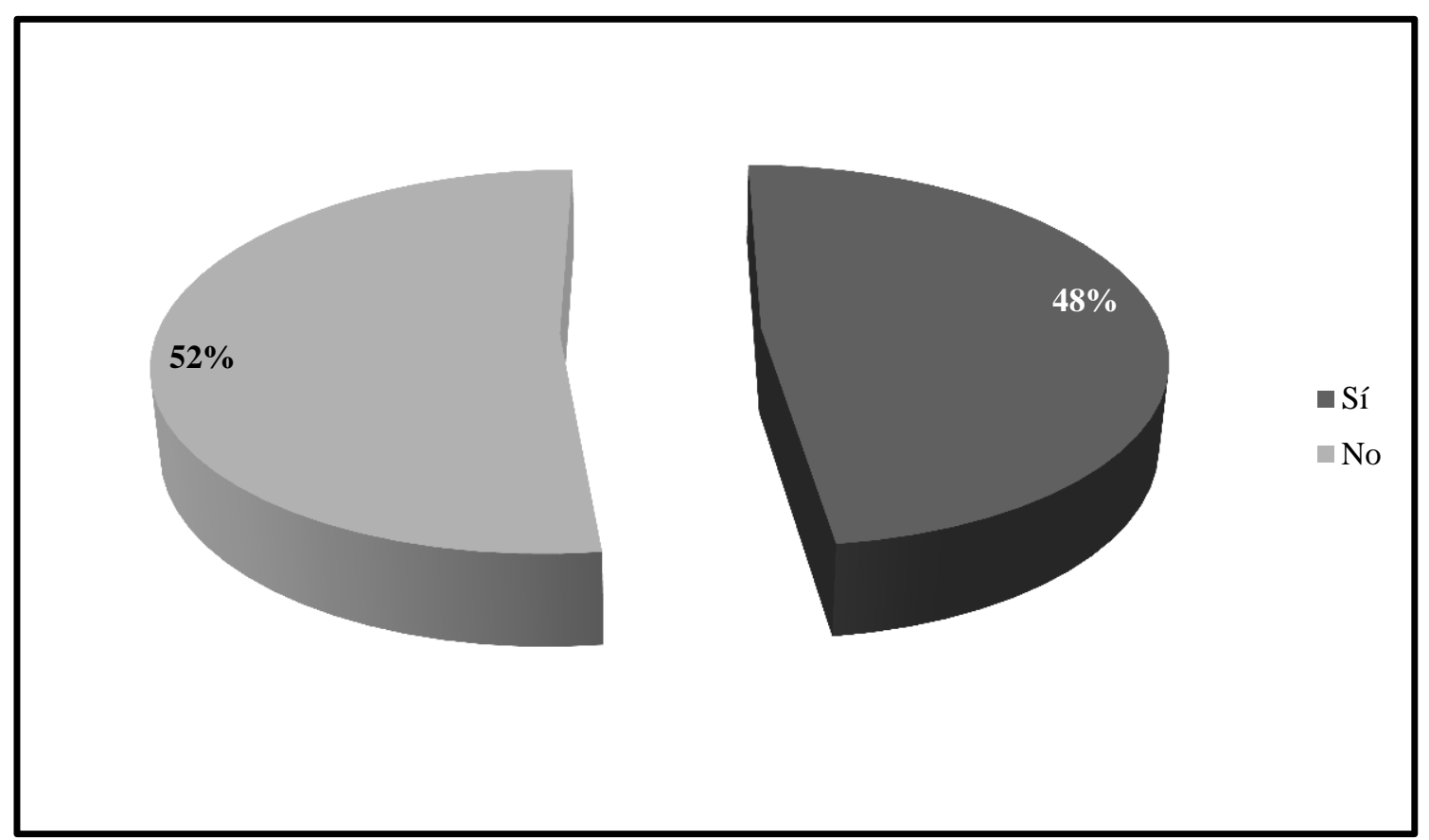

Figura 5. 4. La planificación que llevan a cabo los monitores de actividad física y deporte $(\mathrm{N}=600)$.

En las cuatro próximas tablas (tabla 5.5, tabla 5.6, tabla 5.7 y tabla 5.8) se expresa más detalladamente la planificación según las variables objeto de estudio: sexo, edad, nivel de estudios y experiencia laboral.

Refiriéndonos al sexo, los monitores de actividad física y deporte masculinos planifican un poco más que las mujeres $\left(\mathrm{X}_{\text {hombres }}=48,4 \%\right.$ y $\left.\mathrm{X}_{\text {mujeres }}=47,2 \%\right)\left(\mathrm{x}^{2}=\right.$ 10325; $\mathrm{p}<0,01 ; \Phi=0,792)$. 


\section{Tabla 5.5}

La planificación que llevan a cabo los monitores de actividad física y deporte en relación al sexo $(N=600)$

\begin{tabular}{lcc}
\hline \multirow{2}{*}{ PLANIFICACIÓN } & \multicolumn{2}{c}{ SEXO $(\%)$} \\
\cline { 2 - 3 } & HOMBRE & MUJER \\
\hline No & 51,6 & 52,8 \\
Sí & 48,4 & 47,2 \\
\hline
\end{tabular}

Nota. $\mathrm{p}<0,01 ; \Phi=0,792$.

Si nos referimos a la variable edad (tabla 5.6), los monitores de actividad física y deporte que más planifican son los de 45 años o mayores $(51,8 \%)\left(x^{2}=31880\right.$, p <0,01; $\Phi=0,220)$. A medida que aumenta la edad de los monitores de actividad física y deporte, planifican más.

Tabla 5.6

La planificación que llevan a cabo los monitores de actividad física y deporte en relación a la edad $(N=600)$

\begin{tabular}{cccc}
\hline \multirow{2}{*}{ PLANIFICACIÓN } & \multicolumn{3}{c}{ EDAD $(\%)$} \\
\cline { 2 - 4 } & $\mathbf{1 6 - 2 9}$ & $\mathbf{3 0 - 4 4}$ & $\mathbf{4 5 - 7 0}$ \\
\hline No & 58,9 & 51,8 & 48,2 \\
Sí & 41,1 & 48,2 & 51,8 \\
\hline
\end{tabular}

Nota. $\mathrm{p}<0,01 ; \Phi=0,220$.

En cuanto al nivel de estudios, los monitores de actividad física y deporte según aumentan la formación inicial general, planifican más. Los que más planifican son los titulados universitarios $(56,1 \%)$, seguidos por los que han estudiado formación profesional (49\%), después los que han terminado la educación secundaria $(40,2 \%)$ y por último los que menos planifican son los que han estudiado la educación primaria o incluso menos $(30,8 \%)$. En esta variable se puede observar una diferencia de casi un 
$26 \%$ entre los monitores de actividad física y deporte que más planifican y los que menos $\left(\mathrm{x}^{2}=26994 ; \mathrm{p}<0,01 ; \Phi=0,205\right)$ (véase tabla 5.7).

Tabla 5.7

La planificación que llevan a cabo los monitores de actividad física y deporte en relación al nivel de estudios $(N=600)$

\begin{tabular}{ccccc}
\hline \multirow{2}{*}{ PLANIFICACIÓN } & \multicolumn{4}{c}{ NIVEL DE ESTUDIOS (\%) } \\
\cline { 2 - 5 } & $\begin{array}{c}\text { TITULADO } \\
\text { UNIVERSITARIO }\end{array}$ & $\begin{array}{c}\text { FORMACIÓN } \\
\text { PROFESIONAL }\end{array}$ & $\begin{array}{c}\text { EDUCACIÓN } \\
\text { SECUNDARIA }\end{array}$ & $\begin{array}{c}\text { EDUCACIÓN } \\
\text { PRIMARIA O } \\
\text { MENOR }\end{array}$ \\
\hline No & 43,9 & 51,0 & 59,8 & 69,2 \\
Sí & 56,1 & 49,0 & 40,2 & 30,8 \\
\hline
\end{tabular}

Nota. $\mathrm{p}<0,01 ; \Phi=0,205$.

En la misma línea que la edad, se obtiene en este estudio que los monitores de actividad física y deporte con más experiencia laboral también planifican más (50,5\%). Por lo que se infiere que según aumenta la experiencia aumenta la planificación $\left(\mathrm{x}^{2}=\right.$ $10062 ; \mathrm{p}<0,01 ; \Phi=0,420$ ) (Véase tabla 5.8).

Tabla 5.8

La planificación que llevan a cabo los monitores de actividad física y deporte en relación a la experiencia laboral $(N=600)$

\begin{tabular}{ccc} 
PLANIFICACIÓN & \multicolumn{2}{c}{ EXPERIENCIA LABORAL (\%) } \\
\cline { 2 - 3 } & $<\mathbf{1 0}$ AÑOS & $\geq \mathbf{1 0}$ AÑOS \\
\hline No & 53 & 49,5 \\
Sí & 47 & 50,5 \\
\hline
\end{tabular}

Nota. $\mathrm{p}<0,01 ; \Phi=0,420$. 


\subsubsection{Evaluación}

Continuando con la evaluación, como se puede ver en el figura 5.5, más de la mitad de los monitores de actividad física y deporte, el 58,2\%, evalúan y el 41,8\% de los monitores de actividad física y deporte no evalúa.

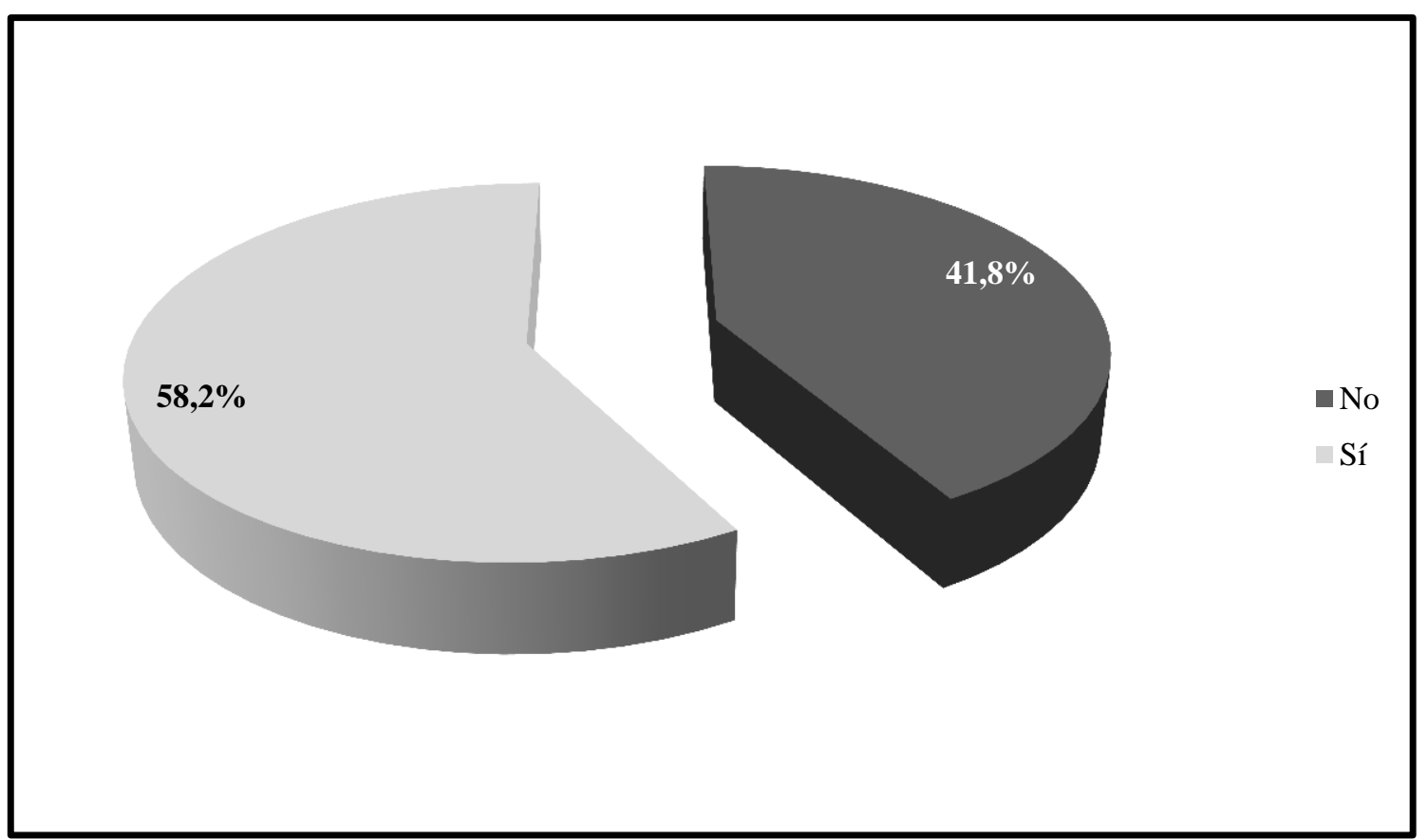

Figura 5. 5. La evaluación de los monitores de actividad física y deporte $(\mathrm{N}=600)$.

De los monitores de actividad física y deporte que sí evalúan, encontramos que el $57,6 \%$ de ellos lo hacen regularmente, en cambio el $42,4 \%$ no lo realizan regularmente (véase figura 5.6). 


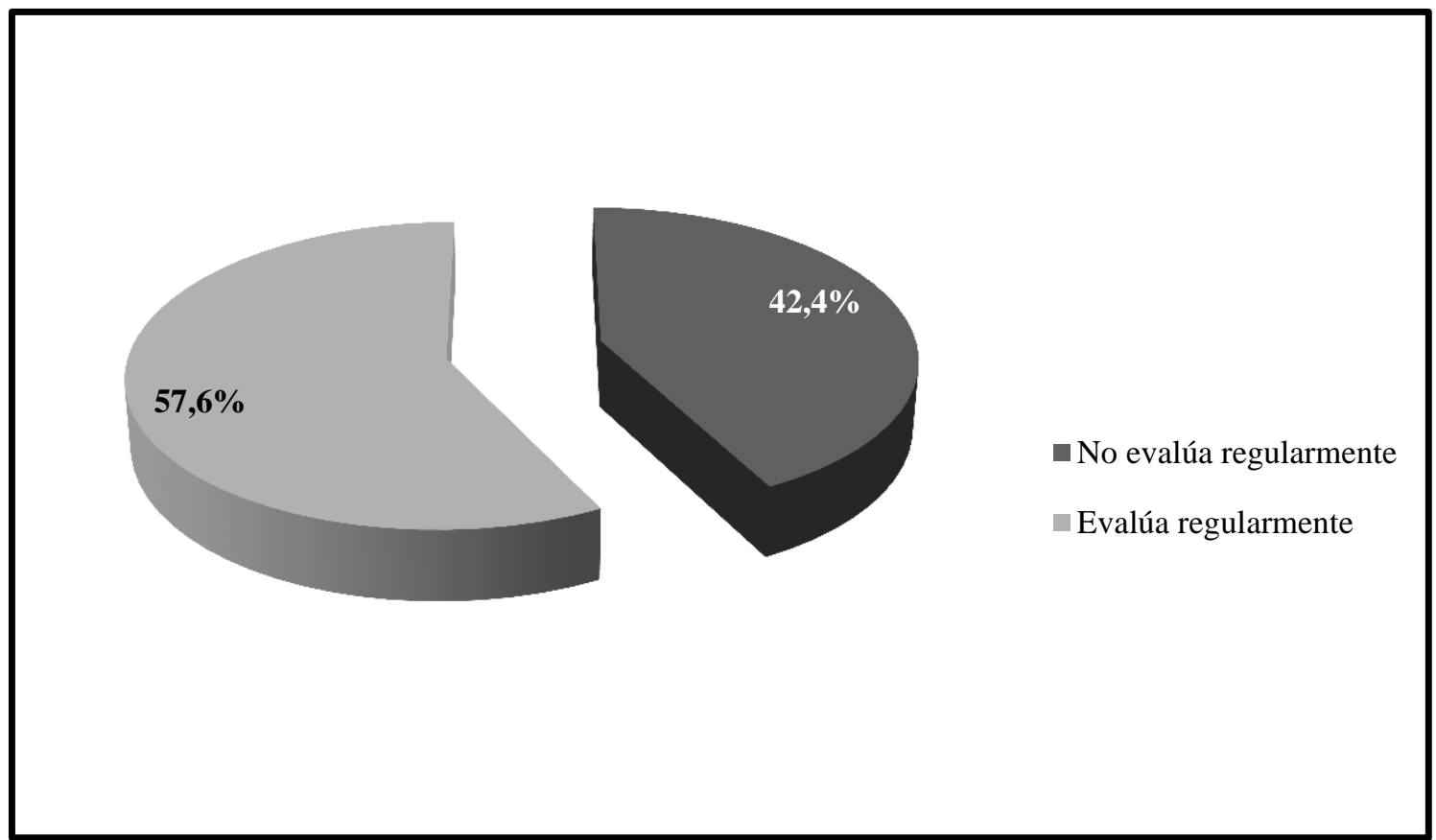

Figura 5. 6. Regularidad con la que evalúan los monitores de actividad física y deporte $(\mathrm{N}=600)$.

Como se observa en la tabla 5.9, la evaluación mostró una diferencia más significativa entre sexos: los varones evalúan más que las mujeres $\left(X_{\text {varones }}=59,6 \%\right.$, $\left.\mathrm{X}_{\text {mujeres }}=55,3 \%\right)\left(\mathrm{x}^{2}=10029 ; \mathrm{p}<0,01 ; \Phi=0,580\right)$.

Tabla 5. 9

Evaluación llevada a cabo por los monitores de actividad física y deporte en relación al $\operatorname{sexo}(N=600)$

\begin{tabular}{ccc}
\hline & \multicolumn{2}{c}{ SEXO $(\%)$} \\
\cline { 2 - 3 } EVALUACIÓN & HOMBRE & MUJER \\
\hline No & 40,4 & 44,7 \\
Sí & 59,6 & 55,3 \\
\hline
\end{tabular}

Nota. $\mathrm{p}<0,01 ; \Phi=0,580$.

En relación a los que sí evalúan, el 57,7\% de los hombres prefieren hacerlo regularmente así como el 57,3\% de las mujeres ( $\mathrm{p}<0,01)$ (véase tabla 5.10). 
Tabla 5.10

Regularidad en la evaluación llevada a cabo por los monitores de actividad física y deporte en relación al sexo $(N=600)$

\begin{tabular}{lcc}
\hline \multirow{2}{*}{ EVALUACIÓN } & \multicolumn{2}{c}{ SEXO(\%) } \\
\cline { 2 - 3 } & HOMBRE & MUJER \\
\hline NO EVALÚA REGULARMENTE & 42,3 & 42,7 \\
EVALÚA REGULARMENTE & 57,7 & 57,3 \\
\hline Nota. $\mathrm{p}<0,01$. & &
\end{tabular}

Nota. $\mathrm{p}<0,01$.

En cuanto a la edad, los monitores de actividad física y deporte de 30 a 44 años evalúan con mayor frecuencia $(65,5 \%)$, seguidos de aquellos de 45 años o mayores $(60,4 \%)$ y por último los que menos evalúan son los de 16 a 29 años, realizándolo menos del 50\% ( $\left.x^{2}=33660 ; p<0,01 ; \Phi=0,230\right)$ (véase tabla 5.11).

Tabla 5. 11

Evaluación llevada a cabo por los monitores de actividad física y deporte en relación a la edad $(N=600)$

\begin{tabular}{cccc}
\hline & \multicolumn{3}{c}{ EDAD $(\%)$} \\
\cline { 2 - 4 } EVALUACIÓN & $\mathbf{1 6 - 2 9}$ & $\mathbf{3 0 - 4 4}$ & $\mathbf{4 5 - 7 0}$ \\
\hline No & 55,5 & 34,5 & 39,6 \\
Sí & 44,5 & 65,5 & 60,4 \\
\hline
\end{tabular}

Nota. $\mathrm{p}<0,01 ; \Phi=0,230$.

Como se puede observar en la tabla 5.12, dentro de los monitores de actividad física y deporte que sí que evalúan se puede observar que los que más regularmente evalúan son aquellos de 30 a 44 años (64,9\%), seguidos de los de 45 años o mayores $(63,7 \%)$ y finalmente de los de 16 a 29 años $(56 \%)(\mathrm{p}<0,01)$. 
Tabla 5.12

Regularidad en la evaluación llevada a cabo por los monitores de actividad física y deporte en relación a la edad $(N=600)$

\begin{tabular}{lccc}
\hline & \multicolumn{3}{c}{ EDAD $(\boldsymbol{\%})$} \\
\cline { 2 - 4 } EVALUACIÓN & $\mathbf{1 6 - 2 9}$ & $\mathbf{3 0 - 4 4}$ & $\mathbf{4 5 - 7 0}$ \\
\hline NO EVALÚA REGULARMENTE & 44 & 35,1 & 36,3 \\
EVALÚA REGULARMENTE & 56 & 64,9 & 63,7 \\
\hline
\end{tabular}

Nota. $\mathrm{p}<0,01$.

En cuanto al nivel de estudios (véase tabla 5.13), los graduados universitarios llevan a cabo la evaluación con mayor frecuencia (71.1\%), obteniendo un porcentaje muy superior a los demás niveles de formación. Estos titulados universitarios están seguidos, en segundo lugar, por los monitores de actividad física y deporte con un título de formación profesional $(57,9 \%)$, después los que poseen la educación primaria o inferior $(46,2 \%)$ y por último los que poseen la educación secundaria $(43,9 \%)\left(x^{2}=\right.$ 34303, $\mathrm{p}<0,01, \Phi=0,303)$.

Tabla 5.13

Evaluación llevada a cabo por los monitores de actividad física y deporte en relación al nivel de formación $(N=600)$

\begin{tabular}{ccccc}
\hline \multirow{2}{*}{ EVALUACIÓN } & \multicolumn{4}{c}{ NIVEL DE FORMACIÓN (\%) } \\
\cline { 2 - 5 } & $\begin{array}{c}\text { TITULADO } \\
\text { UNIVERSITARIO }\end{array}$ & $\begin{array}{c}\text { FORMACIÓN } \\
\text { PROFESIONAL }\end{array}$ & $\begin{array}{c}\text { EDUCACIÓN } \\
\text { SECUNDARIA }\end{array}$ & $\begin{array}{c}\text { EDUCACIÓN } \\
\text { PRIMARIA O } \\
\text { MENOR }\end{array}$ \\
\hline No & 28,9 & 42,1 & 56,1 & 53,8 \\
Sí & 71,1 & 57,9 & 43,9 & 46,2 \\
\hline
\end{tabular}

Nota. $\mathrm{p}<0,01 ; \Phi=0,303$.

En relación a los que sí que evalúan y teniendo en cuenta su nivel de formación, encontramos que los que más regularmente evalúan son los monitores de actividad 
física y deporte con la educación secundaria $(59,5 \%)$, después los que poseen una formación profesional $(58,4 \%)$, en tercer lugar los titulados universitarios $(56,9 \%)$ y en último lugar los que tienen la educación primaria o menos $(50 \%)(\mathrm{p}<0,01)$ (véase tabla $5.14)$.

Tabla 5.14

Regularidad en la evaluación llevada a cabo por los monitores de actividad física y deporte en relación a la formación $(N=600)$

\begin{tabular}{lcccc}
\hline \multirow{2}{*}{ EVALUACIÓN } & \multicolumn{4}{c}{ NIVEL DE FORMACIÓN (\%) } \\
\cline { 2 - 5 } & $\begin{array}{c}\text { TITULADO } \\
\text { UNIVERSITARIO }\end{array}$ & $\begin{array}{c}\text { FORMACIÓN } \\
\text { PROFESIONAL }\end{array}$ & $\begin{array}{c}\text { EDUCACIÓN } \\
\text { SECUNDARIA }\end{array}$ & $\begin{array}{c}\text { EDUCACIÓN } \\
\text { PRIMARIA O } \\
\text { MENOR }\end{array}$ \\
\hline NO EVALÚA REGULARMENTE & 43,1 & 41,6 & 40,5 & 50 \\
EVALÚA REGULARMENTE & 56,9 & 58,4 & 59,5 & 50 \\
\hline
\end{tabular}

Nota. $\mathrm{p}<0,01$.

Como vimos con la planificación, los monitores de actividad física y deporte evalúan más a medida que tienen más experiencia (66\%). Los monitores de actividad física y deporte con menos experiencia evalúan un 53,7\% $\left(\mathrm{x}^{2}=11591, \mathrm{p}<0,01, \Phi=\right.$ 0,500) (véase tabla 5.15).

Tabla 5. 15

Evaluación llevada a cabo por los monitores de actividad física y deporte en relación a la experiencia laboral $(N=600)$

\begin{tabular}{ccc}
\hline \multirow{2}{*}{ EVALUACIÓN } & \multicolumn{2}{c}{ ESPERIENCIA LABORAL $(\%)$} \\
\cline { 2 - 3 } & $<\mathbf{1 0}$ AÑOS & $\geq 10$ AÑOS \\
\hline NO & 46,3 & 34 \\
Sí & 53,7 & 66 \\
\hline
\end{tabular}

Nota. $\mathrm{p}<0,01 ; \Phi=0,500$. 
Dentro de los monitores de actividad física y deporte que sí que evalúan, el $64,1 \%$ de los monitores con diez años de experiencia laboral o más prefiere evaluar regularmente, así como el 54,2\% de los que tienen menos de diez años de experiencia laboral $(\mathrm{p}<0,01)($ tabla 5.16).

Tabla 5. 16

Regularidad en la evaluación llevada a cabo por los monitores de actividad física y deporte en relación a la experiencia laboral $(N=600)$

\begin{tabular}{lcc}
\hline \multirow{2}{*}{ EVALUACIÓN } & \multicolumn{2}{c}{ ESPERIENCIA LABORAL (\%) } \\
\cline { 2 - 3 } & $<\mathbf{1 0}$ AÑOS & $\geq \mathbf{1 0}$ AÑOS \\
\hline NO EVALÚA REGULARMENTE & 45,8 & 35,9 \\
EVALÚA REGULARMENTE & 54,2 & 64,1 \\
\hline
\end{tabular}

Nota. $\mathrm{p}<0,01$.

Siguiendo con el análisis de la evaluación, ahora se procede a estudiar las herramientas de evaluación que utilizan los monitores de actividad física y deporte. Como se puede ver en el figura 5.7, estos profesionales indicaron que la observación diaria es la herramienta más utilizada por los monitores de actividad física y deporte con un $49,6 \%$, seguidamente pero con un tanto por ciento bastante menor, la segunda herramienta de evaluación más utilizada son las pruebas de ejecución (30,2\%). Las demás herramientas de evaluación no son tan utilizadas, en el tercer lugar están las baterías de test/tests estandarizados con un $8,3 \%$, a continuación los test confeccionados por uno mismo o por los compañeros con el 5,7\%, los diarios con un 5,3\% y en último lugar los exámenes teóricos con un $0,8 \%$. 


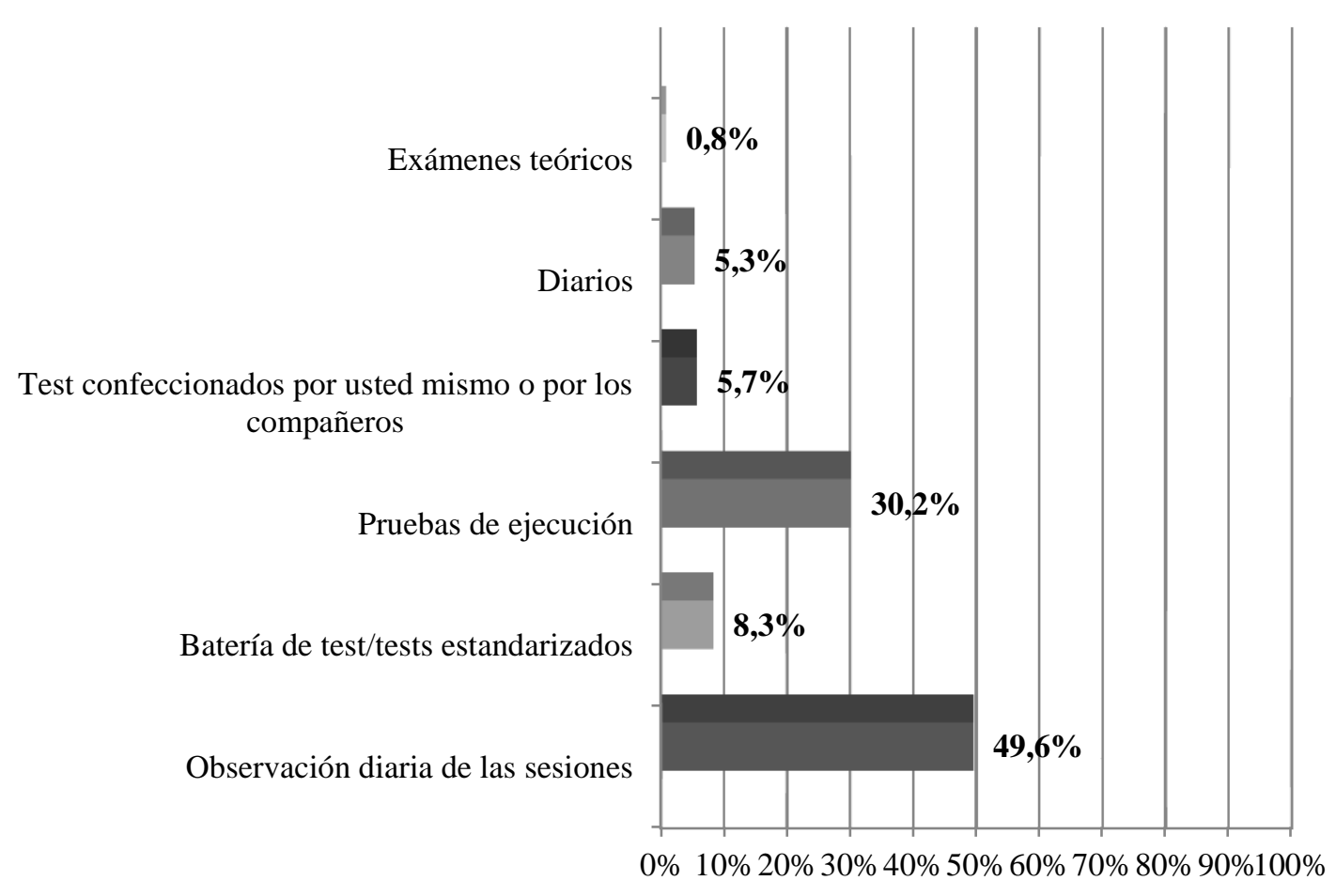

Figura 5. 7. Las herramientas de evaluación usadas por los monitores de actividad física y deporte $(\mathrm{N}=600)$.

Atendiendo a las variables objeto de estudio, la observación diaria es la herramienta más utilizada por los monitores de actividad física y deporte $(49,6 \%)$, independientemente de su sexo $\left(x^{2}=9782 ; p<0,05 ; \Phi=0,353\right)$, su edad $\left(x^{2}=28706, p\right.$ $<0,05, \Phi=0,350)$, su nivel de estudios $\left(\mathrm{x}^{2}=18795, \mathrm{p}<0,05 ; \Phi=0,450\right)$ y su experiencia laboral $\left(\mathrm{x}^{2}=7925, \mathrm{p}<0,05 ; \Phi=0,350\right)$.

En cuanto al sexo, las mujeres utilizan más la herramienta observación diaria de las sesiones que los hombres $\left(\mathrm{X}_{\text {mujeres }}=53,5 \% \mathrm{y} \mathrm{X}_{\text {hombres }}=37,8 \% ; \mathrm{x}^{2}=9782 ; \mathrm{p}<0,05\right) \mathrm{y}$ las pruebas de ejecución $\left(X_{\text {mujeres }}=30,2 \%\right.$ y $\left.X_{\text {hombres }}=30,1 \% ; x^{2}=7998 ; p<0,05\right)$, en cambio, los hombres utilizan más el resto de herramientas $(\mathrm{p}<0,05)$. Ambos seleccionan los exámenes teóricos como la herramienta de evaluación que menos utilizan $\left(\mathrm{X}_{\text {mujeres }}=0,6 \%\right.$ y $\left.\mathrm{X}_{\text {hombres }}=1 \% ; \mathrm{x}^{2}=10143 ; \mathrm{p}<0,05\right)$ (véase tabla 5.17). 
Tabla 5.17

Herramientas de evaluación utilizadas por los monitores de actividad física y deporte en relación al sexo $(N=600)$

\begin{tabular}{|c|c|c|}
\hline \multirow{2}{*}{ HERRAMIENTAS DE EVALUACIÓN } & \multicolumn{2}{|c|}{$\operatorname{SEXO}(\%)$} \\
\hline & HOMBRE & MUJER \\
\hline OBSERVACIÓN DIARIA DE LAS SESIONES & 47,8 & 53,5 \\
\hline BATERÍA DE TEST/TESTS ESTANDARIZADOS & 8,8 & 7 \\
\hline PRUEBAS DE EJECUCIÓN & 30,1 & 30,2 \\
\hline $\begin{array}{l}\text { TEST CONFECCIONADOS } \\
\text { COMPANORER }\end{array}$ & 6,8 & 3,5 \\
\hline DIARIOS & 5,5 & 5,2 \\
\hline EXÁMENES TEÓRICOS & 1 & 0,6 \\
\hline
\end{tabular}

Nota. $\mathrm{p}<0,05 ; \Phi 0,350-0,476$.

En relación con la edad, la observación diaria de las sesiones $\left(\mathrm{X}_{16-29}=51,8 \%\right.$; $\mathrm{X}_{30-44}=50,5 \%$ y $\left.\mathrm{X}_{45-70}=37,3 \% ; \mathrm{x}^{2}=28706 ; \mathrm{p}<0,05\right)$ es la herramienta más utilizada por los monitores de actividad física y deporte independientemente de la edad y los exámenes teóricos la que menos $\left(\mathrm{X}_{16-29}=0,6 \% ; \mathrm{X}_{30-44}=0,4 \%\right.$ y $\mathrm{X}_{45-70}=3 \% ; \mathrm{x}^{2}=23416 ; \mathrm{p}<$ $0,05)$.

En función de cada herramienta podemos constatar que, la observación diaria de las sesiones la realizan en mayor medida los monitores de 16 a 29 años $(51,8 \%$; $\left.x^{2}=28706 ; p<0,05\right)$. La batería de test/tests estandarizados $\left(8,9 \% ; x^{2}=25745 ; p<0,05\right)$, las pruebas de ejecución $\left(34,4 \% ; x^{2}=28100 ; p<0,05\right)$, los test confeccionadas por uno mismo o por los compañeros $\left(19,3 \% ; x^{2}=27733 ; p<0,05\right)$ y los exámenes teóricos $(3 \%$; $\left.\mathrm{x}^{2}=23416 ; \mathrm{p}<0,05\right)$ los monitores de actividad física y deporte de 45 años o mayores. 
Por último los diarios los utilizan más los monitores de 30 a 44 años $\left(5,8 \% ; x^{2}=22985\right.$; $\mathrm{p}<0,05)$ que los demás sujetos (véase tabla 5.18).

Tabla 5. 18

Herramientas de evaluación utilizadas por los monitores de actividad física y deporte en relación a la edad $(N=600)$

\begin{tabular}{lccc} 
& \multicolumn{3}{c}{ EDAD (\%) } \\
\cline { 2 - 4 } \multicolumn{1}{c}{ HERRAMIENTAS DE EVALUACIÓN } & $\mathbf{1 6 - 2 9}$ & $\mathbf{3 0 - 4 4}$ & $\mathbf{4 5 - 7 0}$ \\
\hline OBSERVACIÓN DIARIA DE LAS SESIONES & 51,8 & 50,5 & 37,3 \\
BATERÍA DE TEST/TESTS ESTANDARIZADOS & 7,9 & 8,7 & 8,9 \\
PRUEBAS DE EJECUCIÓN & 30,7 & 27,9 & 34,4 \\
TEST CONFECCIONADOS POR USTED MISMO O POR LOS & 3,6 & 6,7 & 19,3 \\
COMPAÑEROS & & & 4,4 \\
DIARIOS & 5,4 & 5,8 & 3 \\
EXÁMENES TEÓRICOS & 0,6 & 0,4 & \\
\hline
\end{tabular}

Nota. $\mathrm{p}<0,05$.

En cuanto al nivel de estudios (véase tabla 5.19), todos los monitores utilizan preferiblemente como herramienta de evaluación la observación diaria de las sesiones $\left(X_{\text {titulados universitarios }}=46,8 \%, X_{\text {formación profesional }}=52,9 \%, X_{\text {educación secundaria }}=53 \%\right.$ y $X_{\text {educación }}$ primaria o menos $\left.=36,4 \% ; \mathrm{x}^{2}=18795 ; \mathrm{p}<0,05\right)$, por el contrario todos utilizan menos los exámenes teóricos $\left(\mathrm{X}_{\text {titulados }}\right.$ universitarios $=1,5 \%, \quad \mathrm{X}_{\text {formación }}$ profesional $=0 \%, \quad \mathrm{X}_{\text {educación }}$ secundaria $\left.=0 \% ; \mathrm{x}^{2}=17649 ; \mathrm{p}<0,05\right)$ excepto los monitores con educación primaria o menos que la herramienta que menos utilizan son los diarios $\left(0 \% ; \mathrm{x}^{2}=17905 ; \mathrm{p}<0,05\right)$.

En general, los monitores de actividad física y deporte que han estudiado educación primaria o menos suelen usar más las pruebas de ejecución $(36,4 \%$; $\left.\mathrm{x}^{2}=18149 ; \mathrm{p}<0,05\right)$, los test confeccionados por uno mismo o por los compañeros 
$\left(9,1 \% ; x^{2}=17910 ; p<0,05\right)$ y los exámenes teóricos $\left(9,1 \% ; x^{2}=18795 ; p<0,05\right)$ como herramientas de evaluación que sus compañeros. Sin embargo, aquellos con el título de educación secundaria utilizan más la observación diaria $\left(53 \% ; x^{2}=18795 ; \mathrm{p}<0,05\right)$, aquellos con una formación profesional utilizan más las pruebas de ejecución $(28,9 \%$; $\left.\mathrm{x}^{2}=17221 ; \mathrm{p}<0,05\right)$ y los titulados universitarios la batería de test/tests estandarizados $\left(9,4 \% ; x^{2}=19574 ; p<0,05\right)$ y los diarios $\left(8,3 \% ; x^{2}=18533 ; p<0,05\right)$.

Tabla 5. 19

Herramientas de evaluación utilizadas por los monitores de actividad física y deporte en relación al nivel de estudios $(N=600)$

\begin{tabular}{|c|c|c|c|c|}
\hline \multirow{2}{*}{$\begin{array}{l}\text { HERRAMIENTAS DE } \\
\text { EVALUACIÓN }\end{array}$} & \multicolumn{4}{|c|}{ NIVEL DE ESTUDIOS (\%) } \\
\hline & $\begin{array}{c}\text { TITULADO } \\
\text { UNIVERSITARIO }\end{array}$ & $\begin{array}{l}\text { FORMACIÓN } \\
\text { PROFESIONAL }\end{array}$ & $\begin{array}{l}\text { EDUCACIÓN } \\
\text { SECUNDARIA }\end{array}$ & $\begin{array}{c}\text { EDUCACIÓN } \\
\text { PRIMARIA O } \\
\text { MENOR } \\
\end{array}$ \\
\hline $\begin{array}{l}\text { OBSERVACIÓN DIARIA DE LAS } \\
\text { SESIONES }\end{array}$ & 46,8 & 52,9 & 53,0 & 36,4 \\
\hline $\begin{array}{l}\text { BATERÍA DE } \quad \text { TEST/TESTS } \\
\text { ESTANDARIZADOS }\end{array}$ & 9,4 & 8,3 & 6,0 & 9,1 \\
\hline PRUEBAS DE EJECUCIÓN & 28,6 & 28,9 & 33,6 & 36,4 \\
\hline $\begin{array}{llll}\text { TEST CONFECCIONADOS } & \text { POR } \\
\text { USTED MISMO O POR } & \text { LOS } \\
\text { COMPANEEROS } & & & \end{array}$ & 5,4 & 6,6 & 5,4 & 9,1 \\
\hline DIARIOS & 8,3 & 3,3 & 2,0 & 0 \\
\hline EXÁMENES TEÓRICOS & 1,5 & 0 & 0 & 9,1 \\
\hline
\end{tabular}

Nota. $\mathrm{p}<0,05$.

Por último, la observación diaria de las sesiones $\left(\mathrm{X}_{<10 \text { años }}=51,6 \%\right.$ y $\mathrm{X}_{\geq 10 \text { años }}=$ $\left.46,3 \% ; x^{2}=7925 ; p<0,05\right)$ y los exámenes teóricos $\left(X_{<10}\right.$ años $=0,6 \%$ y $X_{\geq 10}$ años $=1,3 \%$; $\left.\mathrm{x}^{2}=8173 ; \mathrm{p}<0,05\right)$ son las herramientas que más y que menos utilizan respectivamente los monitores de actividad física y deporte en función de su experiencia laboral.

En general la observación diaria de las sesiones $\left(51,6 \% ; x^{2}=7925 ; p<0,05\right)$ y la batería de test/tests estandarizados $\left(8,5 \% ; \mathrm{x}^{2}=8771 ; \mathrm{p}<0,05\right)$ son las herramientas que 
utilizan más los monitores de actividad física y deporte con menos de diez años de experiencia laboral que los que tienen más experiencia laboral. En cambio, los monitores con diez años o más utilizan más el resto de herramientas de evaluación (p $<0,05$ ). (Véase tabla 5.20).

Tabla 5. 20

Herramientas de evaluación utilizadas por los monitores de actividad física y deporte en relación a la experiencia laboral $(N=600)$

\begin{tabular}{lcc}
\hline \multirow{2}{*}{ HERRAMIENTAS DE EVALUACIÓN } & \multicolumn{2}{c}{ ESPERIENCIA LABORAL $(\%)$} \\
\cline { 2 - 3 } OBSERVACIÓN DIARIA DE LAS SESIONES & $<\mathbf{1 0}$ AÑOS & $\geq \mathbf{1 0}$ AÑos \\
BATERÍA DE TEST/TESTS ESTANDARIZADOS & 51,6 & 46,3 \\
& 8,5 & 7,9 \\
PRUEBAS DE EJECUCIÓN & 29,3 & 31,5 \\
TEST CONFECCIONADOS POR USTED MISMO O POR LOS & & \\
COMPAÑEROS & 4,7 & 7,4 \\
DIARIOS & 5,3 & 5,6 \\
EXÁMENES TEÓRICOS & 0,6 & 1,3 \\
\hline Nota p $<0,05$ & & \\
\hline
\end{tabular}

\subsubsection{Elementos que priorizan en su enseñanza y desempeño profesional}

Los monitores de actividad física y deporte determinaron los elementos que priorizan en su enseñanza e intervención profesional en una escala de Likert que iba de 1 al 5 (siendo 1 nada importante y 5 muy importante).

Siguiendo los elementos que priorizan en su enseñanza e intervención profesional los monitores de actividad física y deporte, en general los aspectos actitudinales son los más importantes $(X=4,6)$, seguidos de los aspectos psicológicos 
$(X=4,4)$, técnicos $(X=4,3)$, conceptuales $(X=3,9)$, físicos $(X=3,8)$ y finalmente de los aspectos tácticos $(\mathrm{X}=3,3)$ (véase figura 5.8).

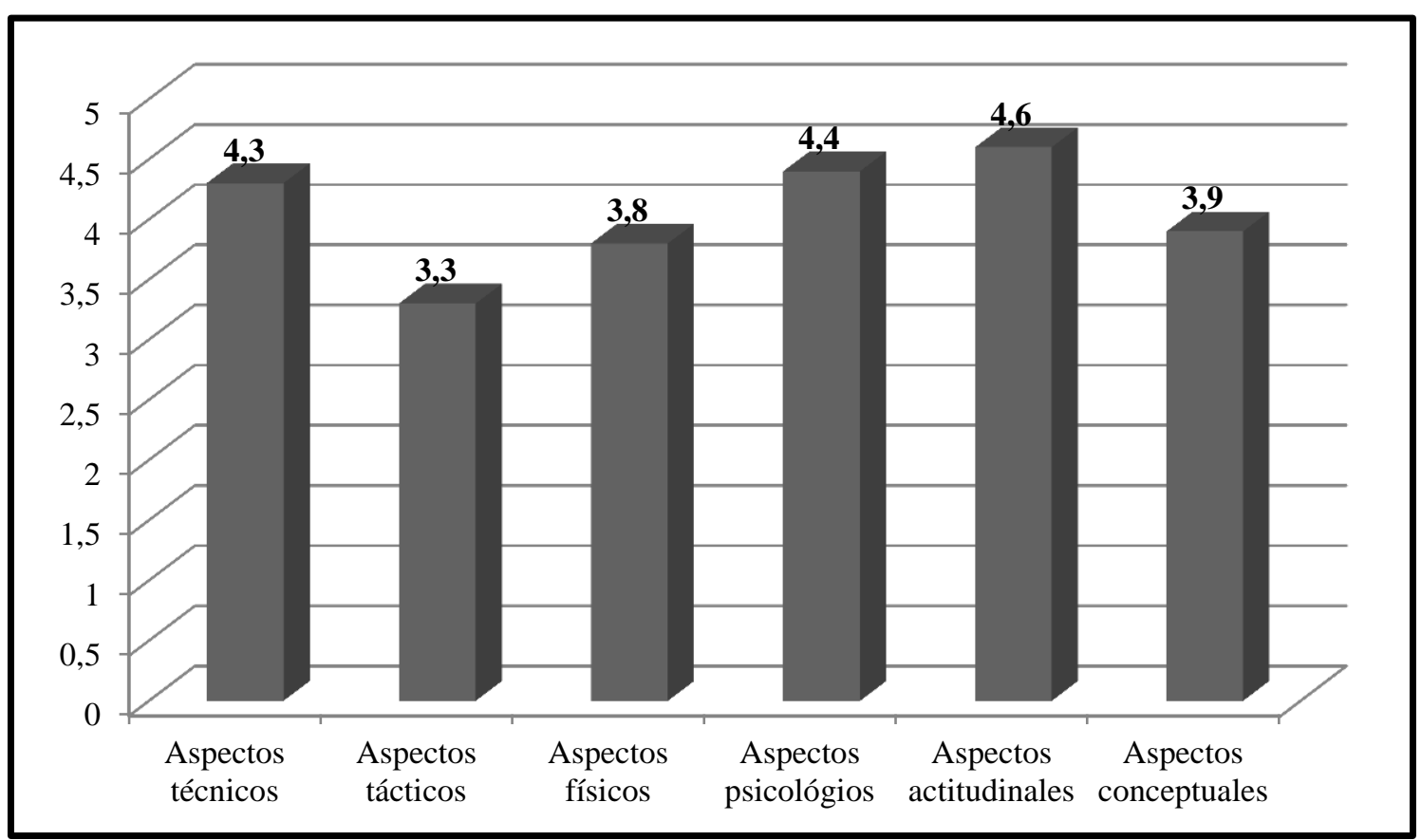

Figura 5. 8. Elementos que priorizan en su enseñanza y desempeño profesional los monitores de actividad física y deporte $(\mathrm{N}=600)$.

Como se ilustra en la tabla 5.21, los hombres, en general, (aspectos técnicos $=$ 4,4; aspectos tácticos $=3,5$; aspectos físicos $=3,9$; aspectos conceptuales $=4,0$ ) tienen medias más elevadas que las mujeres (aspectos técnicos $=4,2$; aspectos tácticos $=3,0$; aspectos físicos $=3,5$; aspectos conceptuales $=3,8$ ) o iguales (aspectos psicológicos $=$ 4,4 y aspectos actitudinales $=4,6$ ). Obteniéndose en la interrelación de los aspectos analizados con la variable sexo una relación de baja a moderada $\Phi=0,193-0,334$ y significativa $\mathrm{p}<0,05$. 
Tabla 5. 21

Elementos que priorizan en su enseñanza y desempeño profesional los monitores de actividad física y deporte en relación al sexo $(N=600)$

\begin{tabular}{|c|c|c|}
\hline \multirow{2}{*}{ ELEMENTOS } & \multicolumn{2}{|c|}{ SEXO } \\
\hline & HOMBRE & MUJER \\
\hline ASPECTOS TÉCNICOS & 4,4 & 4,2 \\
\hline ASPECTOS TÁCTICOS & 3,5 & 3,0 \\
\hline ASPECTOS FÍSICOS & 3,9 & 3,5 \\
\hline ASPECTOS PSICOLÓGICOS & 4,4 & 4,4 \\
\hline ASPECTOS ACTITUDINALES & 4,6 & 4,6 \\
\hline ASPECTOS CONCEPTUALES & 4.0 & 3.8 \\
\hline
\end{tabular}

Nota. Los números se refieren a la media usando una escala de Likert de 5 puntos que varía de 1 a 5. $\mathrm{p}<0,05 ; \Phi=0,193-0,334$.

Asimismo se puede observar en la tabla 5.22 que casi todos los aspectos que priorizan para su enseñanza los monitores de actividad física y deporte aumentan con la edad, siendo los de 45 años y mayores los monitores de actividad física y deporte que tienen las mayores medias en los aspectos técnicos $=4,6$ y aspectos conceptuales $=4$. En el resto de aspectos sus medias son iguales a las de los monitores de 30 a 44 años y superiores a las de los monitores de 16 a 29 años, a excepción de los aspectos actitudinales que en los tres tramos de edad tiene una media de 4,6. Obteniéndose en la interrelación de los aspectos analizados con la variable edad un relación moderada $\Phi$ $=0,304-0,482$ y significativa $\mathrm{p}<0,05)($ véase tabla 5.22). 
Tabla 5.22

Elementos que priorizan en su enseñanza y desempeño profesional los monitores de actividad física y deporte en relación a la edad $(N=600)$

\begin{tabular}{|c|c|c|c|}
\hline \multirow{2}{*}{ ELEMENTOS } & \multicolumn{3}{|c|}{ EDAD } \\
\hline & $16-29$ & $30-44$ & $45-70$ \\
\hline ASPECTOS TÉCNICOS & 4,2 & 4,4 & 4,6 \\
\hline ASPECTOS TÁCTICOS & 3,1 & 3,7 & 3,7 \\
\hline ASPECTOS FÍSICOS & 3,6 & 4,2 & 4,2 \\
\hline ASPECTOS PSICOLÓGICOS & 4,3 & 4,5 & 4,5 \\
\hline ASPECTOS ACTITUDINALES & 4,6 & 4,6 & 4,6 \\
\hline ASPECTOS CONCEPTUALES & 3,8 & 4,2 & 4,3 \\
\hline
\end{tabular}

Nota. Los números se refieren a la media usando una escala de Likert de 5 puntos que varía de 1 a 5. $\mathrm{p}<0,05 ; \Phi=0,304-0,482$.

En relación al nivel de estudios, los monitores de actividad física y deporte con educación primaria o menos otorgan más importancia a los aspectos técnicos $(X=4,5)$, tácticos $(X=3,9)$ y físicos $(X=3,9)$. Sin embargo los titulados universitarios otorgan más importancia que el resto a los aspectos psicológicos $(X=4,5)$ y los actitudinales $(X$ $=4,7)$. Los aspectos conceptuales son valorados con la misma puntuación por los titulados universitarios, por los técnicos deportivos y por los que tienen educación primaria o menos $(\mathrm{X}=4)$. Obteniéndose en la interacción de los aspectos estudiados con los niveles de estudios una relación moderada $\Phi=0,294-0,355$ y significativa $\mathrm{p}<0,05$. (Véase tabla 5.23). 
Tabla 5.23

Elementos que priorizan en su enseñanza y desempeño profesional los monitores de actividad física y deporte en relación al nivel de estudios $(N=600)$

\begin{tabular}{|c|c|c|c|c|}
\hline \multirow{2}{*}{ ELEMENTOS } & \multicolumn{4}{|c|}{ NIVEL DE ESTUDIOS } \\
\hline & $\begin{array}{c}\text { TITULADO } \\
\text { UNIVERSITARIO }\end{array}$ & $\begin{array}{l}\text { FORMACIÓN } \\
\text { PROFESIONAL }\end{array}$ & $\begin{array}{l}\text { EDUCACIÓN } \\
\text { SECUNDARIA }\end{array}$ & $\begin{array}{c}\text { EDUCACIÓN } \\
\text { PRIMARIA O } \\
\text { MENOR }\end{array}$ \\
\hline ASPECTOS TÉCNICOS & 4,4 & 4,3 & 4,3 & 4,5 \\
\hline ASPECTOS TÁCTICOS & 3,3 & 3,2 & 3,5 & 3,9 \\
\hline ASPECTOS FÍSICOS & 3,8 & 3,8 & 3,7 & 3,9 \\
\hline ASPECTOS PSICOLÓGICOS & 4,5 & 4,3 & 4,4 & 4,2 \\
\hline ASPECTOS ACTITUDINALES & 4,7 & 4,6 & 4,6 & 4,4 \\
\hline ASPECTOS CONCEPTUALES & 4,0 & 4,0 & 3,8 & 4,0 \\
\hline
\end{tabular}

Nota. Los números se refieren a la media usando una escala de Likert de 5 puntos que varía de 1 a 5. $\mathrm{p}<0,05 ; \Phi=0,294-0,355$.

Teniendo en cuenta la experiencia laboral, todos los elementos que priorizan en su enseñanza y desempeño profesional son más importantes para los monitores de actividad física y deporte con diez años o más de experiencia (aspectos técnicos $=4,5$; aspectos tácticos $=3,7$; aspectos físicos $=4,1$; aspectos psicológicos $=4,5$; aspectos conceptuales $=4,2$ ), excepto en los aspectos actitudinales que ambos grupos le otorga la misma media $(X=4,6)$. En los aspectos tácticos es donde hay mayor diferencia de valoración entre los dos grupos, habiendo una diferencia de 0,5 puntos. Obteniéndose en la interacción de los aspectos estudiados con los experiencia laboral una relación baja $\Phi$ $=0,186-0,199$ y poco significativa $\mathrm{p}>0,05$ (véase tabla 5.24). 
Tabla 5.24

Elementos que priorizan en su enseñanza y desempeño profesional los monitores de actividad física y deporte en relación a la experiencia laboral $(N=600)$

\begin{tabular}{lcc}
\multicolumn{1}{c}{ ELEMENTOS } & \multicolumn{2}{c}{ EXPERIENCIA LABORAL } \\
\cline { 2 - 3 } & \multicolumn{10}{c}{$\mathbf{1 0}$ AÑos } & $\mathbf{1 0}$ AÑos \\
\hline ASPECTOS TÉCNICOS & 4,2 & 4,5 \\
ASPECTOS TÁCTICOS & 3,2 & 3,7 \\
ASPECTOS FíSICOS & 3,7 & 4,1 \\
ASPECTOS PSICOLÓGICOS & 4,3 & 4,5 \\
ASPECTOS ACTITUDINALES & 4,6 & 4,6 \\
ASPECTOS CONCEPTUALES & 3,9 & 4,2 \\
\hline
\end{tabular}

Nota. Los números se refieren a la media usando una escala de Likert de 5 puntos que varía de 1 a 5. $\Phi=0,186-0,199$.

\subsubsection{Fuentes de conocimiento}

Los monitores de actividad física y deporte valoraron las fuentes de conocimiento en una escala de Likert que iba de 1 al 5 (siendo 1 nunca y 5 siempre).

Los resultados mostraron que la fuente de conocimiento que más usan los monitores de actividad física y deporte son los cursos de formación (con una media de 4 en una escala de 5 puntos) (tabla 5.25). Como segunda y tercera opción eligen el intercambio de información con otros profesionales $(X=3,9)$ y la observación de otros profesionales $(\mathrm{X}=3,9)$. Los monitores de actividad física y deporte consideran que la formación de la titulación de mayor nivel que poseen $(X=3,6)$ y los recursos tecnológicos o internet $(\mathrm{X}=3,3)$ son también muy importantes para su conocimiento. Asimismo, obtienen información de otras fuentes como: la experiencia deportiva en 
competiciones federadas $(X=3,3)$, la experiencia como estudiante de educación física o usuario de actividades deportivas $(X=3,1)$, en libros $(X=2,8)$, en sus propias investigaciones $(X=2,3)$ y en revistas científicas o técnicas $(X=2,1)$. En todos los resultados, la desviación típica es alta, por lo que hay monitores de actividad física y deporte que utilizan una gran cantidad de fuentes de conocimiento y hay otros que las utilizan de una manera muy limitada (véase tabla 5.25).

Tabla 5. 25

Fuentes de conocimiento de los monitores de actividad física y deporte, medias, deviaciones típicas y varianzas $(N=600)$

\begin{tabular}{|c|c|c|c|}
\hline FUENTES DE CONOCIMIENTO & MEDIA & $\begin{array}{l}\text { DESVIACIÓN } \\
\text { TÍPICA }\end{array}$ & $\begin{array}{l}\text { VARIAN- } \\
\text { ZA }\end{array}$ \\
\hline $\begin{array}{l}\text { EN LA EXPERIENCIA DEPORTIVA EN COMPETICIONES } \\
\text { FEDERADAS }\end{array}$ & 3,3 & 1,7 & 2,8 \\
\hline $\begin{array}{l}\text { EN LA EXPERIENCIA COMO ALUMNO EN EDUCACIÓN } \\
\text { FÍSICA O USUARIO EN ACTIVIDADES DEPORTIVAS }\end{array}$ & 3,1 & 1,5 & 2,3 \\
\hline $\begin{array}{l}\text { EN LA FORMACIÓN QUE HA RECIBIDO EN LA TITULACIÓN } \\
\text { DE MAYOR NIVEL QUE POSEE }\end{array}$ & 3,6 & 1,6 & 2,5 \\
\hline EN LOS CURSOS QUE HA RECIBIDO & 4 & 1,3 & 1,7 \\
\hline EN LA OBSERVACIÓN A OTROS PROFESIONALES & 3,9 & 1,2 & 1,6 \\
\hline $\begin{array}{l}\text { EN EL INTERCAMBIO DE INFORMACIÓN CON OTROS } \\
\text { PROFESIONALES }\end{array}$ & 3,9 & 1,2 & 1,5 \\
\hline EN LIBROS & 2,8 & 1,5 & 2,2 \\
\hline EN REVISTAS CIENTÍFICAS Y/O TÉCNICAS & 2,1 & 1,4 & 1,8 \\
\hline EN RECURSOS TECNOLÓGICOS O INTERNET & 3,3 & 1,4 & 1,8 \\
\hline EN SUS PROPIAS INVESTIGACIONES & 2,3 & 1,5 & 2,3 \\
\hline
\end{tabular}

Nota. Los números se refieren a la media usando una escala de Likert de 5 puntos que varía de 1 a 5. 
Al relacionar las fuentes de conocimiento con el sexo, se observa que por lo general los hombres suelen tener medias más elevadas que las mujeres. La fuente de conocimiento que más valoran los hombres es el intercambio de información con otros profesionales $\left(X=4 ; x^{2}=7658\right)$ y la que menos las revistas científicas o técnicas $(X=2,2$; $\left.x^{2}=6775\right)$. Por otro lado las mujeres valoran más los cursos que han recibido $(X=4$; $\mathrm{x}^{2}=1450$ ) e igualmente a los hombres, las revistas científicas o técnicas las que menos $\left(X=2 ; x^{2}=6775\right)$.

En general los hombres tienen medias más altas en la experiencia deportiva en competiciones federadas $\left(X=3,4 ; x^{2}=6467\right)$, en el intercambio de información con otros profesionales $\left(X=4 ; x^{2}=7658\right)$, en los libros $\left(X=2,8 ; x^{2}=1900\right)$, en las revistas científicas o técnicas $\left(X=2,2 x^{2}=6775\right)$ y en sus propias investigaciones $\left(X=2,3 x^{2}=6306\right)$. Por el contrario las mujeres tienen medias más altas en la formación que han recibido en la titulación de mayor nivel que poseen $\left(X=3,6 x^{2}=2111\right)$, en los cursos que ha recibido $\left(X=4 x^{2}=1450\right)$ y en los recursos tecnológicos o internet $\left(X=3,5 x^{2}=17407 ; p<0,01\right)$.

Con respecto a las fuentes de conocimiento y el sexo, phi varió entre 0,150 0,250 (nivel bajo de relación) (véase tabla 5.26). 
Tabla 5. 26

Fuentes de conocimiento de los monitores de actividad física y deporte en relación al sexo $(N=600)$

\begin{tabular}{|c|c|c|}
\hline \multirow{2}{*}{ FUENTES DE CONOCIMIENTO } & \multicolumn{2}{|c|}{ SEXO } \\
\hline & HOMBRE & MUJER \\
\hline EN LA EXPERIENCIA DEPORTIVA EN COMPETICIONES FEDERADAS & 3,4 & 3 \\
\hline $\begin{array}{l}\text { EN LA EXPERIENCIA COMO ALUMNO EN EDUCACIÓN FÍSICA O } \\
\text { USUARIO EN ACTIVIDADES DEPORTIVAS }\end{array}$ & 3,1 & 3,1 \\
\hline $\begin{array}{l}\text { EN LA FORMACIÓN QUE HA RECIBIDO EN LA TITULACIÓN DE MAYOR } \\
\text { NIVEL QUE POSEE }\end{array}$ & 3,5 & 3,6 \\
\hline EN LOS CURSOS QUE HA RECIBIDO & 3,9 & 4 \\
\hline EN LA OBSERVACIÓN A OTROS PROFESIONALES & 3,9 & 3,9 \\
\hline EN EL INTERCAMBIO DE INFORMACIÓN CON OTROS PROFESIONALES & 4 & 3,9 \\
\hline EN LIBROS & 2,8 & 2,7 \\
\hline EN REVISTAS CIENTÍFICAS Y/O TÉCNICAS & 2,2 & 2 \\
\hline EN RECURSOS TECNOLÓGICOS O INTERNET* & $3,2 *$ & $3,5^{*}$ \\
\hline EN SUS PROPIAS INVESTIGACIONES & 2,3 & 2,1 \\
\hline
\end{tabular}

Nota. $* \mathrm{p}<0,01 ; \Phi=0,150-0,250$.

Al analizar las fuentes de conocimiento que los monitores de actividad física y deporte utilizan en función de su edad, se obtiene que aquellos de 16 a 29 años prefieren el intercambio de información con otros profesionales $\left(X=3,9 ; x^{2}=55253 ; p<0,05\right)$ y como última fuente de conocimiento destacan las revistas científicas o técnicas $(X=1,9$; $\left.\mathrm{x}^{2}=74871 ; \mathrm{p}<0,05\right)$. La fuente de conocimiento que más valoran los monitores de 30 a 44 años son los cursos que ha recibido $\left(X=4,3 ; x^{2}=61533 ; p<0,05\right)$ y la que menos las revistas científicas o técnicas $\left(X=2,4 ; x^{2}=74871 ; p<0,05\right)$. Por último los de 45 años o 
mayores, tienen medias más altas en el intercambio de información con otros profesionales $\left(X=4,0 ; x^{2}=55253 ; \mathrm{p}<0,05\right)$ y medias más bajas también en las revistas científicas o técnicas $\left(X=2,4 ; x^{2}=74871 ; p<0,05\right)$ (véase tabla 5.27).

En general los monitores de actividad física y deporte más jóvenes tienen medias más altas en la experiencia como alumno en educación física o usuario en actividades deportivas $\left(X=3,2 ; x^{2}=78223 ; \mathrm{p}<0,05\right)$, los monitores de 30 a 44 años poseen medias más elevadas en la formación que han recibido en la titulación de mayor nivel $(X=3,7$; $\left.\mathrm{x}^{2}=54015 ; \mathrm{p}<0,05\right)$ en los cursos que han recibido $\left(\mathrm{X}=4,3 ; \mathrm{x}^{2}=61533 ; \mathrm{p}<0,05\right)$, en la observación a otros profesionales $\left(X=4 ; x^{2}=50840 ; p<0,05\right)$, en el intercambio de información con otros profesionales $\left(\mathrm{X}=4,1 ; \mathrm{x}^{2}=55253 ; \mathrm{p}<0,05\right)$, en las revistas científicas y técnicas $\left(X=2,4 ; x^{2}=74871 ; p<0,05\right)$ y en los recursos tecnológicos o internet $\left(X=3,5 ; x^{2}=44048 ; \mathrm{p}<0,05\right)$. Asimismo los monitores más mayores han obtenido medias más altas en la experiencia deportiva en competiciones federadas $\left(X=3,3 ; x^{2}=48448 ; p<0,05\right)$, en la observación a otros profesionales $\left(X=3,98 ; x^{2}=50840\right.$; $\mathrm{p}<0,05)$, en los libros $\left(X=3,2 ; \mathrm{x}^{2}=99012 ; \mathrm{p}<0,05\right)$ y en sus propias investigaciones $\left(X=2,5 ; x^{2}=64511 ; p<0,05\right)$.

Con respecto a las fuentes de conocimiento y la edad, phi varió entre 0.350 y 0.406 (nivel moderado de relación) (véase tabla 5.27). 
Tabla 5.27

Fuentes de conocimiento de los monitores de actividad física y deporte en relación a la edad $(N=600)$

\begin{tabular}{|c|c|c|c|}
\hline \multirow{2}{*}{ FUENTES DE CONOCIMIENTO } & \multicolumn{3}{|c|}{ EDAD } \\
\hline & 16-29 & 30-44 & $45-70$ \\
\hline EN LA EXPERIENCIA DEPORTIVA EN COMPETICIONES FEDERADAS & 3,2 & 3,3 & 3,3 \\
\hline $\begin{array}{l}\text { EN LA EXPERIENCIA COMO ALUMNO EN EDUCACIÓN FÍSICA O } \\
\text { USUARIO EN ACTIVIDADES DEPORTIVAS }\end{array}$ & 3,2 & 3,1 & 2,7 \\
\hline $\begin{array}{l}\text { EN LA FORMACIÓN QUE HA RECIBIDO EN LA TITULACIÓN DE MAYOR } \\
\text { NIVEL QUE POSEE }\end{array}$ & 3,5 & 3,7 & 3,1 \\
\hline EN LOS CURSOS QUE HA RECIBIDO & 3,8 & 4,3 & 4 \\
\hline EN LA OBSERVACIÓN A OTROS PROFESIONALES & 3,8 & 4 & 4 \\
\hline EN EL INTERCAMBIO DE INFORMACIÓN CON OTROS PROFESIONALES & 3,9 & 4,1 & 4 \\
\hline EN LIBROS & 2,6 & 3,1 & 3,2 \\
\hline EN REVISTAS CIENTÍFICAS Y/O TÉCNICAS & 1,9 & 2,4 & 2,4 \\
\hline EN RECURSOS TECNOLÓGICOS O INTERNET & 3,3 & 3,5 & 3 \\
\hline EN SUS PROPIAS INVESTIGACIONES & 2,1 & 2,5 & 2,5 \\
\hline
\end{tabular}

Nota. $\mathrm{p}<0,05 ; \Phi=0,350$ - 0,406.

Al analizar las fuentes de conocimiento en relación con el nivel de estudios (tabla 5.28) se puede expresar que los monitores de actividad física y deporte con un título universitario clasifican los cursos recibidos como su fuente preferida de aprendizaje $\left(X=4,1 ; x^{2}=24825 ; p<0,05\right)$. Aquellos con formación profesional prefieren el intercambio de información con otros profesionales $\left(X=4,1 ; x^{2}=22934 ; p<0,05\right)$, así como los recursos tecnológicos o internet $\left(X=4,1 ; x^{2}=36588 ; p<0,01\right)$ como su fuente preferida de adquisición de conocimientos. Por otro lado, los cursos recibidos $(X=3,8$; $\left.x^{2}=24825 ; p<0,05\right)$, la observación a otros profesionales $\left(X=3,8 ; x^{2}=24533 ; p<0,05\right)$ y el 
intercambio de información con otros profesionales $\left(X=3,8 x^{2}=22934 ; p<0,05\right)$ son las fuentes de aprendizaje preferidas por aquellos con la educación secundaria. Finalmente, los monitores de actividad física y deporte con educación primaria o menos determinaron la observación a otros profesionales como su fuente preferida de aprendizaje $\left(X=4,4 ; x^{2}=24825 ; p<0,05\right)$. Con respecto a las fuentes de conocimiento y el nivel de estudios, phi varió entre 0.250 y 0.353 (nivel moderado de relación).

Tabla 5. 28

Las fuentes de conocimiento de los monitores de actividad física y deporte en función del nivel de estudios $(N=600)$

\begin{tabular}{|c|c|c|c|c|}
\hline \multirow[b]{2}{*}{ FUENTES DE CONOCIMIENTO } & \multicolumn{4}{|c|}{ NIVEL DE ESTUDIOS } \\
\hline & $\begin{array}{c}\text { TITULADO } \\
\text { UNIVER- } \\
\text { SITARIO }\end{array}$ & $\begin{array}{l}\text { FORMACIÓN } \\
\text { PROFESIONAL }\end{array}$ & $\begin{array}{l}\text { EDUCACIÓN } \\
\text { SECUNDARIA }\end{array}$ & $\begin{array}{c}\text { EDUCACIÓN } \\
\text { PRIMARIA O } \\
\text { MENOS }\end{array}$ \\
\hline $\begin{array}{l}\text { EN LA EXPERIENCIA DEPORTIVA EN } \\
\text { COMPETICIONES FEDERADAS }\end{array}$ & 3,1 & 3,0 & 3,5 & 3,6 \\
\hline EN LA EXPERIENCIA COMO ALUMNO EN & & & & \\
\hline $\begin{array}{l}\text { EDUCACIÓN FÍSICA O USUARIO EN } \\
\text { ACTIVIDADES DEPORTIVAS }\end{array}$ & 3,2 & 3,2 & 3,0 & 3,4 \\
\hline EN LA FORMACIÓN QUE HA RECIBIDO & & & & \\
\hline $\begin{array}{l}\text { EN LA TITULACIÓN DE MAYOR NIVEL } \\
\text { QUE POSEE }\end{array}$ & 3,9 & 3,8 & 3,0 & 3,4 \\
\hline EN LOS CURSOS QUE HA RECIBIDO & 4,1 & 4,0 & 3,8 & 4,0 \\
\hline $\begin{array}{l}\text { EN LA OBSERVACIÓN A OTROS } \\
\text { PROFESIONALES }\end{array}$ & 3,9 & 4,0 & 3,8 & 4,4 \\
\hline $\begin{array}{l}\text { EN EL INTERCAMBIO DE INFORMACIÓN } \\
\text { CON OTROS PROFESIONALES }\end{array}$ & 3,9 & 4,1 & 3,8 & 4,2 \\
\hline EN LIBROS & 3,1 & 2,9 & 2,5 & 2,8 \\
\hline $\begin{array}{l}\text { EN REVISTAS CIENTÍFICAS Y/O } \\
\text { TÉCNICAS }\end{array}$ & 2,3 & 2,2 & 1,9 & 1,9 \\
\hline $\begin{array}{l}\text { EN RECURSOS TECNOLÓGICOS O } \\
\text { INTERNET }\end{array}$ & 3,4 & 4,1 & 3,2 & 2,0 \\
\hline EN SUS PROPIAS INVESTIGACIONES & 2,4 & 2,2 & 2,1 & 2,3 \\
\hline
\end{tabular}

Nota. Los números se refieren a la media usando una escala de Likert de 5 puntos que varía de 1 a 5. $p<0,05 ; \Phi=0,250-0,353$. 
El análisis de las fuentes de conocimiento de los monitores de actividad física y deporte con respecto a la experiencia laboral se resume en la tabla 5.29. Los resultados demuestran que aquellos con menos de diez años de experiencia laboral prefieren utilizar los cursos $\left(X=3,9 x^{2}=12011 ; p<0,05\right)$, la observación a otros profesionales $\left(X=3,9 ; x^{2}=10378 ; p<0,05\right)$ y el intercambio de información con otros profesionales $\left(X=3,9 ; x^{2}=11398 ; p<0,05\right)$. Por el contrario aquellos más experimentados (diez años o más) usan con mayor frecuencia casi todas las fuentes de conocimiento (experiencia deportiva en competiciones federadas, experiencia como alumno en educación física o usuario en actividades deportivas, la formación que ha recibido en la titulación de mayor nivel que posee, los cursos que ha recibido, el intercambio de información con otros profesionales, los libros, las revistas científicas o técnicas, los recursos tecnológicos o internet y sus propias investigaciones) destacando los cursos por encima de todo $\left(X=4,2 ; x^{2}=12011 ; p<0,05\right)$ y el intercambio de información con otros profesionales $\left(X=4 ; x^{2}=11564 ; p<0,05\right)$. Los monitores de actividad física y deporte con menos de diez años de experiencia tienen una media más alta en la observación de otros profesionales que los más experimentados.

Con respecto a las fuentes de conocimiento y la experiencia laboral, phi varió entre 0,420 y 0,662 (moderado y buen nivel de relación). 
Tabla 5.29

Las fuentes de conocimiento de los monitores de actividad física y deporte en función de la experiencia laboral $(N=600)$

EXPERIENCIA LABORAL

FUENTES DE CONOCIMIENTO

$\begin{array}{cc} & \text { MENOS DE 10 } \\ \text { AÑOS } & \text { AÑOS O MÁS }\end{array}$

EN LA EXPERIENCIA DEPORTIVA EN COMPETICIONES FEDERADAS

3,2

EN LA EXPERIENCIA COMO ALUMNO EN EDUCACIÓN FÍSICA O

USUARIO EN ACTIVIDADES DEPORTIVAS

3,1

3,1

EN LA FORMACIÓN QUE HA RECIBIDO EN LA TITULACIÓN DE MAYOR NIVEL QUE POSEE

EN LOS CURSOS QUE HA RECIBIDO

EN LA OBSERVACIÓN A OTROS PROFESIONALES

EN EL INTERCAMBIO DE INFORMACIÓN CON OTROS PROFESIONALES

3,9

4,0

EN LIBROS

2,7

EN REVISTAS CIENTÍFICAS Y/O TÉCNICAS

2,0

EN RECURSOS TECNOLÓGICOS O INTERNET

3,3

3,4

EN SUS PROPIAS INVESTIGACIONES

2,0

Nota. Los números se refieren a la media usando una escala de Likert de 5 puntos que varía de 1 a 5 . $p<0,05 ; \Phi=0,420-0,662$.

\subsubsection{SATISFACCIÓN LABORAL DE LOS MONITORES DE ACTIVIDAD FÍSICA Y DEPORTE}

Los encuestados en esta investigación fueron 600 monitores de actividad física y deporte de España que trabajaban en diferentes tipos de instalaciones (gimnasios, piscinas, centros deportivos...) y diferentes tipos de organizaciones (entidades públicas, 
entidades deportivas privadas sin ánimo de lucro y empresas o entidades privadas con ánimo de lucro). De los 600 monitores de actividad física y deporte, 545 fueron seleccionados para observar la satisfacción laboral que poseían porque trabajaban para otras personas, mientras que 55 fueron rechazados, ya que eran autónomos.

Los monitores de actividad física y deporte valoraron la satisfacción laboral en una escala de Likert que iba de 1 al 5 (siendo 1 muy satisfechos y 5 nada satisfechos). La media y la desviación típica se proporcionan en la tabla 5.30.

La mayoría de los monitores de actividad física y deporte expresaron niveles de moderados a altos de satisfacción en el trabajo. La mayor satisfacción laboral que experimentan (la media de más de 4 en una escala de 5 puntos) es con respecto a su relación con los compañeros $(X=4,5)$ y a la sensación de que su trabajo y su profesión son valorados por sus compañeros $(X=4,4)$. Asimismo, los monitores de actividad física y deporte expresan niveles altos de satisfacción laboral con respecto a la sensación de que su ocupación es valorada por sus clientes $(X=4,4)$ y la actividad profesional realizada $(X=4,4)$. También, los monitores de actividad física y deporte están satisfechos con el nivel de autonomía $(X=4,3)$ y el desempeño que deben alcanzar $(X=4,2)$. Finalmente, la sensación de que su ocupación es valorada por la organización $(X=4,1)$ es otro ítem que contribuye a la satisfacción laboral experimentada por los monitores de actividad física y deporte (véase tabla 5.30).

Por el contrario, los niveles más bajos de satisfacción laboral son experimentados con respecto a las oportunidades de formación ofrecidas por la organización $(X=3,0)$. Igualmente, los monitores de actividad física y deporte expresan bajos niveles de satisfacción laboral con respecto a las oportunidades de promoción dentro de su organización $(\mathrm{X}=3,1)$ y con la remuneración económica que reciben $(\mathrm{X}=$ 
3,2). Finalmente, las condiciones ambientales generales y de seguridad $(X=3,7)$

también se asocian con baja satisfacción laboral (véase tabla 5.30).

Tabla 5. 30

Ítem, media y desviación típica de la satisfacción laboral de los monitores de actividad física y deporte $(N=545)$

\begin{tabular}{lcc}
\multicolumn{1}{c}{ ÍTEM } & MEDIA & DS \\
\hline ORGANIZACIÓN DEL TRABAJO EN SU ENTIDAD & 3,7 & 1,1 \\
OPORTUNIDADES DE PROMOCIÓN & 3,1 & 1,2 \\
VALORACIÓN Y APOYO DE SUS SUPERIORES & 3,8 & 1,2 \\
ACTIVIDAD PROFESIONAL DESARROLLADA & 4,3 & 0,9 \\
DESEMPEÑO QUE DEBE ALCANZAR & 4,2 & 0,9 \\
NIVEL DE AUTONOMÍA & 4,3 & 0,9 \\
JORNADA LABORAL, VACACIONES, PERMISOS & 4,0 & 1,1 \\
ESTABILIDAD & 3,7 & 1,3 \\
CONDICIONES AMBIENTALES GENERALES Y DE SEGURIDAD & 3,7 & 1,2 \\
REMUNERACIÓN ECONÓMICA & 3,2 & 1,2 \\
OPORTUNIDADES DE FORMACIÓN QUE OFRECE LA ORGANIZACIÓN & 3,0 & 1,4 \\
RELACIÓN CON LOS COMPAÑEROS & 4,5 & 0,8 \\
VALORACIÓN DE LA IMPORTANCIA POR PARTE DE LA ORGANIZACIÓN Y & 4,1 & 1,1 \\
DIRECTIVOS DE SU PROFESIÓN DE ACTIVIDAD FÍSICA Y DEPORTE & & \\
VALORACIÓN DE LA IMPORTANCIA POR PARTE DE LOS COMPAÑEROS DE SU & 4,4 & 0,9 \\
PROFESIÓN DE ACTIVIDAD FÍSICA Y DEPORTE & 4,4 & 0,9 \\
VALORACIÓN DE LA IMPORTANCIA POR PARTE DE LOS CLIENTES/ & & \\
ALUMNOS/PADRES DE SU PROFESIÓN DE ACTIVIDAD FÍSICA Y DEPORTE & & \\
\hline NOI LOS & & \\
\hline
\end{tabular}

$\overline{\text { Nota. Los números de la media han resultado de usar una escala de Likert de } 5 \text { puntos que varía de } 1 \text { a } 5 .}$

Como se observa en la tabla 5.31, las mujeres experimentan niveles menores de satisfacción laboral que los hombres. No hay una gran diferencia entre sexos, pero el hecho es que las mujeres están menos satisfechas que los hombres en cada ítem. La diferencia más grande que se observa es de 0,3 puntos a favor de los hombres en la 
organización del trabajo en su entidad, en las oportunidades de promoción y en la jornada laboral, vacaciones y permisos.

Con respecto a la satisfacción laboral y al sexo, phi varió entre 0,248 y 0,270, teniendo un nivel de relación moderado y una relación significativa $\mathrm{p}<0,05$.

Tabla 5. 31

Satisfacción laboral de los monitores de actividad física y deporte en función del sexo $(N=545)$

\begin{tabular}{|c|c|c|}
\hline \multirow{2}{*}{ ÍTEM } & \multicolumn{2}{|c|}{ SEXO } \\
\hline & HOMBRE & MUJER \\
\hline ORGANIZACIÓN DEL TRABAJO EN SU ENTIDAD & 3,8 & 3,5 \\
\hline OPORTUNIDADES DE PROMOCIÓN & 3,2 & 2,9 \\
\hline VALORACIÓN Y APOYO DE SUS SUPERIORES & 3,9 & 3,7 \\
\hline ACTIVIDAD PROFESIONAL DESARROLLADA & 4,4 & 4,2 \\
\hline DESEMPEÑO QUE DEBE ALCANZAR & 4,2 & 4,1 \\
\hline NIVEL DE AUTONOMÍA & 4,4 & 4,2 \\
\hline JORNADA LABORAL, VACACIONES, PERMISOS & 4,1 & 3,8 \\
\hline ESTABILIDAD & 3,8 & 3,6 \\
\hline CONDICIONES AMBIENTALES GENERALES Y DE SEGURIDAD & 3,7 & 3,5 \\
\hline REMUNERACIÓN ECONÓMICA & 3,3 & 3,1 \\
\hline OPORTUNIDADES DE FORMACIÓN QUE OFRECE LA ORGANIZACIÓN & 3,0 & 3,0 \\
\hline RELACIÓN CON LOS COMPAÑEROS & 4,6 & 4,4 \\
\hline $\begin{array}{l}\text { VALORACIÓN DE LA IMPORTANCIA POR PARTE DE LA ORGANIZACIÓN Y } \\
\text { DIRECTIVOS DE SU PROFESIÓN DE ACTIVIDAD FÍSICA Y DEPORTE }\end{array}$ & 4,1 & 3,9 \\
\hline $\begin{array}{l}\text { VALORACIÓN DE LA IMPORTANCIA POR PARTE DE LOS COMPAÑEROS DE SU } \\
\text { PROFESIÓN DE ACTIVIDAD FÍSICA Y DEPORTE }\end{array}$ & 4,4 & 4,3 \\
\hline VALORACIÓN DE LA IMPORTANCIA POR PARTE DE LOS & & \\
\hline CLIENTES/ALUMNOS/PADRES DE SU PROFESIÓN DE ACTIVIDAD FÍSICA Y & 4,4 & 4,2 \\
\hline DEPORTE & & \\
\hline TOTAL & 4,0 & 3,8 \\
\hline
\end{tabular}

Nota. Los números de la media se refieren a la media usando una escala de Likert de 5 puntos. $\mathrm{p}<0,05 ; \Phi=0,248-0,297$. 
En relación a la edad, a medida que los monitores de actividad física y deporte envejecen experimentan mayores niveles de satisfacción en el trabajo (véase tabla 5.32).

Tabla 5.32

Satisfacción laboral de los monitores de actividad física y deporte en función de la edad $(N=545)$

\begin{tabular}{|c|c|c|c|}
\hline \multirow{2}{*}{ ÍTEM } & \multicolumn{3}{|c|}{ EDAD } \\
\hline & 16-29 & 30-44 & 45-70 \\
\hline ORGANIZACIÓN DEL TRABAJO EN SU ENTIDAD & 3,7 & 3,7 & 4,3 \\
\hline OPORTUNIDADES DE PROMOCIÓN & 3,0 & 2,4 & 3,2 \\
\hline VALORACIÓN Y APOYO DE SUS SUPERIORES & 3,8 & 3,7 & 3,8 \\
\hline ACTIVIDAD PROFESIONAL DESARROLLADA & 4,3 & 4,3 & 4,5 \\
\hline DESEMPEÑO QUE DEBE ALCANZAR & 4,1 & 4,2 & 4,4 \\
\hline NIVEL DE AUTONOMÍA & 4,2 & 4,3 & 4,6 \\
\hline JORNADA LABORAL, VACACIONES, PERMISOS & 3,8 & 4,1 & 4,3 \\
\hline ESTABILIDAD & 3,5 & 3,9 & 4,4 \\
\hline CONDICIONES AMBIENTALES GENERALES Y DE SEGURIDAD & 3,6 & 3,6 & 3,6 \\
\hline REMUNERACIÓN ECONÓMICA & 3,1 & 3,2 & 3,4 \\
\hline OPORTUNIDADES DE FORMACIÓN QUE OFRECE LA ORGANIZACIÓN & 3,0 & 2,8 & 3,2 \\
\hline RELACIÓN CON LOS COMPAÑEROS & 4,1 & 4,5 & 4,4 \\
\hline $\begin{array}{l}\text { VALORACIÓN DE LA IMPORTANCIA POR PARTE DE LA ORGANIZACIÓN Y } \\
\text { DIRECTIVOS DE SU PROFESIÓN DE ACTIVIDAD FÍSICA Y DEPORTE }\end{array}$ & 4,0 & 4,0 & 4,0 \\
\hline $\begin{array}{l}\text { VALORACIÓN DE LA IMPORTANCIA POR PARTE DE LOS COMPAÑEROS DE SU } \\
\text { PROFESIÓN DE ACTIVIDAD FÍSICA Y DEPORTE }\end{array}$ & 4,3 & 4,4 & 4,4 \\
\hline VALORACIÓN DE LA IMPORTANCIA POR PARTE DE LOS & & & \\
\hline $\begin{array}{l}\text { CLIENTES/ALUMNOS/PADRES DE SU PROFESIÓN DE ACTIVIDAD FÍSICA Y } \\
\text { DEPORTE }\end{array}$ & 4,3 & 4,4 & 4,5 \\
\hline TOTAL & 3,8 & 3,8 & 4,0 \\
\hline
\end{tabular}

Nota. Los números de la media se refieren a la media usando una escala de Likert de 5 puntos. $\mathrm{p}<0,05 ; \Phi=0,150-0,208$. 
Los más satisfechos con su trabajo son los que tienen 45 años de edad o más $(\mathrm{X}=4)$, demostrando en todos los ítems que están más satisfechos o por lo menos igual de satisfechos que sus compañeros de ocupación de otras edades a excepción de la variable relación con los compañeros en la cual los monitores de actividad física y deporte de 30 a 44 años tienen una media superior $(X=4,5)$. Depués, los monitores de actividad física y deporte de 30 a 44 años son los segundo más satisfechos, sin embargo, hubo 2 ítems que no seguían esta regla: oportunidades de promoción y oportunidades de formación que ofrece la organización en las cuales los monitores de actividad física y deporte de entre 30 y 44 años están menos satisfechos que los de 16 a 29 años (véase tabla 5.32).

Con respecto a la satisfacción laboral y a la edad, phi varió entre 0,150 y 0,208, teniendo un nivel de relación bajo $(\mathrm{p}<0,05)$.

\subsection{RECURSOS HUMANOS DE LA ACTIVIDAD FÍSICA Y DEPORTE QUE TRABAJAN COMO MONITORES DE FITNESS}

En este apartado se pasan a exponer todos los datos investigados objeto de estudio sobre la formación inicial general, la formación permanente y la intervención docente y profesional de los monitores de fitness, relacionándose estos dos últimos bloques con las variables sexo, edad, experiencia laboral y nivel de estudios. También se expone la satisfacción laboral relacionada con las variables sexo y edad. 


\subsubsection{FORMACIÓN GENERAL INICIAL Y PERMANENTE DE LOS MONITORES DE FITNESS}

Como se observa en el figura 5.9, el análisis de la formación general inicial muestra que el 39,8\% de los monitores de fitness españoles tienen un título universitario, el 23,6\% completó una formación profesional, el 33,4\% terminó la educación secundaria y el 3,2\% estudió educación primaria o menos.

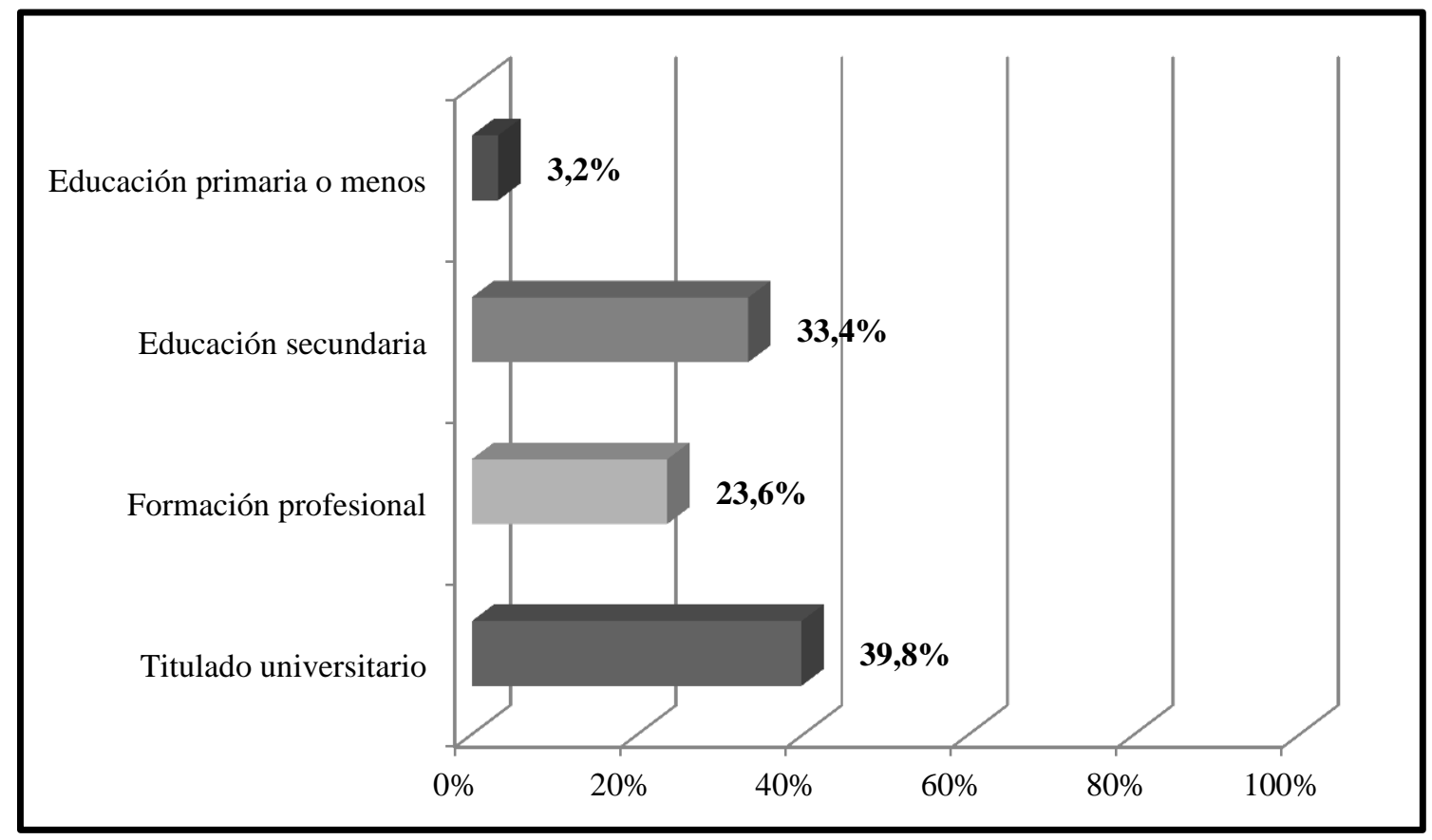

Figura 5. 9. Formación general inicial de los monitores de fitness $(\mathrm{N}=631)$.

Los resultados del figura 5.10 muestran la formación permanente que desarrollan los monitores de fitness españoles. En este caso se puede observar que los monitores de fitness españoles asisten con mayor frecuencia a cursos de formación $(67,4 \%)$ para el desarrollo de su actividad profesional, después asisten a jornadas $(20,1 \%)$ y a congresos $(13,3 \%)$. Asimismo, los monitores de fitness también realizan estudios de posgrado no oficiales $(1,6 \%)$, másteres oficiales $(1 \%)$ y grupos de trabajo $(1 \%)$ pero con porcentajes mucho menores. 


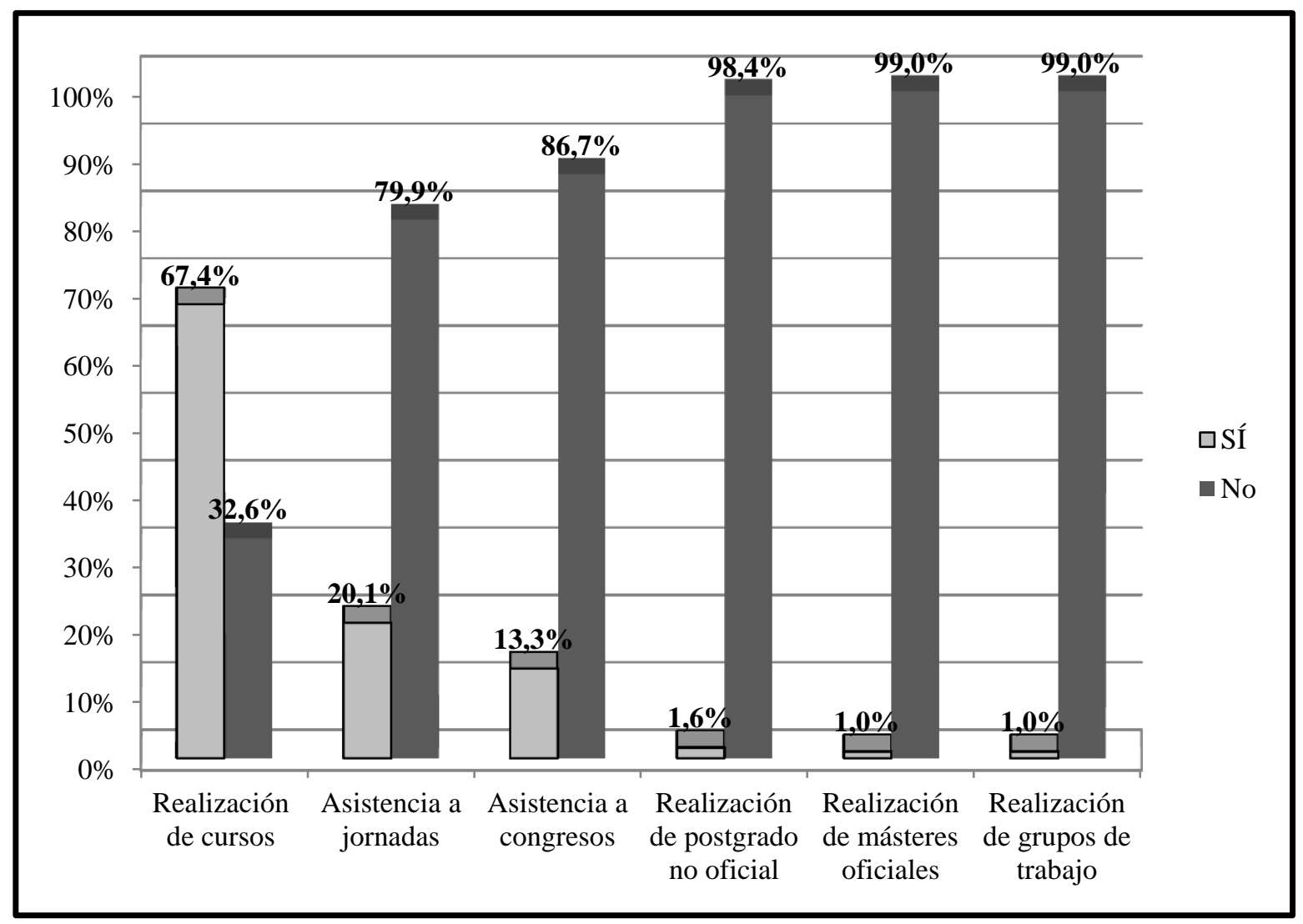

Figura 5. 10. Formación permanente de los monitores de fitnes $(\mathrm{N}=631)$.

En cuanto a la relación existente entre la formación permanente y la variable sexo (tabla 5.33), la formación permanente que más realizan los hombres son los cursos de formación $\left(68,5 \% ; x^{2}=2908 ; p<0,05\right)$ y la que menos la realización de grupos de trabajo $\left(0,8 \% ; x^{2}=2989 ; \mathrm{p}<0,05\right)$, asimismo la formación que más realizan las mujeres son los cursos de formación $\left(65,6 \% ; x^{2}=2908 ; \mathrm{p}<0,05\right)$ y la que menos la realización de postgrados no oficiales $\left(0,8 \% ; \mathrm{x}^{2}=3540 ; \mathrm{p}<0,05\right)$.

En general, los monitores de fitness masculinos asisten más a jornadas (20,6\%; $\left.x^{2}=3787 ; p<0,05\right)$, a congresos $\left(14 \% ; x^{2}=2207 ; p<0,05\right)$, cursos de formación $(68,5 \%$; $\left.\mathrm{x}^{2}=2908 ; \mathrm{p}<0,05\right)$ y realizan más másteres oficiales $\left(1,1 \% ; \mathrm{x}^{2}=3581 ; \mathrm{p}<0,05\right)$ y más postgrados no oficiales $\left(2,1 \% ; x^{2}=3540 ; p<0,05\right)$. Por el contrario, realizar grupos de trabajo $\left(1,2 \% ; x^{2}=2989 ; \mathrm{p}<0,05\right)$ lo llevan a cabo en mayor medida las mujeres (véase 
tabla 5.33). Existe una relación baja entre el sexo y la formación permanente ya que phi oscila entre 0,120 y 0,179 pero se obtiene que es significativa $\mathrm{p}<0,05$.

Tabla 5.33

Actividades de formación permanentes a las que han asistido los monitores de fitness en los últimos tres años en relación al sexo $(N=631)$

\begin{tabular}{lccc}
\hline & & \multicolumn{2}{c}{ SEXO (\%) } \\
\cline { 3 - 4 } ACTIVIDADES DE FORMACIÓN PERMANENTE & HOMBRE & MUJER \\
\hline REALIZACIÓN DE CURSOS & No & 31,5 & 34,4 \\
& Sí & 68,5 & 65,6 \\
ASISTENCIA A JORNADAS & No & 79,4 & 80,6 \\
& Sí & 20,6 & 19,4 \\
ASISTENCIA A CONGRESOS & No & 86 & 87,7 \\
& Sí & 14 & 12,3 \\
REALIZACIÓN DE POSTGRADOS NO & No & 97,9 & 99,2 \\
OFICIALES & Sí & 2,1 & 0,8 \\
REALIZACIÓN DE MÁSTERES & No & 98,9 & 99,2 \\
OFICIALES & Sí & 1,1 & 0,8 \\
REALIZACIÓN DE GRUPOS DE & No & 99,2 & 98,8 \\
TRABAJO & Sí & 0,8 & 1,2 \\
\hline
\end{tabular}

Nota. $\mathrm{p}<0,05 ; \Phi=0,120$ y 0,179 .

En cuanto a la relación entre la edad y la formación permanente (tabla 5.34), para todos los monitores de fitness la realización de cursos de formación son la actividad de formación permanente que más realizan, sin embargo para los monitores de 16 a 29 años y de 45 años en adelante, la actividad que menos realizan son los grupos de trabajo $\left(0,6 \%\right.$ y $0 \%$ respectivamente; $\left.\mathrm{x}^{2}=5915 ; \mathrm{p}<0,05\right)$. Para los monitores de 30 a 44 años, la realización de másteres oficiales es la formación permanente que menos realizan $\left(1 \% ; x^{2}=3928 ; \mathrm{p}<0,05\right)$. 
En general, todos los monitores de entre 30 y 44 años asisten a más cursos $\left(70,7 \% ; x^{2}=4987 ; p<0,05\right)$, a más congresos $\left(13,7 ; x^{2}=1007 ; p<0,05\right)$, a más postgrados no oficiales $\left(1,9 ; x^{2}=1247 ; p<0,05\right)$ y realizan más grupos de trabajo $\left(1,6 \% ; x^{2}=5915\right.$; p $<0,05)$. En comparación, los de 45 años o mayores asisten a más jornadas $\left(25,9 \%\right.$; $x^{2}$ =4943; $\mathrm{p}<0,05)$ y realizan más másteres oficiales $\left(1,8 \% ; \mathrm{x}^{2}=3928 ; \mathrm{p}<0,05\right)$ pero no han realizado ningún grupo de trabajo $\left(0 \% ; x^{2}=5915 ; p<0,05\right)$. Los monitores de fitness de 16 a 29 años no realizan ninguna formación por encima de los demás grupos de edad. Hay una relación baja entre la edad y la formación permanente ya que phi oscila entre 0,170 y 0,214 pero es significativa $p<0,05$.

Tabla 5.34

Actividades de formación permanentes a las que han asistido los monitores de fitness en los últimos tres años en relación a la edad $(N=631)$

\begin{tabular}{|c|c|c|c|c|}
\hline \multirow{2}{*}{\multicolumn{2}{|c|}{$\begin{array}{c}\text { ACTIVIDADES DE } \\
\text { FORMACIÓN PERMANENTE }\end{array}$}} & \multicolumn{3}{|c|}{$\operatorname{EDAD}(\%)$} \\
\hline & & \multirow{2}{*}{$\begin{array}{c}\mathbf{1 6 - 2 9} \\
35,7\end{array}$} & \multirow{2}{*}{$\begin{array}{c}\mathbf{3 0 - 4 4} \\
29,3\end{array}$} & \multirow{2}{*}{$\begin{array}{r}\mathbf{4 5 - 7 0} \\
37\end{array}$} \\
\hline REALIZACIÓN DE CURSOS & No & & & \\
\hline & Sí & 64,3 & 70,7 & 63 \\
\hline \multirow{2}{*}{ ASISTENCIA A JORNADAS } & No & 81,4 & 79,6 & 74,1 \\
\hline & Sí & 18,6 & 20,4 & 25,9 \\
\hline \multirow{2}{*}{ ASISTENCIA A CONGRESOS } & No & 86,3 & 86,3 & 90,8 \\
\hline & Sí & 13,7 & 13,7 & 9,2 \\
\hline \multirow{2}{*}{$\begin{array}{l}\text { REALIZACIÓN DE POSTGRADOS NO } \\
\text { OFICIALES }\end{array}$} & No & 98,9 & 98,1 & 98,2 \\
\hline & Sí & 1,1 & 1,9 & 1,8 \\
\hline \multirow{2}{*}{$\begin{array}{l}\text { REALIZACIÓN DE MÁSTERES } \\
\text { OFICIALES }\end{array}$} & No & 99,2 & 99,0 & 98,2 \\
\hline & Sí & 0,8 & 1 & 1,8 \\
\hline \multirow{2}{*}{ REALIZACIÓN DE GRUPOS DE TRABAJO } & No & 99,4 & 98,4 & 100 \\
\hline & Sí & 0,6 & 1,6 & 0 \\
\hline
\end{tabular}

Nota. $\mathrm{p}<0,05 ; \Phi=0,170$ y 0,214 .

Con respecto a los años de experiencia profesional (tabla 5.35), la actividad permanente preferida para ambos grupos son los cursos de formación y la que menos realizan son los másteres oficiales y los grupos de trabajo. 
En general, los monitores de fitness con menos de diez años de experiencia asisten con más frecuencia a los cursos $\left(68,1 \% ; \mathrm{x}^{2}=4683 ; \mathrm{p}<0,05\right)$ y realizan estudios no oficiales de posgrado en mayor medida $\left(2,1 \% ; x^{2}=4320 ; p<0,05\right)$. Por otro lado, se encontró que los monitores de fitness con diez años de experiencia o más asisten a más jornadas $\left(22,9 \% ; \mathrm{x}^{2}=2990 ; \mathrm{p}<0,05\right)$, a más congresos $\left(13,9 \% ; \mathrm{x}^{2}=4922 ; \mathrm{p}<0,05\right)$, realizan más másteres $\left(1,8 \% ; \mathrm{x}^{2}=5131 ; \mathrm{p}<0,05\right)$ y realizan más grupos de trabajo $(1,8 \%$; $\left.x^{2}=2998 ; p<0,05\right)$

Hay una relación moderada entre la experiencia laboral y la formación permanente ya que phi oscila entre 0,283 y 0,313 y es significativa $p<0,05$.

Tabla 5. 35

Actividades de formación permanentes a las que han asistido los monitores de fitness en los últimos tres años en relación a la experiencia laboral $(N=631)$

\begin{tabular}{|c|c|c|c|}
\hline \multirow{2}{*}{\multicolumn{2}{|c|}{$\begin{array}{l}\text { ACTIVIDADES DE FORMACIÓN } \\
\text { PERMANENTE }\end{array}$}} & \multicolumn{2}{|c|}{ EXPERIENCIA LABORAL (\%) } \\
\hline & & $<10$ AÑOS & $\geq 10$ AÑOS \\
\hline \multirow{2}{*}{ REALIZACIÓN DE CURSOS } & No & 31,9 & 34,1 \\
\hline & Sí & 68,1 & 65,9 \\
\hline \multirow{2}{*}{ ASISTENCIA A JORNADAS } & No & 81,4 & 77,1 \\
\hline & Sí & 18,6 & 22,9 \\
\hline \multirow{2}{*}{ ASISTENCIA A CONGRESOS } & No & 87 & 86,1 \\
\hline & Sí & 13 & 13,9 \\
\hline \multirow{2}{*}{$\begin{array}{l}\text { REALIZACIÓN DE POSTGRADOS } \\
\text { NO OFICIALES }\end{array}$} & No & 98,8 & 97,8 \\
\hline & Sí & 2,1 & 0,8 \\
\hline \multirow{2}{*}{$\begin{array}{l}\text { REALIZACIÓN DE MÁSTERES } \\
\text { OFICIALES }\end{array}$} & No & 99,5 & 98,2 \\
\hline & Sí & 0,5 & 1,8 \\
\hline \multirow{2}{*}{$\begin{array}{l}\text { REALIZACIÓN DE GRUPOS DE } \\
\text { TRABAJO }\end{array}$} & No & 99,5 & 98,2 \\
\hline & Sí & 0,5 & 1,8 \\
\hline
\end{tabular}

Nota. $\mathrm{P}<0,05 ; \Phi=0,283-0,313$.

En cuanto a la tabla 5.36 y refiriéndonos a la relación entre la formación inicial general y la formación permanente, todos los monitores de fitness seleccionan los 
cursos como actividad preferida de formación permanente, sin embargo los titulados universitarios exponen que la actividad que menos realizan son los másteres oficiales $\left(2 \% ; x^{2}=23900 ; p<0,05\right)$, igualmente, los que tienen una formación profesional no realizan ni másteres oficiales $\left(0 \% ; x^{2}=23900 ; p<0,05\right)$, ni grupos de trabajo $\left(0 \% ; x^{2}=\right.$ 22156; p<0,05). Los que han estudiado educación secundaria no realizan grupos de trabajo $\left(0 \% ; \mathrm{x}^{2}=22156 ; \mathrm{p}<0,05\right)$ y por último los que tienen la educación primaria o menos no realizan ni asistencia a congresos $\left(0 \% ; x^{2}=25132 ; p<0,05\right)$, ni postgrados no oficiales $\left(0 \% ; x^{2}=24073 ; p<0,05\right)$, ni másteres oficiales $\left(0 \% ; x^{2}=23900 ; p<0,05\right)$, ni grupos de trabajo $\left(0 \% ; \mathrm{x}^{2}=22156 ; \mathrm{p}<0,05\right)$.

En general, los monitores de fitness que poseen un título universitario realizan más actividades de formación permanente que el resto de monitores $\left(\mathrm{X}_{\text {asistencia a jornadas }}=\right.$ $25,5 \%, \mathrm{x}^{2}=23498 ; \mathrm{X}_{\text {asistencia a congresos }}=16,7 \%, \mathrm{x}^{2}=25132 ; \mathrm{X}_{\text {realización de estudios de posgrado no }}$ oficiales $=3,2 \%, x^{2}=24073 ; X_{\text {realización de másteres }}=2 \%, x^{2}=23900 ; X_{\text {realización de grupos de trabajo }}$ $\left.=2,4 \%, x^{2}=22156 ; p<0,05\right)$. Ellos fueron los que obtienen el porcentaje más alto en todas las actividades de formación excepto en los cursos, que aunque también es alto, no es tanto como el de los monitores de fitness que habían terminado la educación secundaria.

En este análisis hay una relación moderada y significativa estadísticamente $(\Phi=$ 0,323 - 0,378; p <0,05) (véase tabla 5.36). 
Tabla 5.36

Formación permanente que los monitores de fitness han realizado durante los últimos 3 años en relación con la formación inicial general $(n=631)$

\begin{tabular}{|c|c|c|c|c|c|}
\hline \multirow{2}{*}{$\begin{array}{l}\text { ACTIVIDADES } \\
\text { DE FORMACIÓN } \\
\text { PERMANENTES }\end{array}$} & \multicolumn{5}{|c|}{ FORMACIÓN INICIAL GENERAL (\%) } \\
\hline & & $\begin{array}{c}\text { TITULADO } \\
\text { UNIVERSITARIO }\end{array}$ & $\begin{array}{l}\text { FORMACIÓN } \\
\text { PROFESIONAL }\end{array}$ & $\begin{array}{l}\text { EDUCACIÓN } \\
\text { SECUNDARIA }\end{array}$ & $\begin{array}{c}\text { EDUCACIÓN } \\
\text { PRIMARIA O } \\
\text { MENOR }\end{array}$ \\
\hline $\begin{array}{l}\text { REALIZACIÓN DE } \\
\text { CURSOS }\end{array}$ & $\begin{array}{l}\text { No } \\
\text { Sí }\end{array}$ & $\begin{array}{l}35,5 \\
64,5\end{array}$ & $\begin{array}{l}32,2 \\
67,8\end{array}$ & $\begin{array}{l}29,4 \\
70,6\end{array}$ & $\begin{array}{l}35 \\
65\end{array}$ \\
\hline $\begin{array}{l}\text { ASISTENCIA A } \\
\text { JORNADAS }\end{array}$ & $\begin{array}{l}\text { No } \\
\text { Sí }\end{array}$ & $\begin{array}{l}74,5 \\
25,5\end{array}$ & $\begin{array}{l}80,5 \\
19,5\end{array}$ & $\begin{array}{l}84,4 \\
15,6\end{array}$ & $\begin{array}{c}95 \\
5\end{array}$ \\
\hline $\begin{array}{l}\text { ASISTENCIA A } \\
\text { CONGRESOS }\end{array}$ & $\begin{array}{l}\text { No } \\
\text { Sí }\end{array}$ & $\begin{array}{l}83,3 \\
16,7\end{array}$ & $\begin{array}{c}91,3 \\
8,7\end{array}$ & $\begin{array}{l}86,3 \\
13,7\end{array}$ & $\begin{array}{c}100 \\
0\end{array}$ \\
\hline $\begin{array}{l}\text { REALIZACIÓN DE } \\
\text { POSTGRADOS NO } \\
\text { OFICIALES }\end{array}$ & $\begin{array}{l}\text { No } \\
\text { Sí }\end{array}$ & $\begin{array}{c}96,8 \\
3,2\end{array}$ & $\begin{array}{c}99,3 \\
0,7\end{array}$ & $\begin{array}{c}99,5 \\
0,5\end{array}$ & $\begin{array}{c}100 \\
0\end{array}$ \\
\hline $\begin{array}{l}\text { REALIZACIÓN DE } \\
\text { MÁSTERES } \\
\text { OFICIALES }\end{array}$ & $\begin{array}{l}\text { No } \\
\text { Sí }\end{array}$ & $\begin{array}{c}98,0 \\
2,0\end{array}$ & $\begin{array}{c}100 \\
0\end{array}$ & $\begin{array}{c}99,5 \\
0,5\end{array}$ & $\begin{array}{c}100 \\
0\end{array}$ \\
\hline $\begin{array}{l}\text { REALIZACIÓN DE } \\
\text { GRUPOS DE } \\
\text { TRABAJO }\end{array}$ & $\begin{array}{l}\text { No } \\
\text { Sí }\end{array}$ & $\begin{array}{l}97,6 \\
2,4\end{array}$ & $\begin{array}{c}100 \\
0\end{array}$ & $\begin{array}{c}100 \\
0\end{array}$ & $\begin{array}{c}100 \\
0\end{array}$ \\
\hline
\end{tabular}

Para completar este apartado de formación se va a analizar las actividades de formación proporcionadas u organizadas por las organizaciones (figura 5.11) en las que trabajaban los monitores de fitness, obteniéndose que el $28,7 \%$ de las entidades organizaron situaciones de aprendizaje permanente en los últimos 12 meses para sus empleados, el 1,1\% aseguró que algunas organizaciones para las que trabajaban sí organizaba formación permanente pero otras no y en el lado opuesto del espectro, el $70,2 \%$ de los monitores de fitness afirman que sus entidades no organizaron ninguna actividad de formación permanente para ellos en los últimos 12 meses. 


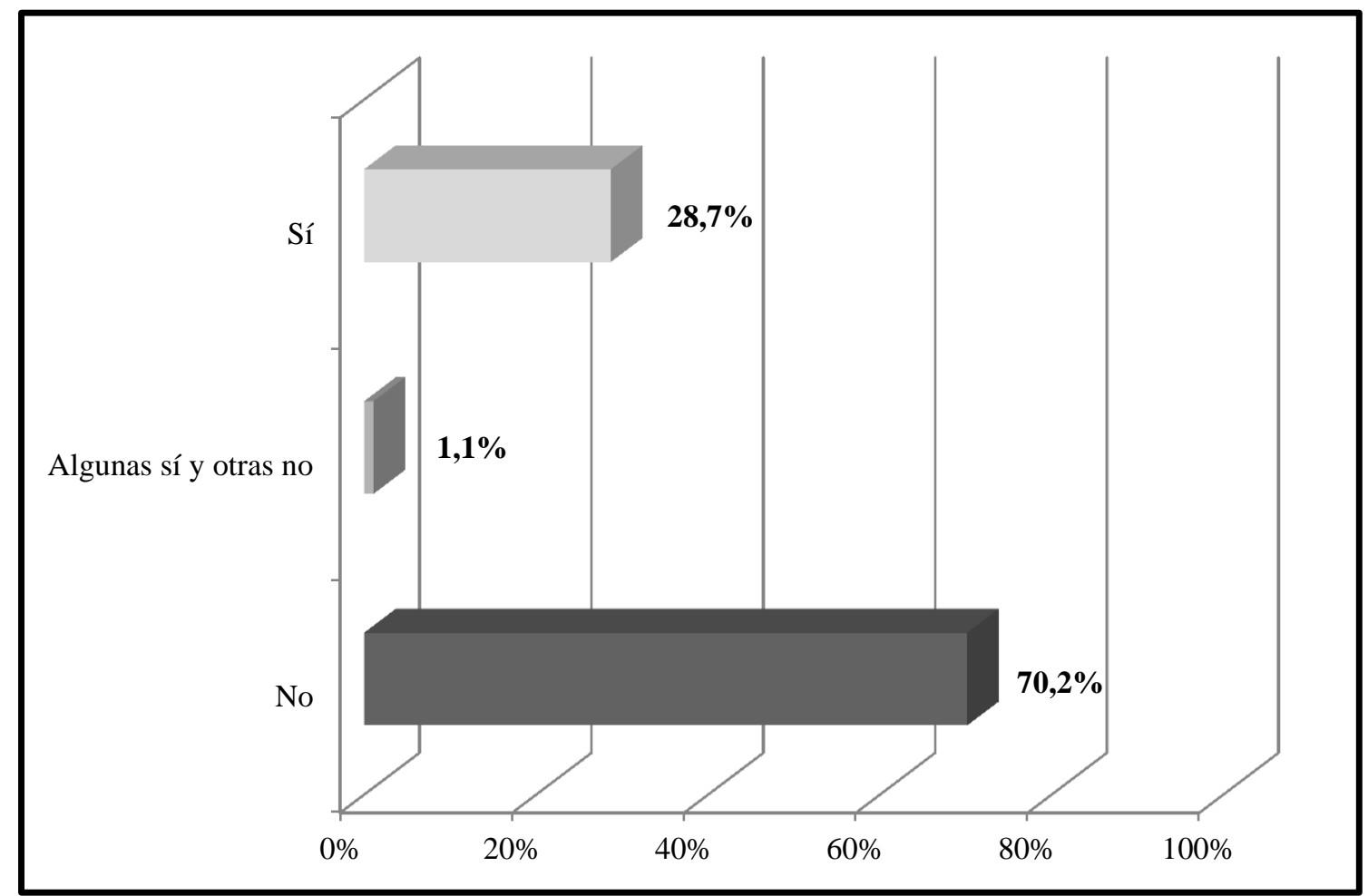

Figura 5. 11. Actividades de formación organizadas por su entidad para los monitores de fitness en los últimos 12 meses $(\mathrm{N}=631)$.

\subsubsection{INTERVENCIÓN DOCENTE Y PROFESIONAL DE LOS MONITORES DE FITNESS}

A continuación se van a tratar los aspectos más relevantes de la intervención docente y profesional en los monitores de fitness como son: la planificación, la evaluación, los elementos que priorizan en su enseñanza y desempeño profesional y las fuentes de conocimiento, así como la relación existentes entre éstos y las variables: edad, sexo, experiencia laboral y nivel de estudios. 


\subsubsection{Planificación}

En el figura 5.12 se puede observar que el $37,9 \%$ de los monitores de fitness planifican sus sesiones, en cambio el $62,1 \%$ de ellos no las planifican.

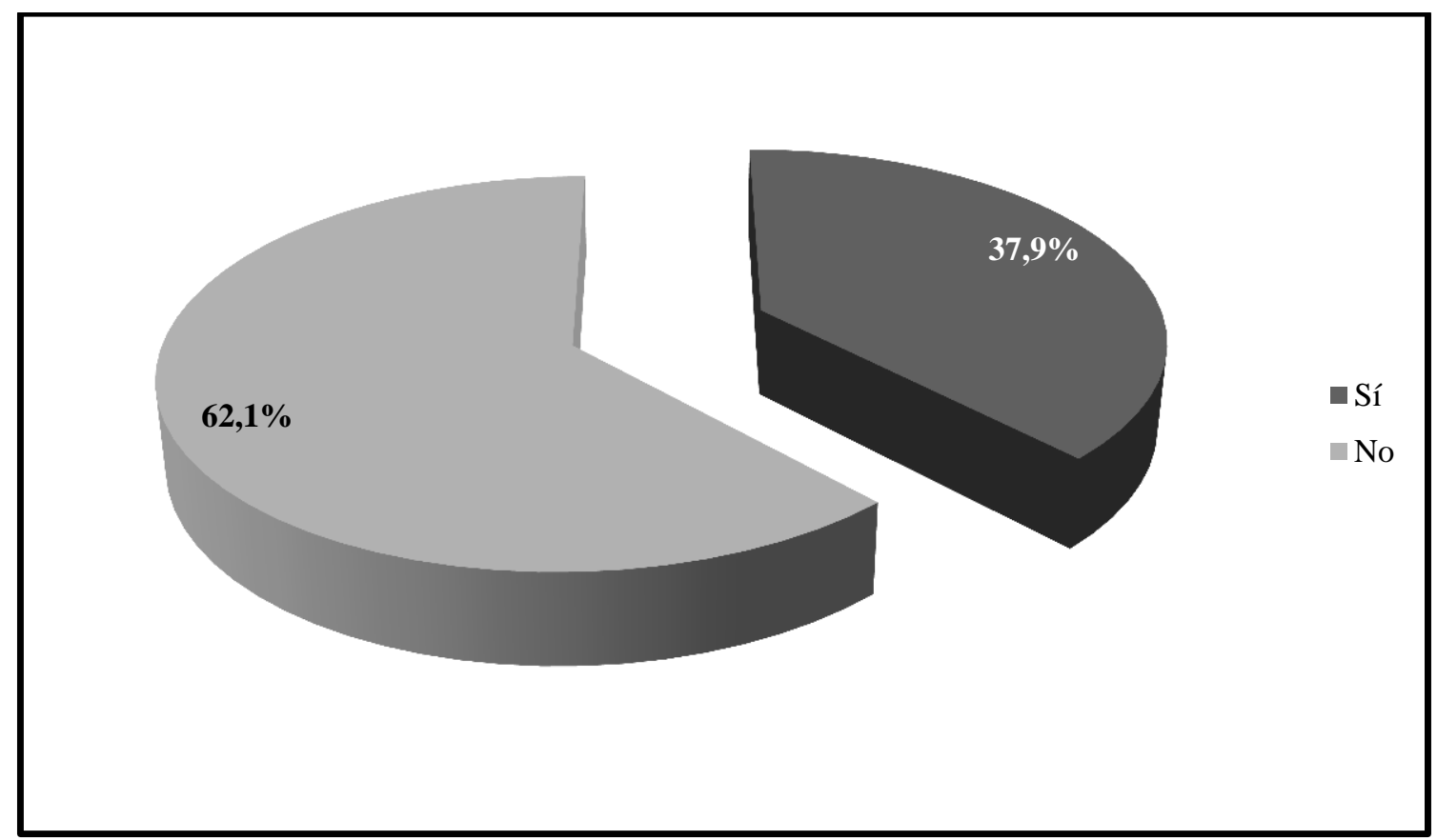

Figura 5. 12. La planificación que llevan a cabo los monitores de fitness $(\mathrm{N}=631)$.

En cuanto a las variables objeto de estudio, los monitores de fitness varones planifican más que las mujeres (tabla 5.37) $\left(\mathrm{X}_{\text {hombres }}=39,7 \%, \mathrm{X}_{\text {mujeres }}=35,2 \%\right.$; $\left.\mathrm{x}^{2}=8965 ; \Phi=0,543 ; \mathrm{p}>0,05\right)$. 
Tabla 5. 37

La planificación que llevan a cabo los monitores de fitness en relación al sexo $(N=$ 631)

\begin{tabular}{lcc}
\hline & \multicolumn{2}{c}{ SEXO $(\%)$} \\
\cline { 2 - 3 } PLANIFICACIÓN & HOMBRE & MUJER \\
\hline No & 60,3 & 64,8 \\
Sí & 39,7 & 35,2 \\
\hline
\end{tabular}

Si nos referimos a la edad, los monitores de fitness que más planifican tienen entre 16 y 29 años $\left(X=41 \% ; x^{2}=10701 ; \Phi=0,445 ; p<0,01\right)$, después los de 30 a 44 años $(36,6 \%)$ y por último los de 45 años o mayores $(29,6 \%)$ (véase la tabla 5.38).

Tabla 5. 38

La planificación que llevan a cabo los monitores de fitness en relación a la edad $(N=$ 631)

\begin{tabular}{cccc}
\hline \multirow{2}{*}{ PLANIFICACIÓN } & \multicolumn{3}{c}{ EDAD $(\%)$} \\
\cline { 2 - 4 } & $\mathbf{1 6 - 2 9}$ & $\mathbf{3 0 - 4 4}$ & $\mathbf{4 5 - 7 0}$ \\
\hline No & 59,0 & 63,4 & 70,4 \\
Sí & 41,0 & 36,6 & 29,6 \\
\hline
\end{tabular}

Nota. $\mathrm{p}<0,01 ; \Phi=0,445$.

En referencia al nivel de estudios, los monitores de fitness que más planifican son los titulados universitarios $\left(X=46,6 \% ; x^{2}=10980 ; \Phi=0,572 ; p<0,01\right)$, después los que tienen formación profesional $(35,6 \%)$, a continuación los que han terminado la educación secundaria $(30,8 \%)$ y en último lugar los que tienen estudios primarios o menores (20\%) (véase tabla 5.39). 
Tabla 5. 39

La planificación que llevan a cabo los monitores de fitness en relación al nivel de estudios $(N=631)$

\begin{tabular}{ccccc}
\hline \multirow{2}{*}{ PLANIFICACIÓN } & \multicolumn{4}{c}{ NIVEL DE ESTUDIOS $(\%)$} \\
\cline { 2 - 5 } & $\begin{array}{c}\text { TITULADO } \\
\text { UNIVERSITARIO }\end{array}$ & $\begin{array}{c}\text { FORMACIÓN } \\
\text { PROFESIONAL }\end{array}$ & $\begin{array}{c}\text { EDUCACIÓN } \\
\text { SECUNDARIA }\end{array}$ & $\begin{array}{c}\text { EDUCACIÓN } \\
\text { PRIMARIA O } \\
\text { MENOR }\end{array}$ \\
\hline No & 53,4 & 64,4 & 69,2 & 80 \\
Sí & 46,6 & 35,6 & 30,8 & 20 \\
\hline
\end{tabular}

Nota. $\mathrm{p}<0,01 ; \Phi=0,400$.

De acuerdo con la tabla 5.40, los monitores de fitness también planifican más según tienen más experiencia $\left(X=41,7 \% ; x^{2}=9638 ; \Phi=0,400 ; p<0,01\right)$.

Tabla 5.40

La planificación que llevan a cabo los monitores de fitness en relación a la experiencia laboral $(N=631)$

\begin{tabular}{ccc}
\hline \multirow{2}{*}{ PLANIFICACIÓN } & \multicolumn{2}{c}{ EXPERIENCIA LABORAL $(\%)$} \\
\cline { 2 - 3 } & $<\mathbf{1 0}$ AÑos & $\geq \mathbf{1 0}$ AÑos \\
\hline No & 64,2 & 58,3 \\
Sí & 35,8 & 41,7 \\
\hline
\end{tabular}

Nota. $\mathrm{p}<0,01 ; \Phi=0,572$.

\subsubsection{Evaluación}

Se continúa analizando la intervención docente y profesional de los monitores de fitness con el apartado de evaluación. Como se puede ver en el figura 5.13, el 39,3\% de 
los monitores de fitness evalúan, sin embargo el 60,7\% de ellos no evalúa (véase figura $5.13)$.

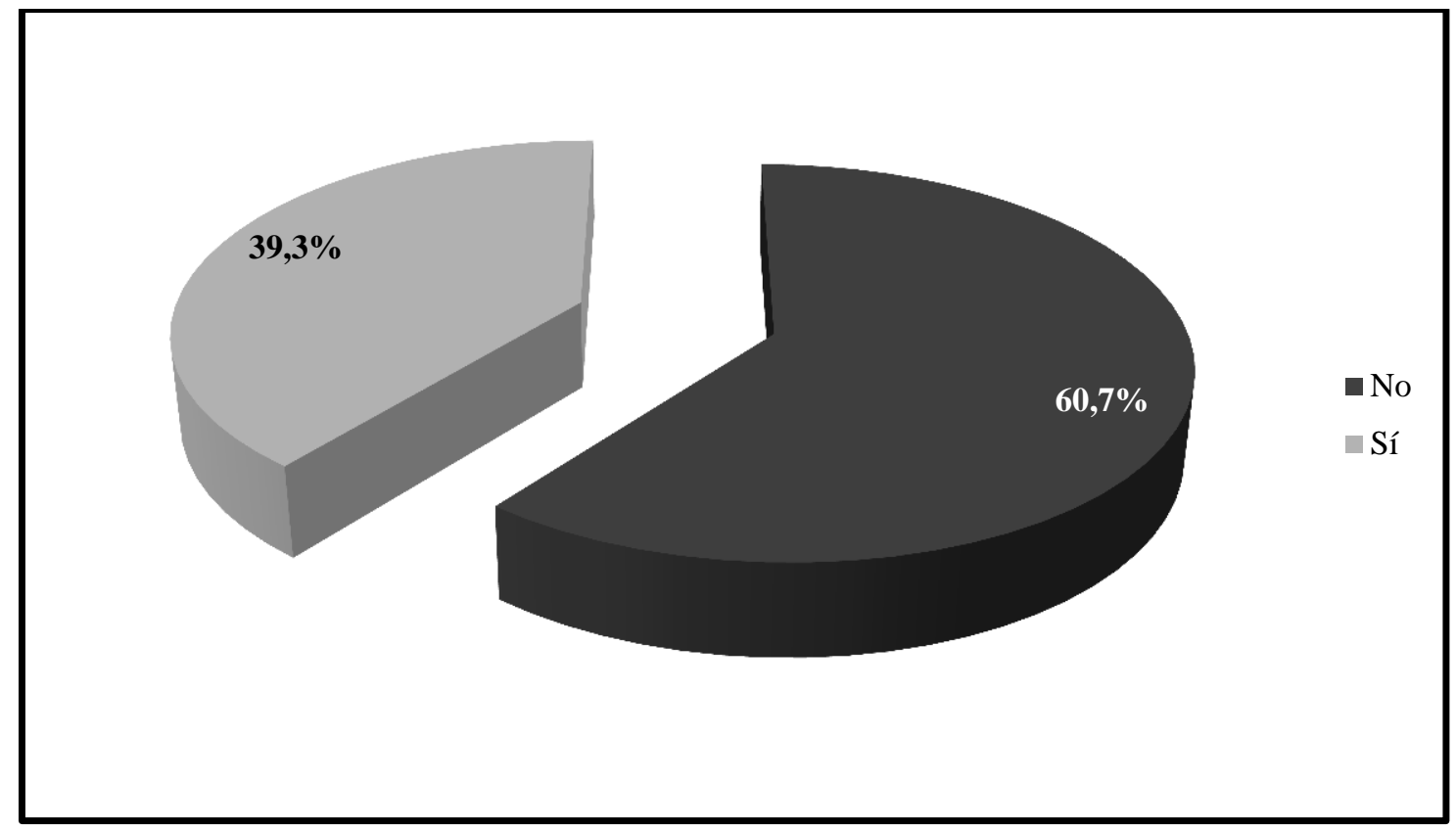

Figura 5. 13. La evaluación llevada a cabo por los monitores de fitness $(\mathrm{N}=631)$.

Centrándonos en los que sí evalúan, se observa que el 50,4\% evalúa regularmente y el 49,6\% no evalúa regularmente (véase figura 5.14).

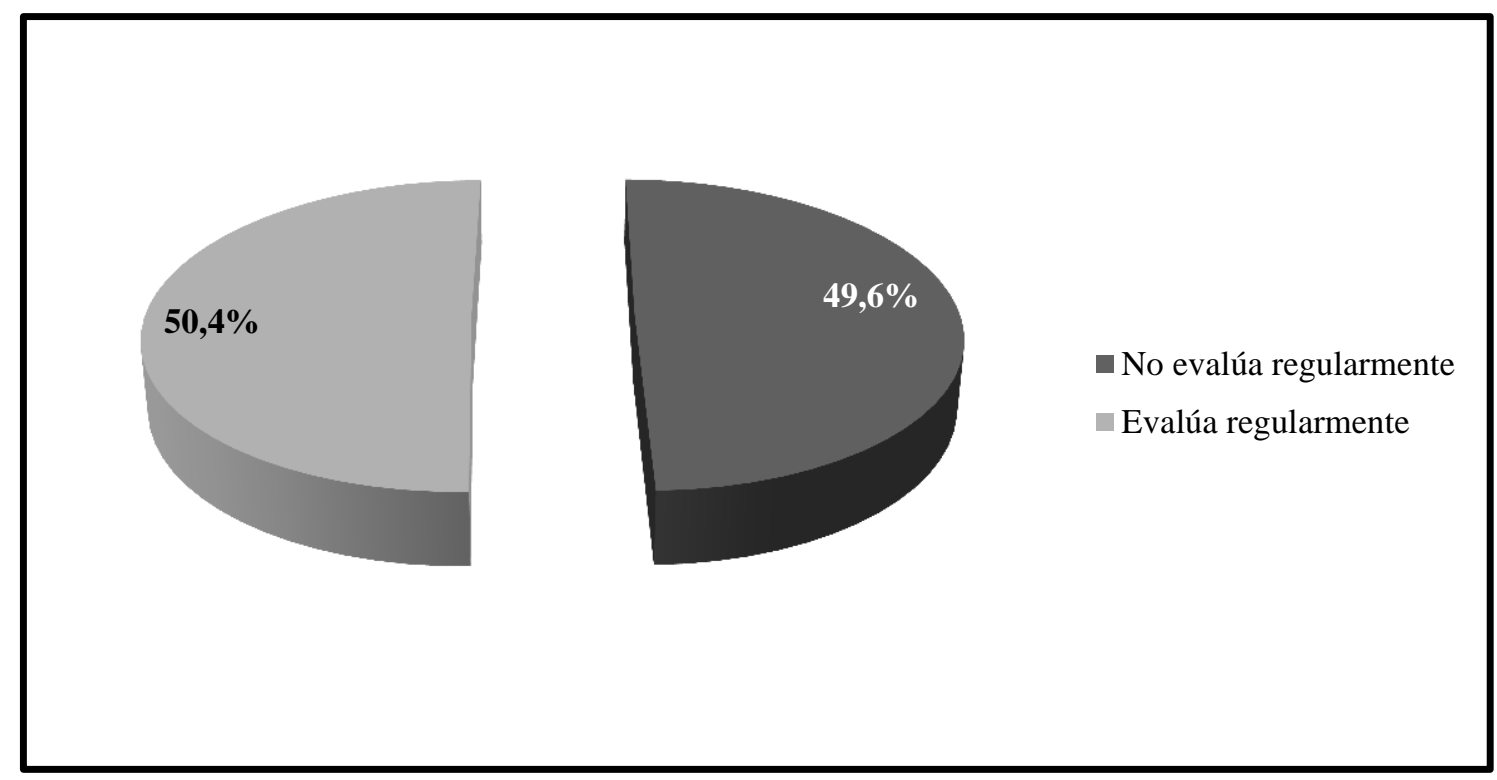

Figura 5. 14. Regularidad con la que los monitores de fitness evalúan (N=631). 
En la tabla 5.41 se constata una diferencia significativa entre los dos sexos, resultando que los hombres evalúan en general más que las mujeres $\left(X_{\text {hombres }}=45,5 \%\right.$, $\left.\mathrm{X}_{\text {mujeres }}=30 \%\right)$ con una diferencia del 15,5\% $\left(\mathrm{x}^{2}=9638 ; \Phi=0,270 ; \mathrm{p}<0,01\right)$.

Tabla 5.41

La evaluación llevada a cabo por los monitores de fitness en relación al sexo $(N=631)$

\begin{tabular}{ccc}
\hline & \multicolumn{2}{c}{ SEXO $(\%)$} \\
\cline { 2 - 3 } EVALUACIÓN & HOMBRE & MuJER \\
\hline No & 54,5 & 70,0 \\
Sí & 45,5 & 30 \\
\hline
\end{tabular}

Nota. $\mathrm{p}<0,01 ; \Phi=0,270$.

Al analizar la regularidad con la que evalúan los monitores de fitness, los monitores de fitness varones que evalúan regularmente son el 54,1\%, pero por el contrario el 58\% de las mujeres no evalúa regularmente (véase tabla 5.42).

Tabla 5.42

Regularidad con la que los monitores de fitness evalúan en relación al sexo $(N=631)$

\begin{tabular}{ccc}
\hline \multirow{2}{*}{ EVALUACIÓN } & \multicolumn{2}{c}{ SEXO(\%) } \\
\cline { 2 - 3 } & HOMBRE & MUJER \\
\hline NO EVALÚA REGULARMENTE & 45,9 & 58 \\
EVALÚA REGULARMENTE & 54,1 & 42 \\
\hline
\end{tabular}

Nota. $\mathrm{p}<0,01$.

Con respecto a la edad de los sujetos del estudio (tabla 5.43), los monitores de fitness de 30 a 44 años (41\%) son los que más evalúan, seguidos de los de 16 a 29 años 
$(39,6 \%)$ y por último los que tienen de 45 a 59 años $(27,8 \%)\left(x^{2}=29768 ; \Phi=0,270 ; p\right.$ $<0,01)$.

Tabla 5.43

La evaluación llevada a cabo por los monitores de fitness en relación a la edad $(N=$ 631)

\begin{tabular}{ccccc}
\hline \multirow{2}{*}{ EVALUACIÓN } & \multicolumn{3}{c}{ EDAD $(\boldsymbol{\%})$} \\
\cline { 2 - 4 } & $\mathbf{1 6 - 2 9}$ & $\mathbf{3 0 - 4 4}$ & $\mathbf{4 5 - 7 0}$ \\
\hline No & 60,4 & 59 & 72,2 \\
Sí & 39,6 & 41 & 27,8 \\
\hline
\end{tabular}

Nota. $\mathrm{p}<0,01 ; \Phi=0,270$.

Analizando la evaluación con respecto a la edad en mayor detalle, se obtiene que más de la mitad de los monitores de fitness de 16 a 29 años evalúan regularmente $(56,8 \%)$, sin embargo los demás monitores de fitness suelen evaluar pero no regularmente (véase tabla 5.44).

Tabla 5.44

Regularidad con la que los monitores de fitness evalúan en relación a la edad $(N=631)$

\begin{tabular}{lccc}
\hline \multirow{2}{*}{ EVALUACIÓN } & \multicolumn{3}{c}{ EDAD $(\%)$} \\
\cline { 2 - 4 } & $\mathbf{1 6 - 2 9}$ & $\mathbf{3 0 - 4 4}$ & $\mathbf{4 5 - 7 0}$ \\
\hline NO EVALÚA REGULARMENTE & 43,2 & 54,4 & 59,3 \\
EVALÚA REGULARMENTE & 56,8 & 45,6 & 40,7 \\
\hline
\end{tabular}

Nota. $\mathrm{p}<0,01$.

En lo que se refiere al nivel de estudios (tabla 5.45), los graduados universitarios son los que más evalúan $(55,4 \%)$, seguidos de los que tienen estudios de formación profesional $(38,2 \%)$, a continuación los que han terminado la educación secundaria 
$(23,2 \%)$ y en último lugar los que tienen estudios primarios o menores (15\%) $\left(\mathrm{x}^{2}=24802 ; \Phi=0,448 ; \mathrm{p}<0,01\right)$.

Tabla 5.45

La evaluación llevada a cabo por los monitores de fitness en relación al nivel de estudios $(N=631)$

\begin{tabular}{ccccc}
\hline \multirow{2}{*}{ EVALUACIÓN } & \multicolumn{4}{c}{ NIVEL DE ESTUDIOS $(\%)$} \\
\cline { 2 - 5 } & $\begin{array}{c}\text { TITULADO } \\
\text { UNIVERSITARIO }\end{array}$ & $\begin{array}{c}\text { FORMACIÓN } \\
\text { PROFESIONAL }\end{array}$ & $\begin{array}{c}\text { EDUCACIÓN } \\
\text { SECUNDARIA }\end{array}$ & $\begin{array}{c}\text { EDUCACIÓN } \\
\text { PRIMARIA O } \\
\text { MENOR }\end{array}$ \\
\hline No & 44,6 & 61,7 & 76,8 & 85 \\
Sí & 55,4 & 38,3 & 23,2 & 15 \\
\hline
\end{tabular}

Nota. $\mathrm{p}<0,01 ; \Phi=0,448$.

Centrándonos en los monitores de fitness que sí que evalúan, en la tabla 5.46 se puede observar la frecuencia con la que lo realizan, viendo que los titulados universitarios no suelen evaluar regularmente $(44,6 \%)$ pero los demás grupos sí, siendo los que han estudiado primaria o menos los que más frecuentemente llevan a cabo la evaluación $(66,7 \%)$ (p <0,01) (véase tabla 5.46).

Tabla 5.46

Regularidad con la que los monitores de fitness evalúan en relación al nivel de estudios (N=631)

\begin{tabular}{ccccc}
\hline \multirow{2}{*}{ EVALUACIÓN } & \multicolumn{4}{c}{ NIVEL DE ESTUDIOS $(\%)$} \\
\cline { 2 - 5 } & $\begin{array}{c}\text { TITULAdO } \\
\text { UNIVERSITARIO }\end{array}$ & $\begin{array}{c}\text { FORMACIÓN } \\
\text { PROFESIONAL }\end{array}$ & $\begin{array}{c}\text { EDUCACIÓN } \\
\text { SECUNDARIA }\end{array}$ & $\begin{array}{c}\text { EDUCACIÓN } \\
\text { PRIMARIA O } \\
\text { MENOR }\end{array}$ \\
\hline NO EVALÚA REGULARMENTE & 55,4 & 42 & 43,1 & 33,3 \\
EVALÚA REGULARMENTE & 44,6 & 58 & 56,9 & 66,7 \\
\hline
\end{tabular}

Nota. $\mathrm{p}<0,01$. 
La tabla 5.47 refleja que los monitores de fitness evalúan más a medida que van adquiriendo más experiencia $(45,3 \%)\left(\mathrm{x}^{2}=8778 ; \Phi=0,300 ; \mathrm{p}<0,01\right)$.

Tabla 5.47

La evaluación llevada a cabo por los monitores de fitness en relación a la experiencia laboral $(N=631)$

\begin{tabular}{ccc}
\hline \multirow{2}{*}{ EVALUACIÓN } & \multicolumn{2}{c}{ ESPERIENCIA LABORAL (\%) } \\
\cline { 2 - 3 } & $<\mathbf{1 0}$ AÑos & $\geq \mathbf{1 0}$ AÑos \\
\hline No & 64 & 54,7 \\
Sí & 36 & 45,3 \\
\hline
\end{tabular}

Nota. $\mathrm{p}<0,01 ; \Phi=0,300$.

En relación a los monitores de fitness que sí evalúan y la experiencia laboral, se encuentra que los que menos experiencia tienen evalúan más regularmente $(59,7 \%)$ que los que tienen 10 años o más de experiencia (36,6\%) (véase tabla 5.48).

Tabla 5.48

Regularidad con la que los monitores de fitness evalúan en relación a la experiencia laboral $(N=631)$

\begin{tabular}{ccc}
\hline \multirow{2}{*}{ EVALUACIÓN } & \multicolumn{2}{c}{ ESPERIENCIA LABORAL $(\%)$} \\
\cline { 2 - 3 } & $<\mathbf{1 0}$ AÑOS & $\geq \mathbf{1 0}$ AÑOS \\
\hline NO EVALÚA REGULARMENTE & 40,3 & 63,4 \\
EVALÚA REGULARMENTE & 59,7 & 36,6 \\
\hline
\end{tabular}

Nota. $\mathrm{p}<0,01$.

A continuación se pasan a detallar las herramientas de evaluación utilizadas por los monitores de fitness. 
Como se ve en el figura 5.15, la observación diaria de las sesiones es la herramienta de evaluación que más utilizan $(46,4 \%)$, seguida de las pruebas de ejecución $(20,3 \%)$ y de las baterías de test estandarizadas (19\%). El uso de las demás herramientas de evaluación (los test confeccionados por uno mismo o por los compañeros, los diarios y los exámenes teóricos) son casi inexistentes, siendo utilizadas todas por debajo del $7 \%$.

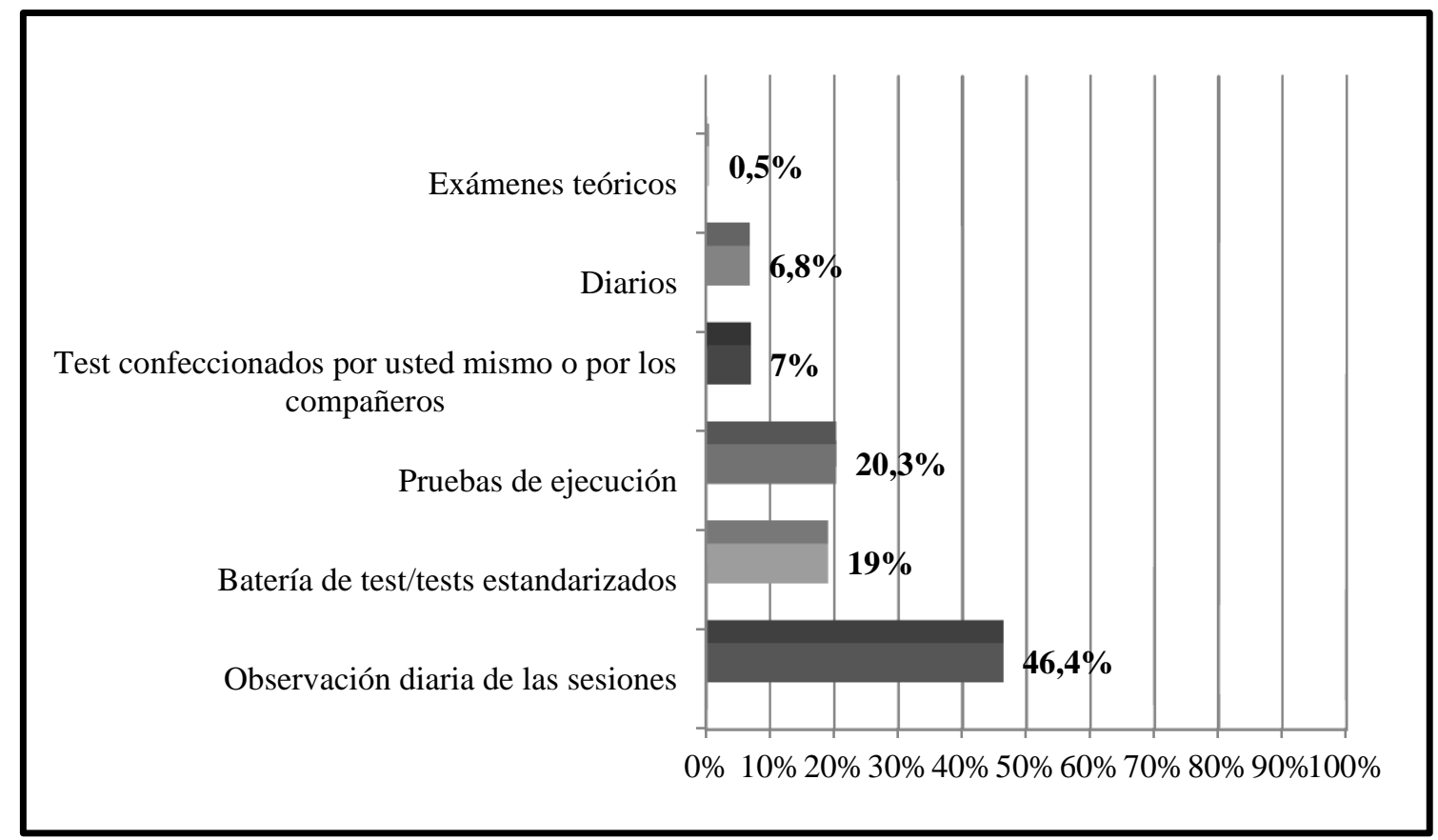

Figura 5. 15. Las herramientas de evaluación usadas por los monitores de fitness (N=631).

En cuanto a la variable objeto de estudio sexo (tabla 5.49), la observación diaria de las clases es la herramienta de evaluación que más utilizan los hombres y las mujeres $\left(X_{\text {hombres }}=43,5 \%\right.$ y $\left.X_{\text {mujeres }}=53,1 \% ; x^{2}=10162 ; p<0,01\right)$, seguida de las pruebas de ejecución $\left(X_{\text {hombres }}=20,4 \%\right.$ y $\left.X_{\text {mujeres }}=20,4 \% ; x^{2}=13644 ; p>0,05\right)$ y de las baterías de test estandarizadas $\left(X_{\text {hombres }}=21,1 \%\right.$ y $\left.X_{\text {mujeres }}=14,2 \% ; x^{2}=12458 ; p<0,01\right)$. Asimismo, los exámenes teóricos son la herramienta que menos utilizan $\left(X_{\text {hombres }}=0,7 \%\right.$ y $X_{\text {mujeres }}=0 \%$; $\left.x^{2}=10117 ; p<0,01\right)$ 
En general, los hombres utilizan en un tanto por ciento más elevado la batería de test/tests estandarizados $\left(21,1 \% ; \mathrm{x}^{2}=12458 ; \mathrm{p}<0,01\right)$, los test confeccionados por ellos mismo o por sus compañeros $\left(7,7 \% ; \mathrm{x}^{2}=10988 ; \mathrm{p}<0,01\right)$ y los exámenes teóricos $(0,7 \%$; $\left.\mathrm{x}^{2}=13409 ; \mathrm{p}<0,01\right)$. Por el contrario, las mujeres utilizan más la observación diaria de las sesiones $\left(53,1 \% ; \mathrm{x}^{2}=10162 ; \mathrm{p}<0,01\right)$ y los diarios $\left(7 \% ; \mathrm{x}^{2}=4058 ; \mathrm{p}>0,05\right)$. Las pruebas de ejecución es la única herramienta que ambos sexos utilizan por igual (20,4\%; $\left.x^{2}=13644 ; p>0,05\right)$.

En este análisis existe una relación de baja a considerable y estadísticamente muy significativa $(\Phi=0,200-0,554 ; \mathrm{p}<0,01)$ excepto para la tercera herramienta de evaluación (las pruebas de ejecución) y la quinta herramienta de evaluación (los diarios) (véase tabla 5.49).

Tabla 5.49

Las herramientas de evaluación utilizadas por los monitores de fitness en relación al $\operatorname{sexo}(N=631)$

\begin{tabular}{lcc}
\hline \multirow{2}{*}{ HERRAMIENTAS DE EVALUACIÓN } & \multicolumn{2}{c}{ SEXO $(\%)$} \\
\cline { 2 - 3 } & HOMBRE & MUJER \\
\hline OBSERVACIÓN DIARIA DE LAS SESIONES & $43,5^{*}$ & $53,1^{*}$ \\
BATERÍA DE TEST/TESTS ESTANDARIZADOS & $21,1^{*}$ & $14,2^{*}$ \\
PRUEBAS DE EJECUCIÓN & 20,4 & 20,4 \\
TEST CONFECCIONADOS POR USTED MISMO O POR LOS & $7,7^{*}$ & $5,3^{*}$ \\
COMPAÑEROS & 6,6 & 7,0 \\
DIARIOS & & $0,7 *$ \\
EXÁMENES TEÓRICOS & & 0,0 \\
\hline
\end{tabular}

Nota. $* \mathrm{p}<0,01 ; \Phi=0,200-0,554$. 
Analizando la variable edad (tabla 5.50) se constata que los monitores de fitness de todas las edades utilizan con mayor frecuencia las herramientas de observación diaria de las sesiones y utilizan con menor frecuencia o incluso no utilizan los exámenes teóricos.

Por otro lado los monitores de fitness de 16 a 30 años tienen mayores medias en la observación diaria de las sesiones $\left(49,3 \% ; x^{2}=18988 ; p<0,01\right)$ y en la batería de test/tests estandarizados $\left(22,2 \% ; x^{2}=15674 ; p>0,05\right)$. Por otro lado los que tienen de 30 a 44 años realizan más exámenes teóricos que el resto $\left(0,9 \% ; x^{2}=15900 ; p>0,05\right)$ y los monitores de fitness de 45 años o mayores utilizan con más frecuencia que sus compañeros las baterías de test/tests estandarizadas $\left(22,2 \% ; x^{2}=16539 ; p>0,05\right)$, las pruebas de ejecución $\left(27,2 \% ; x^{2}=19065 ; \mathrm{p}<0,01\right)$, los test confeccionados por uno mismo o por sus compañeros $\left(8,8 \% ; x^{2}=14798 ; p>0,05\right)$ y los diarios $\left(5,6 \% ; x^{2}=17332\right.$; p>0,05) (véase tabla 5.50).

En este análisis existe una relación de baja a considerable $(\Phi=0,200-0,554)$ en todas las herramientas y estadísticamente muy significativa $(\mathrm{p}<0,01)$ para las herramientas observación diaria de las sesiones y pruebas de ejecución. 
Tabla 5.50

Las herramientas de evaluación utilizadas por los monitores de fitness en relación a la edad $(N=631)$

\begin{tabular}{|c|c|c|c|}
\hline \multirow{2}{*}{ HERRAMIENTAS DE EVALUACIÓN } & \multicolumn{3}{|c|}{$\operatorname{EDAD}(\%)$} \\
\hline & $16-29$ & $30-44$ & 45-70 \\
\hline OBSERVACIÓN DIARIA DE LAS SESIONES & $49,3^{*}$ & $46,0^{*}$ & $37,3^{*}$ \\
\hline BATERÍA DE TEST/TESTS ESTANDARIZADOS & 22,2 & 16,7 & 22,2 \\
\hline PRUEBAS DE EJECUCIÓN & $16,0^{*}$ & $22,8 *$ & $27,2^{*}$ \\
\hline $\begin{array}{l}\text { TEST CONFECCIONADOS POR USTED MISMO O POR LOS } \\
\text { COMPAÑEROS }\end{array}$ & 6,9 & 6,5 & 8,8 \\
\hline DIARIOS & 5,6 & 7,0 & 12 \\
\hline EXÁMENES TEÓRICOS & 0 & 0,9 & 0 \\
\hline
\end{tabular}

Nota. $* \mathrm{p}<0,01 ; \Phi=0,200-0,554$.

Analizando la variable nivel de estudios (tabla 5.51) se constata que los monitores de fitness utilizan con mayor frecuencia las herramientas de observación diaria de las sesiones independientemente de su nivel de estudios. Sin embargo en cuanto a la herramienta que menos utilizan hay diversidad de opiniones, los titulados universitarios y los que poseen una formación profesional utilizan en menor medida los exámenes teóricos $\left(0,8 \% ; x^{2}=16549 ; \mathrm{p}>0,05\right)$, los monitores de fitness con la educación secundaria no utilizan ni los diarios $\left(0 \% ; x^{2}=13820 ; p>0,05\right)$ ni los exámenes teóricos y $\left(0 \% ; x^{2}=16539 ; p>0,05\right)$ y los que tienen la educación primaria o menos no utilizan ni la batería de test/tests estandarizada $\left(0 \% ; x^{2}=13218 ; p>0,05\right)$, ni los tests confeccionado por uno mismo o por los compañeros $\left(0 \% ; x^{2}=17739 ; \mathrm{p}<0,01\right)$, ni los diarios $(0 \%$; $\left.x^{2}=13820 ; p>0,05\right)$ ni los exámenes teóricos $\left(0 \% ; x^{2}=16549 ; p>0,05\right)$. 
En esta tabla también se puede observar que los monitores de fitness que solamente han estudiado educación primaria o menos utilizan por encima de los demás la observación diaria de la clase $\left(75 \% ; x^{2}=18008 ; \mathrm{p}<0,01\right)$ y las pruebas de ejecución $\left(25 \% ; x^{2}=15679 ; p>0,05\right)$. Por el contrario los que poseen una formación profesional utilizan más las baterías de test/tests estandarizadas (28\%) y los diarios (8\%) que el resto de monitores de fitness. Por último los titulados universitarios utilizan más en comparación con los demás grupos, los test confeccionados por uno mismo o por los compañeros $(8 \%)$ y los exámenes teóricos $(0,8 \%)$.

En este análisis existe una relación moderada $(\Phi=0,270-0,402)$ en todas las herramientas y estadísticamente muy significativa $(\mathrm{p}<0,01)$ para las herramientas observación diaria de las sesiones, los tests confeccionado por uno mismo o por los compañeros y los diarios (véase tabla 5.51).

Tabla 5.51

Las herramientas de evaluación utilizadas por los monitores de fitness en relación al nivel de formación $(N=631)$

\begin{tabular}{|c|c|c|c|c|}
\hline \multirow[b]{2}{*}{$\begin{array}{l}\text { HERRAMIENTAS DE } \\
\text { EVALUACIÓN }\end{array}$} & \multicolumn{4}{|c|}{ NIVEL DE ESTUDIOS (\%) } \\
\hline & $\begin{array}{c}\text { TITUlado } \\
\text { UNIVERSITARIO }\end{array}$ & $\begin{array}{r}\text { FORMACIÓN } \\
\text { PROFESIONAL }\end{array}$ & $\begin{array}{l}\text { EDUCACIÓN } \\
\text { SECUNDARIA }\end{array}$ & $\begin{array}{c}\text { EDUCACIÓN } \\
\text { PRIMARIA O } \\
\text { MENOR }\end{array}$ \\
\hline $\begin{array}{l}\text { OBSERVACIÓN DIARIA DE LAS } \\
\text { SESIONES }\end{array}$ & $45,2 *$ & $36,0^{*}$ & $74,4^{*}$ & $75,0^{*}$ \\
\hline $\begin{array}{l}\text { BATERÍA DE TEST/TESTS } \\
\text { ESTANDARIZADOS }\end{array}$ & 17,3 & 28,0 & 9,3 & 0 \\
\hline PRUEBAS DE EJECUCIÓN & 21,1 & 22,0 & 11,6 & 25,0 \\
\hline $\begin{array}{llll}\text { TEST CONFECCIONADOS } & \text { POR } \\
\text { USTED MISMO O } & \text { POR } & \text { LOS } \\
\text { COMPAÑEROS } & & & \end{array}$ & $8,0^{*}$ & $6,0^{*}$ & $4,7 *$ & $0^{*}$ \\
\hline DiARIOS & 7,6 & 8,0 & 0 & 0 \\
\hline EXÁMENES TEÓRICOS & 0,8 & 0 & 0 & 0 \\
\hline
\end{tabular}


Por último, los monitores de fitness con más experiencia laboral (diez años o más) utilizan más a menudo las pruebas de ejecución $\left(23,2 \% ; x^{2}=4149 ; p>0,05\right)$, los diarios $\left(7,7 \% ; x^{2}=9219 ; p<0,01\right)$ y los exámenes teóricos $\left(1,1 \% ; x^{2}=4068 ; p>0,05\right)$. Por el contrario, los monitores de fitness con menos experiencia (menos de diez años) prefieren utilizar la observación diaria de las sesiones $\left(48,8 \% ; x^{2}=9849 ; p<0,01\right)$, las baterías de test/tests estandarizadas $\left(20,2 \% ; x^{2}=8150 ; p<0,01\right)$ y los test confeccionados por uno mismo o por los compañeros $\left(7,4 \% ; \mathrm{x}^{2}=6152 ; \mathrm{p}<0,01\right)$.

En este análisis existe una relación moderada $(\Phi=0,253-0,482)$ en todas las herramientas y estadísticamente muy significativa $(\mathrm{p}<0,01)$ para las herramientas observación diaria de las sesiones, baterías de test/tests estandarizadas, los tests confeccionado por uno mismo o por los compañeros y los diarios (véase tabla 5.52).

Tabla 5.52

Las herramientas de evaluación utilizadas por los monitores de fitness en relación a la experiencia laboral $(N=631)$

\begin{tabular}{lcc}
\hline \multirow{2}{*}{ HERRAMIENTAS DE EVALUACIÓN } & \multicolumn{2}{c}{ ESPERIENCIA LABORAL $(\%)$} \\
\cline { 2 - 3 } & $<\mathbf{1 0}$ AÑOS & $<\mathbf{1 0}$ AÑOS \\
\hline OBSERVACIÓN DIARIA DE LAS SESIONES & $48,8^{*}$ & $43,6^{*}$ \\
BATERÍA DE TEST/TESTS ESTANDARIZADOS & $20,2^{*}$ & $17,7^{*}$ \\
PRUEBAS DE EJECUCIÓN & 17,7 & 23,2 \\
TEST CONFECCIONADOS POR USTED MISMO O POR & $7,4^{*}$ & $6,6^{*}$ \\
LOS COMPAÑEROS & $5,9^{*}$ & $7,7^{*}$ \\
DIARIOS & 0 & 1,1 \\
EXÁMENES TEÓRICOS &
\end{tabular}




\subsubsection{Elementos que priorizan en su enseñanza y desempeño profesional}

Los monitores de fitness determinaron los elementos que priorizan en su enseñanza e intervención profesional en una escala de Likert que iba de 1 al 5 (siendo 1 nada importante y 5 muy importante).

En general, los aspectos actitudinales y los aspectos técnicos $(\mathrm{X}=4,5)$ fueron los más importantes, seguidos de los aspectos psicológicos $(X=4,4)$, aspectos físicos $(X=4,2)$, aspectos conceptuales $(X=4)$ y aspectos tácticos $(X=3,2)$ (véase figura 5.16).

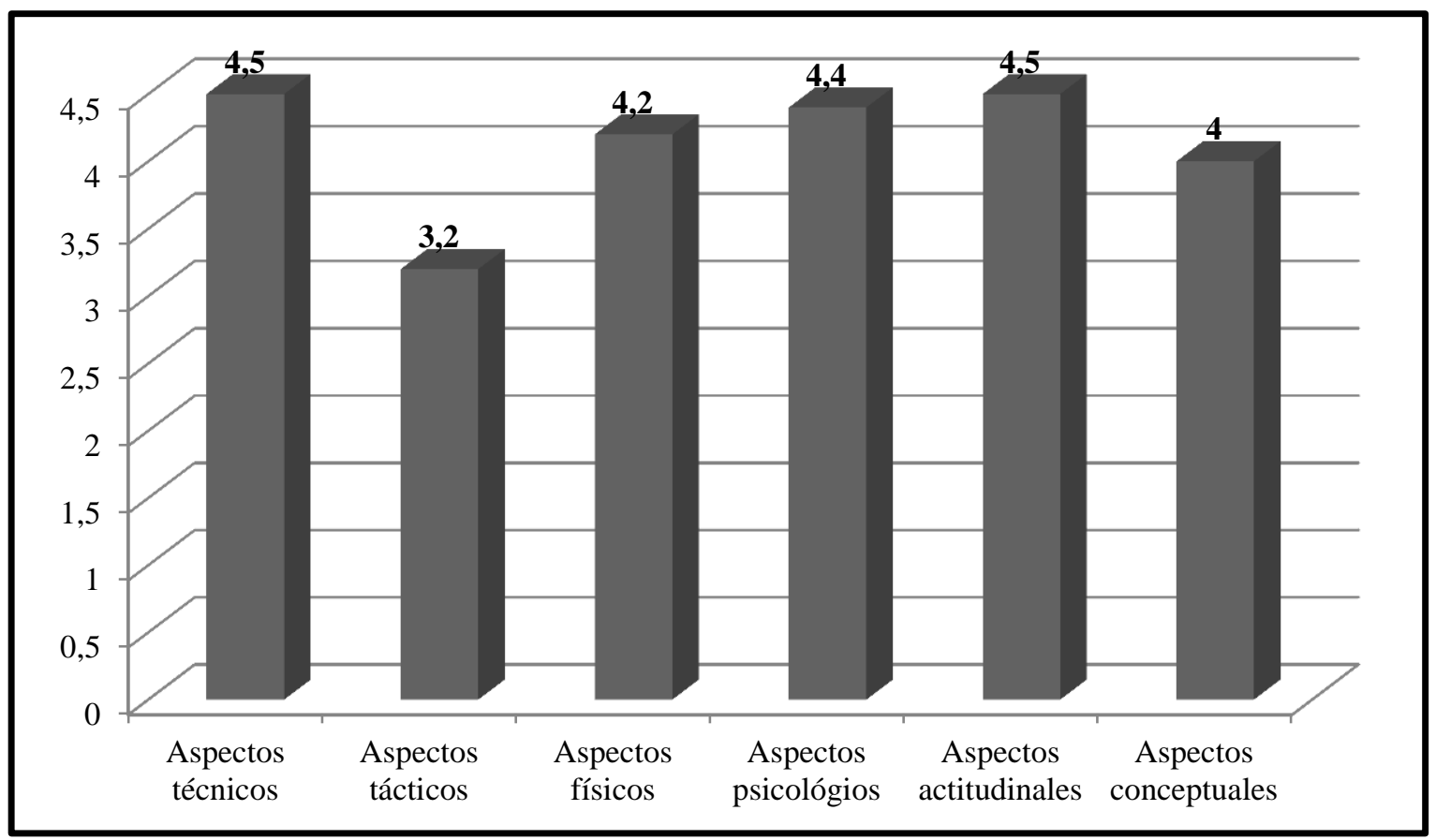

Figura 5. 16. Elementos que priorizan en su enseñanza y desempeño profesional los monitores de fitness $(\mathrm{N}=631)$.

Si prestamos atención a los elementos que priorizan en su enseñanza e intervención profesional en función de la variable sexo; los aspectos técnicos y actitudinales son los más importantes para ambos monitores de fitness, seguidos por los 
aspectos psicológicos, aspectos físicos, aspectos conceptuales y, por último, los aspectos tácticos.

En función del sexo, los hombres (aspectos técnicos $=4,5$; aspectos tácticos $=$ 3,3 ; aspectos físicos $=4,3$; aspectos psicológicos $=4,4$; aspectos actitudinales $=4,5 \mathrm{y}$ aspectos conceptuales $=4,1$ ) tienen medias más altas en todos ellos que las mujeres $\left(\mathrm{X}_{\text {mujeres }}=\right.$ aspectos técnicos $=4,4 ;$ aspectos tácticos $=3,1$; aspectos físicos $=4,2$; aspectos psicológicos $=4,4$; aspectos actitudinales $=4,5$ y aspectos conceptuales $=3,9$ ), a excepción de en los aspectos psicológicos y en los actitudinales, que obtienen la misma media. En este análisis existe una relación de baja a moderada $(\Phi=0,193$ 0,334), estadísticamente muy significativa $(\mathrm{p}<0,01)$ en los aspectos actitudinales y estadísticamente significativa $(\mathrm{p}<0,05)$ en los aspectos físicos (véase tabla 5.53).

Tabla 5.53

Elementos que priorizan en su enseñanza y desempeño profesional los monitores de fitness en función del sexo $(N=631)$

\begin{tabular}{lcc} 
& \multicolumn{2}{c}{ SEXO } \\
\cline { 2 - 3 } \multicolumn{1}{c}{ ELEMENTOS } & HOMBRE & MUJER \\
\hline ASPECTOS TÉCNICOS & 4,5 & 4,4 \\
ASPECTOS TÁCTICOS & 3,3 & 3,1 \\
ASPECTOS F́́sICOS & $4,3^{* *}$ & $4,2^{* *}$ \\
ASPECTOS PSICOLÓGICOS & 4,4 & 4,4 \\
ASPECTOS ACTITUDINALES & $4,5^{*}$ & $4,5^{*}$ \\
ASPECTOS CONCEPTUALES & 4,1 & 3,9 \\
\hline
\end{tabular}

Nota. Los números se refieren a la media usando una escala de Likert de 5 puntos que varía de 1 a 5 . $*=\mathrm{p}<0,01 ; * *=\mathrm{p}<0,05 ; \Phi=0,193-0,334$. 
Analizando los elementos que priorizan en su enseñanza y desempeño profesional los monitores de fitness en función de la edad, los aspectos técnicos y actitudinales son los más importantes para todos los monitores de fitness, seguidos por los aspectos psicológicos, aspectos físicos, aspectos conceptuales $\mathrm{y}$, por último, los aspectos tácticos.

En general, todas las medias aumentan progresivamente con la edad, es decir, cuantos más años tienen los monitores de fitness más valoran los aspectos expuestos en la tabla al impartir sus clases, a excepción de los aspectos físicos, siendo los monitores de fitness de 45 años o mayores los que tienen las medias más bajas. En este análisis existe una relación moderada $(\Phi=0,304-0,482)$, estadísticamente muy significativa ( $\mathrm{p}<0,01$ en los aspectos actitudinales y conceptuales y estadísticamente significativa $(\mathrm{p}<0,05)$ en los aspectos físicos (véase tabla 5.54).

Tabla 5.54

Elementos que priorizan en su enseñanza y desempeño profesional los monitores de fitness en función de la edad $(N=631)$

\begin{tabular}{|c|c|c|c|}
\hline \multirow{2}{*}{ ELEMENTOS } & \multicolumn{3}{|c|}{ EDAD } \\
\hline & $16-29$ & $30-44$ & 45-70 \\
\hline ASPECTOS TÉCNICOS & 4,4 & 4,4 & 4,6 \\
\hline ASPECTOS TÁCTICOS & 3,1 & 3,2 & 3,6 \\
\hline ASPECTOS FÍSICOS & $4,2 * *$ & $4,3^{* *}$ & $4,1 * *$ \\
\hline ASPECTOS PSICOLÓGICOS & 4,3 & 4,4 & 4,5 \\
\hline ASPECTOS ACTITUDINALES & $4,4^{*}$ & $4,5^{*}$ & $4,6^{*}$ \\
\hline ASPECTOS CONCEPTUALES & $3,8^{*}$ & $4,0^{*}$ & $4,3 *$ \\
\hline
\end{tabular}

Nota. Los números se refieren a la media usando una escala de Likert de 5 puntos que varía de 1 a 5 $*=\mathrm{p}<0,01 ; * *=\mathrm{p}<0,05 ; \Phi=0,304-0,482$. 
En cuanto al nivel de estudios, los monitores universitarios priorizan los aspectos psicológicos y actitudinales $(X=4,5)$, los que tiene una formación profesional priorizan los aspectos actitudinales $(\mathrm{X}=4,4)$, los que han terminado la educación secundaria confieren mayor importancia a los aspectos psicológicos $(X=4,7)$ y los que tienen estudios primarios o menores prefieren enseñar los aspectos técnicos $(X=4,8)$. Por otro lado, todos los monitores de fitness, independientemente del nivel de estudios que posean, no priorizan los aspectos tácticos.

Si se hace un análisis por cada aspecto en relación al nivel de estudios, se observa que los titulados universitarios priorizan más los aspectos físicos $(X=4,2)$ y actitudinales $(X=4,5)$ que el resto de monitores. Sin embargo, los que han terminado la educación secundaria priorizan los aspectos psicológicos $(X=4,7)$, los aspectos actitudinales $(\mathrm{X}=4,5)$ y los aspectos conceptuales $(\mathrm{X}=4,1)$ por delante de sus compañeros y los que han terminado la educación primaria o menos prefieren enseñar más los aspectos técnicos $(\mathrm{X}=4,8)$, los aspectos tácticos $(\mathrm{X}=3,7)$ y los aspectos conceptuales $(X=4,1)$ que sus compañeros.

En este análisis existe una relación moderada $(\Phi=0,294-0,355)$, estadísticamente muy significativa $(\mathrm{p}<0,01)$ en los aspectos técnicos y estadísticamente significativa $(\mathrm{p}<0,05)$ en los aspectos tácticos y físicos (véase tabla 5.55). 
Tabla 5. 55

Elementos que priorizan en su enseñanza y desempeño profesional los monitores de fitness en función del nivel de estudios $(N=631)$

\begin{tabular}{|c|c|c|c|c|}
\hline \multirow[b]{2}{*}{ ELEMENTOS } & \multicolumn{4}{|c|}{ NIVEL DE ESTUDIOS } \\
\hline & $\begin{array}{c}\text { TITULADO } \\
\text { UNIVERSITARIO }\end{array}$ & $\begin{array}{c}\text { FORMACIÓN } \\
\text { PROFESIONAL }\end{array}$ & $\begin{array}{l}\text { EDUCACIÓN } \\
\text { SECUNDARIA }\end{array}$ & $\begin{array}{c}\text { EDUCACIÓN } \\
\text { PRIMARIA O } \\
\text { MENOR }\end{array}$ \\
\hline ASPECTOS TÉCNICOS & $4,3^{*}$ & $4,3^{*}$ & $4,6^{*}$ & $4,8^{*}$ \\
\hline ASPECTOS TÁCTICOS & $3,2 * *$ & $3,1 * *$ & $3,3 * *$ & $3,7 * *$ \\
\hline ASPECTOS FÍSICOS & $4,2 * *$ & $4,1 * *$ & $4,3^{* * *}$ & $4,1 * *$ \\
\hline ASPECTOS PSICOLÓGICOS & 4,5 & 4,3 & 4,7 & 4,3 \\
\hline ASPECTOS ACTITUDINALES & 4,5 & 4,4 & 4,5 & 4,3 \\
\hline ASPECTOS CONCEPTUALES & 3,9 & 4,0 & 4,1 & 4,1 \\
\hline
\end{tabular}

Nota. Los números se refieren a la media usando una escala de Likert de 5 puntos que varía de 1 a 5. $*=\mathrm{p}<0,01 ; * *=\mathrm{p}<0,05 ; \Phi=0,294-0,355$.

Teniendo en cuenta la experiencia laboral, según aumenta la experiencia de los monitores de fitness poseen medias superiores o iguales en todos los elementos que priorizan en su enseñanza e intervención profesional que los que tienen menos de diez años de experiencia, pero nunca inferiores. Siendo los aspectos actitudinales los preferidos por los monitores de fitness con menos de diez años de experiencia $(X=4,5)$ y los aspectos técnicos, psicológicos y actitudinales los preferidos por los monitores de fitness con más experiencia $(\mathrm{X}=4,5)$. Para ambos grupos los aspectos tácticos son los menos importantes $(\mathrm{X}=3,2)$.

En este análisis existe una relación baja $(\Phi=0,186$ - 0,199) y estadísticamente muy significativa $(\mathrm{p}<0,01)$ en los aspectos técnicos, físicos y actitudinales (véase tabla $5.56)$. 
Tabla 5.56

Elementos que priorizan en su enseñanza y desempeño profesional los monitores de fitness en función de la experiencia laboral $(N=631)$

\begin{tabular}{|c|c|c|}
\hline \multirow{2}{*}{ ELEMENTOS } & \multicolumn{2}{|c|}{ EXPERIENCIA LABORAL } \\
\hline & $<10$ AÑOS & $\geq 10$ AÑOS \\
\hline ASPECTOS TÉCNICOS & $4,4^{*}$ & 4,5 \\
\hline ASPECTOS TÁCTICOS & 3,2 & 3,2 \\
\hline ASPECTOS FÍSICOS & $4,2^{*}$ & 4,2 \\
\hline ASPECTOS PSICOLÓGICOS & 4,4 & 4,5 \\
\hline ASPECTOS ACTITUDINALES & $4,5^{*}$ & $4,5^{*}$ \\
\hline ASPECTOS CONCEPTUALES & 3,9 & 4,1 \\
\hline
\end{tabular}

Nota. Los números se refieren a la media usando una escala de Likert de 5 puntos que varía de 1 a 5. $*=\mathrm{p}<0,01 ; \Phi=0,186-0,199$.

\subsubsection{Fuentes de conocimiento}

La media, la desviación típica y la varianza para las diez fuentes de conocimiento se presentan en la tabla 5.57. Esta tabla resume los resultados correspondientes a las fuentes de conocimiento identificadas como las más importantes para el desarrollo de los conocimientos de los monitores de fitness. Los monitores de fitness puntuaron las fuentes de conocimiento en una escala de Likert que iba de 1 al 5 (siendo 1 nunca y 5 siempre).

La fuente de conocimiento más mencionada es los cursos recibidos, con una media de 4,2 en una escala de 5 puntos. A continuación, la segunda y tercera fuentes de conocimiento más importantes son el intercambio de información con otros profesionales $(X=4)$ y la observación a otros profesionales $(X=3,9)$. Los monitores de fitness consideran que la formación recibida en la titulación de mayor nivel y los 
recursos tecnológicos o internet son también muy importantes para su conocimiento, con una media de 3,4 y 3,3 respectivamente. Asimismo, estos profesionales también obtienen información de otras fuentes, tales como: su experiencia como alumno de educación física o usuario de actividades deportivas $(X=3)$, libros $(X=2,9)$, revistas científicas o técnicas $(X=2,5)$ y experiencia deportiva en competiciones federadas $(X=2,4)$.

Tabla 5. 57

Fuentes de conocimiento de los monitores de fitness, medias, deviaciones típicas y varianzas $(N=631)$

\begin{tabular}{lccc}
\hline \multicolumn{1}{c}{ FUENTES DE CONOCIMIENTO } & MEDIA & $\begin{array}{c}\text { DESVIACIÓN } \\
\text { TÍPICA }\end{array}$ & $\begin{array}{c}\text { VARIAN- } \\
\text { ZA }\end{array}$ \\
\hline EN LA EXPERIENCIA DEPORTIVA EN COMPETICIONES & 2,4 & 1,6 & 2,5 \\
EN LA EXPERIENCIA COMO ALUMNO EN EDUCACIÓN FÍSICA O & 3 & 1,4 & 2 \\
USUARIO EN ACTIVIDADES DEPORTIVAS & & & \\
EN LA FORMACIÓN QUE HA RECIBIDO EN LA TITULACIÓN DE & 3,4 & 1,6 & 2,6 \\
MAYOR NIVEL QUE POSEE & 4,2 & 1,1 & 1,2 \\
EN LOS CURSOS QUE HA RECIBIDO & 3,9 & 1,2 & 1,3 \\
EN LA OBSERVACIÓN A OTROS PROFESIONALES & & & 1,2 \\
EN EL INTERCAMBIO DE INFORMACIÓN CON OTROS & 4 & 1,1 & 2,1 \\
PROFESIONALES & 2,9 & 1,5 & 1,9 \\
EN LIBROS & 2,5 & 1,4 & 1,6 \\
EN REVISTAS CIENTÍFICAS Y/O TÉCNICAS & 3,3 & 1,3 & 2,4 \\
EN RECURSOS TECNOLÓGICOS O INTERNET & 2,4 & 1,6 & \\
EN SUS PROPIAS INVESTIGACIONES & & & \\
\hline
\end{tabular}

Nota. Los números se refieren a la media usando una escala de Likert de 5 puntos que varía de 1 a 5.

Al relacionar las fuentes de conocimiento con el sexo, se observa que por lo general los hombres suelen tener medias más elevadas que las mujeres. La fuente de conocimiento que más valoran los hombres y las mujeres son los cursos recibidos 
$\left(X_{\text {hombres }}=4,1 ; X_{\text {mujeres }}=4,2\right)$ y la que menos sus propias investigaciones $\left(X_{\text {hombres }}=2,5\right.$; $\left.\mathrm{X}_{\text {mujeres }}=2,2\right)$.

En general los hombres tienen medias más altas en la experiencia deportiva en competiciones federadas $\left(X=2,5 ; x^{2}=14278\right)$, en la experiencia como alumnos en educación física o usuario de actividades deportivas $\left(X=3,1 ; x^{2}=2505\right)$, en la formación que ha recibido en la titulación de mayor nivel $\left(X=3,5 ; x^{2}=4673\right)$, en el intercambio de información con otros profesionales $\left(X=4 ; x^{2}=7199\right)$, en los libros $\left(X=3 ; x^{2}=13998\right)$, en las revistas científicas o técnicas $\left(X=2,6 ; x^{2}=5241\right)$ y en sus propias investigaciones $\left(X=2,5 ; x^{2}=5715\right)$. Por otro lado las mujeres tienen más altas en los cursos que ha recibido $\left(X=4,2 ; x^{2}=7052\right)$, en la observación a otros profesionales $\left(X=4 ; x^{2}=7741\right)$ y en los recursos tecnológicos o internet $\left(X=3,4 ; x^{2}=10419\right)$. Con respecto a las fuentes de conocimiento y el sexo, phi varió entre 0.150 y 0.306 (nivel de bajo a moderado de relación) (véase tabla 5.58).

Tabla 5.58

Fuentes de conocimiento de los monitores de fitness en relación al sexo $(N=631)$

\begin{tabular}{lcc}
\hline \multicolumn{1}{c}{ FUENTES DE CONOCIMIENTO } & \multicolumn{2}{c}{ SEXO } \\
\cline { 2 - 3 } EN LA EXPERIENCIA DEPORTIVA EN COMPETICIONES FEDERADAS & HOMBRE & MUJER \\
EN LA EXPERIENCIA COMO ALUMNO EN EDUCACIÓN FÍSICA O & 2,5 & 2,2 \\
USUARIO EN ACTIVIDADES DEPORTIVAS & 3,1 & 2,7 \\
EN LA FORMACIÓN QUE HA RECIBIDO EN LA TITULACIÓN DE MAYOR & 3,5 & 3,4 \\
NIVEL QUE POSEE & 4,1 & 4,2 \\
EN LOS CURSOS QUE HA RECIBIDO & 3,8 & 4 \\
EN LA OBSERVACIÓN A OTROS PROFESIONALES & 4 & 3,9 \\
EN EL INTERCAMBIO DE INFORMACIÓN CON OTROS PROFESIONALES & 3 & 2,8 \\
EN LIBROS & 2,6 & 2,3 \\
EN REVISTAS CIENTÍFICAS Y/O TÉCNICAS & 3,2 & 3,4 \\
EN RECURSOS TECNOLÓGICOS O INTERNET & 2,5 & 2,2 \\
EN SUS PROPIAS INVESTIGACIONES & &
\end{tabular}

Nota. $\Phi=0,150-0,306$. 
$\mathrm{Al}$ analizar las fuentes de conocimiento que los monitores de fitness utilizan en función de su edad, se obtiene que todos, independientemente de la edad que tengan, prefieren utilizar como fuente de conocimiento los cursos que han recibido $\left(x^{2}=31186\right.$; $\mathrm{p}>0,05)$ y en último lugar destacan sus propias investigaciones $\left(\mathrm{x}^{2}=42379 ; \mathrm{p}>0,05\right)$. Asimismo los monitores de fitness de 45 años o mayores también utilizan la observación a otros profesionales $\left(X=4 ; x^{2}=37208 ; p>0,05\right)$ como fuente preferida de conocimiento.

En general los monitores de actividad física y deporte más jóvenes tienen medias más altas en la experiencia como alumno en educación física o usuario en actividades deportivas $\left(x=2,4 ; x^{2}=36576 ; p>0,05\right)$, en la formación que han recibido en la titulación de mayor nivel $\left(x=3,6 ; x^{2}=36184 ; p>0,05\right)$, en el intercambio de información con otros profesionales $\left(x=4 ; x^{2}=32946 ; p>0,05\right)$ y en los recursos tecnológicos o internet $(x=3,3$; $\left.x^{2}=50349 ; p>0,05\right)$. Los monitores de 30 a 44 años utilizan más que sus compañeros los conocimientos de los cursos que han recibido $\left(x=4,3 ; x^{2}=31186 ; p>0,05\right)$. Por último los monitores de fitness de 45 años o mayores tienen medias más elevadas en la experiencia deportiva en competiciones federadas $\left(x=2,7 ; x^{2}=43424 ; p>0,05\right)$, en la observación a otros profesionales $\left(x=4 ; x^{2}=37208 ; p>0,05\right)$, en las revistas científicas o técnicas $\left(x=2,6 ; x^{2}=42379 ; p>0,05\right)$ y en sus propias investigaciones $\left(x=2,5 ; x^{2}=37182 ; p>0,05\right)$.

Con respecto a las fuentes de conocimiento y la edad, phi varió entre 0.150 y 0.300 (nivel de bajo a moderado de relación) (véase tabla 5.59). 
Tabla 5. 59

Fuentes de conocimiento de los monitores de fitness en relación a la edad ( $N=631)$

\begin{tabular}{|c|c|c|c|}
\hline \multirow{2}{*}{ FUENTES DE CONOCIMIENTO } & \multicolumn{3}{|c|}{ EDAD } \\
\hline & 16-29 & 30-44 & 45-70 \\
\hline EN LA EXPERIENCIA DEPORTIVA EN COMPETICIONES FEDERADAS & 2,4 & 2,4 & 2,7 \\
\hline $\begin{array}{l}\text { EN LA EXPERIENCIA COMO ALUMNO EN EDUCACIÓN FÍSICA O } \\
\text { USUARIO EN ACTIVIDADES DEPORTIVAS }\end{array}$ & 3,2 & 3 & 2,6 \\
\hline $\begin{array}{l}\text { EN LA FORMACIÓN QUE HA RECIBIDO EN LA TITULACIÓN DE MAYOR } \\
\text { NIVEL QUE POSEE }\end{array}$ & 3,6 & 2,8 & 3 \\
\hline EN LOS CURSOS QUE HA RECIBIDO & 4,1 & 4,3 & 4 \\
\hline EN LA OBSERVACIÓN A OTROS PROFESIONALES & 3,9 & 3,9 & 4 \\
\hline EN EL INTERCAMBIO DE INFORMACIÓN CON OTROS PROFESIONALES & 4 & 3,7 & 3,9 \\
\hline EN LIBROS & 2,9 & 2,9 & 2,9 \\
\hline EN REVISTAS CIENTÍFICAS Y/O TÉCNICAS & 2,4 & 2,4 & 2,6 \\
\hline EN RECURSOS TECNOLÓGICOS O INTERNET & 3,3 & 3,2 & 2,8 \\
\hline EN SUS PROPIAS INVESTIGACIONES & 2,2 & 2,1 & 2,5 \\
\hline
\end{tabular}

Al analizar las fuentes de conocimiento de los monitores de fitness españoles en relación con el nivel de estudios (tabla 5.60), se puede observar que los monitores de fitness con un título universitario señalan la formación que han recibido en la titulación de mayor nivel como su fuente preferida de aprendizaje $\left(X=4 ; x^{2}=20069 ; p<0,01\right)$ al igual que el intercambio de información con otros profesionales $\left(X=4 ; x^{2}=22309\right.$; $\mathrm{p}<0,05)$. Por otro lado, los monitores de fitness con una formación profesional prefieren el intercambio de información con otros profesionales $\left(X=4,1 ; x^{2}=22309 ; \mathrm{p}<0,05\right)$. Aquellos que han cursado la educación secundaria y primaria o menos califican los cursos como la fuente de conocimiento que más utilizan $\left(X=4,1 ; x^{2}=21569 ; p>0,05\right)$. 
Por otro lado todos los monitores de fitness, independientemente del nivel de estudios, califican sus propias investigaciones como la fuente de conocimiento que menos utilizan $\left(\mathrm{x}^{2}=23009 ; \mathrm{p}>0,05\right)$.

En general, los monitores de fitness con niveles más altos de estudios reportaron usar todas las fuentes de conocimiento más que aquellos con niveles de estudios más bajos. Esto es especialmente cierto para las fuentes de información basadas en la evidencia, tales como la formación que ha recibido en la titulación de mayor nivel $\left(X=4 ; x^{2}=20069 ; \quad p<0,01\right), \quad$ los libros $\left(X=3,2 ; x^{2}=19744 ; p<0,01\right)$ y los recursos tecnológicos o internet $\left(X=3,4 ; x^{2}=17865 ; \mathrm{p}<0,05\right)$. La fuente de conocimiento que utilizaron menos estos monitores de fitness es la experiencia deportiva en competiciones federadas $\left(X=2,5 ; x^{2}=12248 ; p>0,05\right)$.

Con respecto a las fuentes de conocimiento y el nivel de educación, phi varió entre 0,256 y 0,498, teniendo una relación moderada (véase tabla 5.60). 
Tabla 5.60

Fuentes de conocimiento de los monitores de fitness en relación al nivel de estudios ( $N$ $=631)$

\begin{tabular}{|c|c|c|c|c|}
\hline \multirow[b]{2}{*}{ FUENTES DE CONOCIMIENTO } & \multicolumn{4}{|c|}{ NIVEL DE ESTUDIOS } \\
\hline & $\begin{array}{l}\text { TITULADO } \\
\text { UNIVER- } \\
\text { SITARIO }\end{array}$ & $\begin{array}{l}\text { FORMACIÓN } \\
\text { PROFESIONAL }\end{array}$ & $\begin{array}{l}\text { EDUCACIÓN } \\
\text { SECUNDARIA }\end{array}$ & $\begin{array}{c}\text { EDUCACIÓN } \\
\text { PRIMARIA O } \\
\text { MENOS }\end{array}$ \\
\hline $\begin{array}{l}\text { EN LA EXPERIENCIA DEPORTIVA EN } \\
\text { COMPETICIONES FEDERADAS }\end{array}$ & 2,5 & 2,5 & 2,3 & 2,1 \\
\hline $\begin{array}{l}\text { EN LA EXPERIENCIA COMO ALUMNO } \\
\text { EN EDUCACIÓN FÍSICA O USUARIO EN } \\
\text { ACTIVIDADES DEPORTIVAS }\end{array}$ & $3,2 * *$ & $3,1 * *$ & $2,8 * *$ & $2,9 * *$ \\
\hline $\begin{array}{l}\text { EN LA FORMACIÓN QUE HA RECIBIDO } \\
\text { EN LA TITULACIÓN DE MAYOR NIVEL } \\
\text { QUE POSEE }\end{array}$ & $4,0^{*}$ & $3,5^{*}$ & $2,7 *$ & $2,6^{*}$ \\
\hline EN LOS CURSOS QUE HA RECIBIDO & 4,2 & 4,2 & 4,1 & 4,1 \\
\hline $\begin{array}{l}\text { EN LA OBSERVACIÓN A OTROS } \\
\text { PROFESIONALES }\end{array}$ & $3,9 * *$ & $4,0 * *$ & $3,8 * *$ & $3,9 * *$ \\
\hline $\begin{array}{l}\text { EN EL INTERCAMBIO DE } \\
\text { INFORMACIÓN CON OTROS }\end{array}$ & 4,0 & 4,1 & 3,8 & 3,7 \\
\hline PROFESIONALES & & & & \\
\hline EN LIBROS & $3,2 *$ & $2,9 *$ & $2,8^{*}$ & $1,9 *$ \\
\hline $\begin{array}{l}\text { EN REVISTAS CIENTÍFICAS Y/O } \\
\text { TÉCNICAS }\end{array}$ & $2,6 * *$ & $2,6 * *$ & $2,3 * *$ & $2,1 * *$ \\
\hline $\begin{array}{l}\text { EN RECURSOS TECNOLÓGICOS O } \\
\text { INTERNET }\end{array}$ & $3,4 * *$ & $3,3 * *$ & $3,3 * *$ & $2,7 * *$ \\
\hline EN SUS PROPIAS INVESTIGACIONES & $2,6^{* *}$ & $2,5 * *$ & $2,2 * *$ & $1,8 * *$ \\
\hline
\end{tabular}


La tabla 5.61 ofrece una visión general de las fuentes de conocimiento de los monitores de fitness españoles en relación con la experiencia laboral. Los monitores con menos de diez años de experiencia prefieren utilizan como fuentes de conocimiento la experiencia como alumno en educación física o usuario de actividades deportivas $\left(X=3,1 ; x^{2}=7741 ; p>0,05\right)$ y los recursos tecnológicos o internet $\left(X=3,4 ; x^{2}=9474\right.$; p>0,05) en comparación con los monitores de fitness con diez años o más de experiencia. Por el contrario, los que tienen una mayor experiencia prefieren la fuentes de conocimiento que se basan en la experiencia deportiva en competiciones federadas $\left(X=2,6 ; x^{2}=6281 ; p>0,05\right)$, el intercambio de información con otros profesionales $(X=4$; $\left.x^{2}=6850 ; p>0,05\right)$, los libros $\left(X=3 ; x^{2}=6399 ; p>0,05\right)$, las revistas científicas o técnicas $\left(X=2,6 ; x^{2}=7987 ; p>0,05\right)$ y sus propias investigaciones $\left(X=2,6 ; x^{2}=11941 ; p<0,05\right)$.

El resultado más llamativo es que los monitores de fitness con diez años de experiencia o más consideran los cursos recibidos como una fuente bastante menos importante de conocimiento que los monitores de fitness que tenían menos de diez años de experiencia $\left(X=2,9\right.$ frente a $X=4,1$ respectivamente; $\left.x^{2}=8543 ; p>0,05\right)$.

Con respecto a las fuentes de conocimiento y la experiencia laboral, phi varió entre 0,208 y 0,347, teniendo una relación de baja a moderada (véase tabla 5.61). 
Tabla 5. 61

Fuentes de conocimiento de los monitores de fitness en relación a la satisfacción laboral $(N=631)$

\begin{tabular}{|c|c|c|}
\hline \multirow{2}{*}{ FUENTES DE CONOCIMIENTO } & \multicolumn{2}{|c|}{ EXPERIENCIA LABORAL } \\
\hline & $\begin{array}{l}\text { MENOS DE } 10 \\
\text { AÑOS }\end{array}$ & 10 AÑos O MÁS \\
\hline EN LA EXPERIENCIA DEPORTIVA EN COMPETICIONES FEDERADAS & 2,3 & 2,6 \\
\hline $\begin{array}{l}\text { EN LA EXPERIENCIA COMO ALUMNO EN EDUCACIÓN FÍSICA O } \\
\text { USUARIO EN ACTIVIDADES DEPORTIVAS }\end{array}$ & 3,1 & 2,9 \\
\hline EN LOS CURSOS QUE HA RECIBIDO & 4,1 & 2,9 \\
\hline EN LA OBSERVACIÓN A OTROS PROFESIONALES & 3,9 & 3,9 \\
\hline EN EL INTERCAMBIO DE INFORMACIÓN CON OTROS PROFESIONALES & 3,9 & 4,0 \\
\hline EN LIBROS & 2,9 & 3,0 \\
\hline EN REVISTAS CIENTÍFICAS Y/O TÉCNICAS & 2,4 & 2,6 \\
\hline EN RECURSOS TECNOLÓGICOS O INTERNET & 3,4 & 3,3 \\
\hline EN SUS PROPIAS INVESTIGACIONES & $2,3^{* *}$ & $2,6^{* *}$ \\
\hline
\end{tabular}

Nota. Los números se refieren a la media usando una escala de Likert de 5 puntos que varía de 1 a 5 . $* * p<0,05 ; \Phi=0,208$ y 0,347 .

\subsubsection{SATISFACCIÓN LABORAL DE LOS MONITORES DE FITNESS}

Los encuestados en esta investigación fueron 631 monitores de fitness de España que trabajaban en diferentes tipos de instalaciones (gimnasios, centros deportivos...) y diferentes tipos de organizaciones (entidades públicas, entidades deportivas privadas sin ánimo de lucro y empresas o entidades privadas con ánimo de lucro). De los 631 
monitores de fitness, 519 fueron seleccionados para observar la satisfacción laboral que poseían porque trabajaban para otras personas, mientras que 112 fueron rechazados, ya que eran autónomos.

Los monitores de fitness puntuaron la satisfacción laboral en una escala de Likert que iba de 1 al 5 (siendo 1 muy satisfechos y 5 nada satisfechos). La media y la desviación típica para las 15 facetas de la satisfacción en el trabajo se proporcionan en la tabla 5.62.

La mayoría de los monitores de fitness expresaron niveles de moderados a altos de satisfacción en el trabajo (3,9 de media en una escala de 5 puntos). Como se puede ver en la tabla 5.62, la mayor satisfacción en el trabajo que experimentan es con respecto a las relaciones con los compañeros, a la valoración de la importancia por parte de sus compañeros y por parte de los clientes de su profesión, a la actividad profesional desarrollada, al nivel de autonomía, al desempeño que debe alcanzar, a la valoración de la importancia por parte de su organización de su profesión y a la jornada laboral, vacaciones y permisos $(X=4,5 ; 4,4 ; 4,3 ; 4,3 ; 4,3 ; 4,2 ; 4,0$ y 4,0 respectivamente). La percepción de la remuneración económica, las oportunidades de formación ofrecidas por la organización y las oportunidades de promoción fueron los factores que reflejaron una menor satisfacción ( $\mathrm{X}=3,3 ; 3,2$ y 3,1 respectivamente). Además, percibían un nivel moderado de satisfacción con respecto a la valoración y el apoyo de sus superiores jerárquicos del trabajo que realizan, las condiciones ambientales generales y seguridad, estabilidad y organización del trabajo en su entidad $(\mathrm{X}=3,9 ; 3,8 ; 3,8$ y 3,7 respectivamente) (véase tabla 5.62). 
Tabla 5.62

Ítem, media y desviación típica de la satisfacción laboral de los monitores de fitness ( $N$ $=519)$

\begin{tabular}{|c|c|c|}
\hline ÍTEM & MEDIA & DS \\
\hline ORGANIZACIÓN DEL TRABAJO EN SU ENTIDAD & 3,7 & 1,0 \\
\hline OPORTUNIDADES DE PROMOCIÓN & 3,1 & 1,2 \\
\hline VALORACIÓN Y APOYO DE SUS SUPERIORES & 3,9 & 1,2 \\
\hline ACTIVIDAD PROFESIONAL DESARROLLADA & 4,3 & 0,9 \\
\hline DESEMPEÑO QUE DEBE ALCANZAR & 4,2 & 0,9 \\
\hline NIVEL DE AUTONOMÍA & 4,3 & 0,9 \\
\hline JORNADA LABORAL, VACACIONES, PERMISOS & 4,0 & 1,1 \\
\hline ESTABILIDAD & 3,8 & 1,1 \\
\hline CONDICIONES AMBIENTALES GENERALES Y DE SEGURIDAD & 3,8 & 1,0 \\
\hline REMUNERACIÓN ECONÓMICA & 3,3 & 1,1 \\
\hline OPORTUNIDADES DE FORMACIÓN QUE OFRECE LA ORGANIZACIÓN & 3,2 & 1,3 \\
\hline RELACIÓN CON LOS COMPAÑEROS & 4,5 & 0,8 \\
\hline $\begin{array}{l}\text { VALORACIÓN DE LA IMPORTANCIA POR PARTE DE LA ORGANIZACIÓN Y } \\
\text { DIRECTIVOS DE SU PROFESIÓN DE ACTIVIDAD FÍSICA Y DEPORTE }\end{array}$ & 4,0 & 1,1 \\
\hline $\begin{array}{l}\text { VALORACIÓN DE LA IMPORTANCIA POR PARTE DE LOS COMPAÑEROS DE } \\
\text { SU PROFESIÓN DE ACTIVIDAD FÍSICA Y DEPORTE }\end{array}$ & 4,4 & 0,9 \\
\hline VALORACIÓN DE LA IMPORTANCIA POR PARTE DE LOS & & \\
\hline CLIENTES/ALUMNOS/PADRES DE SU PROFESIÓN DE ACTIVIDAD FÍSICA Y & 4,3 & 0,8 \\
\hline
\end{tabular}

Nota. Los números se refieren a la media usando una escala de Likert de 5 puntos.

Según los resultados del estudio (ver tabla 5.63), hombres y mujeres reportaron el mismo nivel de satisfacción en el trabajo $\left(X_{\text {hombres }}=3,9, X_{\text {mujeres }}=3,9\right)$. La mayor satisfacción laboral la obtienen con respecto a las relaciones con los compañeros $\left(\mathrm{X}_{\text {hombres }}=4,5 ; \mathrm{X}_{\text {mujeres }}=4,4 ; \mathrm{x}^{2}=8,182 ; \mathrm{p}<0,05\right)$ y los niveles más bajos de 
satisfacción en el trabajo los obtienen con respecto a las oportunidades de promoción $\left(X_{\text {hombres }}=3,1 ; X_{\text {mujeres }}=3,1 ; x^{2}=8,576 ; p<0.05\right)$. Con respecto a la satisfacción laboral y el sexo, phi varió entre 0.500 y 0.650 (buen nivel de relación).

Tabla 5.63

Satisfacción laboral de los monitores de fitness en relación al sexo $(N=519)$

\begin{tabular}{|c|c|c|}
\hline \multirow{2}{*}{ ÍTEM } & \multicolumn{2}{|c|}{ SEXO } \\
\hline & HOMBRE & MUJER \\
\hline ORGANIZACIÓN DEL TRABAJO EN SU ENTIDAD & 3,7 & 3,7 \\
\hline OPORTUNIDADES DE PROMOCIÓN & 3,1 & 3,1 \\
\hline VALORACIÓN Y APOYO DE SUS SUPERIORES & 3,8 & 3,9 \\
\hline ACTIVIDAD PROFESIONAL DESARROLLADA & 4,3 & 4,3 \\
\hline DESEMPEÑO QUE DEBE ALCANZAR & 4,2 & 4,2 \\
\hline NIVEL DE AUTONOMÍA & 4,3 & 4,3 \\
\hline JORNADA LABORAL, VACACIONES, PERMISOS & 4,0 & 3,9 \\
\hline ESTABILIDAD & 3,9 & 3,7 \\
\hline CONDICIONES AMBIENTALES GENERALES Y DE SEGURIDAD & 3,8 & 3,9 \\
\hline REMUNERACIÓN ECONÓMICA & 3,3 & 3,3 \\
\hline OPORTUNIDADES DE FORMACIÓN QUE OFRECE LA ORGANIZACIÓN & 3,3 & 3,2 \\
\hline RELACIÓN CON LOS COMPAÑEROS & 4,5 & 4,4 \\
\hline $\begin{array}{l}\text { VALORACIÓN DE LA IMPORTANCIA POR PARTE DE LA ORGANIZACIÓN Y } \\
\text { DIRECTIVOS DE SU PROFESIÓN DE ACTIVIDAD FÍSICA Y DEPORTE }\end{array}$ & 4,0 & 4,1 \\
\hline $\begin{array}{l}\text { VALORACIÓN DE LA IMPORTANCIA POR PARTE DE LOS COMPAÑEROS DE SU } \\
\text { PROFESIÓN DE ACTIVIDAD FÍSICA Y DEPORTE }\end{array}$ & 4,4 & 4,3 \\
\hline VALORACIÓN DE LA IMPORTANCIA POR PARTE DE LOS & & \\
\hline $\begin{array}{l}\text { CLIENTES/ALUMNOS/PADRES DE SU PROFESIÓN DE ACTIVIDAD FÍSICA Y } \\
\text { DEPORTE }\end{array}$ & 4,4 & 4,3 \\
\hline TOTAL & 3,9 & 3,9 \\
\hline
\end{tabular}

Nota. Los números se refieren a la media usando una escala de Likert de 5 puntos. $\mathrm{p}<0.05 ; \Phi=0.500-0,650$. 
En cuanto a la edad, los monitores de fitness de 16 a 29 años experimentan mayores niveles de satisfacción total $(X=4,3)$. Los monitores de fitness de 45 años o mayores son los segundos $(X=4,1)$ y los de 30 a 44 experimentan los niveles más bajos de satisfacción laboral $(X=4,0)$. Si analizamos cada rango de edad, podemos ver, a diferencia de otros ítems, que hay mucha disparidad entre ellos. Los monitores de fitness de edades comprendidas entre los 16 y los 29 años están más satisfechos en general con todos los ítems a excepción de la organización del trabajo en su entorno $(X=4)$, las oportunidades de formación que ofrece la organización $(X=3,5)$ y la relación con los compañeros $(\mathrm{X}=4,5)$, para los cuales los monitores de 45 años o mayores tienen las mayores medias.

Los monitores de fitness de edades comprendidas entre los 16 y los 29 años están más satisfechos con la sensación de que su ocupación es valorada por sus compañeros y por sus clientes $(X=4,9$ y $X=4,9$ respectivamente $)\left(x^{2}=32,776 ; p>0,05\right.$ y $\mathrm{x}^{2}=28,380 ; \mathrm{p}>0,05$ respectivamente) $\mathrm{y}$ se mostraron menos satisfechos con las oportunidades de formación ofrecidas por su organización $(X=3,5)\left(x^{2}=50,006 ; p\right.$ $<0,05)$. La relación con los compañeros fue el ítem con el que los monitores de fitness entre 30 y 44 años y entre 45 y 70 años, experimentaron mayor satisfacción $\left(X_{30-44 \text { años }}=\right.$ $\left.4,5, \mathrm{X}_{45-70 \text { años }}=4,6\right)\left(\mathrm{x}^{2}=29,358 ; \mathrm{p}>0,05\right)$. Por el contrario, las oportunidades de promoción son el ítem donde experimentan el nivel más bajo de satisfacción en el trabajo $\left(\mathrm{X}_{30-44 \text { años }}=3,1, \mathrm{X}_{45-70 \text { años }}=3,1\right)\left(\mathrm{x}^{2}=30,123 ; \mathrm{p}>0,05\right)$. Además, los monitores de fitness de 45 años o mayores puntúan alto la actividad profesional desarrollada $(X=$ $4,6)\left(x^{2}=27,903 ; p>0,05\right)$.

En relación a la satisfacción en el trabajo y la edad, phi varió entre 0,060 y 0,353 (nivel de relación bajo y moderado) (véase tabla 5.64). 
Tabla 5.64

Satisfacción laboral de los monitores de fitness en relación a la edad $(N=519)$

\begin{tabular}{|c|c|c|c|}
\hline \multirow{2}{*}{ ÍTEM } & \multicolumn{3}{|c|}{ EDAD } \\
\hline & 16-29 & $30-44$ & $45-70$ \\
\hline ORGANIZACIÓN DEL TRABAJO EN SU ENTIDAD & 4,0 & 3,8 & 4,2 \\
\hline OPORTUNIDADES DE PROMOCIÓN & 3,8 & 3,1 & 3,1 \\
\hline VALORACIÓN Y APOYO DE SUS SUPERIORES & 4,3 & 3,9 & 4,0 \\
\hline ACTIVIDAD PROFESIONAL DESARROLLADA & 4,8 & 4,4 & 4,6 \\
\hline DESEMPEÑO QUE DEBE ALCANZAR & 4,6 & 4,2 & 4,5 \\
\hline NIVEL DE AUTONOMÍA & 4,8 & 4,3 & 4,5 \\
\hline JORNADA LABORAL, VACACIONES, PERMISOS & 4,4 & 4,1 & 4,2 \\
\hline ESTABILIDAD & 4,1 & 4,0 & 3,9 \\
\hline CONDICIONES AMBIENTALES GENERALES Y DE SEGURIDAD & 4,3 & 3,9 & 3,8 \\
\hline REMUNERACIÓN ECONÓMICA & 3,7 & 3,6 & 3,3 \\
\hline OPORTUNIDADES DE FORMACIÓN QUE OFRECE LA ORGANIZACIÓN & 3,5 & 3,3 & 3,6 \\
\hline RELACIÓN CON LOS COMPAÑEROS & 4,5 & 4,5 & 4,6 \\
\hline $\begin{array}{l}\text { VALORACIÓN DE LA IMPORTANCIA POR PARTE DE LA ORGANIZACIÓN Y } \\
\text { DIRECTIVOS DE SU PROFESIÓN DE ACTIVIDAD FÍSICA Y DEPORTE }\end{array}$ & 4,5 & 4,1 & 4,2 \\
\hline $\begin{array}{l}\text { VALORACIÓN DE LA IMPORTANCIA POR PARTE DE LOS COMPAÑEROS DE SU } \\
\text { PROFESIÓN DE ACTIVIDAD FÍSICA Y DEPORTE }\end{array}$ & 4,9 & 4,3 & 4,4 \\
\hline VALORACIÓN DE LA IMPORTANCIA POR PARTE DE LOS & & & \\
\hline CLIENTES/ALUMNOS/PADRES DE SU PROFESIÓN DE ACTIVIDAD FÍSICA Y & 4,9 & 4,4 & 4,4 \\
\hline DEPORTE & & & \\
\hline TOTAL & 4,3 & 4,0 & 4,1 \\
\hline
\end{tabular}

Nota. Los números se refieren a la media usando una escala de Likert de 5 puntos. $\Phi=0.060-0.353$. 

CAPÍTULO 6. DISCUSIÓN DE LOS RESULTADOS

\section{OBTENIDOS}





\section{CAPÍTULO 6. DISCUSIÓN DE LOS RESULTADOS OBTENIDOS}

En el presente capítulo se contrastan y comparan los resultados más relevantes obtenidos en esta investigación con la literatura relacionada con el objeto de estudio. Para poder contrastar y comparar los resultados obtenidos de una manera adecuada, va a ser necesario apoyarse en los estudios realizados en otras ocupaciones y funciones laborales de actividad física y deporte como la de entrenador deportivo o profesor de educación física, entre otras, ya que en ellas hay una mayor investigación realizada.

Este apartado se organiza en función de los objetivos de la investigación y siguiendo la distribución del capítulo dedicado a los resultados del estudio. De esta forma el presente capítulo se estructura en dos grandes grupos:

- Monitores de actividad física y deporte.

- Monitores de fitness.

Y dentro de cada grupo se expresan y comparan de forma detallada, los aspectos formativos (formación inicial general y formación permanente), la intervención docente y profesional (planificación, evaluación, los elementos que priorizan en la enseñanza y fuentes de conocimiento) y la satisfacción laboral que poseen primero los monitores de actividad física y deporte y después los monitores de fitness.

Además, todos los aspectos se analizan y comparan aisladamente y la formación permanente y la intervención docente y profesional en función de las variables sexo, edad, nivel de estudios y experiencia laboral. La satisfacción laboral se analiza y compara aisladamente y en función de las variables sexo y edad. 


\subsection{RECURSOS HUMANOS DE LA ACTIVIDAD FÍSICA Y DEPORTE QUE TRABAJAN COMO MONITORES DE ACTIVIDAD FÍSICA Y DEPORTE}

A continuación se van a discutir los resultados de la presente investigación sobre la formación general inicial, la formación permanente y la intervención docente y profesional de los monitores de actividad física y deporte, comparado y analizado en función de otros estudios y los dos últimos bloques en relación a las variables sexo, edad, nivel de estudios y experiencia laboral. Asimismo, se van a discutir los resultados de la satisfacción laboral de los monitores de actividad física y deporte en relación a las variables sexo y edad.

\subsubsection{FORMACIÓN GENERAL INICIAL Y PERMANENTE DE LOS MONITORES DE ACTIVIDAD FÍSICA Y DEPORTE}

En España el 38\% de los monitores de actividad física y deporte han estudiado una carrera universitaria y el $24,2 \%$ han estudiado formación profesional. Sin embargo el $35,7 \%$ solo han estudiado educación secundaria y el 2,1\% estudios primarios o inferiores. Siguiendo a Spencer (1999) el panorama estadounidense y canadiense es diferente al que nos podemos encontrar en España en la profesión de entrenador deportivo, ya que los entrenadores deportivos siempre han solido estar en posesión de una licenciatura. Asimismo, Gillentine y Hunt (2000) apuntan que casi todos los que trabajan en profesiones de actividad física y deporte tienen una carrera universitaria. De igual forma, en la investigación de Wethner y Trudel (2009) se manifiesta que el 93\% 
de los entrenadores tienen una licenciatura y solo el $7 \%$ no posee una titulación universitaria. Por el contrario, un estudio en el sur de California ha obtenido unos datos similares a los hallados en este estudio, demostrado que sólo el 3\% de los profesionales de la actividad física y deporte estaban en posesión de un máster, el $27 \%$ poseía una licenciatura y el $70 \%$ tenía algún estudio pero inferior a la licenciatura o ningún estudio (Malek et al., 2002). Igualmente, en el estudio de McInnis et al. (1997) se ha podido comprobar que sólo el $34 \%$ de los clubes tenían a todos los monitores con una licenciatura.

Aunque en el presente estudio solo se analiza la formación general inicial y no la específica de la actividad física y el deporte, parece apropiado hacer una reflexión sobre ésta. Siguiendo a Campos-Izquierdo (2016), el 38\% de las personas que trabajan en actividad física y deporte en España no posee ninguna de las diferentes titulaciones de actividad física y deporte, y éstos representan el grupo más numeroso. En el caso de los monitores de actividad física y deporte, en España, los que no tienen titulación de actividad física y deporte son el 29,8\% (Campos-Izquierdo, 2016). Anteriormente, el estudio realizado sobre la formación inicial de las personas que trabajaban en actividad física y deporte en España de Martínez del Castillo (1991) ya demostró que había una formación incial de actividad física y deporte deficiente, obteniéndose que el 36,7\% no tiene ninguna titulación de actividad física y deporte. A lo largo de los años se han ido exponiendo resultados similares en las distintas ocupaciones de actividad física y deporte demostrando que un alto porcentaje de profesionales del deporte trabajan en actividades físico-deportivas sin una formación inicial de actividad física y deporte adecuada (Campos-Izquierdo, 2005; 2016; Fraile, 1996; 2001; González-Rivera, 2008; Nuviala et al., 2007). Partiendo de este contexto se puede deducir que hay un alto porcentaje de monitores de actividad física y deporte en nuestro estudio que no cumplen 
con los requisitos de titulación en actividad física y deporte para acceder a la dicha ocupación.

Por otro lado, los monitores de actividad física y deporte que participaron en el presente estudio aseguran llevar a cabo una formación permanente escasa. Contrariamente a la afirmación de Vargas-Tonsing (2007) en la que se sostiene que los entrenadores se forman permanentemente, siendo este tipo de formación esencial y necesaria, el presente estudio demuestra que más de la mitad de los monitores de actividad física y deporte españoles no han llevado a cabo ninguna formación permanente en los últimos tres años. Las investigaciones de Martínez-Serrano (2007) y Campos-Izquierdo $(2005 ; 2016)$ mostraron, al contrario que los resultados del estudio que nos ocupa, que los profesionales de la actividad física y deporte que trabajan en general en todas las ocupaciones de actividad física y deporte, cada vez realizan más formación permanente.

Sin embargo, Erickson et al. (2007), tuvieron resultados similares a los del presente estudio, obteniendo que todos los entrenadores invierten solo una mínima cantidad de su tiempo en su formación permanente.

En la investigación que nos ocupa se obtiene también que la asistencia a cursos es la formación permanente que más realizan los monitores de actividad física y deporte, prevaleciendo sobre la asistencia a jornadas, la asistencia a congresos, la realización de postgrados no oficiales, la realización de másteres oficiales y la realización de grupos de trabajo, siendo estas tres últimas actividades minoritarias. Estos resultados van en la misma línea que los del estudio de Werthner y Trudel (2009), los cuales manifestaron que los cursos de formación son las situaciones de aprendizaje más comunes para los entrenadores, además después de realizarlos confían más en sus habilidades (Feltz et al. 1999). Por todo ello es muy importante que en la formación 
permanente de estos profesionales se favorezca la reflexión constante, las experiencias prácticas y la crítica constructiva (González-Rivera y campos-Izquierdo, 2014).

Respecto a las variables objeto de estudio, se observa que la formación permanente es más adecuada en aquellos monitores que poseen estudios superiores generales, siendo muy escasa en los demás profesionales que poseen estudios menores. Esta observación también se ha hallado en el estudio de Feu et al. (2012) en el cual se obtuvo diferencias entre las formación permanente de los entrenadores según sus estudios, siendo más adecuada y más completa en aquellos profesionales con mayor formación inicial. En la misma línea, Campos-Izquierdo (2016) también investigó que cuanto mayor es la formación inicial, la formación permanente es más amplia y diversa, por lo tanto se preocupan por la mejora y desarrollo constante de su desempeño profesional pretendiendo la excelencia (González-Rivera y Campos-Izquierdo, 2014).

La formación permanente en rasgos generales es bastante similar en ambos sexos, siendo ligeramente superior en los hombres. Tal y como sugirieron Misener y Danylchuk (2009) y Nash y Sproule (2011) aunque los hombres en sus estudios realicen más formación permanente que las mujeres, se necesita más investigación en este ámbito ya que el número de mujeres que trabajan en ocupaciones de actividad física y deporte está aumentando (González-Rivera, 2008; 2016). Si se analiza de una forma más detallada la formación permanente con respecto al sexo, encontramos que las mujeres realizan más cursos de formación, más másteres oficiales y más grupos de discusión. En cambio los hombres, son lo que mayores porcentajes muestran en asistencia a jornadas y a congresos y en realización de postgrados no oficiales.

Por último, al analizar las variables edad y experiencia laboral, se encuentran que los monitores de actividad física y deporte de 45 años o mayores son los que más se forman, siendo los que mayores porcentajes obtienen en todos los tipos de formación 
excepto en realización de grupos de trabajo, en la cual su participación es inexistente. Por lo tanto se puede inferir que la formación permanente aumenta progresivamente según aumenta la edad. Algo similar ocurre con la experiencia laboral, los monitores de actividad física y deporte que más experiencia tienen son los que más se forman, expresando porcentajes superiores en todos los tipos de formación. En esta línea y analizando la ocupación de entrenador deportivo, aquellos con una menor experiencia no se formaban permanentemente (Feu et al., 2012).

Otro tema de interés son las actividades de formación permanente propuestas u organizadas por las diversas organizaciones de actividad física y deporte para las que trabajan los monitores de este estudio. En esta investigación se analizaron las actividades organizadas para los trabajadores en los últimos 12 meses. Más del $80 \%$ de los entrevistados afirmaron que las entidades para las que trabajaban no organizaron ninguna actividad de formación permanente para ellos, estando este resultado en consonancia con la investigación de Nash y Sproule (2009). Esta podría ser una de las causas que justifique la escasa formación permanente de los monitores de actividad física y deporte españoles ya que los medios más frecuentes según Misener y Danylchuk (2009) para averiguar sobre un curso es a través de la organización deportiva. Al ser tan bajo el porcentaje de organizaciones que organizan actividades de formación en España, es más difícil que los monitores de actividad física y deporte realicen una adecuada formación permanente. Por lo cual, este resultado es un indicador de la necesidad de fomentar una formación de mayor calidad y más adaptada para satisfacer las necesidades específicas de los monitores de actividad física y deporte (Dorgo, 2009) y conseguir que la realización de formación permanente por parte de éstos en España aumente. Siguiendo a Sullivan et al. (2012), las organizaciones de actividad física y deporte deben fomentar la realización de los programas de formación 
ya que son una inversión en mejora de la eficacia del desempeño profesional y para la calidad del servicio de actividad física y deporte ofrecido y desarrollado. Además son una inversión en eficacia, compromiso, desarrollo personal, éxito organizativo, calidad y seguridad (Bayón, 2002). Este aumento puede ser a través de formación permanente interna por parte de las organizaciones de actividad física y deporte así como la colaboración público-privada para impulsar programas de formación permanente para esos profesionales (Campos-Izquierdo, 2010).

\subsubsection{INTERVENCIÓN DOCENTE Y PROFESIONAL DE LOS MONITORES DE ACTIVIDAD FÍSICA Y DEPORTE}

En este apartado se van a discutir los resultados obtenidos sobre la planificación, evaluación, elementos que priorizan en su enseñanza y desempeño profesional y fuentes de conocimiento de los monitores de actividad física y deporte. Todo ello comparado y analizado en función de otros estudios y en relación a las variables sexo, edad, nivel de estudios y experiencia laboral.

\subsubsection{Planificación}

Uno de los elementos fundamentales en la enseñanza de las actividades físicodeportivas es la realización de una planificación anual con la finalidad de que se plasmen, de una forma coherente, los planteamientos y elementos didácticos que se deseen desarrollar y, así, asegurar una reflexión sobre los factores más importantes que 
influirán en su labor docente y evitar que la intervención o acción educativa sea improvisada (Giménez y Sáenz-López, 2000; Viciana, 2002). Sin embargo, los resultados del estudio actual sugieren que los monitores de actividad física y deporte planifican poco ya que, en promedio, menos de la mitad de los monitores de actividad física y deporte (48\%) planifican sus clases. Este porcentaje es levemente inferior al obtenido por Saura (1996) y superior al obtenido por González-Rivera (2008). Al respecto, en el estudio de Saura (1996) se obtuvo que un 49,46\% de los entrenadores del deporte escolar manifestaban realizar una programación anual y en el de GonzálezRivera (2008) se manifestó que solo el 31,3\% de los monitores de actividades físicodeportivas extraescolares planifica sus sesiones. Asimismo, Delgado et al. (2002) observaron que muy pocos entrenadores realizan una planificación anual de su entrenamiento. Esto es contrario a lo que se ha observado en el estudio de Buceta (2004) en entrenadores. Según este autor, la planificación es una de las funciones más importantes del entrenador, ésta es un proceso continuo (Dorgo, 2009), y se tiene que revisar y modificar en respuesta a factores relacionados con la práctica, los clientes, el profesional de la actividad física y deporte y su intervención profesional o el contexto (Dorgo, 2009, Feu et al., 2007). Los mismos resultados fueron obtenidos por Nash et al. (2011), quienes expusieron que es vital que los entrenadores adopten una planificación a largo plazo en todos los aspectos de su práctica. En la misma línea, Vallé y Bloom (2005) encontraron que los entrenadores expertos siempre elaboraban un plan completo para la temporada. Y siguiendo a Pereira (2002), el 76,2\% de los maestros especialistas de educación física planifican sus clases.

Una explicación posible de nuestros resultados es que el monitor de actividad física y deporte en España está en cierta manera infravalorado y muchos de los profesionales que trabajan como monitor de actividad física y deporte no son 
conscientes de la importancia que tiene esta ocupación y, como tal, su intervención profesional (Viciana, 2002). Además y debido a que muchos de ellos no tienen una formación inicial específica y adecuada de actividad física y deporte como muestra Campos-Izquierdo (2016) y que no están acorde a la profesión que desempeñan, como dictan las diferentes leyes de las comunidades autónomas que ordenan el ejercicio de las profesiones del deporte, pueden no ser capaces de llevar a cabo una adecuada intervención docente y profesional (González-Rivera y Campos-Izquierdo, 2010). Todo ello parece evidenciar falta de profesionalidad y eso conlleva a que el $52 \%$ de los monitores de actividad física y deporte de este estudio no planifiquen su intervención docente y profesional en el servicio de actividad física y deporte que desarrollan. Otra posible causa para este porcentaje tan bajo de planificación puede ser que las organizaciones para las que trabajan no les exigen que planifiquen y por ello no lo hacen. En esta línea González-Rivera (2008) aseguró que solo el 22\% de las organizaciones para las que trabajan los monitores de actividades físico-deportivas extraescolares exigen a sus monitores tener una planificación. Asimismo, otras causas pueden ser: porque no la necesitan, porque no saben realizarla o porque creen que lo importante son las actividades del día a día (González-Rivera, 2008).

Si analizamos las diferentes variables objeto de estudio, observamos que los hombres y las mujeres otorgan casi la misma importancia a la planificación, planificando un poco más los monitores de actividad física y deporte varones que las mujeres. Estos datos concuerdan con los obtenidos por Côté y Samela (1996), ya que concluyen su investigación sosteniendo que los entrenadores masculinos y los femeninos planifican de forma muy similar. Por el contrario, Ikonomopoulos el at. (2001) afirmaron que la variable sexo no afecta a la planificación. En cuanto a la edad, los monitores de 45 años o mayores son los que más planifican, seguidos por los de $30 \mathrm{y}$ 
44 años y finalmente los de 16 y 29 años. Además, la planificación aumenta según aumenta la experiencia laboral. Con base en estos resultados, los monitores de actividad física y deporte con más edad y más experiencia en la ocupación elaboran planificaciones más completas para la temporada, ya que necesitan planificar para hacer un trabajo mejor, lo que concuerda con lo obtenido por Vallée y Bloom (2005). Además como muestran Dejardins (1996) y Dorgo (2009) los entrenadores con más experiencia tienen en cuenta más variables dentro de sus planificaciones y las llevan a cabo de una forma continua. En cuanto a la formación inicial general, los monitores de actividad física y deporte con un título universitario son los que más planifican, constatándose que según aumenta la formación inicial general aumenta la planificación. Asimismo el estudio de Hall y Smith (2006) coincide con que los profesores de educación física con más experiencia laboral y mayores estudios son más eficientes y desarrollan mejor el proceso de planificación. Al igual que lo obtenido por Ikonomopoulos el at. (2001) quienes afirmaron que la experiencia y la formación influyen positivamente en la planificación y por Vallée y Bloom (2005) quienes observaron que las planificaciones más completan se llevan a cabo por los entrenadores más experimentados y como mayor formación. Por otro lado, también se observa en este estudio que cuanto menor es el nivel de estudios que poseen los monitores de actividad física y deporte, menor es la planificación que desarrollan (González-Rivera, 2008), constatando con este punto la necesidad de una formación inicial de actividad física y deporte acorde a la ocupación de actividad física y deporte que se va a desempeñar para realizar una adecuada intervención docente y profesional (González-Rivera y Campos-Izquierdo, 2010). 


\subsubsection{Evaluación}

La evaluación es otro paso esencial en la enseñanza de la actividad física y deporte. Es considerada como uno de los papeles primarios del entrenador deportivo y de cualquier profesional de la actividad física y deporte (Kidman y Harahan, 2011) y uno de los aspectos más críticos implicados en el establecimiento de la calidad educativa y de la intervención docente y profesional (Derri et al., 2012). En esta investigación una mayoría de los monitores de actividad física y deporte $(58,2 \%)$ asegura evaluar, entendiendo la necesidad que tiene este aspecto para desarrollar bien su trabajo. De los monitores que sí evalúan, un 57,6\% afirma hacerlo regularmente, mientras que un 42,4\% evalúa pero no regularmente. Como asegura Sáenz- López, (2006), es fundamental que la evaluación se realice regularmente para valorar los aspectos motores, cognoscitivos y socio-afectivos de los deportistas. Además, siguiendo a Cushion et al. (2013), es necesario que los procedimientos y resultados, así como la intervención docente y profesional, sean constantemente revisados y evaluados. De la misma forma, autores como Gould et al., (1999), Pérez (2002) y Vallée y Bloom (2005) encontraron en sus estudios que la mayoría de los entrenadores deportivos evalúa, siendo uno de los aspectos que consideran más importantes.

Los resultados de este estudio son superiores a los obtenidos por GonzálezRivera (2008) donde investigó que la mayoría del profesorado de actividades físicodeportivas extraescolares $(69,7 \%)$ aseguraba no realizar ninguna evaluación convirtiéndose en el elemento curricular más descuidado y olvidado en sus programaciones anuales y por González-Rivera y Campos-Izquierdo (2011) donde encontraron que el $60,7 \%$ de los docentes aseguran no evaluar. En este aspecto parece que se evoluciona positivamente a lo largo de los años, viéndose una ligera progresión y 
aumento en cuanto a la evaluación que llevan a cabo los profesionales de la actividad física y deporte.

Analizando las variables objeto de estudio, los monitores de actividad física y deporte varones priorizan la evaluación más que las mujeres. Este resultado es contrario a la bibliografía existente. Derri et al. (2012) investigaron que las profesoras de educación física saben mejor cómo evaluar a los estudiantes comparándolas con sus compañeros varones. Del mismo modo, Papatheofilou et al. (2008) encontraron que las percepciones de las profesoras sobre sus prácticas en la evaluación son más altas que las de sus colegas masculinos. En cuanto a la edad, los monitores de actividad física y deporte de 30 a 44 años son los que más evalúan seguidos por los de 44 a 70 años y en último lugar, con unos porcentajes mucho menores, los de 16 a 29 años, igualmente los monitores de actividad física y deporte mayores de 30 años evalúan más regularmente. Centrándonos en el nivel de estudios, los monitores de actividad física y deporte que más evalúan son aquellos con un título universitario, lo que concuerda con lo obtenido por Ikonomopoulos et al. (2001). Asimismo, Pestana (2006) unos años antes ya investigó, en referencia a la formación específica de actividad física y deporte, que los entrenadores con una licenciatura en Ciencias de la Actividad Física y del Deporte evalúan más que los que no tienen esta licenciatura. Este hecho vuelve a constatar la necesidad de una adecuada formación inicial específica en actividad física y deporte en el desempeño profesional de la actividad física y deporte. Por último y teniendo en cuenta la experiencia laboral, los trabajadores que tienen más experiencia laboral evalúan más. Este resultado apoya lo que reveló el estudio de Gilber y Trudel (2001) donde los profesionales más experimentados desarrollan más estrategias de evaluación a través de procesos de reflexión y experimentación. 
En consecuencia, estos resultados determinan que la evaluación es clave en la enseñanza de la actividad física y deporte y en la intervención docente y profesional de los monitores de actividad física y deporte.

Debido a la amplia gama de conductas y comportamientos que pueden ser evaluados en la actividad física y deporte, se han generado una variedad de herramientas de evaluación (Díaz Lucea, 2005). Una buena evaluación formativa y educativa en general ha de utilizar instrumentos que permitan esta toma de decisiones para una correcta regulación (Díaz Lucea, 2005). Entre las herramientas de evaluación más utilizadas por los monitores que realizan evaluación, predomina la observación diaria. Apoyando este punto, los autores Cregan et al. (2007) investigaron que los entrenadores son como analizadores; observan aspectos de sus deportistas y deciden mejorar su desempeño. Esto también es apoyado por Kidman y Hanrahan (2011), quienes estudiaron que la observación debe ser considerada uno de los papeles principales del entrenador. Asimismo, Díaz Lucea (2005) sostiene que este tipo de instrumento de evaluación se está generalizando mucho también en la educación física escolar. La segunda herramienta más utilizada son las pruebas de ejecución, esta herramienta es destacada por Díaz Lucea (2005), ya que ha sido la más utilizada por los profesores de educación física y por González-Rivera (2008), siendo la más utilizada por los monitores de actividades físico-deportivas extraescolares.

Otras herramientas de evaluación que los monitores de actividad física y deporte usan con frecuencia son las baterías de test/tests estandarizadas, al igual que se obtuvo en el estudio de González-Rivera (2008). Por consiguiente, y debido a que estas dos últimas herramientas de evaluación tratan de realizar una evaluación lo más objetiva posible (Díaz Lucea, 2005), se indica que la mayoría los monitores utilizan los instrumentos de evaluación como un fin cuantitativo o tipológico donde se miden los 
resultados de ejecución de sus alumnos/as, lo que también denota que el profesorado orienta su enseñanza a una forma más competitiva (Díaz Lucea, 2005; González-Rivera, 2008). Por otro lado, las herramientas de evaluación que utilizan en menor medida los monitores de actividad física y deporte son los exámenes de conocimientos teóricos y el diario. Al igual que en el estudio de González-Rivera (2008) los diarios del profesor en los que se anotan las características más relevantes del alumnado y los exámenes teóricos fueron las dos herramientas menos usadas. Esto indica que un escaso porcentaje de los monitores tiene en cuenta los aspectos cualitativos (González-Rivera, 2008) y que posiblemente, estas herramientas de evaluación no midan con precisión las habilidades y cualidades de los deportistas si no que sirven sobre todo para registrar de manera sistemática las vivencias y percepciones de una clase o de una actividad (Díaz Lucea, 2005).

\subsubsection{Elementos que priorizan en su enseñanza y desempeño profesional}

De manera similar, es necesario discutir los aspectos de intervención profesional en una sesión incluidos en el estudio. Los aspectos actitudinales son los más importantes para los monitores de actividad física y deporte. Estos hallazgos son consistentes con el trabajo de Lubanski (2008), quien manifestó que todos los entrenadores son responsables de mantener, animar y enseñar el interés, la actitud y la disciplina, tres aspectos muy importantes que llevarán al éxito general del grupo. Además de la higiene y los hábitos saludables.

El segundo aspecto más importante para los monitores de actividad física y del deporte es el psicológico. Hay muchos autores que piensan que el desarrollo psicológico 
de los deportistas es un objetivo primordial para los entrenadores (Côté, Bruner, Erickson, Strachar y Fraser Thomas, 2010; Grobbelaar, 2007; Paquette y Sullivan, 2012) y enfatizan la importancia de integrar la psicología en los entrenamientos (Côté y Gilbert, 2009; Fraser-Thomas y Côté, 2009).

El tercer aspecto más valorado por los monitores de actividad física y deporte del presente estudio es la técnica. Es importante enseñar los aspectos técnicos (DurandBush y Samela, 1996), aunque este autor pone de manifiesto que no son los únicos ni los primeros, ya que los entrenadores están a favor de una formación integral (Bloom et al, 1999; Pérez, 2002). Estos resultados son consistentes con los de Carreras y Giménez (2010) que revelaron que la técnica es el factor más importante para los instructores de tenis.

En los últimos puestos, los monitores de actividad física y deporte han valorado los aspectos conceptuales, los aspectos físicos y en último lugar los aspectos tácticos. Este último resultado da lugar a bastante discusión ya que hay profesionales que creen que la táctica es muy importante y otros que no lo es tanto. Dentro de grupo de los investigadores que están a favor de los aspectos tácticos, encontramos a Bloom et al. (1999) los cuales expusieron que las instrucciones tácticas son las más importantes, sobre todo en los entrenadores de alto nivel; a Leite et al. (2009), quienes sostienen que el trabajo táctico debería ser desarrollado entre los 11 y los 14 años y después de los 19 años y a Fuentes y Gusi (1996) quienes afirman que el modelo metodológico más representativo de la enseñanza es el táctico. Dentro del segundo grupo, donde la técnica es más importante que la táctica, estaría el estudio de González-Rivera (2008) en el cual se obtiene que la enseñanza de la técnica prevalece sobre la táctica y el de Yagüe (1998) donde se aprecia que los entrenadores utilizan un modelo de enseñanza predominantemente técnico en detrimento de la táctica. 
Para finalizar este apartado, se ha demostrado que las variables objeto de estudio de los monitores de actividad física y deporte (sexo, edad, nivel de estudios y experiencia laboral) no influyen en los resultados para desarrollar las habilidades o aspectos de intervención en una sesión, ya que la importancia que otorgan los monitores de actividad física y deporte a cada uno de los aspectos es muy similar, no encontrando diferencias significativas en ellos. Por ejemplo, dentro del sexo, los hombres en general tienen medias en todos los aspectos ligeramente superiores o iguales que las mujeres. Igualmente, la importancia de casi todos los aspectos que priorizan para su enseñanza los monitores de actividad física y deporte aumentan con la edad y con la experiencia. En cuanto al nivel de estudios iniciales generales, los monitores de actividad física y deporte con una licenciatura tienen medias más elevadas en los aspectos psicológicos y actitudinales y aquellos con la educación primaria o menos en los aspectos técnicos, tácticos y físicos.

\subsubsection{Fuentes de conocimiento}

Los resultados de este estudio indicaron que la educación formal es sólo una de las muchas oportunidades para mejorar la intervención docente y profesional de los monitores de actividad física y deporte, ya que las tres fuentes principales de conocimiento en las que se apoyan los monitores de actividad física y deporte para la preparación de sus clases son tanto formales, no formales como informales. Las fuentes de conocimiento utilizadas con mayor frecuencia son los cursos de formación recibidos, el intercambio de información con otros profesionales y la observación a otros profesionales. 
El hallazgo de que los monitores de actividad física y deporte con mayor frecuencia realicen los cursos de formación como su fuente más importante de conocimiento es consistente con los estudios previos en entrenadores. Lemyre et al. (2007) encontraron que los entrenadores deportivos de deportistas juveniles suelen usar la información de los cursos y Wright et al. (2007) informaron de que los entrenadores usan los cursos para elaborar sus clases, utilizándolos frecuentemente. Sin embargo, este hallazgo parece contrastar con la investigación de Nash y Sproule (2009) quienes sostienen que los cursos en su forma actual no permiten a los entrenadores satisfacer sus necesidades, por ello los entrenadores no los tienen en cuenta para sus entrenamientos. Los resultados del presente estudio también muestran que los monitores de actividad física y deporte adquieren su conocimiento a través de fuentes informales como el intercambio de información con compañeros y la observación a otros profesionales. Estos hallazgos atribuyen apoyo a otros estudios en los que los métodos de aprendizaje informal son los preferidos para los entrenadores (González-Rivera et al., 2017; Wright et al., 2007). El papel de los compañeros y mentores es central también en el proceso de aprendizaje del estudio de Wright et al. (2007). Asimismo, el intercambio de información con otros profesionales es una fuente muy importante de conocimiento y se ha encontrado que se valora positivamente en otros estudios (Erickson et al., 2008). Además, las observaciones de otras sesiones de entrenamiento pueden proporcionar una mayor comprensión del juego y ayudar a aprender a interactuar con sus deportistas. Más específicamente, pueden aprender qué hacer y qué no hacer con los errores observados (González-Rivera et al., 2017).

La cuarta fuente de conocimiento en la que se basan para el desarrollo de su ocupación es la formación que reciben de las titulaciones actividad física y deporte de 
mayor nivel. Esto parece ser común en los entrenadores, especialmente en los entrenadores de categorías juveniles (Erickson et al., 2008; Feu et al., 2012).

Igualmente, internet es otra fuente importante de conocimiento porque les ayuda a adquirir nuevas ideas para mejorar sus prácticas e interactuar con sus clientes y compañeros (Wright et al., 2007). Varios estudios previos han destacado el hecho de que los entrenadores están otorgando más consideración a internet como una estrategia importante para resolver problemas específicos y del día a día (Erickson et al., 2008). Asimismo, Juan-Llamas (2015) expresó internet se utiliza frecuentemente $(87,4 \%)$.

Después, los monitores de actividad física y deporte eligieron sus experiencias en competencias federadas, sus experiencias como estudiante de educación física o usuarios de actividades deportivas y los libros. Estos hallazgos no van en la misma línea que la literatura anterior. Feu et al. (2012), contrariamente, observaron que la experiencia como jugador se convierte en la principal fuente de conocimiento, especialmente en los primeros años. También en el estudio de González-Rivera et al. (2017) se expone que las experiencias como deportistas son la tercera fuente de conocimiento más importante para los entrenadores deportivos. Tal vez, una posible explicación de estos resultados es que la ocupación objeto de estudio no es tan competitiva y por lo tanto los monitores no se basan tanto en sus propias experiencias. Wright et al. (2007), por otro lado y contrariamente a esta investigación, encontraron que los entrenadores adquirieron una variedad de información a través de libros.

Finalmente, sus propias investigaciones y las revistas científicas o técnicas son la fuente de conocimiento menos utilizadas. Estas dos fuentes de conocimiento son más especializadas y a veces difíciles de obtener. Además y volviendo al principio de esta discusión, para poder obtener conocimiento de estas dos fuentes es necesario poseer una adecuada titulación de actividad física y deporte. Como solución a este problema se 
propone que se organicen cursos de formación relacionados con la búsqueda de artículos en revistas científicas y el fomento de la investigación básica (GonzálezRivera et al., 2017).

Aunque las tres fuentes de conocimiento que hemos expuesto al principio fueron las más usadas por todos los monitores de actividad física y deporte en el presente estudio de investigación, hubo diferencias en su orden de frecuencia cuando se consideraron las variables nivel de estudios y experiencia laboral, sexo y edad. Los monitores de actividad física y deporte universitarios utilizan fuentes de conocimiento más basadas en evidencias. Estos resultados son similares a los de Feu et al. (2012) en entrenadores, los cuales afirman que cuanto más formados están los profesionales de actividad física y deporte, más utilizan las fuentes formales de conocimiento para adquirir un conocimiento más complejo y superior. Por otro lado, los monitores de actividad física y deporte con educación primaria o inferior prefieren utilizar su experiencia deportiva en competencias federadas, su experiencia como estudiante de educación física o deportista y las observaciones e interacciones con otros profesionales.

También se encontró una diferencia significativa con la variable experiencia laboral. Los monitores de actividad física y deporte más experimentados utilizan todas las fuentes de conocimiento en mayor medida, excepto su experiencia como estudiante de educación física o usuario de actividades deportivas que es utilizada igual por ambos grupos y la observación a otros profesionales que la emplean en menor medida que aquellos monitores de actividad física y deporte con menos experiencia. Feu y col. (2012) apoya estos resultados, asegurando que los entrenadores con poca experiencia utilizan principalmente sus experiencias como jugador en sus primeras etapas de entrenamiento. 
Siguiendo con la variable sexo, se observa que, los hombre en general tienen medias más elevadas en todas las fuentes de conocimiento que las mujeres. Los monitores de actividad física y deporte varones valoran más el intercambio de información con otros profesionales y las mujeres los cursos de formación. Ambos grupos valoran las revistas científicas o técnicas en último lugar. Esto refleja los resultados del estudio de González-Rivera et al. (2017), en el cual se obtuvo que los entrenadores varones prefieren intercambiar información con otros profesionales y que la fuente de conocimiento que menos utilizan son las revistas científicas o técnicas. Igualmente al estudio de González-Rivera et al. (2017), las mujeres manifiestan usar más las fuentes de conocimiento formales que los hombres.

En cuanto a la edad, los monitores de actividad física y deporte de 16 a 29 y de 45 años o más prefieren el intercambio de información con otros profesionales y los de 30 a 44 años los cursos de formación. Igualmente, los tres grupos de edad no utilizan o utilizan mínimamente las revistas científicas o técnicas.

\subsubsection{SATISFACCIÓN LABORAL DE LOS MONITORES DE ACTIVIDAD FÍSICA Y DEPORTE}

La mayoría de los monitores de actividad física y deporte expresaron niveles de moderados a altos de satisfacción en el trabajo, lo cual es positivo, ya que si están satisfechos van a dar una imagen positiva de su organización deportiva e impartirán mejores las clases (Li, 1993). Este es el hallazgo constante que se ha observado en estudios relacionados con la satisfacción laboral en el campo de la actividad física y deporte (Chelladurai y Ogasawara, 2003; Koehler, 1988; Koustelios et al., 2003). 
En general, la relación con los compañeros y la valoración de la importancia por parte de sus compañeros y de sus clientes de su profesión de actividad física y deporte son los dos factores que les proporcionan más satisfacción laboral a los monitores de actividad física y deporte de este estudio. Oshagbemi (1997) investigó en la misma línea sobre la satisfacción laboral en educadores y demostró que el comportamiento de los compañeros de trabajo, la simpatía y la amistad y la colaboración con los colegas día a día juegan un papel muy importante en la satisfacción laboral. En base a los resultados obtenidos en este estudio, es fundamental que los monitores de actividad física y deporte tengan buenas relaciones interpersonales, ya que podría reducir el conflicto interno y mejorar la satisfacción en el trabajo (Herzberg et al., 1959; Lawer y Porter, 1967; Robbins, 2004; Singh y Surujlal, 2006). La camaradería y el sentido de comunidad, y en relación con ello la cultura organizativa, pueden ser un factor distintivo entre aquellos que se perciben a sí mismos trabajando en un buen trabajo de aquellos que se identifican trabajando en un gran trabajo (Dixon y Warner, 2010).

Los monitores de actividad física y deporte también expresaron niveles altos de satisfacción laboral con respecto al nivel de autonomía y la actividad profesional desarrollada. Los mismos resultados fueron obtenidos por Koustelios et al. (2003) el cual encontró que los profesores también están satisfechos con el trabajo en sí mismo y por Chelladurai y Ogasawara (2003) los cuales observaron que los entrenadores reportaron los niveles más altos de satisfacción laboral con respecto a elementos intrínsecos, como el trabajo en sí y la autonomía. Por su parte, Li (1985) también afirmó que el sentido de responsabilidad que los profesores perciben de su trabajo es importante para su satisfacción laboral.

Asimismo, los monitores de actividad física y deporte también sienten satisfacción en el trabajo debido a la valoración de la importancia por parte de la 
organización y directivos de su profesión, con el desempeño que deben alcanzar y con la jornada laboral, vacaciones y permisos. Estos resultados van acorde con lo investigado por Herzberg et al. (1959), Lawler y Porter (1967), Oshagbemi (1997) y Puchol (1997).

Al examinar los aspectos con los que los monitores de actividad física y del deporte experimentan una moderada satisfacción laboral nos encontramos con las oportunidades de formación ofrecidas por la organización. Este fue también un factor de preocupación en la investigación realizada por Moodley y Coopoo (2006) en la que los entrenadores personales y los monitores de fitness expresaron insatisfacción al no tener oportunidades de formación que les hicieran mejorar sus habilidades existentes. Por su parte, Gerber, Nel y Van Dyk (1998) sostienen que proporcionando a los trabajadores formación se mejora su competencia y autoconfianza (Gerber et al., 1998). Asimismo, Locke (1976) defiende que las oportunidades de aprendizaje y las oportunidades de formación están asociadas a la satisfacción laboral teniendo una relación directamente proporcional.

En este estudio, los niveles bajos de satisfacción laboral también se relacionan con la remuneración financiera. El salario es un determinante clave de la satisfacción laboral, habiendo muchos estudios que encontraron que es un factor que disminuye la satisfacción laboral de los empleados (Barrett et al., 2002; Moodley y Coopoo, 2006). Apoyando los hallazgos sobre la insatisfacción laboral entre los monitores de actividad física y deporte, Barrett et al. (2002) investigaron que los entrenadores que ganan 50,000 dólares o más están casi un 15\% más satisfechos que aquellos que ganan 49,999 dólares o menos. Smucker y Kent (2004), indican que los bajos niveles de satisfacción en el trabajo van acompañados de bajos salarios, falta de promoción y condiciones de trabajo negativas. Estos hallazgos son similares a los reportados por Chelladurai y 
Ogasawara (2003), Howell y Higgins (2005), Sánchez-Alcaraz y Parra-Meroño (2012) y Singh y Surujlal (2006).

Por último, los monitores de actividad física y del deporte expresan los niveles más bajos de satisfacción laboral con respecto a las oportunidades de promoción dentro de su organización. Del mismo modo, Puchol (1997) encontró este elemento como insatisfactorio. La falta de oportunidades de promoción conduce a tener sentimientos negativos, a trabajar peor y a la insatisfacción general. Estos sentimientos negativos surgen cuando los empleados no son promocionados cuando se consideran aptos para ello (Smucker y Kent, 2004).

A pesar de que no hubo una diferencia significativa entre la variable sexo, en esta investigación las mujeres experimentan ligeramente menores niveles de satisfacción laboral que los varones. Esto podría atribuirse a que las mujeres se sienten menos valoradas o porque sus salarios son generalmente más bajos que los de los varones (González-Rivera, 2008). Similar a estos resultados, Howell y Higgins (2005) en su estudio sobre directores del deporte americanos y canadienses empleados en programas de actividad física y deporte recreativos encontraron que los hombres mostraban mayores niveles de satisfacción laboral. En cuanto a la edad los monitores de actividad física y deporte más satisfechos son los de 45 años en adelante, por lo que se puede concluir que la satisfacción laboral es proporcional a la edad. Los resultados de Davis y Newstrom (1999) y Barrett et al (2002) iban en esta misma línea, lo cuales sostuvieron que los niveles más altos de satisfacción tienden a estar relacionados con una edad más avanzada. A una determinada edad, las tareas diarias del trabajo se vuelven más familiares, facilitando el trabajo y creando una mejor sensación de satisfacción en él (Campos-Izquierdo, et al., 2016). 


\subsection{RECURSOS HUMANOS DE LA ACTIVIDAD FÍSICA Y DEPORTE QUE TRABAJAN COMO MONITORES DE FITNESS}

A continuación se van a discutir los resultados de la presente investigación sobre la formación general inicial, la formación permanente y la intervención docente y profesional de los monitores de fitness, todo ello comparado y analizado en función de otros estudios y los dos últimos bloques en relación a las variables sexo, edad, nivel de estudios y experiencia laboral. Asimismo, se van a discutir los resultados de la satisfacción laboral de los monitores de fitness en relación a las variables sexo y edad.

\subsubsection{FORMACIÓN GENERAL INICIAL Y PERMANENTE DE LOS MONITORES DE FITNESS}

Los resultados de este estudio indican que en España el 39,8\% de los monitores de fitness que trabaja en funciones de acondicionamiento físico para entidades y/o en instalaciones deportivas han cursado estudios universitarios y el 23,6\% han terminado la formación profesional. Asimismo, el 36,6\% tienen titulaciones menores a la de formación profesional (33,4\% habían cursado educación secundaria y el 3,2\% habían cursado estudios primarios o menores). No obstante, investigaciones como la de Boned et al. (2015) señalan porcentajes superiores en las titulaciones universitarias en la ocupación de monitor de fitness ya que el 50,1\% de los profesionales analizados en su estudio tenía alguna titulación de carácter universitario (19,0 \% de diplomados; 22,4 \% de licenciados; y 8,7 \% de postgraduados). Asimismo, Juan-Llamas (2015) aseguró, a 
diferencia de nuestro estudio, que el $96,4 \%$ de los monitores de fitness tienen una titulación superior a la educación secundaria.

Sin embargo, este hallazgo confiere cierto apoyo al estudio que examina el conocimiento actual de 115 profesionales de la actividad física y deporte realizado por Malek et al. (2002), quienes declaran que la mayoría de los encuestados no tienen ningún título universitario. Estos resultados también estuvieron relacionados con los del estudio de McInnis et al. (1997) llevado a cabo en 110 clubes de deportivos, donde sólo en el $34 \%$ de los clubes todos los monitores de fitness poseían una licenciatura.

A continuación se va a hacer una reflexión sobre la formación específica de la actividad física y el deporte, aunque en el presente estudio únicamente se analice la formación general inicial. Siguiendo el estudio de Campos-Izquierdo (2016), la formación inicial específica de actividad física y deporte inadecuada ha aumentado en las últimas décadas, lo que impide garantizar la calidad y la eficiencia de los servicios de actividad física y deporte y puede causar daños y riesgos a la salud de los ciudadanos (Campos-Izquierdo, 2010; Martín-Mariscal, 2012). Campos-Izquierdo (2016), en el estudio más reciente sobre esta temática, investigó que el $38 \%$ de las personas que trabajan en actividad física y deporte en España no posee ninguna de las diferentes titulaciones de actividad física y deporte, siendo el grupo más numeroso. Dentro de la ocupación de monitor de fitness, el 56,9\% no posee ninguna titulación de actividad física y deporte (Campos-Izquierdo, 2016). De forma similar otros estudios vienen investigando esta realidad en las profesiones de actividad física y deporte (CamposIzquierdo, 2005; Fraile, 1996; 2001; González-Rivera, 2008; Martín-Mariscal, 2012; Martínez del Castillo, 1991; Nuviala et al., 2007), constatando que un porcentaje muy alto de los profesionales que trabajan en la actividad física y deporte no está cualificado para la ocupación que desempeña. Debido a esta problemáticas, la Ley 6/2016, de 24 de 
noviembre, por la que se ordena el ejercicio de las profesiones del deporte en la Comunidad de Madrid; la Ley 3/2008, de 23 de abril, del ejercicio de las profesiones del deporte de Cataluña, la Ley 15/2015, de 16 de abril, por la que se ordena el ejercicio de las profesiones del deporte en Extremadura, la Ley 1/2015, de 23 de marzo, del ejercicio físico y del deporte de La Rioja y la Ley 5/2016, de 19 de julio, del Deporte de Andalucía, exponen qué titulaciones de actividad física y deporte son necesarias para ejercer la ocupación de monitor de fitness en España. Aun así se puede afirmar que un porcentaje de los monitores de fitness de este estudio no está cualificado con la titulación de actividad física deporte necesaria.

Asimismo, en el presente estudio se observa que los monitores de fitness españoles han realizado formación permanente durante los últimos 3 años. Las actividades que más se realizan son la asistencia a cursos de formación, la asistencia a jornadas y la asistencia a congresos. Por otro lado, la realización de postgrado no oficiales, la realización de másteres oficiales y la realización de grupos de trabajo es bastante escasa ya que no superan el $1,6 \%$.

La formación permanente más solicitada son los cursos de formación ya que un 68,5\% de los monitores de fitness han asistido a un curso de este tipo durante los últimos 3 años. La asistencia a cursos siempre es destacada, como lo demuestra Campos-Izquierdo (2005). Siguiendo con la ocupación de monitor de fitness, JuanLlamas (2015) obtuvo que un 56,7\% de los consultados en su estudio declararon tomar parte en cursos de una a tres veces al año o más de tres veces al año. Recientemente, Campos-Izquierdo, (2016) también ha manifestado que la mayoría de las personas, un $53,8 \%$, que trabajan en ocupaciones de actividad física y deporte ha realizado en los últimos tres años al menos un curso de actividad física y deporte. Estos resultados están igualmente en conexión con el estudio de Fuller et al. (1995), quienes observaron que 
los cursos son la fuente más común de aprendizaje a lo largo de toda la vida, pero enfatizan que ningún curso había sido realizado por más del $60 \%$ de los profesionales de la actividad física y deporte que entrevistaron. Según Misener y Danylchuk (2009), los cursos de formación aumentan la motivación, la estrategia, la técnica y la construcción del carácter.

Como se observa, la importancia de los cursos de formación como herramienta de formación permanente va incrementando a lo largo de los años, en 1991 Martínez del Castillo observó que solo el $37 \%$ de los profesionales de la actividad física y deporte había asistido a un curso en los últimos 5 años, siendo también la formación permanente más demandada. Años más tarde, en 2005 Campos-Izquierdo investigó que el 48,3\% de los profesionales de la actividad física y deporte había realizado uno o varios cursos en los últimos 4 años. En la actualidad, la realización de cursos como principal fuente de formación permanente supera el 50\% (Campos-Izquierdo, 2016; Juan-Llamas, 2015).

Las siguientes formaciones permanentes más comunes en nuestra investigación son la asistencia a jornadas con un $20,1 \%$ y la asistencia a congresos con un $13,3 \%$. Éstas están apoyadas también por los estudios de Juan-Llamas (2015), CamposIzquierdo (2016) y Campos-Izquierdo et al. (2012). Por su parte, Juan-Llamas (2015) manifestó que el 46,8\% de los monitores de fitness asisten a jornadas, convenciones, congresos y seminarios. De la misma forma, Campos-Izquierdo (2016) expresó que el $28,4 \%$ de los profesionales que trabajan en ocupaciones de actividad física y deporte asisten a jornadas o a congresos. Por último, Campos-Izquierdo et al. (2012) obtienen que el 68,6\% de los profesores de educación física en 2004 y el 66,1\% de ellos en 2006, asistieron a jornadas o congresos.

Las situaciones prácticamente inexistentes en la formación permanente de los monitores de fitness son la realización de estudios no oficiales de posgrado con el 1,6\%, 
la realización de másteres oficiales con el 1\% y la realización de grupos de trabajo con el $1 \%$.

Una de las razones para estos porcentajes tan bajos se menciona en el estudio de Juan-Llamas (2015) donde afirma que los monitores de fitness no asisten a más eventos de formación debido: razones de trabajo $(25,5 \%)$, razones económicas $(19,9 \%)$, razones logísticas al realizarse lejos de su lugar de residencia (19\%), porque son excesivamente teóricos $(5,1 \%)$ o porque no son interesantes $(5,1 \%)$.

En cuanto a la variable sexo, los monitores de fitness varones asistieron a más formación permanente que las mujeres. Misener y Danylchuk (2009) informaron también en su estudio en entrenadores que los hombres realizan más formación permanente que las mujeres. En cuanto a edad y experiencia laboral, los monitores de fitness de 30 a 44 años, seguidos de los de 45 años o mayores y con diez años de experiencia o más realizaron más formación permanente (Feu et al., 2012).

Al vincular la formación inicial general con la formación permanente, se observa que cuanto más avanzada es la formación inicial general, más diversa y compleja es la formación permanente que los monitores de fitness realizan, estando en conexión con lo que sostiene Campos-Izquierdo (2016) en relación a todos los profesionales de la actividad física y el deporte. Se observa también en los resultados, que los monitores de fitness con una licenciatura participan en menos cursos de formación que el resto. Sin embargo, asisten en mayor medida a todas las demás actividades de formación. Estos resultados son apoyados por Stacey et al. (2010), quienes investigaron que los monitores de fitness con mayores niveles de formación participan en actividades más específicas de formación permanente. Campos-Izquierdo, (2016); González-Rivera y Campos-Izquierdo, (2014) y Medina, (1999) también constataron que cuanto mayor es 
la formación inicial, mayor es el porcentaje de personas que realizan la formación permanente.

Finalmente, aunque la promoción y la realización de formación permanente por parte de las organizaciones es de elevada importancia, en España no parece que las organizaciones dedicadas al sector del fitness lo tengan en cuenta. Ante la pregunta de si su entidad había organizado alguna actividad de formación permanente para ellos durante los últimos tres años, el 70,2\% de los monitores de fitness aseguró que "no", sólo el 28,7\% declaró que "sín” y el 1,1\% contestó que "a veces". Las organizaciones de actividad física y deporte españolas deben tener en cuenta que la formación es la base de un trabajo bien hecho y por consiguiente deben ofrecer formación según las necesidades de sus empleados (Campos-Izquierdo, 2010), ya que estos programas son una inversión en eficacia (Sullivan, et al., 2012). Sin embargo, según los resultados de nuestro estudio y lo que se expone en otros, sólo unas pocas organizaciones deportivas ofrecen la tan necesaria formación permanente (Nash y Sproule, 2009; National Association for Sport and Physical Education, 2008).

\subsubsection{INTERVENCIÓN DOCENTE Y PROFESIONAL DE LOS MONITORES DE FITNESS}

En este apartado se van a discutir los resultados obtenidos sobre la planificación, la evaluación, los elementos que priorizan en su enseñanza y las fuentes de conocimiento de los monitores de fitness. Todo ello comparado y analizado en función de otros estudios y en relación a las variables sexo, edad, nivel de estudios y experiencia laboral. 


\subsubsection{Planificación}

Una de las primeras funciones para poder enseñar adecuadamente en el ámbito de la actividad física y deporte es la planificación (Buceta, 2004). Además, la planificación tiene que ser un proceso continuo, revisando frecuentemente el programa original creado para ajustarlo a las nuevas condiciones con las que se van encontrando (Dorgo, 2009). Aunque casi toda la literatura en este ámbito está de acuerdo con estas premisas escritas anteriormente, los resultados del presente estudio sugieren que los monitores de fitness españoles planifican poco, ya que, en promedio, solo el 37,9\% de ellos planifican sus clases. Una posible razón para estos resultados puede ser que la ocupación de monitor de fitness en España, en general, no es de calidad debido a la ausencia de profesionales adecuados y cualificados (Campos-Izquierdo, 2016; Feu, 2004; Nuviala et al, 2007), ya que un elevado porcentaje de ellos no tienen una formación inicial específica y adecuada de actividad física y deporte como muestra Campos-Izquierdo (2016) y no están capacitados para desarrollar la ocupación en unas condiciones óptimas (Boned, Rodríguez, López de Viñaspre, 2004a). Además, muchos de esos trabajos son a tiempo parcial (González-Rivera, 2008) por lo que, tal vez, no los dediquen el tiempo que se merecen.

Sin embargo, este resultado es contrario a lo que está siendo investigado por varios autores en la figura del entrenador deportivo (Nash et al., 2008; 2011; Olusoga et al., 2010; Pérez, 2002). De acuerdo con Nash et al. (2008) y Nash et al. (2011), los entrenadores de sus estudios afirman que, la planificación diaria y la planificación a largo plazo en todos los aspectos que pueden influir en la formación de los deportistas es muy importante. Asimismo, todos los entrenadores que Pérez (2002) estudió afirman que la planificación es un aspecto muy importante a tener en cuenta y que ellos sí que 
planifican. De igual forma, la investigación llevada a cabo por Pereira (2002) en profesores de educación física, reveló que el 76,2\% de los maestros especialistas en educación física planifican sus clases, sin embargo, el mismo estudio mostró que dedican poco tiempo a esa planificación.

Al observar la variable sexo dentro del ítem de planificación se constata que los monitores de fitness masculinos planifican más que las mujeres. Contrariamente a este resultado, Papatheofilou et al. (2008) encontraron que las percepciones de las profesoras sobre sus prácticas en la planificación son más altas que las de sus colegas masculinos. Haciendo referencia a la variable edad, los monitores de fitness que más planifican son los que tienen entre 16 y 29 años, seguidos de los de 30 a 44 y por último los que menos planifican son los de 45 años o mayores. Por lo tanto dentro de la ocupación de monitores de fitness se manifiesta que la planificación es inversamente proporcional a la edad, es decir que la planificación aumenta al disminuir la edad. Estos resultados van en línea diferente con lo investigado en otras ocupaciones de la actividad física y deporte (Vallée y Bloom, 2005). Otro dato que destacamos de esta investigación es que cuanta más experiencia y más estudios generales iniciales tienen los monitores de fitness, más planifican. Basándonos en estos resultados, los instructores de fitness más experimentados con un grado universitario elaboran planes más completos para la temporada, necesitando planificar con el fin de hacer un mejor desempeño profesional (Dejardins, 1996; Dorgo, 2009; Vallée y Bloom, 2005). Del mismo modo, los profesores de educación física con experiencia son más eficientes en el proceso de planificación (Hall y Smith, 2006) 


\subsubsection{Evaluación}

En esta investigación se obtiene que los monitores de fitness españoles, en general, no realizan el proceso de evaluación debidamente. Solo el 39,3\% de los monitores de fitness evalúa, haciéndolo el 50,4\% de ellos regularmente y el 49,6\% de ellos no regularmente. De la misma forma, Alves et al. (2008) exponen que los monitores de fitness españoles no evalúan demasiado. Estos resultados también concuerdan con lo obtenido por González-Rivera y Campos-Izquierdo (2011) donde el $39,3 \%$ de los docentes del deporte escolar, exactamente el mismo tanto por ciento que el encontrado en el presente estudio, afirmaba evaluar.

Por el contrario números autores afirmaron que la evaluación es muy importante, que los entrenadores siempre evalúan y que normalmente desarrollan estrategias a través de un proceso de reflexión y evaluación (Cregan, Bloom y Reid, 2007; Da Costa et al., 2009; Gould et al., 1999; Kidman y Harahan, 2011; Pérez, 2002, Vallée y Bloom, 2005). Además, Vallée y Bloom (2005) consideran que la autoevaluación también es muy importante como parte del proceso de aprendizaje, consiguiendo con ella mejorar cada día sus clases.

Una de las posibles razones para estos resultados, de acuerdo con GonzálezRivera y Campos-Izquierdo (2011) es la falta de exigencia en la realización de una evaluación en esta ocupación por parte de la organización. Desafortunadamente, la evaluación probablemente constituye el elemento curricular más descuidado en la actividad física y deporte (Gimeno y Pérez, 1992; Sáenz-López, 2006), por lo que viendo la importancia de la evaluación y constatando que se lleva a cabo en un tanto por

ciento muy bajo, cabe destacar que debe impulsarse y potenciarse en España, especialmente en el terreno del fitness (Mertler, 2009). 
A continuación se van a ver cómo interactúan las variables objeto de estudio con la evaluación. Con respecto al sexo se observa, contrariamente a los estudios de Derri et al. (2012) y Papatheofilou et al. (2008), que los monitores de fitness varones evalúan más que las mujeres. Derri et al. (2012) investigaron que las profesoras de educación física saben mejor cómo evaluar a los estudiantes. En otra línea, Ikonomopoulos, et al. (2001) revelaron que las percepciones de los profesores de educación física sobre sus prácticas en la evaluación son influenciadas por su experiencia y formación, pero no por el sexo.

En conexión con la idea de Ikonomopoulos et al. (2001) y, haciendo referencia a la variable edad, los monitores de fitness que más evalúan son los que tienen entre $30 \mathrm{y}$ 44 años. Otro dato que destacamos es que cuanta más experiencia y más estudios tienen los monitores de fitness, más evalúan. Del mismo modo, Da Costa et al. (2009) investigaron que los monitores de fitness con más experiencia evalúan y dan feedbacks con más frecuencia. Esto nos lleva a creer que la evaluación es un aspecto muy importante y que la experiencia laboral y la formación inicial general sí influyen en ella (Hall y Smith, 2006).

Por otro lado, las herramientas de evaluación son una pieza clave, gracias a ellas obtenemos los datos que necesitamos de una forma más sencilla (Díaz Lucea, 2005). En esta línea, Wright et al. (2012) señalan que hay muchas herramientas para utilizar ya que tienen que ser elementos de flexibilidad para poder evaluar a todos los agentes que intervienen en una clase.

Los resultados del presente estudio señalan que se utilizan varias herramientas de evaluación, siendo la más utilizada la observación diaria. De la misma forma, Alves et al. (2008) y Da Costa et al. (2009) también encontraron que la observación es la herramienta de evaluación que más utilizan los monitores de fitness de sus estudios. 
Apoyando este punto, Cregan et al. (2007) exponen que los entrenadores son como analizadores, ellos velan por todos los aspectos de sus deportistas y de ver cómo se llevan a cabo. La segunda herramienta más utilizada por los monitores de fitness son las pruebas de ejecución, asimismo esta herramienta es destacada por Díaz Lucea (2005), González-Rivera (2008) y González-Rivera y Campos-Izquierdo (2011), ya que ha sido la más utilizada en sus estudios. Después, la batería de test estandarizada, siendo la tercera más utilizada y por último los diarios, los test confeccionados por ellos mismos y los exámenes teóricos (González-Rivera, 2008).

Sin embargo, la herramienta de evaluación por excelencia utilizada por los monitores de fitness en base a los tantos por ciento de los resultados es la observación diaria de las clases (Alves et al., 2008; Da Costa et al., 2009). Según Derri et al. (2012), sólo un tercio de los profesores de educación física griegos conocen herramientas para evaluar el dominio cognitivo, además, menos de la mitad de ellos estaban familiarizados con los elementos cognitivos y motores que debían evaluar. En este sentido, y aunque los monitores de fitness de esta investigación sí utilizan en cierta medida las herramientas de evaluación, deben utilizar todas las que tienen a su disposición.

Con relación al sexo, los resultados obtenidos en este estudio siguen la línea de la investigación de Sáenz-López et al. (2010). Las mujeres utilizan más la observación que los hombres, siendo la única herramienta de evaluación junto con los diarios, que usan más. Con respecto a la edad, en general los monitores de fitness más mayores utilizan más variedad de instrumentos de evaluación. Con respecto a la variable experiencia laboral y nivel de estudios se puede afirmar que no influyen en la determinación de las herramientas de evaluación, ya que no siguen ningún patrón. Da Costa et al. (2009) sostienen que futuras investigaciones deben de relacionar la evaluación con otras variables como la edad, el sexo o en nivel de estudios. 


\subsubsection{Elementos que priorizan en su enseñanza y desempeño profesional}

Un elemento significativo de la intervención docente y profesional de los monitores de fitness es la toma de decisiones para el desarrollo de la sesión y los aspectos de intervención en una sesión. Después de muchos años en los que la principal preocupación era desarrollar habilidades motrices, los recientes avances científicos han demostrado la importancia de los procesos cognitivos en la toma de decisiones, la necesidad de proporcionar autonomía o la influencia de las emociones en la adecuada elección de las respuestas (Iglesias et al., 2007). De acuerdo con eso, en el presente estudio se ha encontrado que los aspectos técnicos y de actitud fueron los más importantes para los monitores de fitness. El primer resultado está en relación con la investigación de Carreras y Giménez (2010) donde se obtuvo que el modelo técnico es el modelo predominante y el segundo resultado apoya a lo mencionado en el artículo de Lubanski (2008) en el que se manifiesta que todos los entrenadores son responsables de fomentar y enseñar valores como la generosidad, la disciplina y los hábitos saludables (tres variables fundamentales dentro de los aspectos actitudinales).

Los aspectos psicológicos están en el tercer lugar, seguidos de los aspectos físicos, aspectos conceptuales y, por último, los aspectos tácticos. Tradicionalmente, los aspectos psicológicos fueron relegados a un segundo plano (Harwood, 2008).

A diferencia de este estudio, el de Bloom et al. (1999) expone que las instrucciones tácticas son las más importantes, pero sobre todo en un nivel alto de competición. El presente estudio no se basa en ese nivel por lo que tiene sentido que los aspectos tácticos estén relegados al último lugar. Además, esta parte del estudio sólo concernía a los monitores de fitness, y el aspecto táctico es a menudo más importante 
para los entrenadores deportivos que para los monitores de fitness, sobre todo para los que se centran en preparar y potenciar habilidades para la competición.

Independientemente de las variables objeto de estudio, los aspectos que se tienen en cuenta a la hora de intervenir en las clases son muy similares, siendo los aspectos técnicos y de actitud los más utilizados y los aspectos tácticos los menos usados.

\subsubsection{Fuentes de conocimiento}

Este estudio ha demostrado que los monitores de fitness españoles mejoran la intervención docente y profesional a través de diferentes situaciones de aprendizaje. No obstante, las fuentes más comunes de aprendizaje son los cursos que habían recibido, el intercambio de información con otros profesionales, la observación a otros profesionales, la formación recibida en la titulación de mayor nivel y los recursos tecnológicos o internet (Abad et al., 2011; Erickson et al., 2008; González-Rivera et al., 2016; Lemyre et al., 2007; Mesquita et al., 2010; Sage, 1989; Stacey et al., 2010).

El hallazgo de que los monitores de fitness utilizaran los cursos como fuente principal de conocimiento va en línea contraria con algunos hallazgos previos sobre las fuentes de conocimiento en los monitores de fitness (Abad et al., 2011, Juan-Llamas, 2015; Stacey et al., 2010). Estos autores expusieron que los cursos se consideran de menor calidad ya que algunos conocimientos pueden ser anticuados. Contrariamente a lo expuesto con anterioridad, nuestro hallazgo es consistente con la literatura en entrenadores deportivos (Erickson et al., 2008; Mesquita et al., 2010).

El intercambio de información con otros profesionales como segunda fuente de conocimiento es apoyada por muchos autores (Erickson et al., 2008; González-Rivera et 
al., 2016; Mesquita et al., 2010; Stacey et al., 2010) y es un tema central en la teoría del aprendizaje social de Wenger (1998). Siguiendo la tendencia confirmada en Stacey et al (2010), el trabajo en red con otros compañeros de profesión es una de las fuentes de información más comunes en los monitores de fitness. Para estos profesionales, las intervenciones como las comunidades de práctica y los líderes de opinión locales son fuentes atractivas de conocimiento (Stacey et al., 2010). Erickson et al. (2008) también encontraron que los entrenadores consideran al intercambio de información con otros profesionales como una fuente valiosa y muy accesible ya que tienen la oportunidad de adherirse a estas interacciones o intercambios durante todo su desarrollo como entrenador. Como resultado, existen actualmente numerosos ejemplos de iniciativas de desarrollo en todo el mundo que incorporan comunidades de práctica para el aprendizaje y el intercambio de conocimientos (Culver y Trudel, 2008).

La tercera fuente más frecuente de conocimiento es la observación a otros profesionales. La observación a otros profesionales más experimentados ha desempeñado un papel clave en el desarrollo de las profesiones del deporte e incluso en la socialización (Sage, 1989). Erickson et al. (2008) y González-Rivera et al. (2016) indicaron que es una fuente real, valiosa y preferida para adquirir conocimientos nuevos por parte de los entrenadores.

Después, los monitores de fitness de nuestra investigación se basan en la formación que habían recibido en la titulación de mayor nivel para realizar su actividad profesional, por lo que también valoran el potencial de aprendizaje de un entorno educativo formal (Feu, 2004; Viciana y Zabalza, 2004). En esta línea y siguiendo a Feu (2004) y Viciana y Zabalza (2004), los conocimientos utilizados, por los entrenadores que estudiaron para su actividad diaria, proviene principalmente de la formación inicial específica de actividad física y deporte. 
Asimismo, los recursos tecnológicos o internet son importantes también para los monitores de fitness. Este hallazgo está relacionado con los estudios de Forsyth et al., (2005) y Stacey et al. (2010). El principal uso de internet es probablemente localizar sitios web donde puedan acceder a una base de datos de ejercicios, crear sus propios ejercicios (Wright et al., 2007) y comprar libros de referencia (Lemyre et al., 2007).

Por otro lado, la experiencia como alumno de educación física o usuario de actividades físico-deportivas, los libros, las revistas científicas o técnicas, su propia investigación y la experiencia deportiva en competencias federadas son las fuentes de conocimiento que los monitores de fitness españoles citan en último lugar. Sin embargo, Stacey et al. (2010) descubrieron que las revistas de fitness y los documentos de investigación son fuentes de conocimiento preferidos por los monitores de fitness. Asimismo, González-Rivera et al. (2016) identificaron en entrenadores que las experiencias previas como deportista son la tercera fuente de conocimiento más importante para ellos.

Siguiendo con las variables objeto de estudio, los monitores de fitness varones suelen tener medias más elevadas en todas las fuentes de conocimiento que las mujeres. Ambos exponen que los cursos recibidos son la fuente de conocimiento que más valoran y sus propias investigaciones la que menos, como también se manifiesta en el estudio de González-Rivera et al. (2017).

En relación a la edad, todos los monitores de fitness independientemente de la edad, declaran que los cursos recibidos son la fuente de conocimiento que más utilizan y sus propias investigaciones las que menos.

Por otro lado, los monitores de fitness españoles con altos niveles de formación inicial general han usado más a menudo todas las fuentes de conocimiento que aquellos con menos formación inicial general. Esto fue especialmente cierto para la formación 
que han recibido en la titulación de mayor nivel (Feu et al., 2012), los libros, sus propias investigaciones y los recursos tecnológicos o internet. Por otro lado, los monitores de fitness que poseen la educación secundaria o estudios inferiores califican estas fuentes de conocimiento por debajo de la media. Al respecto, Mesquita et al. (2010) determinan que los entrenadores con un título universitario consideran para su aprendizaje, situaciones de aprendizaje informal y no formal. Stacey et al. (2010) siguen esta línea en su investigación con monitores de fitness, pero también observan que a veces es difícil determinar si el nivel educativo influye en la elección de la fuente de conocimiento.

Vinculando las fuentes de conocimiento de los monitores de fitness y su experiencia laboral, se observa que los monitores más experimentados y los menos experimentados anotaron todos los ítems de forma muy similar excepto el ítem de los cursos recibidos. Los monitores de fitness con diez años de experiencia o más consideran los cursos recibidos como una fuente menos importante de conocimiento que los monitores de fitness que tenían menos experiencia. Esto se debe a que la acumulación de años de experiencia favorece el uso del conocimiento que proviene de la experiencia personal (Feu et al., 2012).

\subsubsection{SATISFACCIÓN LABORAL DE LOS MONITORES DE FITNESS}

En primer lugar y apoyando las investigaciones previas que han cuestionado la satisfacción laboral en el campo de la actividad física y deporte (Koehler, 1998), los resultados indican que los monitores de fitness españoles expresan niveles de moderados a altos de satisfacción laboral. La media general ascendía a 3,9 puntos en una escala tipo Likert donde el máximo eran 5 puntos, siendo un valor alto. Sin 
embargo, ciertos aspectos laborales resultan más satisfactorios que otros a los monitores de fitness españoles.

En general, las relaciones con los compañeros y la importancia de que su trabajo es valorado por sus compañeros parecen ser los factores de trabajo que les genera mayores niveles de satisfacción. La amistad y las buenas relaciones sociales son un punto clave cuando se trata de tener una buena satisfacción en el trabajo y es un factor distintivo de poseer un gran trabajo (Campos-Izquierdo et al., 2016; Singh y Surujlal, 2006).

Volviendo a la investigación en curso, la valoración de la importancia por parte de los clientes de la profesión desarrollada, el nivel de autonomía y la propia actividad en sí misma son también elementos que generan una gran satisfacción. Estos resultados parecen claros; cuando haces un trabajo que te gusta y que está reconocido por tus clientes te sientes auto realizado. Además, tener autonomía significa que tus jefes confían en tu trabajo y desempeño profesional. Asimismo, estos factores también proporcionan satisfacción laboral a los monitores de fitness griegos (Koustelios et al., 2003).

Al examinar la insatisfacción laboral en los monitores de fitness españoles, los niveles más bajos de satisfacción laboral se experimentan con respecto a las oportunidades de promoción. Este resultado fue apoyado por Campos-Izquierdo et al. (2016). Los sentimientos negativos aparecen cuando los empleados no son promocionados cuando se consideran dignos de ello. Otros dos ítems que generan bajos niveles de satisfacción en el trabajo a los monitores de fitness son las oportunidades de formación ofrecidas por la organización y la remuneración económica. El salario es un determinante clave de la satisfacción en el trabajo y ambos están relacionados (Barrett et al., 2002), habiendo muchos estudios en monitores de fitness consideran que es un 
factor que disminuye la satisfacción laboral de los empleados (Koehler, 1988; Koustelios et al., 2003; Moodley y Coopoo, 2006). En cuanto a las oportunidades de formación, los monitores de fitness parecen estar interesados en ella pero sus organizaciones deportivas no las promueven (Misener y Danylchuk, 2009). Esto también fue un factor de preocupación en la investigación realizada por Moodley y Coopoo (2006), en la que los monitores de fitness y entrenadores personales expresaron que no tenían oportunidad de mejorar sus habilidades ya que sus organizaciones no promovían la formación permanente. Los esfuerzos deben continuar para desarrollar situaciones de aprendizaje relevantes y útiles para los monitores de fitness y también para ampliar sus conocimientos en nuevas áreas.

Estos resultados sugieren que el contenido del trabajo es más importante que el salario y otras variables mediadas por la organización (Chelladurai y Ogasawara, 2003). Por consiguiente, si se mejora el trabajo en sí, los monitores de fitness obtendrán mayor satisfacción. Además, éstos también obtienen mayor satisfacción cuando controlan la situación por ellos mismos (Singh y Surujlal, 2006). El estudio de Barranco (2013) en monitores de fitness expuso, por el contrario, que hay una relación significativa entre las buenas prácticas de gestión en el entorno de trabajo y la satisfacción laboral.

En segundo lugar y valorando las variables objeto de estudio, los resultados de esta investigación coinciden con los de Barrett et al. (2002), quienes indicaron que las diferencias de sexo no repercuten en la satisfacción laboral global. El promedio global de satisfacción laboral anotado entre hombres y mujeres en cada ítem obtuvo una diferencia de 0 a 0,1 puntos, excepto el ítem de la estabilidad, que obtuvo una diferencia de 0,2 puntos en favor de los hombres. Esto sugiere que las monitoras de fitness se sienten más inseguras en sus trabajos que los hombres, lo cual puede estar motivado por la realidad de que las mujeres tienen más contratos temporales que los hombres 
desempeñando el mismo puesto de trabajo y menos oportunidades laborales (Koehler, 1988; González-Rivera, 2008).

En cuanto a la satisfacción laboral y la edad, los monitores de fitness más satisfechos con su trabajo fueron los que tenían de 16 a 29 años y después lo de 45 años o mayores con una diferencia de 0,2 puntos a favor de los primeros. De forma diferente, Davis y Newstrom (1999) y Barrett et al. (2002) afirmaron que a medida que la edad aumenta, también lo hace la satisfacción laboral, siendo los trabajadores más mayores los más satisfechos. Pero sorprendentemente, los monitores de fitness de 16 a 29 son los más satisfechos. Este es un resultado novedoso y puede ser debido a que comienzan a trabajar con más entusiasmo. Otro hallazgo de este estudio respecto a la edad es que los monitores de fitness de 45 años o mayores son los que están más insatisfechos con su salario, seguidos de los de 30 a 44 años. 


\section{CAPÍTULO 7. CONCLUSIONES}





\section{CAPÍTULO 7. CONCLUSIONES}

En este capítulo se muestran las conclusiones obtenidas una vez expuestos los resultados del estudio y la discusión de los mismos. Este capítulo se estructura en dos apartados en función de los objetivos del estudio y va a seguir la distribución de los capítulos resultados del estudio y discusión de los resultados obtenidos De esta forma el presente capítulo se estructura en dos grandes grupos:

- Monitores de actividad física y deporte

- Monitores de fitness.

Asimismo, se incluyen posibles investigaciones futuras en relación con el tema objeto de estudio.

\subsection{MONITORES DE ACTIVIDAD FÍSICA Y DEPORTE}

- La mayoría de los monitores de actividad física y deporte tienen estudios de formación profesional o de menor nivel, donde más de un tercio de los monitores poseen estudios de educación secundaria o de menor nivel educativo.

- Más de la mitad de los monitores de actividad y deporte no han realizado ningún tipo de formación permanente durante los últimos 3 años.

- La formación permanente más realizada son los cursos de formación, seguida de la asistencia a jornadas y de la asistencia a congresos. La realización de postgrados no oficiales, la realización de másteres oficiales y la realización de grupos de trabajo, por el contrario, son minoritarias. 
- Según aumenta su edad, nivel educativo y experiencia laboral, los monitores de actividad física y deporte realizan una mayor formación permanente en general. Siendo el perfil general de los monitores de actividad física y deporte que más realizan formación permanente: hombres, mayores de 44 años, con estudios universitarios y con diez o más años de experiencia laboral.

- Una gran mayoría de monitores de actividad física y deporte afirma que las entidades en las que trabajan no organizaron actividades de formación permanente para ellos en los últimos 12 meses.

- La mayoría de los monitores de actividad física y deporte no planifican su intervención docente y profesional.

- Los monitores de actividad física y deporte planifican más según va aumentando su edad, nivel educativo y experiencia laboral. Siendo los monitores de actividad física y deporte que más planifican: los hombres, con una titulación universitaria, mayores de 44 años y con diez años o más de experiencia.

- Solamente, cerca de la mitad de los monitores de actividad física y deporte evalúan en su intervención docente y profesional, prefiriendo hacerlo regularmente.

- Los monitores de actividad física y deporte que más evalúan son: hombres, con una titulación universitaria, de 30 a 44 años y con diez o más años de experiencia.

- La observación diaria en su intervención docente y profesional es la herramienta de evaluación más utilizada por los monitores de actividad física y deporte independientemente de la variable estudiada, seguida de las pruebas de ejecución y de las baterías de test/tests estandarizado. Por el contrario, las herramientas de 
evaluación que menos emplean son por este orden: el examen teórico, el diario, los test confeccionados por ellos mismos o por compañeros.

- Los aspectos actitudinales son los más importantes para los monitores de actividad física y deporte, priorizándolos en su enseñanza y desempeño profesional, seguidos de los aspectos psicológicos, técnicos, conceptuales, físicos y por último los tácticos.

- Los cursos son la fuente de conocimiento más utilizada por los monitores de actividad física y deporte, estando en íntima interrelación con los datos obtenidos de que la actividad de formación permanente que más realizan los monitores son los cursos de formación. Después, son mas utilizadas, las siguientes fuentes de conocimiento: el intercambio de información con otros profesionales, la observación a otros profesionales y la formación recibida en la titulación de mayor nivel que poseen.

- La elección de las fuentes de conocimiento es un proceso complejo que no sigue un patrón específico, donde los monitores de actividad física y deporte usan fuentes de conocimiento asociadas con el aprendizaje de las vías formal, no formal e informal.

- Las monitoras de actividad física y deporte y los que poseen diez años o más de experiencia prefieren utilizar las fuentes de conocimiento formales.

- Los monitores de actividad física y deporte experimentan una elevada satisfacción en el trabajo.

- La mayor satisfacción laboral que experimentan los monitores de actividad física y deporte está vinculada con la relación con sus compañeros y con la sensación de que su trabajo y su profesión son valorados por sus compañeros. Sin embargo, se sienten insatisfechos con las oportunidades de formación ofrecidas 
por su organización, con las oportunidades de promoción dentro de su organización y con la remuneración.

- Aunque no hay una gran diferencia, los monitores de actividad física y deporte varones experimentan mayores niveles de satisfacción laboral que las mujeres, al igual que los monitores de actividad física y deporte más mayores.

\subsection{MONITORES DE FITNESS}

- La mayoría de los monitores de fitness poseen estudios de formación profesional o de menor nivel, donde más de un tercio de los monitores representan personas que tienen estudios de educación secundaria o de menor nivel educativo.

- Una gran mayoría de los monitores de fitness han completado alguna formación permanente durante los últimos 3 años, siendo las más comunes los cursos de formación, seguida de la asistencia a jornadas y la asistencia a congresos. La realización de postgrados no oficiales, másteres oficiales y la realización de grupos de trabajo son casi inexistentes.

- El perfil general de los monitores de fitness que realizan una mayor formación permanente es: hombres, de 30 a 44 años, con estudios universitarios y con diez o más años de experiencia laboral.

- Una gran mayoría de monitores de fitness afirma que las entidades en las que trabaja no organizaron actividades de formación para ellos en los últimos 12 meses.

- La mayoria de los monitores de fitness no planifican su intervención docente y profesional. 
- En general, los monitores de fitness hombres, titulados universitarios, de entre 16 y 29 años y con diez años de experiencia o más son los que más planifican.

- La mayoría de los monitores de fitness no evalúan en su intervención docente y profesional.

- Los monitores de fitness que más evalúan son: hombres, de 30 a 44 años, titulados universitarios y con diez años o más de experiencia.

- La observación diaria en su intervención docente y profesional es la herramienta de evaluación que más utilizan los monitores de fitness, seguido de las pruebas de ejecución y por las baterías de test estandarizadas. Por el contrario, las herramientas de evaluación que menos utilizan son por este orden: exámenes teóricos, los diarios, y los test confeccionados por ellos mismos o por los compañeros.

- Los aspectos actitudinales y los técnicos son los más importantes para los monitores de fitness, seguidos de los aspectos psicológicos, físicos, conceptuales y por último los tácticos.

- Los monitores de fitness utilizan fuentes conocimiento asociadas con un amplio aprendizaje, tanto de las vías formal, no formal como informal.

- Las fuentes de conocimiento más utilizadas son los cursos recibidos, estando relacionada con el hallazgo de que los cursos de formación son la actividad de formación permanente que más realizan; en segundo lugar utilizan la interacción con otros profesionales, después la observación de otros profesionales, la formación de los títulos de nivel superior y los recursos tecnológicos o internet.

- Los monitores de fitness con estudios universitarios prefieren utilizar las fuentes de conocimiento formales. 
- Los monitores de fitness tienen un nivel de moderado a alto de satisfacción en el trabajo.

- Las relaciones con los compañeros, la valoración de la importancia por parte de sus compañeros y por parte de los clientes de su profesión, la actividad profesional desarrollada, el nivel de autonomía y el desempeño que debe alcanzar son los factores de trabajo más satisfactorios para los monitores de fitness. Sin embargo, los niveles más bajos de satisfacción laboral son experimentados con respecto a las oportunidades de promoción, las oportunidades de formación ofrecidas por la organización y la percepción de la remuneración económica.

- Las diferencias de sexo no afectan a la satisfacción general en el trabajo. En cambio en relación a la edad, los monitores de fitness de 16 a 30 años experimentan el nivel más alto de satisfacción laboral.

\subsection{FUTURAS LÍNEAS DE INVESTIGACIÓN}

Este estudio sienta las bases para futuras investigaciones ya que el análisis de las personas que trabajan como monitores de actividad física y deporte y como monitores de fitness así como su intervención docente y profesional son objetos de interés para posibles líneas futuras de investigación. Los datos que de ellas se obtengan y sus conclusiones pueden contribuir, entre otras finalidades, a la mejora de la intervención docente y profesional así como a la mejora de la situación de las personas que trabajan en las ocupaciones de monitor de actividad física y deporte y de monitor de fitness, y 
por ello, a la mejora de la calidad y profesionalidad de la propia actividad física y deporte.

A continuación se muestran algunas de las futuras posibles líneas de investigación:

- Realizar un estudio de este tipo periódicamente en el ámbito español e incluso europeo, pudiéndose así determinar guías y planes de actuación.

- Futuras investigaciones deberían, y de hecho va ser uno de mis objetivos futuros, analizar mediante metodología cualitativa la intervención docente y profesional de los monitores de actividad física y deporte y de los monitores de fitness.

- En cuanto a las fuentes de conocimiento, una posible línea de investigación futura sería estudiarlas en mayor profundidad. Además, la investigación futura podría centrarse en profundizar los aspectos cuantitativos y cualitativos con la que estos profesionales utilizan las fuentes de conocimiento y su utilidad.

- Estudiar la formación permanente también en mayor profundidad determinando qué tipo de formación es más útil para cada función laboral y ocupación, así como qué entidades son las que mejor formación permanente ofrecen.

- Otra futura línea de investigación sería conocer qué decisiones organizativas se están llevando a cabo en las organizaciones de actividad física y deporte para la puesta en marcha de políticas orientadas a la mejora de la ocupación de monitor de actividad física y deporte y la ocupación de monitor de fitness. 



\section{REFERENCIAS BIBLIOGRÁFICAS}





\section{REFERENCIAS BIBLIOGRÁFICAS}

Abad, M. T., Benito, P. J., Giménez, F. J. y Robles, J. (2011). La formación de los entrenadores de fútbol base en la provincia de Huelva. Cultura, Ciencia y Deporte, 6(18), 171-183. doi: 10.12800/ccd.v6i18.44

Abbott A. (2009). Fitness professionals: certified, qualified and justified. The exercise standars and malpractice reporter, 23(2), 17-22.

Abraham, A., Collins, D. y Martindale, R. (2006). The coaching schematic: validation through expert coach consensus. Journal of Sports Sciences,24, 549-564.

Akindutire, I. O. (1993). Determinants of satisfaction in career expectations of Nigerian coaches. International Journal of Sport Psychology, 1(24), 18-29.

Aldag, R. J. y Brief, A. P. (1975). Age and reactions to task characteristics. Industrial Gerontology, 2, 223-229.

Almeida, C. (2007). O emprego e as profissões do desporto. En: J. Olimpo, J. M. Constantino. Em defesa do desporto (pp.123-145). Coimbra: Almedina.

Alves, S. C., da Costa, V. A., Castañer, M., Fernández, J. J. y Anguera, M. T. (2013). La conducta de los instructores de Fitness: triangulación entre la percepción de los practicantes, auto-percepción de los instructores y conducta observada. Revista de Psicología del Deporte, 22(2), 321-329.

Alves, S. C., Fernandes, J. J. y Castañer, M. (2008). Pedagogic behavior of the instructors of classes of group of localized fitness. Fitness \& Performance, 7(4), 251-263.

Alvira, F. (2002). Diseños de investigación social: Criterios operativos. En F. Alvira, M. García Ferrando y J. Ibáñez (Comps.), El análisis de la realidad social. Métodos y técnicas de investigación (3 ${ }^{\mathrm{a}}$ Ed.) (pp. 99-125). Madrid: Alianza editorial. 
Alvira, F. (2004). La encuesta: una perspectiva general metodológica. Madrid: CIS.

Amarantidou, S., Mantis, K. y Koustelios, A. (2009). Relation between job security and job satisfaction among PE teachers in Greece. International Journal Of Physical Education, 46(1), 20-23.

Arends, R. (1995) Aprender a enseñar. Lisboa: Editora McGraw-Hill.

Arnold, H. J. Y Feldman, D. C. (1988). Organizational behaviour. New York, NY: McGraw-Hill.

Azorín, F. y Sánchez-Crespo J.L. (1994). Métodos y aplicaciones de muestreo. Madrid: Alianza editorial.

Bain, L. (1990). Physical Education Teacher Education. En R. H. Houston (Ed.), Handbook of research on teacher education (pp.758-781). Nueva York: MacMillan Publishing.

Balzer, W. K., Smith, P. C., Kravitz, D. A., Lovell, S. E., Paul, K. B... Reilly, C. E. (1990). User's manual for the job descriptive index (JDI) and the job in general (JIG) scales. Bowling Green, OH: Bowling Green State University.

Barranco, D. (2013). Buenas prácticas de gestión, satisfacción laboral, burnout e intención de abandono en profesionales del sector del fitness. (Tesis doctoral inédita). Universidad Europea de Madrid, Madrid.

Barrett, J. J., Gillentine, A., Lamberth, J. y Daughtrey, C. L. (2002). Job satisfaction of NATABOC certified athletic trainers at division one National Collegiate Athletic Association institutions in the Southeastern Conference. International Sports Journal, 6(2), 1-13.

Bayo, A. y Merino, J. (2002). Las prácticas de recursos humanos de alto compromiso: un estudio de los factores que influyen sobre su adopción en la industria española. Cuadernos de Economía y Dirección de la empresa, 12, 227-246. 
Bayón, F. (2002). Organizaciones y recursos humanos. Madrid: Síntesis.

Blázquez D. (1990). Evaluar en Educación Física. Barcelona: Inde.

Blázquez, D. (1993). Perspectivas de evaluación en la educación física y deporte. Apunts, 31, 5-16.

Bloom, G. A., Crumpton, R. R. y Anderson, J. E. (1999). A systematic observation study of the teaching behaviors of an expert basketball coach. The Sport Psychologist, 13(2), 157-170.

Boned, C. J., Felipe, J. L., Barranco, D., Grimaldi-Puyana, M. y Crovetto, M. (2015). Perfil profesional de los trabajadores de los centros de fitness en España. Revista Internacional de Medicina y Ciencias de la Actividad Física y el Deporte, 15(58), 195-210.

Boned, D., Rodríguez, R. y López de Viñaspre, P. (2004b). Aproximación a la situación de los profesionales en el sector del fitness. Comunicación presentada en el III Congreso de la Asociación Española de Ciencias del Deporte, Valencia.

Boned, C. J., Rodríguez, G., Mayorga, J. I. y Merino, A. (2004a). Competencias profesionales del licenciado en ciencias de la actividad física y deporte. European Journal of Human Movement, 15, 1-6.

Briones, G. (1996). Metodología de la investigación cuantitativa en las ciencias sociales. Bogotá: I.C.F.E.S.

Brunet, L. (1983). Le Climat du Travail dans les Organizations. Montreal: Les Editions de la Agence D’Arc.

Bryman, A. (2004). Social research methods. New Cork: Oxford University Press.

Buceta, J.M. (2004). Estrategias psicológicas para entrenadores de deportistas jóvenes. Madrid: Dykinson. 
Cagigal (1964). El deporte escolar y extraescolar. Consejo de Europa. Luxemburgo. s.n.

Calabuig, F., Quintanilla, I. y Mundina, J. (2008). La calidad percibida de los servicios deportivos: diferencias según la instalación, sexo, edad tipo de usuario en servicios náutico. Revista Internacional de Ciencias del Deporte, 10(4), 25-43. http://dx.doi.org/10.5232/ricyde2009.01407

Campbell, T. y Sullivan, P. J. (2005). The effect of a standardized coaching education program on the efficacy of novice coaches. Avante, 11, 38-45.

Campos-Izquierdo, A. (2000). Calidad en el mercado de la actividad física y deporte desde la perspectiva de ordenación adecuada de los recursos humanos. En J.P. Fuentes y M. Macías (Eds.), I Congreso de la Asociación de Ciencias del deporte (pp. 451-460). Cáceres: Universidad de Extremadura.

Campos-Izquierdo, A. (2005). Situación profesional de las personas que trabajan en funciones de actividad física y deporte en la comunidad autónoma valenciana. (Tesis doctoral inédita). Universidad de Valencia, Valencia.

Campos-Izquierdo, A. (2007). Los profesionales de la actividad física y deporte como elemento de garantía y calidad de los servicios. Cultura, Ciencia y Deporte, 7, $51-57$

Campos-Izquierdo, A. (2008). La organización de los recursos humanos de la actividad física y deporte desde la perspectiva de sus funciones laborales. Motricidad. European Journal of Human Movement, 21, 142-167.

Campos-Izquierdo, A. (2010). Dirección de recursos humanos en las organizaciones de la actividad física y deporte ( $1^{\mathrm{st}}$ ed.). Madrid: Síntesis.

Campos-Izquierdo, A. (2011) Elaboración y validación del cuestionario 'PROAFIDE: recursos humanos de la actividad física y deporte'. Análisis de la situación y 
actuación profesional de los profesionales de actividad física y deporte. Actividad Física y Deporte: Ciencia y Profesión, 15, 53-4.6

Campos Izquierdo, A. (dir.) (2013). Proyecto de investigación Fundamental de I+D+i: Estructura ocupacional y organizativa de los recursos humanos de actividad física y deporte en España. Encuesta en los ámbitos de docencia, entrenamiento, recreación, gestión y actividad física y salud. Madrid: Ministerio de Ciencia e Innovación. Manuscrito no publicado.

Campos-Izquierdo, A. (2016). La formación de los profesionales de actividad física y deporte en España. Movimento, 22(4), 1351-1364.

Campos-Izquierdo, A., González-Rivera, M. D. y Jiménez-Beatty, J. R. (2012). El perfil profesional del profesorado de educación física en educación secundaria. Educación XX1: Revista de la Facultad de Educación, 15(1), 135-155.

Campos-Izquierdo, A., González-Rivera, M., Pablos, C. y Jimenez-Beatty, J. E. (2008). Situación laboral y formativa de los recursos humanos que desarrollan la dirección y organización de actividad física y el deporte. Ponencia presentada en el IV Congreso Internacional y Nacional de Educación Física de la Universidad de Córdoba, Córdoba.

Campos-Izquierdo, A., González-Rivera M. D. y Taks M. (2016). Multi-functionality and occupations of sport and physical activity professionals in Spain. European Sport Management Quarterly, 16(1), 106-126.

Campos-Izquierdo, A. y Martín-Acero, R. (2016) Percepción de las competencias profesionales de los graduados en Ciencias de la Actividad Física y del Deporte. Revista de Psicología del Deporte, 25(2), 339-346.

Campos-Izquierdo, A., Martínez, J., Mestre, J. A. y Pablos, C. (2007). Los profesionales de la organización y gestión de actividad física y deporte en las instalaciones 
deportivas y entidades: características socio-demográficas y formativas. Revista Internacional de Ciencias del Deporte, 8(3), 25-38. http://dx.doi.org/10.5232/ricyde2007.00803

Campos-Izquierdo, A. y Viaño, J. (1999). Calidad en la Actividad Física y Deporte: Regulación profesional. Revista de Educación Física, 76, 38-41.

Camy, J. y Le Roux, N. (1998). Lémploi dans le secteur et la filièredu sport en Europe: situation et perspectivas. Actas del congreso II diploma e la laurea in educazione física nella realta professionale attuale e nelle prospettive future (pp. 27-37). Lombardía: ISEF.

Camy, J., Chantelat, P. y Le Roux, N. (1999). Sport et emploi en Europe. France: Comisión Europeenne.

Carreras, J. C. y Giménez, J. (2010). Metodología de enseñanza utilizada en la enseñanza del tenis durante la etapa de iniciación. Retos. Nuevas tendencias en Educación Física, Deporte y Recreación, 18, 60-65.

Carter, A. D. y Bloom, G. A. (2009). Coaching knowledge and success: going beyond athletic experiences. Journal of Sport Behavior; 32, 419-437.

Caslavova, E., Kraft, J. y Voracek, J. (2011). Diagnostics of Personal Work at Sport Organizations in the Czech Republic. Inzinerine Ekonomika-Engineering Economics, 22 (5), 519-526.

Cea, M. A. (1998). Metodología cuantitativa. Estrategias y técnicas de investigación social. Madrid: Síntesis.

Cea, M. A. (2004). Métodos de encuesta. Teoría y práctica, errores y mejora. Madrid: Síntesis.

Cervelló, E. y Moreno, F. J. (2001). Diseños descriptivos, correlacionales y experimentales de investigación aplicada a las ciencias del deporte. En F. Del 
Villar y J.P. Fuentes (Eds.), Nuevas perspectivas de Investigación en la Ciencias del Deporte (pp. 31-53). Cáceres: Universidad de Extremadura.

Chelladurai, P. (1999). Human resource management in sport and recreation. Champaign, IL: Human Kinetics.

Chelladurai, P. y Ogasawara, E. (2003). Satisfaction and commitment of American and Japanese collegiate coaches. Journal of Sport Management, 17(1), 62-73.

Consejo de Europa (1975). Carta Europea del deporte. Bruselas: Consejo de Europa. Consejo de Europa (1992). Carta Europea del deporte. Rodas: Consejo de Europa. Consejo Superior de Deportes (2000). El deporte español ante el siglo XXI. Madrid: CSD-MEC

Consejo Superior de Deportes (2007). Memoria y texto articulado anteproyecto de ley sobre ordenación del ejercicio de determinadas profesiones del deporte. Madrid: CSD.

Coombs, P. H. y Ahmed, M. (1974). Attacking Rural Poverty: How Nonformal Education Can Help. Baltimore: University Press.

Côté, J. (2006). The development of coaching knowledge. International Journal of Sports Sciences and Coaching, 1(3), 217-222.

Côté, J. y Gilbert, W.D. (2009). An integrative definition of coaching effectiveness and expertise. International Journal of Sports Science \& Coaching, 4(3), 307-323.

Côté, J. y Salmela, J. H. (1996). The organizational tasks of high-performance gymnastic coaches. The Sport Psychologist, 10, 247-260.

Côté, J., Bruner, M., Erickson, K., Strachan, L.y Fraser-Thomas, J. F. (2010). Athlete development and coaching. En J. Lyle y C. Cushion (Eds.). Professionalization and practice (pp. 63-83). London: Churchill Livingstone. 
Côté, J., Samela, J. H. y Russell, S. (1995). The knowledge of high-performance gymnastic coaches: competition and training considerations. The Sport Psychologist, 9(1), 76-95.

Côté, J., Young, B., North, J. y Duffy, P. (2007). Towards a definition of excellence in sport coaching. International Journal of Sports Science and Coaching, 1, 3-17.

Cregan, K., Bloom G. A. y Reid, G. (2007). Career evolution and knowledge of elite coaches of swimmers with a physical disability. Research Quarterly for Exercise and Sport, 78(4), 339-350.

Culver, D., y Trudel, P. (2008). Clarifying the concept of communities of practice in sport. International Journal of Sports Science \& Coaching, 3, 1-10

Cushion, C. J., Armour, K. M. y Jones, R. L. (2013). Locating the coaching process in practice: Models 'for' and 'of' coaching. Physical Education and Sport Pedagogy, 11(1), 83-99.

Da Costa, V. A., Alves, S. C. y Fernandes, J. J. (2009). Study from the pedagogical feedback in located gymnastics instructors, with different levels of professional experience. Fitness y Performance, 8(3), 174-182.

Davis, J. W. Y Newstrom (1999). Comportamiento Humano en el Trabajo. 10ª edición. México: McGraw-Hill.

Dawis, R, y Lofquist, L. (1984). A Psychological Theory of Work Adjustment. MI: University of Minnesota Press.

De Saá, P. y Ortega, R. (2004). La formación. En J. Bonache y A. Cabrera (Coord.), Diccionario de recursos humanos (pp. 591-596). Madrid: Pearson Educación.

Del Villar, F. (Coord.) (2004). Propuesta de grado en Ciencias de la Actividad Física y el Deporte. Cáceres: Universidad de Extremadura. 
Delgado, M. A.; Espinar, J. A. y Goncé, D. C. (2002). Experiencia práctica sobre el análisis de entrenadores en edad escolar. Comunicación presentada en el II Congreso Nacional del Deporte en Edad Escolar, Sevilla.

Derri, V., Avgerinos, A., Emmanouilidou, K. y Kioumourtzoglou, E. (2012). What do Greek physical education teachers know about elementary student assessment? Journal of Human Sport y Exercise, 7(3), 658-670.

Desjardins, G. (1996). The mission. En C. N. Vallée y G. A. Bloom (2005). Building a successful university sport program: Key and common elements of expert coaches. Journal of Applied Sport Psychology, 17(3), 179-196.

Di Cola G. (2006). Beyond the scoreboard. Youth employment opportunities and skills development in the sports sector. Geneva: International Labour Organization;

Díaz Lucea, J. (2005) La evaluación formativa como instrumento de aprendizaje en Educación Física. Barcelona: INDE

Dixon, M. A. y Warner, S. (2010). Employee satisfaction in sport: Development of a multi-dimensional model in coaching. Journal of Sport Management, 24(1), 139-168.

Dolan, S., Shuler, R. y Valle, R. (2007). La gestión de los recursos humanos. McGrawHill: Madrid.

Dorgo, S. (2009). Unfolding the practical knowledge of an expert strength and conditioning coach. International Journal of Sport Science and Coaching, 4(1), $17-30$.

Duda, J. (1991). Motivating older adults for physical activity: it's never too late. JOPERD, 62, 44-48.

Durand-Bush, N. y Salmela, J. H. (1996). Nurture over Nature: A new twist to the development of expertise. Avante, 2(2), 87-109. 
Erickson, K., Bruner, M. W., MacDonald, D. J. y Côté, J. (2008). Gaining insight into actual and preferred sources of coaching knowledge. International Journal of Sport Science \& Coaching, 3(4), 527-538.

Erickson, K., Côté J. y Fraser-Thomas, J. (2007). Sport experiences, milestones, and educational activities associated with high-performance coaches' development. The Sport Psychologist, 21(1), 302-316.

Escudero, J. M. (1998). Consideraciones y propuestas sobre la formación permanente del profesorado. Revista de Educación, 317, 11-29.

European Health and Fitness Association (2011). EHFA standards EQF level 3 fitness and group fitness instructor. Brussels: European Commission.

European Observatoire of Sport and Employment (2011). LLL Sport European Report. Lyon: EOSE.

European Observatoire of Sport and Employment (2014). V Sport. Strategy for a competent workforce. Lyon: EOSE.

Feltz, D. A., Hepler, T. J., Roman, N. y Paiement, C. (2009). Coaching efficacy and volunteer youth sport coaches, The Sport psychologist, 23(1), 24-41.

Fernández-Ríos (1995). Análisis y descripción de puestos de trabajo: teoría, métodos y ejercicios. Madrid: Díaz Santos.Estudio de los modelos

Feu, S. (2004). Estudio de los modelos y de las variables que afectan al entrenador español de balonmano. (Tesis doctoral inédita). Universidad de Extremadura, Cácers.

Feu, S., Ibáñez, S. J. y Gozalo, M. (2007). Propiedades Psicométricas de los cuestionarios EDD y EPD para evaluar el estilo de planificación y decisión de los entrenadores. Revista de Psicología del Deporte, 16(2), 185-199. 
Feu, S., Ibáñez, S. J., Lorenzo, A., Jiménez, S. y Cañadas, M. (2012). El conocimiento profesional adquirido por el entrenador de balonmano: experiencias y formación. Revista de Psicología del Deporte, 21(1), 107-115.

Fink, A. (1995). How to simple in surveys. Thousand Oaks: Sage.

Forsyth, G., Handcock, P., Rose, E. y Jenkins, C. (2005). Fitness instructors: How does their knowledge on weight loss measure up? Health Education Journal, 64(2), 154-167. doi: 10.1177/001789690506400207

Fowler, F. J. y Mangione, T. W. (1990). Standardized survey interviewing: minimizing interviewer-related error. California: Sage.

Fraile, A. (1996). Reflexiones sobre la presencia del deporte en la escuela. Revista de educación Física. Renovar la teoría y la práctica, 64, 5-10.

Fraile, A. (2001). Una propuesta de deporte recreativo para el tiempo extraescolar. En V. Manzón, D. Sarabia, D., F.J. Canales, y F. Ruiz (Coords.), La enseñanza de la Educación Física y el Deporte Escolar. Actas del IV Congreso Internacional. Santander: A.D.E.F. Cantabria.

Fraser-Thomas, J. y Côté, J. (2009). Understanding adolescents' positive and negative developmental experiences in sport. The Sport Psychologist, 23, 3-23.

Friedlander, F. (1964). Job characteristics as satisfiers and dissatisfiers. The Journal of Applied Psychology, 48, 388-392.

Fuentes, J. P. y Gusi, N. (1996). Iniciación jugada a la técnica y a la táctica en el tenis. Espacios reducidos y poco material. Cáceres: Servicio de publicaciones de la Universidad de Extremadura

Fuller, B. B., Feyrer-Melk, S., Thomas, D. Q. y Harding, F. V. (1994). A statistical analysis of the academic preparation and knowledge of fitness instructors in the 
Southwestern United States from 1992-1995. San Diego: The annual meeting of the Southwestern Chapter American College of Sports Medicine.

Fundación Europea para la Gestión de la Calidad (2003). EFQM. Introducción a la excelencia. Bruselas: EFQM

Gallardo, J. y Campos-Izquierdo, A. (2011). Situación profesional de los recursos humanos de la actividad física y deporte en el municipio de Coslada. Revista Internacional de Medicina y Ciencias de la actividad física y deporte 11 (43), $440-454$

Gambau, V. (2011). Deporte y empleo en España: dificultades de estudio y de intervención. Revista Española de Educación Física y el Deporte, 394, 13-36.

García-Bernal, J., Gargallo, A., Marzo, M. y Rivera, P. (2005): Job satisfaction: empirical evidence of gender differences. Women in Management Review, 20 (4), 279-288.

García Ferrando, M. (1990). Aspectos sociales del deporte. Una reflexión sociológica. Madrid: CSD-Alianza editorial.

García Ferrando, M. (2002). La encuesta. En F. Alvira, M. García, J. Ibáñez (Eds.), El análisis de la realidad social. Métodos y técnicas de investigación (pp. 167202). Madrid: Alianza Editorial.

García-Merino, S. (2011). Características de los centros de fitness de titularidad privada en la Comunidad de Madrid. (Tesis doctoral inédita). Universidad Europea de Madrid, Madrid

García, S. y García, E. (2007). Los recursos humanos aplicados a la gestión deportiva. Barcelona: Inde 
García, M. y Llopis, R. (2011). Ideal democrático y bienestar personal. Encuesta sobre hábitos deportivos en España 2010. Madrid: Centro de Investigaciones Sociológicas y Consejo Superior de Deportes.

Gerber, P. B., Nel, P. S. y Van Dyk, P. S. (1998). Human resources management (4th ed.). Johannesburg, South Africa: International Thomson Publishing.

Ghaye, A. y Ghaye, K. (2001). Teaching and learning through critical reflective practice. UK: Cromwell Press.

Gilbert, W. y Trudel, P. (2001). Learning to coach through experience: reflection in model youth sport coaches. Journal of Teaching in Physical Education, 21, 1634.

Gillentine, A. y Hunt, B. (2000). Factors affecting the sportsmanship attitudes of interscholastic coaches. Applied Research in Coaching and Athletics Annual, 15, 24-38.

Giménez, F. J. (2000). Estudio praxiológico de la estructura de las situaciones de enseñanza de los deportes de cooperación/oposición de espacio común y participación simultánea: balonmano y fútbol sala. (Tesis doctoral inédita). Universidad de Las Palmas de Gran Canaria, Las Palmas de Gran Canaria.

Giménez, F. J. y Sáenz-López, P. (2000). Programación de iniciación deportiva en la escuela. En F. J. Giménez (Ed.), Fundamentos básicos de la iniciación deportiva en la escuela. Wanceulen: Sevilla.

Gimeno, J. y Pérez, A. (1992).Comprender y transformar la enseñanza. Madrid: Morata.

Gómez Tafalla, A.M. (2003). El rol del gestor deportivo municipal en la Comunidad Valenciana, pasado, presente y futuro. (Tesis doctoral inédita). Universitat de València, Valencia 
González-Rivera, M. D. (2008). El deporte escolar en la Comunidad Autónoma de Madrid: intervención didáctica y recursos humanos en las actividades físico deportivas extraescolares en los centros educativos (Tesis doctoral inédita). Universidad de Valencia, Valencia.

González-Rivera, M. D. (2016). Latin american women and sport in Spain. En R. López De D'Amico, T. Benn y G. Pfister. (eds). Women and Sport in Latin America (pp. 213-224). London and New York: Routledge.

González-Rivera, M. D. y Campos-Izquierdo A. (2010). La intervención didáctica del docente del deporte escolar, según su formación inicial. Revista de Psicodidáctica, 15(1), 101-120.

González-Rivera, M. D. y Campos-Izquierdo A. (2011). La evaluación en las actividades deportivas fuera del horario escolar en los centros educativos de educación primaria. Tándem: Didáctica de la educación física, 36, 61-70

González-Rivera, M. D. y Campos-Izquierdo, A. (2014). La intervención docente en educación física en secundaria y en el deporte escolar. Madrid: Editorial Síntesis.

González-Rivera, M. D., Campos-Izquierdo, A, Villalba, A. I. y Hall, N. D. (2017). Sources of knowledge used by Spanish coaches: A study according to competition level, gender and professional experience. International Journal of Sports Science \& Coaching, 12(2), 1-13.

González, J. y Wagenaar, R. (2003). Tuning Educational Structures in Europe. Informe Final Fase Uno. Bilbao: Universidad de Deusto.

Gonzalo, L. A. (2013). Diagnostico de la situación del deporte en edad escolar en la ciudad de Segovia (Tesis doctoral inédita). Universidad de Valladolid, Valladolid. 
Gould, D, Medbery, R., Damarjian, N. y Lauer, L. (1999). A survey of mental skills taining knowledge, opinions, and practices of junior tennis coaches. Journal of Applied Sport Psychology, 11(1), 28-50.

Griffey, D. C., y Housner, L. D. (1991). Differences between experienced and inexperienced teachers' planning decisions, interactions, student engagement, and instructional climate. Research Quarterly for Exercise and Sport, 52, 196204.

Grobbelaar, H. W. (2007). A survey of South African provincial netball coaches' opinions, abilities and limitations regarding mental skills training. South African Journal for Research in Sport, Physical Education \& Recreation, 29(2), 27-39.

Gruneberg, M. M. (1979). Understanding job satisfaction. New York: John Wiley \& Sons, Inc.

Gutiérrez-Dávila, M. y Oña, A. (2005). Metodología en las Ciencias de Deporte. Madrid: Síntesis.

Hardcastle, S. y Taylor, A. H. (2001). Looking for more than weight loss and fitness gain: psychosocial dimensions among older women in a primary-care exercisereferral program. Journal Aging and physical activity, 9 (3), 313-328.

Harwood, C. (2008). Developmental consulting in a professional football academy: the 5cs coaching efficacy program. The Sport Psychologist, 22(1), 109-133.

Heinemann, K. (2003). Introducción a la metodología de la investigación empírica. Barcelona: Paidotribo.

Herzberg, F., Mausner, B. y Snyderman, B. (1959). The motivation to work. NewYork: John Wiley.

Heyes, J. y Stuart, M. (1996) "Does training matter? Employee experiences and attitudes. Human resources management journal, 6(3), 7-21. 
Hoppock, R. (1935). Job Satisfaction. New York: Harper.

Howell, J. M. y Higgins, C. A. (2005). Job satisfaction and security of sport administrators employed in American and Canadian recreation programs. The Sport Journal, 29(1), 24-29.

Hoyos, L. A., Gutiérrez, C. y Pérez, Á. (2012). Caracterización de los programas de deporte escolar en Bogotá. Educación física y deporte, 31(1), 853-86.

Hulin, C. y Smith, P. (1967). An Empirical investigation of two implications of the two factor theory of job satisfaction. The Journal of Applied Psychology, 51, 396402.

Ibáñez, J. (2002). Perspectivas de investigación social: el diseño en las tres perspectivas. En F. Alvira, M. García Ferrando y J. Ibáñez (Comps.), El análisis de la realidad social. Métodos y técnicas de investigación (3 ${ }^{\mathrm{a}}$ ed.) (pp. 49-84). Madrid: Alianza editorial

Iglesias, D., Cárdenas, D. y Alarcón, F. (2007). La Comunicación durante la intervención didáctica del entrenador, consideraciones para el desarrollo del conocimiento táctico y la mejora en la toma de decisiones en baloncesto. Cultura, Ciencia y Deporte, 3(7), 43-50.

Ikonomopoulos G., Tzetzis G., Kioumourtzoglou E. y Tsorbatzoudis C. H. (2001). Perceptions of physical education teachers regarding the issue of assessing school performance in elementary physical education. Physical activity and quality of life, 2, 46-62.

Instituto Nacional de las Cualificaciones-Consejo Superior de Deportes. (2008). La Familia Profesional de las Actividades Físicas y Deportivas. Madrid: Ministerio de Educación, Política Social y Deporte. Gobierno de España. 
International Health \& Racquet Sports Association. (2011). IHRSA Global Report .The State of the Health Club Industry. Boston: IHRSA.

International Health \& Racquet Sports Association. (2013). IHRSA Global Report. The State of the Health Club Industry. Boston: IHRSA.

Irwin, G., Hanton, S. y Kervin, D. (2004). Reflective practice and the origins of elite coaching knowledge. Reflective Practice, 5, 425-442.

Jiménez, S., Lorenzo, A. y Gómez, M. A. (2009). Medios de formación de los entrenadores expertos en baloncesto. Cultura, Ciencia y Deporte; 4, 119-125.

Juan-Llamas, C. (2015). Perfil profesional de los instructores de clases colectivas en España. AGON: International Journal of Sport Sciences, 5(2), 114-125.

Juillet, N., Buisine, S. Gouju, J. L. (2013). Panorama des situations professionnelles du champ des activités physiques et sportives. Paris: Cafemas.

Kano, N. (1984). Attractive quality and must-be quality. The Journal of the Japanese Society for Quality Control, 14, 39-48.

Kidman, L. y Hanrahan, S. J. (2011) The Coaching Process - a practical guide to becoming an effective sports coach ( $3^{\text {rd }}$ ed.). New York: Ed. Routledge.

Koehler, L.S. (1998). Job satisfaction and corporate fitness managers. Journal of Sport Management, 22(1), 100-105.

Koustelios, A., Kouli, O. y Theodorakis, N. (2003). Job security and job satisfaction among Greek fitness instructors. Perceptual and Motor Skills, 97, 192-194.

Koustelios, A. y Tsigilis, N. (2005). The relationship between burnout and job satisfaction among physical education teachers: A multivariate approach. European Physical Education Review, 11(2), 189-203. doi: $10.1177 / 1356336 \times 05052896$ 
Lam, S. S. K. (1995). Total quality management programs and job satisfaction in Hong Kong. International Journal of Management, 12(1), 96-101.

Landy, F. J. y Trumbo, D. A. (1980). Psychology of work behavior. Homewood: The Dorsey Press.

Latorre, A. (2003). La investigación-acción. Conocer y cambiar la práctica educativa. Barcelona: Graó.

Latorre, A., Del Rincón, D. y Arnal, J. (1996). Bases metodológicas de la investigación. Barcelona: Hurtado Ediciones

Lawler, E. E. y Porter, L. W. (1967). The Effect of Performance on Job Satisfaction. Industrial Relations: A Journal of Economy and Society, 7, 20-28. doi:10.1111/j.1468-232X.1967.tb01060.x

Le Roux, N., Chantelat, P. y Camy, J. (1999). Sport et emploi en Europe. Lyon: Comisión Europeenne.

Leal, A., Alfaro De Prado, A., Rodríguez, L. y Román, M. (1999): El Factor Humano en las Relaciones Laborales. Madrid: Editorial Pirámide.

Lee, K. S., Malete, L. y Feltz, D. L. (2002). The effect of a coaching education program on coaching efficacy. International Journal of Applied Sport Sciences, 14, 5567.

Leite, N., Vicente, P. y Sampaio, J. (2009). Coaches Perceived Importance of Tactical Items in Basketball Players`' Long-Term Development. Revista de Psicología del Deporte, 18, 481-485.

León O. G. y Montero, I. (2003). Métodos de Investigación en Psicología y Educación ( $3^{\mathrm{a}}$ ed.). Mc Graw Hill: Madrid.

Lemyre, F., Trudel, P. y Durand-Bush, N. (2007). How youth-sport coaches learn to coach. The sport psychologist, 21, 191-209. 
Ley 7/2007, de 12 de abril, del Estatuto básico del Empleado Público. (BOE, 13 de abril de 2007).

Ley Orgánica 10/1990 de 15 de octubre, del Deporte. (BOE, de 17 de octubre).

Ley Orgánica 3/2008, de 23 de abril, del ejercicio de las profesiones del deporte (BOE, de 30 de mayo).

Ley Orgánica 1/2015, de 23 de marzo, del ejercicio físico y del deporte de La Rioja (BOE, de 15 de abril).

Ley Orgánica 15/2015, de 16 de abril, por la que se ordena el ejercicio de las profesiones del deporte en Extremadura (BOE, de 19 de mayo).

Ley Orgánica 5/2016, de 19 de julio, del Deporte de Andalucía. (BOE, de 5 de agosto).

Ley Orgánica 6/2016, de 24 de noviembre, por la que se ordena el ejercicio de las profesiones del deporte en la Comunidad de Madrid (BOE, de 22 de marzo).

Li, M. (1985). Evaluation of the organizational performance of the spare-time sports schools. Zhejiang Physical Culture, 4, 9-12.

Li, M. (1993). Job satisfaction and performance of coaches of the spare-time sports schools in China. Journal of Sport Management, 7, 132-140.

Liu R. y Xu, X. (2016). Management of Social Sport Instructors in China. Comunicación en 3rd International Conference on Social Science, Shaanxi.

Lledo, E., Martínez-Serrano, G. y Huertas, F. (2014). Perfil del entrenador de fútbol en la etapa escolar en escuelas de clubes de élite de la Comunitat Valenciana. Cultura, Ciencia y Deporte, 9(25), 57-68.

Locke, E. A. (1976). The nature and causes of job satisfaction. En M.D. Dunnette (ed.) Handbook of Industrial and Organizational Psychology. Chicago: Rand McNally. 
Locke, E. A. (1984). Job satisfaction. En M. Gruneberg y T. Wall (eds.) Social Psychology and Organizational Behaviour. Chichester: Wiley.

López, A. (2001). La formación del gerente público del deporte. Barcelona. Apunts: Educación física y deportes, 66, 64-69.

López Pintor, R. y Wert, J. I. (2002). El análisis de los datos de una encuesta. En F. Alvira, M. García Ferrando y J. Ibáñez (Comps.), El análisis de la realidad social. Métodos y técnicas de investigación (3 ${ }^{\mathrm{a}}$ ed.) (pp. 525-554). Madrid: Alianza editorial

Lubanski, P. (2008). Coaches must assess discipline when appropriate. Hockey Weekly, 34(21), 29.

Lyle, J. (2002). Sports coaching concepts: a framework for coaches' behavior. London: Routledge.

Lynn, P. y Lievesley, D. (1991). Drawing general population samples in Great Britain. Londres: Social and Company Planning Resrarch.

Macphail, A. (2011). Professional learning as a physical education teacher educator. Physical education \& sport pedagogy, 16(4), p.435-451.

Madella, A. (2002). Le professioni dello sport. SDS: Rivista di Cultura Sportiva, 21(55), 2-9.

Malek M., Nalbone P., Berger D. E. y Coburn J. W. (2002). Importance of health science education for personal fitness trainers. Journal of Strength and Conditional Research, 16(1), 19-24.

Martín-Mariscal, V. (2012). El problema del intrusismo profesional en el sector del fitness. Posibilidades de solución mediante la regulación de las titulaciones deportivas. Revista Wanceulen E.F. Digital, 9, 120-129. 
Martínez-Serrano, G. (2007) Los recursos humanos de la actividad física y deporte en la Comunidad Autónoma valenciana (Tesis doctoral inédita). Universidad de Valencia, Valencia.

Martínez-Serrano, G., Campos-Izquierdo, A., Pablos, C. y Mestre, J.A. (2008). Los recursos humanos de la actividad física y deporte: funciones y características sociodemográficas, laborales y formativas. Valencia: Tirant lo Blanch.

Martínez del Castillo, J. (1991). La estructura ocupacional del deporte en España: encuesta de los sectores de entrenamiento, docencia, animación y dirección. Madrid: Consejo Superior de Deportes

Martínez del Castillo, J. (1992). Proyección del mercado deportivo laboral en la España de los noventa. En los sectores de entrenamiento, docencia, animación y dirección. Madrid: Consejo Superior de Deportes.

Mathieu, J. E. y Zajac, D. M. (1990). A review and meta-analysis of the antecedents, correlates, and consequences of organizational commitment. Psychological Bulletin, 108, 171-194.

Matzler, K., Fuchs, M., y Schubert, A. (2004). Employee satisfaction: Does Kano's model apply? Total Quality Management \& Business Excellence, 15(9/10), $1179-1198$.

McInnis, K. J., Hayakawa, S. y Balady, G. J. (1997). Cardiovascular screening and emergency procedures at health clubs and fitness centers. American Journal of Cardiology, 80, 380-383.

Medina, A. (1999). Formación permanente del profesorado de ESO: desafíos de una nueva etapa. Educación XX1, 2(1), 183-221. 
Meliá, J. L. y Peiró, J. M. (1989). La medida de la satisfacción laboral en contextos organizacionales: El Cuestionario de Satisfacción S20/23. Psicologemas, 5, 5974.

Meliá, J. L., Peiró, J. M. y Calatayud, C. (1984). La satisfacción de los miembros de la organización. Trabajo presentado al I Congreso de Evaluación Psicológica, Madrid.

Mertler, C. A. (2009). Teachers' assessment knowledge and their perceptions of the impact of classroom assessment professional development. Improving Schools. 12, 101-113.

Mesquita, I., Isidro, S. y Rosado, A. (2010). Portuguese coaches' perceptions of and preferences for knowledge sources related to their professional background. Journal of Sports Science and Medicine, 9, 480-489.

Mestre, J. A. (1995). Planificación deportiva. Teoría y práctica. Barcelona: INDE.

Ministerio de Educación, Cultura y Deporte (2013). Anuario de estadísticas deportivas. Madrid: MECD.

Ministerio de Educación, Cultura y Deporte (2017). Anuario de estadísticas deportivas. Madrid: MECD.

Misener, K. E. y Danylchuk, K. E. (2009). Coaches' perceptions of Canada's National Coaching Certification Program (NCCP): Awareness and value. International Journal of Sport Science \& Coaching, 4(2), 233-243.

Moodley, P. y Coopoo, Y. (2006). Job satisfaction of self-employed trainers and personal trainers employed at commercial gymnasiums: A comparative study. South African Journal for Research in Sport, Physical Education and Recreation, 28(2), 105-112. 
Nash, C., y Sproule, J. (2009). Career development of expert coaches. International Journal of Sports Science and Coaching, 4(1), 121-138.

Nash, C. y Sproule, J. (2011). Insights into experiences: reflections of an expert \& novice coach. International Journal of Sports Science and Coaching, 6, 149-161.

Nash, C. S., Sproule, J. y Horton, P. (2008). Sport Coaches' Perceived Role Frames and Philosophies. International Journal of Sports Science y Coaching, 3(4), 538-554.

Nash, C. S., Sproule, J. y Horton, P. (2011). Excellence in coaching: the art and skill of elite practitioners. Research Quarterly for Exercise and Sport, 82(2), 229-238.

National Association for Sport and Physical Education, (2008). National Coaching Report, VA: Reston.

Nelson, L. J., Cushion, C. J. y Potrac, P. (2006). Formal, nonformal and informal coach learning: A holistic conceptualization. International Journal of Sports Science \& Coaching, 1, 247-259. doi: 10.1260/174795406778604627

Nunnally, J. C. (1978). Psychometric theory (2nd ed.). New York, NY: McGraw Hill.

Nuviala, A., León, J. A., Gálvez, J. y Fernández, A. (2007). Qué actividades deportivas escolares queremos: qué técnicos tenemos. Revista Internacional de Medicina y Ciencias de la actividad física y deporte, 7(25), 1-9.

Nuviala, A., Tamayo, J. A., Iranzo, J., y Falcón, D. (2008). Creación, diseño, validación y puesta en práctica de un instrumento de medición de la satisfacción de usuarios de organizaciones que prestan servicios deportivos. Retos. Nuevas tendencias en Educación Física, Deporte y Recreación, 14(2), 10-16.

Oksenberg, L. y Cannell, Ch. (1988). Effects of interviewer vocal characteristics on non-response. En R. M. Groves, P. P. Biemer, L.E. Lyberg, J. T. Massey, W. L. Nicholls II y J. Waksberg (Eds.), Telephone survey methodology (pp. 257-269). Nueva York: John Wiley and Sons. 
Olusoga, P., Butt, J., Maynard, I. y Hays, K. (2010). Stress and coping: a study of world class coaches. Journal of Applied Sport Psychology, 22(3), 274-293.

Orden ECI/3857/2007, de 27 de diciembre, por la que se establecen los requisitos para la verificación de los títulos universitarios oficiales que habiliten para el ejercicio de la profesión de Maestro en Educación Primaria (BOE, 29 de diciembre).

Ortega, E. (2010). Medios técnico-tácticos colectivos en baloncesto en categorías de formación. Revista Internacional de Medicina y Ciencias de la actividad física y deporte, 10(38), 234-244.

Oshagbemi, T. (1997). Job satisfaction and dissatisfaction in higher education. Education and Training, 39(9), 354-459.

Oshagbemi, T. (2000). Correlates of pay satisfaction in higher education. The International Journal of Educational Management, 14, 95-107.

Pablos, C. (2006). Empleo y Deporte: situación laboral de las personas que trabajan en actividad física y deporte en la Comunidad Valenciana. Consellería de Cultura y Educación: UIRFIDE.

Pablos, C. (Coord.) (2007). Empleo y Deporte: situación laboral de las personas que trabajan en actividad física y deporte en la Comunidad Valenciana. Valencia: Consejería de Cultura y Educación.

Pablos, J. M. y Biedma, J. M. (2013). La evaluación del rendimiento individual. Un instrumento válido para lograr la eficiencia en la gestión de Recursos Humanos en las administraciones públicas. Gestión y Análisis de Políticas Públicas, 10, 118. 
Padilla, J. L., González, A. y Pérez, C. (1998). Elaboración del cuestionario. En A. Rojas, J. Fernández y C. Pérez (Eds.), Investigar mediante encuestas (pp. 115140). Madrid: Síntesis.

Padua, J. (1979). Técnicas de investigación aplicadas a las ciencias sociales. México: Fondo cultural económico.

Papatheofilou, S., Derri, V. y Kyrgyridisp, A. (2008). Factors that affect the physical educators' opinion about the characteristics of their instruction. Greece: $16^{\text {th }}$ International Congress of Physical Education and Sport.

Paquette, K. J. y Sullivan, P. (2012). Canadian Curling Coaches' Use of Psychological Skills Training. The Sport Psychologist, 26(1), 29-42.

Pardo, A. y Ruiz, M. A. (2005). Análisis de datos con SPSS 13 base. Madrid: McGraw Hill.

Parlamento Europeo (2008). Diario Oficial de la Unión Europea de 6 de mayo de 2008 por el que se establece la recomendación del Parlamento Europeo y del Consejo de 23 de abril de 2008 relativa a la creación del marco europeo de cualificaciones para el aprendizaje permanente. Recuperado de $\langle$ https://ec.europa.eu/ploteus/sites/eac-eqf/files/journal_es.pdf $>$. Acesso en; 15 set. 2016.

Peiró, J. M. y Prieto, F. (1999). El factor humano en las relaciones laborales. Barcelona: Martínez Roca.

Peiró, J. M. y Ramos, J. (1995). Gestión de instalaciones deportivas: una perspectiva psicosocial. Valencia: Nau Llibres.

Pereira, P. (2002). A planificação dos professores em Educação Física: Alguns contributos para o seu estudo. Revista Horizonte, 92, 14-18. 
Pérez, M. C. (2002). Estudio Cualitativo sobre Entrenadores de Alto Rendimiento Deportivo. Revista de Psicología del Deporte, 11(1), 9-33.

Pestana, R. (2006). O sucesso comunicativo nas actividades deportivas. Estudo do feedback do treinador e do deportista no ensino das actividades desportivas. Revista Horizonte, 21(124), 29-35.

Petitpas, A. J., Cornelius, A. E., Van Raalte, J. L. y Jones, T. (2005). A framework for planning youth sport programs that foster psychosocial development. The Sport Psychologist, 19(1), 63-80.

Petry, K; Froberg, K y Madella, A. (Edit.) (2006). Thematic Network Project AEHESIS. Report of the third year. Cologne: German Sport University Cologne.

Petry, K., Froberg, K., y Madella, A. (2008). Higher education in sport in Europe: From labour market demand to training supply. Aachen: Meyer \& Meyer.

Petty, M. M., McGee, G. W. y Cavender, J. W. (1984). A meta-analysis of the relationships bewteen individual job satisfaction and individual performance. Academy of Management Review, 9, 712-721.

Porret, M. (2006). Recursos humanos. Dirección y gestión de personas en las organizaciones. Madrid: ESIC.

Porter, L. W., Lawler, E. E. y Hackman, J. R. (1975). Behaviours in Organisations. New York: McGrawHill.

Porter, L. W., Steers, R. M., Mowday, R. T. y Boulian, P. V. (1974). Organizational commiment, job satisfaction, and turnover among psychiatric technicians. Journal of Applied Psychology, 59, 603-609.

Puchol, L. (1997). Dirección y Gestión de Recursos Humanos. Madrid: ESIC.

Puchol, L. (2005). Dirección y gestión de recursos humanos. Madrid: Diaza Santos. 
Puig, N. y Viñas, J. (2006). Estructura ocupacional de licenciado y licenciadas en el INEF-Cataluña, 1980-2005. Barcelona: Promociones.

Raedeke, T. D., Warren, A. H. y Granzyk, T.L. (2002). Coaching commitment and turnover: A comparison of current and former coaches. Research Quarterly for Exercise and Sport, 73(1), 73-86.

Reade, I., Rodgers, W. y Hall, N. (2008). Knowledge transfer: How do high performance coaches access the knowledge of sport scientists? Intenational Journal of Sports Science and Coachimg; 3: 319-334.

Real Decreto 1076/2012, de 13 de julio, por el que se establecen seis certificados de profesionalidad de la familia profesional Actividades físicas y deportivas que se incluyen en el Repertorio Nacional de certificados de profesionalidad. (BOE, 5 de septiembre).

Real Decreto 1209/2009, de 17 de julio, por el que se establece un certificado de profesionalidad de la familia profesional de actividades físicas y deportivas que se incluye en el Repertorio Nacional de certificados de profesionalidad. (BOE, 6 de agosto).

Real Decreto 1363/2007, de 24 de octubre, por el que se establece la ordenación general de las enseñanzas deportivas de régimen especial. (BOE, 8 de noviembre).

Real Decreto 1440/1991, de 30 de agosto, por el que se establece el título universitario, oficial de Maestro, en sus diversas especialidades y las directrices generales propias de los planes de estudios conducentes a su obtención. (BOE, $11 \mathrm{de}$ octubre).

Real Decreto 1518/2011, de 31 de octubre, por el que se establecen tres certificados de profesionalidad de la familia profesional Actividades Físicas y Deportivas que 
se incluyen en el Repertorio Nacional de certificados de profesionalidad. (BOE, 10 de diciembre).

Real Decreto 1612/2010, de 7 de diciembre, por el que se declaran oficiales las cifras de población resultantes de la revisión del padrón municipal referidas al 1 de enero de 2010. (BOE, 23 de diciembre).

Real Decreto 1670/1993, de 24 de septiembre, por el que se establece el título universitario oficial de Licenciado en Ciencias de la Actividad Física y del Deporte y las directrices generales propias de los planes de estudios conducentes a la obtención del mismo.(BOE, 20 de octubre)

Real Decreto 2049/1995, de 22 de diciembre, por el que se establece el título de Técnico en Conducci6n de Actividades Físico-Deportivas en el Medio Natural y las correspondientes enseñanzas mínimas.(BOE, 14 de febrero).

Real Decreto 611/2013, de 2 de agosto, por el que se establecen dos certificados de profesionalidad de la familia profesional Actividades físicas y deportivas que se incluyen en el Repertorio Nacional de certificados de profesionalidad y se actualizan los certificados de profesionalidad establecidos como anexos II y III del Real Decreto 711/2011, de 20 de mayo.(BOE, 7 de septiembre).

Real Decreto 651/2017, de 23 de junio, por el que se establece el título de Técnico Superior en acondicionamiento físico y se fijan los aspectos básicos del currículo. (BOE, 8 de julio).

Real Decreto 652/2017, de 23 de junio, por el que se establece el título de Técnico en actividades ecuestres y se fijan los aspectos básicos del currículo. (BOE, 8 de julio). 
Real Decreto 653/2017, de 23 de junio, por el que se establece el título de Técnico Superior en enseñanza y animación sociodeportiva y se fijan los aspectos básicos del currículo. (BOE, 15 de julio).

Real Decreto 711/2011, de 20 de mayo, por el que se establecen tres certificados de profesionalidad de la familia profesional Actividades físicas y deportivas que se incluyen en el Repertorio Nacional de certificados de profesionalidad y se actualiza el certificado de profesionalidad establecido en el Real Decreto 1209/2009, de 17 de julio.(BOE, 10 de junio).

Real Decreto 982/2013, de 13 de diciembre, por el que se establecen dos certificados de profesionalidad de la familia profesional Actividades físicas y deportivas que se incluyen en el Repertorio Nacional de certificados de profesionalidad. (BOE, 10 de enero).

Real Decreto 99/2011, de 28 de enero, por el que se regulan las enseñanzas oficiales de doctorado. (BOE, 10 de febrero).

Rial, A., Alonso, D., Rial, J. y Picón, E. (2009). Un intento de segmentación integral de los usuarios de centros deportivos. Apunts Educación Física y Deportes, 95, 8291.

Roberts, S. J., Fairclough, S. J., Ryrie, G. y Sharpe, L. (2012). A computer-based observational analysis of physical education teachers and youth sport coaches pedagogic behaviour. International Journal of Performance Analysis In Sport, $12(3), 498-506$.

Rodríguez, J. (2002). La muestra: teoría y aplicación. En F. Alvira, M. García Ferrando y J. Ibáñez (Comps.), El análisis de la realidad social. Métodos y técnicas de investigación (ed. $3^{\mathrm{a}}$ ) (pp. 445-482). Madrid: Alianza editorial 
Rogers, J. D., Clow, K. E. y Kash, T. J. (1994). Increasing job satisfaction of service personnel. Journal of Services Marketing, 8(1), 14-26.

Rosales, C. (2010). La planificación de la enseñanza por competencias: ¿Qué tipo de innovación implica? Innovación Educativa, 20, 77-88.

Saavedra, I., Pérez, E., Rodrigo, B. y Fernández, V. (2008). Dirección de recursos humanos. Madrid: UNED.

Sáenz-López, P. (2006) Justificación del deporte en la escuela. Comunicación presentada en el I Congreso Iberoamericano del deporte en edad escolar, Madrid.

Sáenz-López, P., Sicilia, A. y Manzano, J. I. (2010). La opinión del profesorado sobre la enseñanza de la educación física en función del sexo. Revista Internacional de Medicina y Ciencias de la actividad física y deporte, 10(37), 167-180.

Sage, G. H. (1989). Becoming a high school coach: From playing sports to coaching. Research Quarterly for Exercise and Sport, 60, 81-92. doi: $10.1080 / 02701367.1989 .10607417$

Salanova, M. y Grau, R. (1999). Análisis de necesidades formativas y evaluación de la formación en contextos de cambio tecnológico. Psicología General Aplicada, 52(2-3), 329-350.

Sánchez-Alcaraz, B. J. y Parra-Meroño, M. C. (2012). La satisfacción laboral de los técnicos deportivos. International Journal of Sports Law and Management, 18(1), 92-109.

Sarker, S. J., Crossman, A. y Chinmeteepituck, P. (2003) The relationship of age and length of service with job satisfaction: an examination of hotel employees in Thailand. Journal of Managerial Psychology, 18 (7/8), 745-758.

Saura, J. (1996): El entrenador en el deporte escolar. Lleida: Fundació Pública Institut d’Estudis Llerdencs. 
Schempp, P. G., Webster, C. A., McCullick, B. A. y Sannen, I. (2007). How the best get better: an analysis of the self-monitoring strategies used by expert golf instructors. Sport Education and Society, 12, 175-192.

Serrano, J. y Barba, M. I. (2012). La gestión de recursos humanos en las corporaciones locales. Cuadernos de Gestión, 12(2), 149-168

Sharma R. D., y Jyoti J. (2009). Job satisfaction of university teachers: an empirical study. Journal of Services Research, 9(2), 51-80.

Sierra Bravo, R. (1992). Técnicas de investigación social. Teoría y ejercicios. Madrid: Paraninfo.

Sierra Bravo, R. (2001). Técnicas de investigación social. Teoría y ejercicios. Madrid: Paraninfo. Madrid: Dykinson.

Singh, P. C. y Surujlal, J. (2006). Factors affecting the job satisfaction of South African sport coaches. South African Journal for Research in Sport, Physical Education and Recreation, 28(1), 127-136.

Smucker, M. K. y Kent, A. (2004). The influence of referent selection on pay, promotion, supervision, work and co-worker satisfaction across three distinct sport industry segments. International Sports Journal, 30(2), 11-16.

Spencer, A. (1999). A case study of an exemplary American college physical educator tennis coach. Journal of Sport Pedagogy, 5, 1-27.

Stacey, D., Hopkins, M., Adamo, K. B., Shorr, R. y Prud’homme, D. (2010). Knowledge translation to fitness trainers: a systematic review. Implementation science, 5(28), 1-9.

Stewart, T. A. (1996) La Satisfacción de los Empleados en España. Una Perspectiva Europea. Capital Humano, 93, 16-22. 
Sullivan, P., y Gee, C. (2008). The effect of different coaching education content on the efficacy of coaches. International Journal of Coaching Science, 2, 59-66.

Sullivan, P., Paquette, K. J., Holt, N. L., y Bloom, G. A. (2012). The relation of coaching context and coach education to coaching efficacy and perceived leadership behaviors in youth sport. The Sport Psychologist, 26, 122-134.

Tenutto, M., Brutti, C. y Algaraña, S. (2010). Planificar, enseñar, aprender y evaluar por competencias. Conceptos y propuestas. Argentina: Diagramación: Digital \& Papel.

Thomas, J. R., Nelson, J. K. y Silverman, S. (2011). Research Methods in Physical Activity (6th ed.). Champaign, IL: Human Kinetics Publishers

Trudel P. y Gilbert W. D. (2006). Coaching and coach education. En: D. Kirk, M. O’Sullivan y D. McDonald (Eds.), Handbook of physical education. London: Sage. 516-539.

Unión Profesional (2009). Deontología profesional: los códigos deontológicos. Madrid: Unión Profesional

Vallée, C. N. y Bloom, G. A. (2005). Building a successful university sport program: Key and common elements of expert coaches. Journal of Applied Sport Psychology, 17(3), 179-196.

Vargas-Tonsing, T. M. (2007). Coaches' preferences for continuing coaching education. International Journal of Sports Science \& Coaching, 2, 25-35.

Viallon, R., Camy, J. y Collins, F. (2003). The European integration of a new occupation, the training and education strategies of national professional organizations: The case of the fitness sector in France and the United Kingdom. Managing Leisure, 8, 85-96.

Viciana, J. (2002). Planificar en educación física. Zaragoza: INDE publicaciones. 
Viciana, J. y Zabala, N. (2004). El papel educativo y la responsabilidad de los entrenadores deportivos. Una investigación sobre las instrucciones a escolares en fútcol de competición. Revista de Educación, 335, 163-187.

Villardón, M. L. (2006). Evaluación del aprendizaje para promover el desarrollo de competencias. Educatio Siglo XXI, 24, 57-76.

Vroom, V. H. (1964). Work and motivation. New York: Wiley.

Wenger, E. (1998). Communities of practice: learning, meaning and identity. Cambridge: Cambridge University Press.

Werthner, P. y Trudel, P. (2009). Investigating the idiosyncratic learning paths of elite Canadian coaches. International Journal of Sports Science \& Coaching, 4, 433449.

Whaley, M. H. (2003a). ACSM raising the bar in 2003. ACSM'S Health \& Fitness Journal, 7(2), 32-33.

Whaley, M. H. (2003b). ACSM credentialing: The move towards formal education. ACSM'S Health \& Fitness Journal, 7(4), 31-32.

Wilson, L. M., Bloom, G. A. y Harvey, W. J. (2010). Sources of knowledge acquisition: perspectives of the high school teacher/coach. Physical Education and Sport Pedagogy, 15(1), 383-399.

Winchester, G., Culver, D. y Camire, M. (2013). Understanding how Ontario high school teacher-coaches learn to coach. Physical Education and Sport Pedagogy, $18,412-426$.

Wright, C., Atkins, S. y Jones, B. (2012). An analysis of elite coaches' engagement with performance analysis services (match, notational analysis and technique analysis). International Journal of Performance Analysis in Sport, 12(2), 436451. 
Wright, T., Trudel, P. y Culver, D. (2007). Learning how to coach: the different learning situations reported by youth ice hockey coaches. Physical Education and Sport Pedagogy, 12, 127-144.

Yagüe, J. M. (1998). El trabajo colaborativo como estrategia de formación permanente del entrenador de fútbol. (Tesis doctoral inédita). Universidad de Valladolid, Valladolid.

Yániz, C. y Villardón, L. (2006). Planificar desde competencias para promover el aprendizaje. Bilbao: Mensajero.

Zournatzi, E., Tsigilis, N., Koustelios, A. y Pintzopoulou, E. (2006). Job satisfaction in primary and secondary Physical Education teachers. Sport \& Recreation Management, 3(2), 18-28. 
ANEXOS 



\begin{abstract}
ANEXO 1.
Dimensiones, variables e items de la entrevista estandarizada por medio de cuestionario

"PROAFIDE. Recursos humanos de la actividad
\end{abstract} física y deporte" 

DIMENSIÓN 1: CARACTERÍSTICAS SOCIODEMOGRÁFICAS DE LOS

RECURSOS HUMANOS DE LA ACTIVIDAD FÍSICA Y DEPORTE

VARIABLES

ITEMS

\section{Edad}

Sexo

Origen

\section{Pregunta 1}

Pregunta 2

Pregunta 3

DIMENSIÓN 2: FUNCIONES LABORALES DE ACTIVIDAD FÍSICA Y

DEPORTE

\begin{tabular}{|c|c|}
\hline$V A R I A B L E S$ & ITEMS \\
\hline Funciones actuales y pasadas & Pregunta 4 \\
\hline Preferencia de funciones & Pregunta 5 \\
\hline Satisfacción profesional general & Pregunta 6 \\
\hline Percepción del desempeño del trabajo & Pregunta 7 \\
\hline
\end{tabular}

DIMENSIÓN 3: ACTUACIÓN (DESEMPEÑO) PROFESIONAL ESPECÍFICA

\section{VARIABLES}

Competencias

Planificación general

Evaluación

Aspectos de intervención en la sesión

Tipos de actividad

Nivel de enseñanza de educación física

Actividades físico-deportivas extraescolares

Competición

Realización de informe

Preparación de la intervención profesional
ITEMS

Preguntas 9 y 10

Pregunta 11

Preguntas 12 y 13

Pregunta 14

Pregunta 15

Pregunta 16

Preguntas 17 y 18

Preguntas 19 y 20

Pregunta 21

Pregunta 22 
Intervención en dirección y organización

Tipología de población específica

Tipología de instalación deportiva
Preguntas 23, 24, 25,26, 27 y 28

Pregunta 29

Pregunta 30

DIMENSIÓN 4: CARACTERÍSTICAS LABORALES DE LOS RECURSOS HUMANOS DE LA ACTIVIDAD FÍSICA Y DEPORTE

VARIABLES

Entidades

Subcontratación

Relación laboral

Tipo de contratación

Dedicación

Años trabajando

Denominación del puesto de trabajo

Ingresos económicos

Conocimiento aspectos laborales

Cantidad personas instalación deportiva

Satisfacción laboral

Selección y obtención de empleo
ITEMS

Preguntas 31 y 40

Pregunta 32

Pregunta 33

Preguntas 34 y 35

Preguntas 36 y 39

Pregunta 37

Pregunta 38

Pregunta 41

Pregunta 42

Pregunta 43

Pregunta 44

Preguntas 52, 53, 54 y 55

\section{DIMENSIÓN 5: CARACTERÍSTICAS FORMATIVAS DE LOS RECURSOS}

HUMANOS DE LA ACTIVIDAD FÍSICA Y DEPORTE

\section{VARIABLES}

Formación inicial

Licenciado en Ciencias de la actividad física y Preguntas 49 y 50

deporte

Relación formación inicial con desempeño en Pregunta 51

ITEMS

Preguntas 45, 46, 47 y 48 
funciones laborales de actividad física y deporte

Formación permanente

Preguntas 56 y 57

Nota. Recuperado de Campos-Izquierdo (2011, pp.50-60). 